\title{
ANÁLISE DA INSTABILIDADE ESTRUTURAL GLOBAL E LOCAL PELO MEF POSICIONAL COM DETERMINAÇÃO DE PONTOS CRÍTICOS NA TRAJETÓRIA DE EQUILÍBRIO
}

\author{
VERSÃO DEFINITIVA \\ A versão de defesa encontra-se na Escola de Engenharia de São Carlos
}

Tese apresentada ao Departamento de Estruturas da Escola de Engenharia de São Carlos da Universidade de São Paulo, como parte dos requisitos necessários à obtenção do título de Doutor em Ciências do programa de Engenharia Civil (Estruturas).

Orientador: Prof. Dr. Humberto Breves Coda

SÃO CARLOS 
AUTORIZO A REPRODUCÃO TOTAL OU PARCIAL DESTE TRABALHO, POR QUALQUER MEIO COONVENCIONAL OU ELETRÔNICO, PARA FINS DE ESTUDO E PESQUISA, DESDE QUE CITADA A FONTE. NA TRAJETÓRIA DE EQUILÍBRIO / Aref Kalilo Lima Kzam; orientador Humberto Breves Coda. São Carlos, 2016.

Tese (Doutorado) - Programa de Pós-Graduação em Engenharia de Estruturas -- Escola de Engenharia de são Carlos da Universidade de São Paulo, 2016.

1. Método dos elementos finitos. 2. Análise não-linear geométrica. 3. Instabilidade estrutural. I. Título. 


\section{FOLHA DE JULGAMENTO}

Candidato: Engo. AREF KALILO LIMA KZAM.

Título da Tese: "Análise da instabilidade estrutural global e local pelo MEF posicional com determinação de pontos críticos na trajetória de equilíbrio".

Data da defesa: 04/02/2016

\section{Comissão Julgadora:}

Prof. Titular Humberto Breves Coda (Orientador) (Escola de Engenharia de São Carlos/EESC)

Prof. Dr. Edson Denner Leonel (Escola de Engenharia de São Carlos/EESC)

Prof. Dr. Rodrigo Ribeiro Paccola (Escola de Engenharia de São Carlos/EESC)

Prof. Dr. José Benaque Rubert (Universidade Federal de São Carlos/UFSCar)

Prof. Dr. Alex Sander Clemente de Souza (Universidade Federal de São Carlos/UFSCar)

\section{Resultado:}

Aprovac'o

Aprovado

Aprovaso
APRONADO

Aprovado

Coordenador do Programa de Pós-Graduação em Engenheira Civil (Engenharia de Estruturas):

Prof. Titular Humberto Breves Coda

Presidente da Comissão de Pós-Graduação: Prof. Associado Paulo Sergio Lima Segantine 

DICATÓRIA

Dedico este trabalho à minha amada filha Cecília e ao meu eterno sobrinho Davi (in memoriam). 



\section{AGRADECIMENTOS}

Agradeço,

À Deus Pai e Filho e a Nossa Senhora de Nazaré por conduzir meu caminho.

Aos meus pais, Neuza e Cristinaldo, a minha tia Bia e aos meus irmãos Áthila e Aline que sempre acreditaram nos meus objetivos me incentivado em todos os momentos.

A minha companheira Tayná pelo carinho e compreensão e por ter me proporcionado a emoção de compartilhar todos os dias o dom da vida com a chegada da nossa amada Cecília.

Ao professor Coda pelos ensinamentos, dedicação e amizade durante a orientação deste trabalho. Ao professor Venturini (in memorian) pelas inúmeras conversas prazerosas e inesquecíveis.

Aos funcionários do Departamento de Estruturas (SET), que disponibilizaram todos os recursos físicos e humanos durante a minha estada nessa instituição.

À Coordenação de Aperfeiçoamento de Pessoal de Nível Superior (CAPES) pelo auxílio financeiro durante o período da pesquisa.

Aos amigos do Departamento de Engenharia de Estruturas que estiveram sempre à disposição, contribuindo com valiosas ideias e compartilhando conhecimentos. Em especial aos amigos Fabio, Rafael, Dorival, Jesus e Maria do Socorro.

Aos professores e funcionários do Instituto Latino Americano de Tecnologia, Infraestrutura e Território (ILATIT) e aos alunos do curso de Engenharia Civil de Infraestrutura da Universidade Federal da Integração Latino Americana (UNILA) pelo apoio. 

"O senhor faz cálculos? Se não faz cálculos, suas previsões nada valem: se as obtém pelo cálculo, duvido muito delas. É preciso desconfiar sete vezes do cálculo, e cem vezes do calculista. ${ }^{\dagger \dagger}$

${ }_{\dagger}$ Provérbio indiano dito pelo rei El-Harit na anedota contada pelo poeta Iezid Abul-Hamid em "O Homem que Calculava" de Malba Tahan. 



\section{RESUMO}

KZAM, A. K. L. Análise da instabilidade estrutural global e local pelo MEF posicional com determinação de pontos críticos na trajetória de equilíbrio. 2016. 236 f. Tese de Doutorado - Escola de Engenharia de São Carlos, Universidade de São Paulo, 2016.

Nesta tese, apresenta-se o método dos elementos finitos posicional descrito em um referencial Lagrangiano total dedicado à análise de instabilidade de estruturas tridimensionais. Três tipos de elementos finitos são implementados e testados, a saber: os elementos de barra simples, casca e barra geral. A análise de instabilidade para o elemento de barra simples é efetuada determinando-se os pontos críticos ao longo da trajetória de equilíbrio em grandes deslocamentos. Essas trajetórias são determinadas utilizando-se os algoritmos de NewtonRaphson e arc-length, estratégias particularmente interessantes na definição de estruturas multiestáveis de uso crescente na indústria de alta tecnologia. Para o estudo da instabilidade empregando-se os elementos finitos de casca e barra geral realizam-se as análises para pequenos níveis de carga e deslocamentos por meio do cálculo dos autovalores e autovetores da matriz de rigidez da estrutura. Avaliam-se também as trajetórias de equilíbrio em grandes deslocamentos considerando-se pequenas imperfeições na geometria dos elementos estruturais. Quando os elementos de casca são utilizados na modelagem de perfis estruturais esbeltos surgem naturalmente modos de falha locais associados à mudança de forma da seção transversal. Com a finalidade de inserir essas mobilidades no elemento de barra geral propõemse uma metodologia que considera os aprimoramentos na cinemática da barra. Esses aprimoramentos são tratados como parâmetros nodais generalizados e estão associadas a intensidade da mudança de forma de seção transversal, incluindo os modos de empenamento. Descreve-se originalmente uma metodologia de decomposição da matriz Hessiana usada para o cálculo dos valores e vetores próprios em pequenos deslocamentos. Essa metodologia possui importância adicional pois é utilizada na preparação e avaliação do parâmetro de carga em cinemáticas alternativas da formulação posicional. Emprega-se o algoritmo de Lanczos na determinação das cargas e modos de falha por meio de chamadas a biblioteca ARPACK. Os algoritmos são testados em exemplos modelados com os elementos finitos propostos. Próximo aos pontos críticos realiza-se a separação da matriz Hessiana procurando-se possíveis modos de colapso da estrutura. Além dos modos de falha globais é possível se identificar os modos de falha locais e distorcionais. O equilíbrio do sistema mecânico é garantido pelo princípio da estacionariedade da energia potencial total. Nas análises com os elementos de casca e barra 
geral, a solução do sistema não-linear é obtida empregando-se apenas o método incremental iterativo de Newton-Raphson. Os aprimoramentos sugeridos nesta pesquisa são acoplados ao código computacional utilizado pelo grupo de mecânica computacional do departamento de engenharia de estruturas, onde diversas funcionalidades estão disponíveis, como análise dinâmica e não-linearidade material. Exemplos selecionados são apresentados ao longo da tese para demonstrar a eficiência dos elementos propostos e a aplicabilidade da técnica. Por fim, são realizadas comparações com estratégia de solução já consagradas, como por exemplo: o método das faixas finitas e a teoria generalizadas de vigas. Os resultados obtidos na tese justificam as contribuições originais da presente pesquisa destacando-se originalidade da formulação posicional aplicada ao estudo da instabilidade das estruturas.

Palavras-chave: Método dos elementos finitos. Análise não linear geométrica. Instabilidade estrutural. 


\begin{abstract}
KZAM, A. K. L. Global and local structural instability analysis by positional MEF with identification of critical points in the equilibrium path. 2016. 236 p. Doctoral Thesis - Sao Carlos School of Engineering, University of Sao Paulo, Sao Carlos, 2016.
\end{abstract}

This thesis presents the positional finite element method in a total Lagrangian framework dedicated to instability analysis of the three-dimensional structures. Three types of finite elements are implemented and tested, namely: truss, shells and frames. The instability analysis for truss element is computed using equilibrium path in large displacements. The critical points are computed using Newton-Raphson and arc-length algorithm, particularly interesting in the definition of multi-stable and large displacements structures widely used in high-tech industry. For shell and frame geometrically non-linear finite elements, the instability phenomenon is studied from the eigenvalues and eigenvectors analysis for small levels of loads and displacements. It is also evaluate the equilibrium trajectories for large displacements, considering small imperfections in the geometry of the structure. When using the shell elements to model the frames structures local failure modes associated with changing of the cross section shape arise. In order to consider the mobility in frame element new improvements are propose in the kinematic. These improvements are treated as generalized nodal parameters and are associated with the intensity of the cross-sectional change, including warping. The originally methodology of decomposition of the Hessian matrix are described and used for calculating eigenvalues and eigenvectors of the stiffness matrix. This methodology has additional importance because it is used in the preparation and evaluation of load parameter in kinematic alternatives of the positional formulation. The Lanczos algorithm is used to determining the loads and failure modes, through calls to ARPACK library for calculating eigenvalues and eigenvectors. The algorithms are tested on the examples modeled by proposed finite elements. Near the critical point takes place the separation of the Hessian matrix for possible identification of the failure modes. In addition to global failure methods, local and distortion failure are captured by this methodology. The balance of the mechanical system is guaranteed by the stationarity of the total potential energy principle. In the analysis using shells and frames elements the solution of the nonlinear system is calculated using the iterative incremental Newton-Raphson method. The improvements suggested in this research are coupled to the computer code used by computational mechanics group of the structures engineering department, where several features are available like dynamic and plasticity analysis. Selected 
examples are presented throughout the thesis to demonstrate the efficiency of the proposed elements and applicability of the technique. Finally, comparisons are carried out with already established solving strategy such as the finite strip methods and the generalized beam theory. The results justified the original contributions of this research to study of unstable structures.

Keywords: Finite element method. Nonlinear geometric analysis. Structural instability. 


\section{LISTA DE FIGURAS}

Figura 1: Colapso da ponte Tacoma, 1941. Fonte: American Association of Physics Teachers (2000).

Figura 2: Colapso da cobertura do Hatford Coliseum, 1978. Fonte: Connecticut Historical

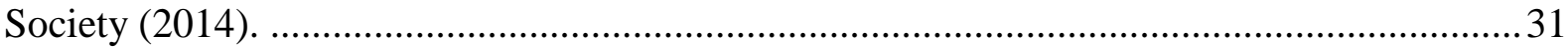

Figura 3: Mudança de configuração de um sólido deformável ..............................................53

Figura 4: Partição do intervalo para o elemento finito unidimensional .................................67

Figura 5: Partição do intervalo para o elemento finito bidimensional triangular ...................... 71

Figura 6: Partição do intervalo para o elemento finito bidimensional quadrilateral ............... 74

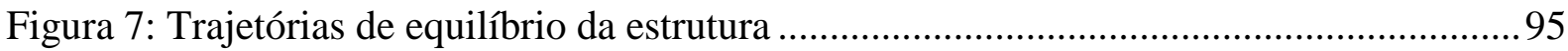

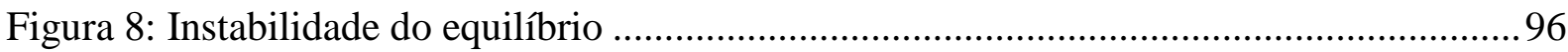

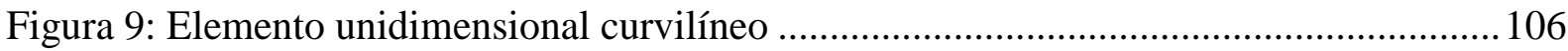

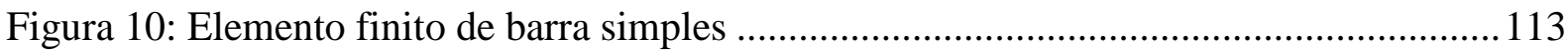

Figura 11: Treliça de Von Mises na configuração inicial e deslocada.................................. 116

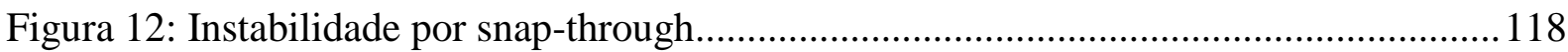

Figura 13: Trajetória de equilíbrio com controle de deslocamento....................................... 119

Figura 14: Treliça de Von com dois graus de liberdade..................................................... 121

Figura 15: Trajetória de equilíbrio da treliça com dois graus de liberdade ............................. 123

Figura 16: Domo com 24 elementos de barra simples ......................................................... 124

Figura 17: Trajetória de equilíbrio do ponto de aplicação do carregamento.......................... 125

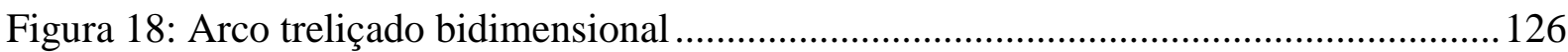

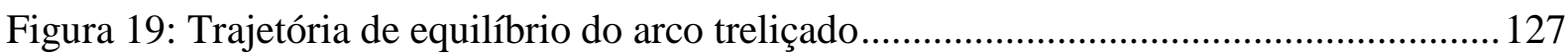

Figura 20: Geometria e propriedades dos materiais do domo de Schwedler ......................... 128

Figura 21: Trajetória de equilíbrio para o domo de Schwedler............................................. 129

Figura 22: Carregamento considerado para a análise dos autovalores do domo..................... 132

Figura 23: Trajetória de equilíbrio fundamental e bifurcadas para o elemento de treliça.

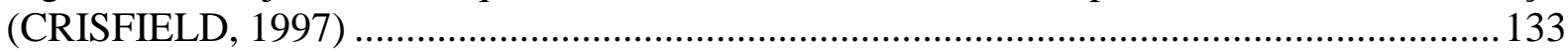

Figura 24: Autovetores dos cinco primeiros parâmetros de bifurcação ................................. 134

Figura 25: Trajetórias fundamental e bifurcadas obtidas com o elemento de treliça posicional

Figura 26: Trajetória fundamental do domo com o método do arc-length........................... 135

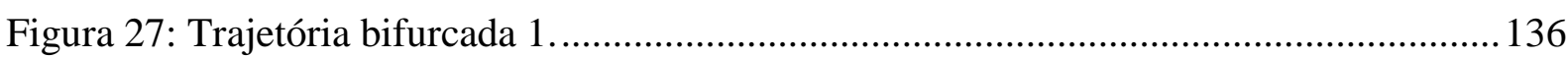

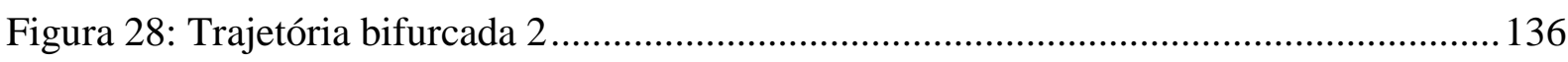

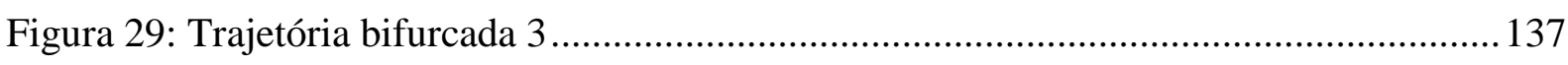

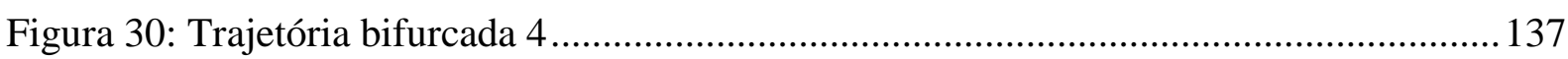


Figura 31: Trajetória bifurcada 5 138

Figura 32: Mapeamento do elemento finito de casca não linear geométrico

Figura 33: Mapeamento ao longo da espessura do elemento

Figura 34: Chapa simplesmente apoiada sob compressão uniforme

Figura 35: Modos de instabilidade local de chapa

Figura 36: Carga crítica e modos de instabilidade do flange

Figura 37: Modos de flambagem a flexão da coluna larga .

Figura 38: Trajetória de equilíbrio da coluna larga

Figura 39: Deslocamentos no passo de carga final para a coluna larga.

Figura 40: Perfil C sob compressão uniforme

Figura 41: Corte AB. Imperfeições na seção transversal no meio do vão

Figura 42: Carga e modos de instabilidade para o caso 1. Fonte: (GARCEA, 2001)............ 156

Figura 43: Autovalores e autovetores com elemento de casca posicional, caso 1 ................. 156

Figura 44: Trajetória de equilíbrio para o caso 1. Resultado da presente pesquisa e de (GARCEA, 2001).

Figura 45: Parâmetro de carga limite dos elementos propostos por (GARCEA, 2001). Caso 1

Figura 46: Carga e modos de instabilidade para o caso 2. Fonte: (GARCEA, 2001)............ 158

Figura 47: Autovalores e autovetores com elemento de casca posicional. Caso 2 ................ 158

Figura 48: Trajetória de equilíbrio para o caso 2. Resultado da presente pesquisa e de (GARCEA, 2001).

Figura 49: Parâmetro de carga limite dos elementos propostos por (GARCEA, 2001). Caso 2

Figura 50: Carga e modos de instabilidade para o caso 3. Fonte: (GARCEA, 2001).

Figura 51: Autovalores e autovetores com elemento de casca posicional. Caso 2. 160

Figura 52: Trajetória de equilíbrio para o caso 3. Resultado da presente pesquisa e de (GARCEA, 2001). 160

Figura 53: Parâmetro de carga limite dos elementos propostos por (GARCEA, 2001). Caso 3 161

Figura 54: Mapeamento em posições e vetores generalizados 164

Figura 55: Elemento de barra geral na configuração inicial e atual. 166

Figura 56: Aprimoramentos na cinemáticos da seção transversal ..... 170

Figura 57: Coluna ideal, flambagem de Euler 171

Figura 58: Curva de instabilidade para a viga coluna da Figura 57. 174

Figura 59: Análise de convergência dos autovalores. 176

Figura 60: Autovetores referentes aos cinco primeiros modos de instabilidade 176

Figura 61: Trajetória de equilíbrio pós-crítica, com imperfeições geométricas 
Figura 62: Cargas críticas e modos de flambagem para esbeltez variável. (PSOTNý e

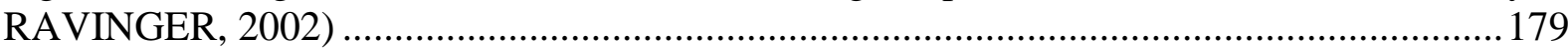

Figura 63: Autovalores e autovetores obtidos com o elemento de barra geral rotulado ........ 180

Figura 64: Autovalores e autovetores obtidos para a inercia EI=0,08 ............................... 181

Figura 65: Trajetória fundamental e bifurca da Treliça de Mises ......................................... 182

Figura 66: Flambagem lateral da viga engastada com seção retangular delgada ................... 183

Figura 67: Trajetória de deslocamentos da extremidade livre............................................. 184

Figura 68: Modelo de barra geral usado na análise de instabilidade lateral .......................... 186

Figura 69: Modelo de casca usado na análise de instabilidade lateral ................................. 186

Figura 70: Análise paramétrica para vigas em balanço. (FRUCHTENGARTEN, 2005) ...... 189

Figura 71: Análise paramétrica para vigas em balanço. Fator de ajuste do momento crítico 190

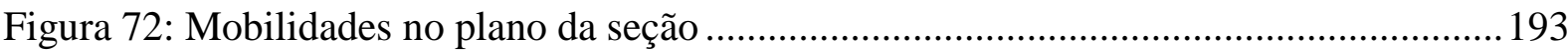

Figura 73: Modelo da coluna com o elemento de barra geral ..............................................203

Figura 74: Mobilidades no plano da seção transversal ..........................................................2 204

Figura 75: Mobilidades fora do plano da seção transversal .................................................205

Figura 76: Curva de flambagem e diagrama de participação modal do GBTUL................... 206

Figura 77: Modos críticos gerados pelo GBTUL em função do comprimento da coluna......206

Figura 78: Curva de flambagem e diagrama e participação modal CUFSM...........................207

Figura 79: Modos críticos gerados pelo CUFSM em função do comprimento da coluna .....207

Figura 80: Curvas de flambagem para o primeiro modo.......................................................... 208

Figura 81: Modos críticos gerados pelo elemento finito de casca posicional em função do

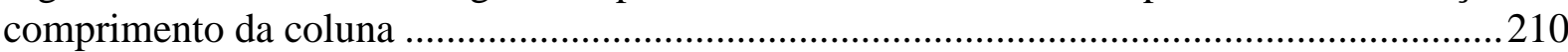

Figura 82: Gráfico e tabela com os valores das cargas de flambagem - GBTUL ..................211

Figura 83: Gráfico e tabela com os valores das cargas de flambagem - CUFSM.................211

Figura 84: Gráfico e tabela com os valores das cargas de flambagem - Barra Geral............212

Figura 85: Gráfico e tabela com os valores das cargas de flambagem - Casca ......................212

Figura 86: Vetores generalizados na configuração inicial.................................................... 233 



\section{LISTA DE TABELAS}

Tabela 1: Parâmetros de carregamento correspondentes aos pontos críticos ......................... 133

Tabela 2: Pontos críticos para a chapa simplesmente apoiada ............................................. 150

Tabela 3: Pontos críticos para o flange simplesmente apoiada ........................................... 152

Tabela 4: Cargas de bifurcação da coluna larga .................................................................... 152

Tabela 5: Cargas de bifurcação para a coluna com cinco metros......................................... 175

Tabela 6: Parâmetros de carregamento para a rigidez a flexão EI=0,04 .............................. 180

Tabela 7: Parâmetros de carregamento para a rigidez a flexão EI=0,08 ............................... 181

Tabela 8: Momentos de flambagem lateral ............................................................................. 184

Tabela 9: Momento crítico para vigas engastadas com carga na extremidade livre .............. 190

Tabela 10: Carregamentos do primeiro modo de flambagem ...............................................208

Tabela 11: Tabela com os vinte primeiros autovalores obtidos com o elemento de barra geral

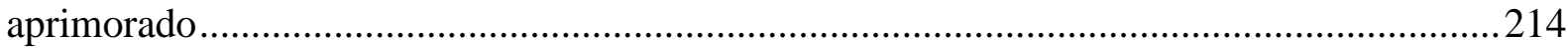

Tabela 12: Tabela com os vinte primeiros autovalores obtidos com o elemento de casca ....215 



\section{LISTA DE QUADROS}

Quadro 1: Sub-rotina de geração das funções de forma do elemento unidimensional de ordem qualquer 69

Quadro 2: Sub-rotina de geração das funções de forma do elemento bidimensional triangular

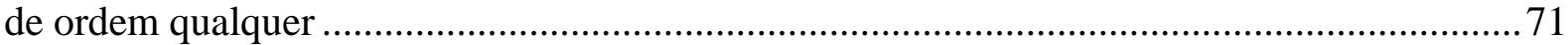

Quadro 3: Sub-rotina das funções de forma do elemento bidimensional quadrilateral de ordem

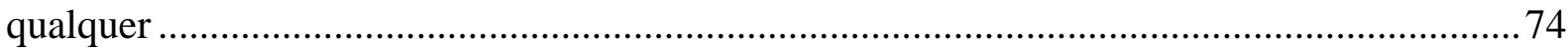

Quadro 4: Pontos e pesos da quadratura de Gauss-Legendre................................................... 77

Quadro 5: Pontos e pesos da integração de Hammer .................................................................. 78 



\section{LISTA DE SÍMBOLOS}

\begin{tabular}{|c|c|}
\hline$P_{c r}$ & Carga Crítica de Euler \\
\hline$E$ & Módulo de Rigidez Longitudinal \\
\hline I & Momento de Inércia \\
\hline$L$ & Comprimento da Coluna \\
\hline$w$ & Deslocamento Transversal ao Eixo da Coluna \\
\hline$(.)^{\prime},(.)^{\prime \prime}$ & Operador Primeira e Segunda Derivada \\
\hline$\hat{e}_{i}$ & Base Ortonormal \\
\hline$\delta_{i j}$ & Tensor de Kronecker \\
\hline$\varepsilon_{i j k}$ & Tensor de Levi-Civita \\
\hline$P$ & Ponto Material \\
\hline $\mathcal{B}$ & Espaço Euclidiano \\
\hline$\Omega_{0}, \Omega_{1}$ & Domínio Inicial e Atual \\
\hline$\vec{X}, X_{i j}$ e $\vec{Y}, Y_{i j}$ & Vetor Posição Inicial e Atual \\
\hline$t_{0}, t$ & Instante Inicial e Atual \\
\hline$\vec{F}$ & Transformação \\
\hline$\vec{f}_{0}, \vec{f}_{1}$ & Mudança de Configuração Inicial e Atual \\
\hline$(.) \circ()$. & Operador Função Composta \\
\hline$(.)^{-1}$ & Operador Matriz Inversa \\
\hline$(.)^{T}$ & Operador Matriz Transposta \\
\hline$():.()$. & Operador Contração Tensorial \\
\hline$(.) \otimes()$. & Operador Produto Tensorial \\
\hline$A$ & Gradiente da Transformação \\
\hline $\boldsymbol{A}^{0}, A_{i j}^{0}$ e $\boldsymbol{A}^{1}, A_{i j}^{1}$ & Gradiente da Mudança de Configuração Inicial e Atu \\
\hline$J$ & Jacobiano da Transformação \\
\hline $\boldsymbol{C}, C_{m n}$ & Tensor de Cauchy-Green \\
\hline $\boldsymbol{E}, E_{k \ell}$ & Tensor de Green-Lagrange \\
\hline I & Tensor Identidade de Segunda Ordem \\
\hline $\boldsymbol{S}, S_{m n}$ & Tensor de Piola-Kirchhoff Segunda Espécie \\
\hline$\sigma$ & Tensor de Tensão de Cauchy \\
\hline $\mathbb{I}$ & Tensor Identidade de Quarta Ordem \\
\hline $\mathbb{C}$ & Tensor de Quarta Ordem de Rigidez Elástica \\
\hline$G$ & Módulo de Rigidez Transversal \\
\hline$v$ & Coeficiente de Poisson \\
\hline$u_{e}$ & Energia Específica de Deformação \\
\hline$U_{\rho}$ & Energia Potencial das Deformações \\
\hline
\end{tabular}




\begin{tabular}{|c|c|}
\hline$P$ & Energia Potencial das Forças Externas \\
\hline$\Pi$ & Energia Potencial Total \\
\hline$V_{0}, V_{1}$ & Volume Inicial e Final \\
\hline$\vec{F}_{e x t}$ & Vetor de Forças Externas \\
\hline$\vec{F}_{\text {int }}, F_{i j}^{\text {int }}$ & Vetor de Forças Internas \\
\hline $\mathcal{L}$ & Lagrangiana do Sistema \\
\hline$\vec{q}$ & Vetor de Coordenadas Generalizadas \\
\hline$\xi_{1}, \xi_{2}$ e $\xi_{3}$ & Coordenadas do Espaço Adimensional \\
\hline$\xi_{i}, \xi_{j}$ e $\xi_{k}$ & Coordenadas dos Pontos de Integração \\
\hline$\omega_{i}, \omega_{j}$ e $\omega_{k}$ & Pesos da Integração \\
\hline$H_{\alpha \beta \gamma \delta}$ & Matriz Hessiana \\
\hline$r$ & Razão da Progressão Aritmética \\
\hline$p$ & Pontos da Partição do Intervalo \\
\hline$n$ & Grau da Aproximação \\
\hline$\xi_{i}, \eta_{i}$ & Coordenadas da Partição \\
\hline$a_{i j}$ & Coeficientes do Polinômio \\
\hline$\varphi_{k}, \vartheta_{k}$ & Polinômio Interpolador \\
\hline tol & Tolerância Numérica \\
\hline$\Delta Y_{i}^{\ell}$ & Correção da Posição no Passo \\
\hline$\Delta \lambda^{\ell}$ & Correção do Parâmetro de Carregamento no Passo \\
\hline$\delta Y_{i}^{\ell}$ & Incremento da Posição no Passo \\
\hline$\delta \lambda^{\ell}$ & Incremento do Parâmetro de Carregamento no Passo \\
\hline$\zeta$ & Fator de escala \\
\hline$\psi$ & Ponderador \\
\hline$i_{m}$ & Número de Iterações \\
\hline $\boldsymbol{K}_{T}, \boldsymbol{K}_{G}$ & Matriz de Rigidez Tangente e Geométrica \\
\hline$\lambda_{i}, \Lambda_{i j}$ & Autovalor e Autovetor \\
\hline$\phi_{i}, \varphi_{i}, \vartheta_{i}, \bar{\psi}_{i}$ & Funções de Forma \\
\hline$x_{i j}, y_{i j}$ & Grau de Liberdade das Posições \\
\hline$\alpha_{i}^{1}, \alpha_{i}^{2}$ & Coordenadas Auxiliares da Seção Transversal \\
\hline$a_{i}$ & Intensidade das Deformações Transversais \\
\hline$v_{i}^{1}, v_{i}^{2}$ & Componentes Iniciais dos Vetores Generalizados \\
\hline$g_{i}^{1}, g_{i}^{2}$ & Componentes Atuais dos Vetores Generalizados \\
\hline$\varpi_{i}$ & Modo de Empenamento \\
\hline$\tau_{i}$ & Mobilidades da Seção Transversal \\
\hline
\end{tabular}




\section{SUMÁRIO}

1 Introdução ............................................................................................ 29

1.1 Apresentação do Tema …………………………………………………... 29

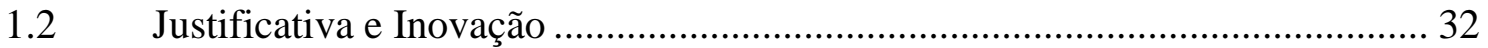

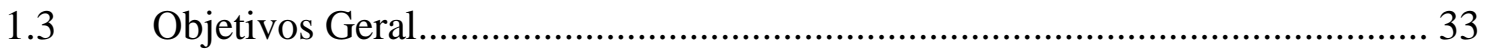

$1.4 \quad$ Objetivos Específicos e Metodologia.............................................................. 33

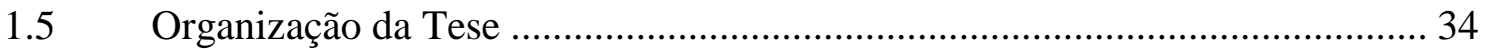

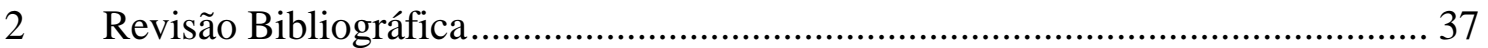

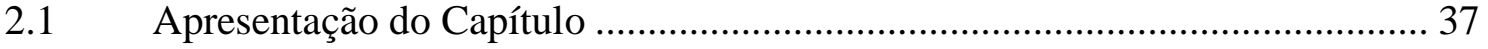

2.2 Instabilidade Estrutural - Aspectos Analíticos ……………………………..... 37

2.3 Instabilidade Estrutural - Aspectos Numéricos ............................................... 42

2.4 Formulação Posicional: Estado da arte no Departamento de Estruturas........... 45

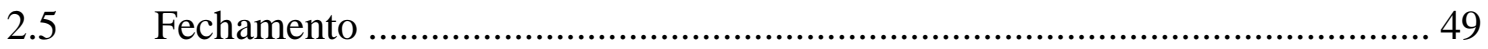

3 Fundamentos da Análise Não - Linear Geométrica …………………………….... 51

$3.1 \quad$ Apresentação do Capítulo ......................................................................... 51

3.2 Formulação Não - Linear Geométrica dos Sólidos Deformáveis....................... 51

3.2.1 Cinemática dos Sólidos Deformáveis ......................................................... 52

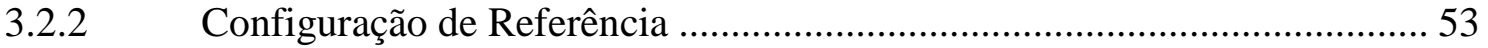

3.2.3 Configuração Atual.............................................................................. 53

3.2.4 Transformação dos Sólidos Deformáveis .................................................... 54

3.2.5 Descrição Lagrangiana do Movimento.......................................................... 54

3.2.6 Gradiente da Transformação................................................................. 55

3.2.7 Tensor dos Estiramentos à Direita de Cauchy-Green..................................... 55

3.2.8 Tensor das Deformações de Green-Lagrange............................................... 56

3.2.9 Lei Constitutiva de Saint Venant-Kirchhoff................................................. 56

3.2.10 Tensor de Tensão de Piola-Kirchhoff Segunda Espécie................................ 57

3.3 Princípios Fundamentais da Mecânica dos Sólidos ......................................... 57

3.3.1 Princípio da Conservação da Energia Mecânica …………………………... 58

3.3.2 Princípio da Mínima Ação...................................................................... 58

3.4 Método dos Elementos Finitos Posicional ………………………………........ 60

3.4.1 Energia Potencial das Deformações .............................................................. 60

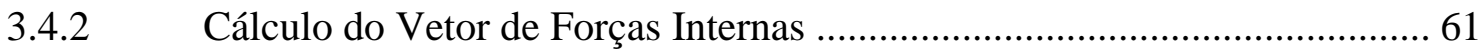

3.4.3 Cálculo da Matriz Hessiana .......................................................................... 62

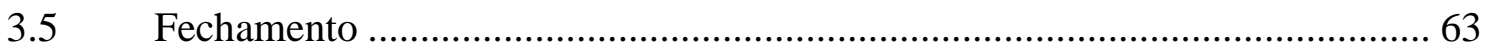


4 Métodos Numéricos para Análise Não - Linear de Estruturas ............................. 65

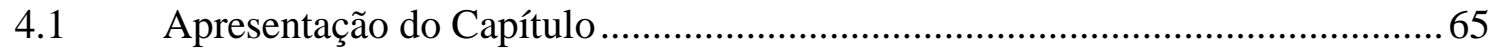

4.2 Interpolação Polinomial: Funções de Forma de Ordem Qualquer ....................65

4.2.1 Funções de Forma Unidimensionais ........................................................... 66

4.2.2 Funções de Forma Bidimensionais Triangulares …................................... 70

4.2.3 Funções de Forma Bidimensionais Quadrilaterais.....................................73

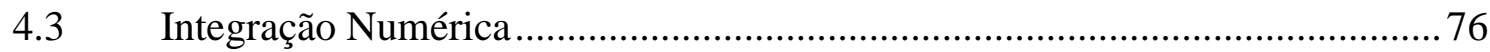

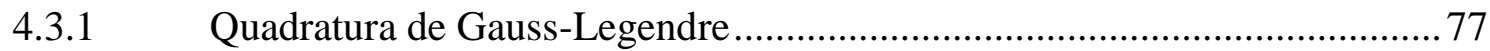

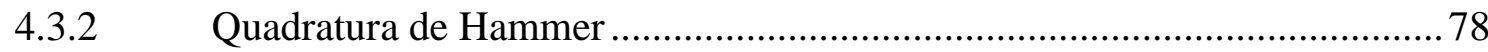

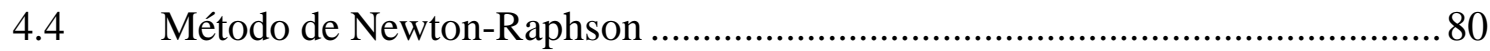

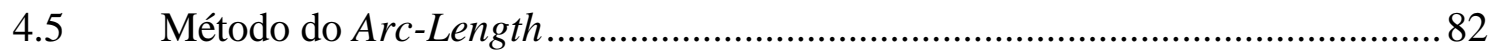

4.6 Autovalores e Autovetores: Método de Lanczos ............................................... 86

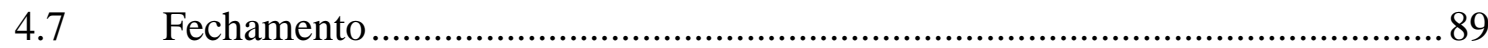

$5 \quad$ Fundamentos da Estabilidade Estrutural .............................................................. 91

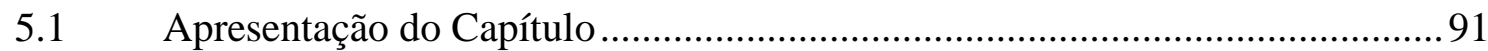

5.2 Instabilidade Estrutural: Definições.......................................................... 91

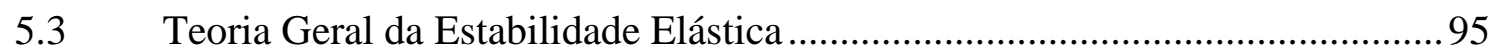

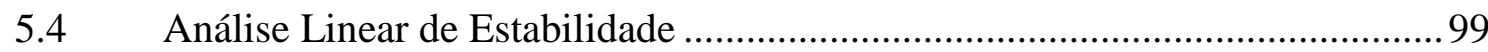

5.4.1 Decomposição da Matriz Hessiana dos Elementos Finitos Posicional....... 101

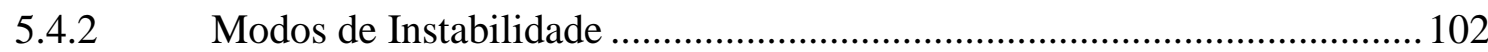

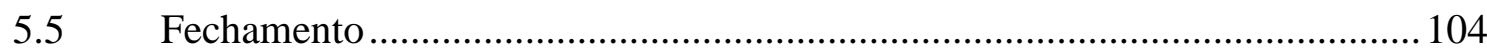

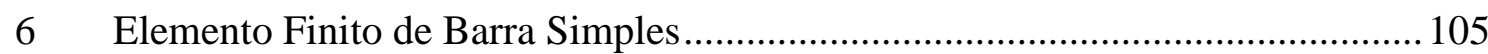

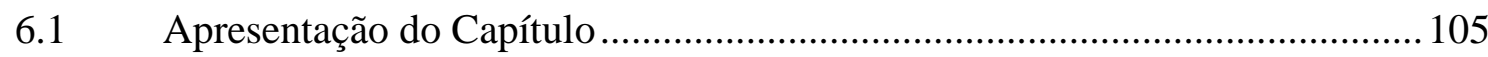

6lemento Finito Curvilíneo ……….................................................................. 105

6.3 Elemento Finito de Barra Reta.................................................................... 113

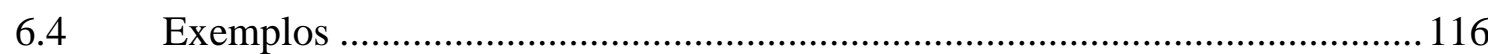

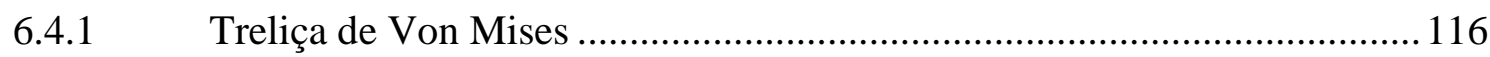

6.4.2 Treliça de Von Mises com mola acoplada. .............................................. 120

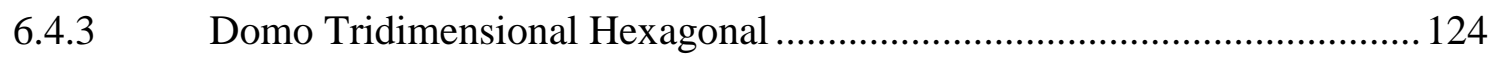

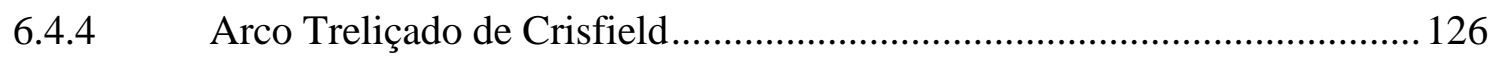

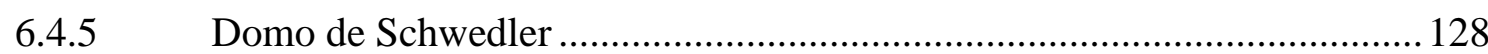

6.5 Análise Linear de Instabilidade do Elemento de Barra Rígida....................... 130

6.5.1 Análise de Autovalor do Domo Hexagonal ............................................. 132

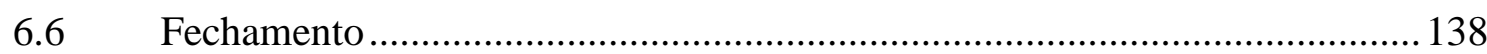

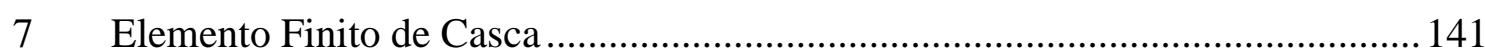




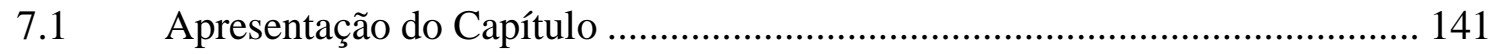

7.2 Elemento de Casca Não Linear Geométrico ……………………………….... 141

7.3 Gradiente da Transformação .................................................................... 144

7.3.1 Gradiente na Configuração Inicial........................................................... 145

7.3.2 Gradiente na Configuração Atual ........................................................... 145

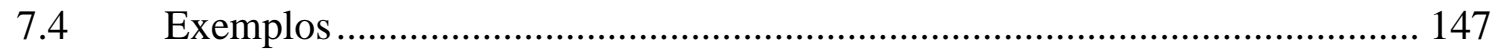

7.4.1 Flambagem de Chapas, Flanges e Colunas Delgadas................................. 147

7.4.2 Instabilidade Estrutural do Perfil C ............................................................. 154

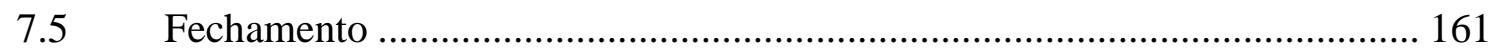

8 Elemento Finito de Barra Geral ……………………….................................. 163

8.1 Apresentação do Capítulo ............................................................................. 163

8.2 Mapeamento em Posições e Vetores Generalizados .......................................... 163

8.3 Função Mudança de Configuração................................................................ 165

8.4 Aprimoramentos na Cinemática da Seção Transversal...................................... 167

8.4.1 Aprimoramento nas Deformaç̃os transversais ............................................ 167

8.4.2 Aprimoramento Devido ao Modo de Empenamento..................................... 168

8.5 Primeira Série de Exemplos: Elemento Finito de Barra Geral........................ 170

8.5.1 Carga Crítica de Euler ....................................................................... 171

8.5.2 Flambagem da Treliça de Von Mises com Elemento de Barra Geral ....... 178

8.5.3 Instabilidade Lateral de Vigas Esbeltas .................................................. 182

8.6 Aprimoramentos nas Mobilidades da Seção Transversal................................ 192

8.6.1 Aprimoramentos no Plano da Seção Transversal ....................................... 192

8.6.2 Mobilidades Transversais como Parâmetros Nodais ................................... 194

8.6.3 Aprimoramentos Fora do Plano da Seção Transversal................................ 198

8.7 Gradiente da Transformação ....................................................................... 199

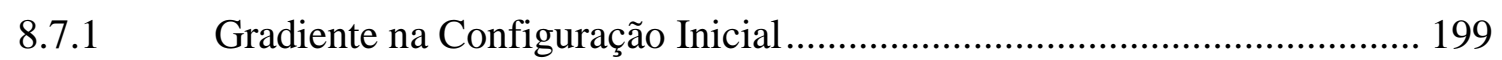

8.7.2 Gradiente na Configuração Atual ............................................................. 199

8.8 Segunda Série de Exemplos: Barra Geral com Aprimoramentos ................... 202

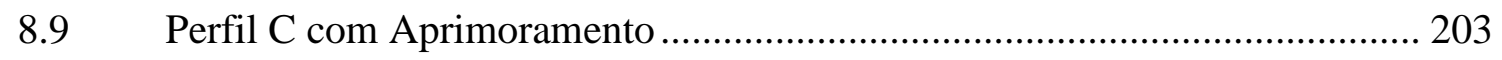

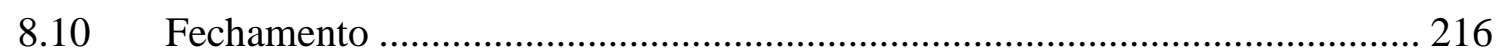

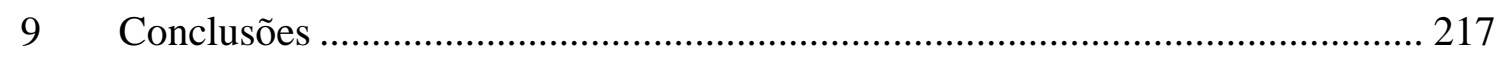

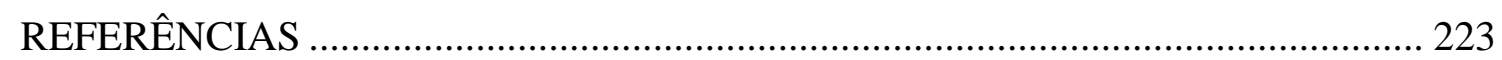

APÊNDICE A: Base de Vetores da Seção Transversal ............................................... 233 



\section{Introdução}

\subsection{Apresentação do Tema}

$\mathrm{Na}$ prática tradicional de projeto a capacidade portante das estruturas é limitada aos valores de carregamentos críticos. De acordo com (BAžANT e CEDOLIN, 2010), distinguemse dois critérios básico no projeto de estruturas, nomeadamente: critério de resistência e critério de estabilidade. No primeiro, o carregamento crítico ocorre quando a resistência última do material é atingida ou quando se inicia a formação de mecanismos plásticos localizados. No segundo, a carga crítica é definida antes mesmo do material romper ou plastificar, provocada por níveis não toleráveis de deslocamentos, devido a perda de estabilidade estrutural.

No entanto, vários de sistemas mecânicos apresentam níveis excessivos de deslocamentos e/ou deformações, sem a ocorrência de ruptura, plastificação ou perda de estabilidade. Estas estruturas trabalham com níveis de carregamentos além dos valores críticos. De acordo com (BIGONI, 2015), estruturas com essas características são amplamente empregadas na indústria de alta tecnologia como a aeroespacial, off-shore, eletrônica e de nanocomponentes.

Frente a consideração de níveis elevados de deslocamentos, o analista estrutural deverá estar ciente que modelos mais sofisticados precisam ser considerados nas análises e o desenvolvimento de ferramentas de cálculo mais realistas tornam-se indispensáveis, como por exemplo, a consideração da não-linearidade geométrica.

$\mathrm{Na}$ análise não-linear geométrica o equilíbrio da estrutura é avaliado na configuração deslocada, também denominada configuração atual, independentemente do nível de deslocamentos serem grandes ou pequenos. Nesse caso as relações cinemáticas, as quais exprimem a dependência entre as deformações e os deslocamentos são consideradas exatas, ou seja, são conceitualmente mais consistentes.

Em razão da generalidade introduzida pela formulação não-linear geométrica é possível se identificar os níveis de carregamento crítico que definem o estado transitório das configurações de estáveis para instáveis. A consideração de um comportamento geometricamente não-linear permite se descrever completamente o histórico de configurações de equilíbrio, a partir da relação entre carga e deslocamento, comumente denominada, trajetória de equilíbrio. 
Com esse arcabouço teórico o analista estará apto em estabelecer as condições necessárias para o bom desempenho dos elementos estruturas e identificar os principais fatores que levam à perda de estabilidade do sistema estrutural como um todo.

De acordo com (BAžANT e CEDOLIN, 2010), as principais causas associadas ao fenômeno de instabilidade têm suas origens na natureza das solicitações ou devido as imperfeições originárias dos processos de fabricação, transporte e montagem das estruturas.

Em (MILNE, RITCHIE e KARIHALOO, 2003) são descritos alguns dos acidentes estruturais mais famosos da história mostrando, que de alguma forma, o fenômeno de instabilidade é uma das principais causas que levam as estruturas ao colapso.

Dentre os acidentes descritos pelos autores, o mais famoso, talvez seja, o desastre ocorrido na ponte Tacoma Narrow, ver Figura 1.

Em 1940, a ponte construída sobre o estreito de Tacoma, nos Estados Unidos, veio ao colapso devido ao fenômeno de instabilidade aerodinâmica. Rajadas de vento de baixa intensidade produziram vibrações excessivas que amplificaram os deslocamentos do tabuleiro, provocando modos de falhas torcionais que levaram a estrutura a ruína.
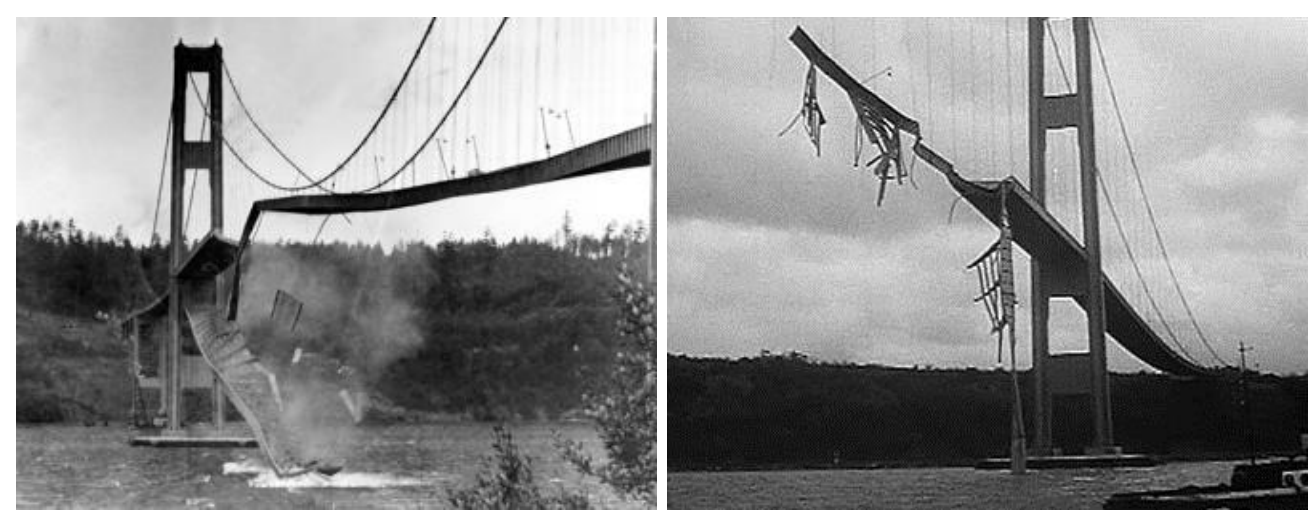

Figura 1: Colapso da ponte Tacoma, 1941. Fonte: American Association of Physics Teachers (2000).

Num contexto mais geral, o fenômeno de instabilidade remete a uma abordagem dinâmica da resposta estrutural. Para que um sistema mecânico seja dito estável, pequenas perturbações na condição de equilíbrio devem conduzir a oscilações em torno da configuração equilibrada da estrutura. Caso contrário, se a resposta estrutural for conduzida a oscilações sempre crescente, o equilíbrio torna-se instável, como no caso da ponte de Tacoma. 
Essa definição geral se deve a (LYAPUNOV, 1892). Porém, no contexto estático de resposta estrutural uma configuração de equilíbrio é dita estável se uma pequena perturbação no sistema conduzir a uma configuração de equilíbrio, tão próxima da inicial, quanto menor a intensidade da perturbação. Caso contrário, diz-se que o equilíbrio do sistema é instável.

Portanto, em regime estático, ou quase-estático, deve-se prever o ponto de instabilidade controlando-se o nível de carregamento verificando-se sempre o limite de resistência do material ou a deslocabilidade da estrutura.

Caso essas condições não sejam atendidas poderão ocorrer consequências desastrosas como a citada por (MILNE, RITCHIE e KARIHALOO, 2003) que ilustram o acidente de grandes proporções ocorrido em Connecticut, no centro cívico do Hatford Coliseum, em 1978.

A arena entrou em colapso após a flambagem prematura das barras que compunham os banzos inferiores das treliças (THORNTON e LEW, 1983) apud (MILNE, RITCHIE e KARIHALOO, 2003).
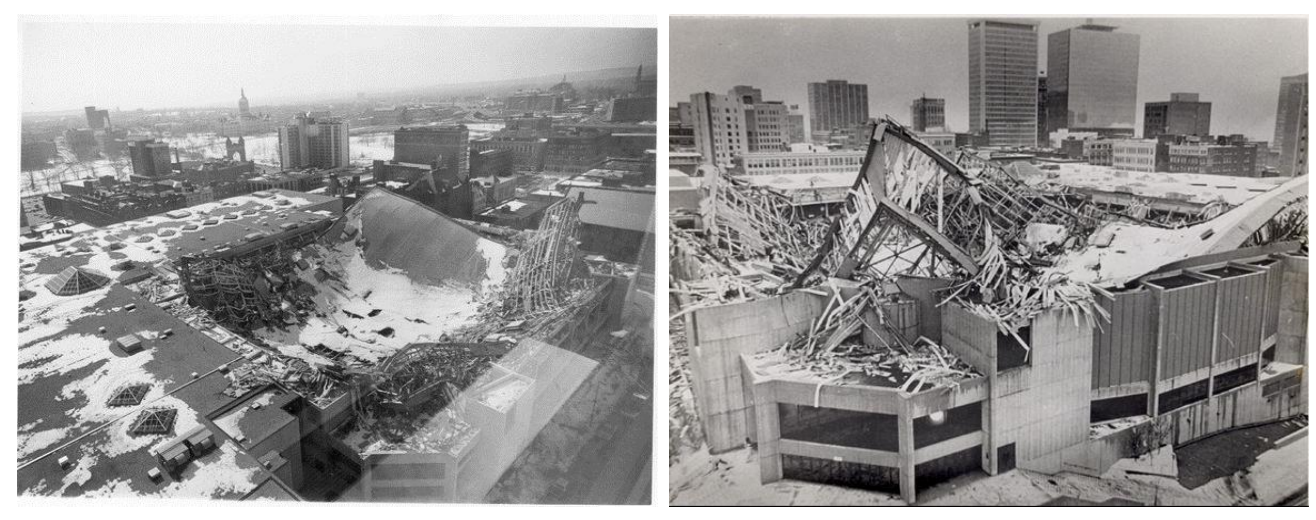

Figura 2: Colapso da cobertura do Hatford Coliseum, 1978. Fonte: Connecticut Historical Society (2014).

Nesse caso, as barras atingiram o modo de falha antes que a capacidade resistente do material fosse alcançada, provocando deformações transversais excessivas, no fenômeno muito conhecido e estudado, denominado flambagem estrutural.

Com esses exemplos ilustrativos é possível constatar que o fenômeno de instabilidade estrutural é um campo de análise amplo e compreende o estudo dos mais variados domínios, como por exemplo: a instabilidade de estruturas elásticas e inelásticas; com resposta estática e dinâmica; de comportamento linear ou não-linear. Além desses domínios, (BAžANT, 2000) inclui a instabilidade estrutural como a principal causa dos processos de danificação e faturamento das estruturas. 
Embora os problemas de cada um desses domínios pareçam desconectados, a existência de uma característica comum entre as respostas destes processos tem apontado para o fenômeno de instabilidade e uma avaliação rigorosa desse comportamento é tema de uma série de estudos, como exposto por (BAžANT, 2003).

De acordo com (LACARBONARA, 2013), na última década foram produzidos centenas de trabalhos técnicos com a finalidade de desenvolver modelos capazes de reproduzir com significativa precisão o fenômeno de instabilidade estrutural. Dentre as técnicas, o autor destaca o desenvolvimento de ferramentas numérico-computacionais, como o método dos elementos finitos.

Dentre os modelos encontrados na literatura, (GENOESE, GENOESE, et al., 2014) apontam para os modelos de barras tridimensionais, denominados, solid-like elements e os modelos de casca não-linear. Os autores destacam que esses modelos figuram entre os principais tipos de elementos finitos utilizados na análise de instabilidade de estruturas, devido sua grande eficiência.

Nesta tese, apresenta-se o fenômeno de instabilidade estrutural, a luz da formulação nãolinear geométrica com o objetivo de promover o desenvolvimento do método dos elementos finitos posicional proposto por (CODA, 2009). Apresentam-se os desenvolvimentos de três formulações Lagrangianas totais com destaque para os aprimoramentos na cinemática do elemento finito de barra geral.

\subsection{Justificativa e Inovação}

De posse do exposto, este trabalho tem como justificativa, adequar os elementos finitos posicional de barra simples, casca e barra geral não-linear geométricos, ao contexto da instabilidade linear e não linear das estruturas.

No âmbito da análise linear de instabilidade, justifica-se a inovação na metodologia de decomposição da matriz Hessiana para o cálculo e análise dos valores e vetores próprios a partir do algoritmo de Lanczos.

Dado o caráter não-linear geométrico, inerente à formulação, as análises no contexto da instabilidade não-linear são automaticamente satisfeitas, bastando se levar em consideração as leis relacionadas a imperfeição geométrica. 
Justifica-se também o uso do elemento de barra geral aprimorado, pois com essa formulação pretende-se detectar as mudanças de forma da seção transversal devido aos modos de instabilidade local. Esse aprimoramento consiste numa inovação no contexto da cinemática Lagrangiana total.

Alguns avanços no estudo da instabilidade estrutural a partir de métodos numéricos já foram realizados por diversos pesquisadores, dos quais destacam-se os grupos de pesquisas envolvidos com o estudo da teoria generalizada de vigas (GBT) (SILVESTRE, 2005), com a implementação do método das faixas finitas (FSM) (LI, 2011) e com a teoria assintótica de Koiter (KASP) (ZAGARI, 2009).

Sendo assim, é de interesse que novas ferramentas sejam desenvolvidas com a possibilidade de conferir ao analista mais precisão na elaboração de projetos, justificando o assunto da presente pesquisa e o caráter inovador da formulação.

\subsection{Objetivos Geral}

O objetivo geral desta pesquisa consiste em se empregar a formulação Lagrangiana total do método dos elementos finitos posicional no estudo do fenômeno de instabilidade das estruturas. Para isso, empregam-se os elementos de barra simples, casca e barra geral nas análises lineares e não-lineares de instabilidade.

Para tornar a abordagem mais didática e definir a metodologia da pesquisa, o objetivo geral da tese é divido nos seguintes objetivos específicos.

\subsection{Objetivos Específicos e Metodologia}

Realizar o levantamento bibliográfico das pesquisas relacionadas a análise de instabilidade com bases em diferentes metodologias teórico-computacionais.

Desenvolver a formulação posicional para os elementos finitos de barra simples com a finalidade de se determinar os pontos críticos na trajetória de equilíbrio usando as estratégias de solução do tipo path-following.

Empregar a biblioteca ARPACK de onde são chamadas as rotinas de autovalores e autovetores para o cálculo das cargas e modos de flambagem com o uso do algoritmo de Lanczos. 
Empregar o algoritmo de Lanczos próximo a carga limite, a fim de se determinar o parâmetro de carga o qual a matriz Hessiana torna-se singular.

Desenvolver a formulação posicional do elemento de casca não-linear geométrico e aplicar a metodologia de decomposição da matriz para se proceder a análise linear de instabilidade a partir da determinação dos autovalores e autovetores.

Realizar as análises em grandes deslocamentos com e comprovar a aplicabilidade do método no regime pós-crítico.

Desenvolver a formulação posicional do elemento finito de barra geral introduzindo-se novas mobilidades nas deformações da seção transversal.

Acoplar as funcionalidades desenvolvidas nesta tese ao código de análise estrutural desenvolvido pelo grupo de mecânica computacional do departamento de engenharia de estruturas, onde diversas funcionalidades estão disponíveis.

Empregar as formulações propostas na resolução de uma série de exemplos de modo a comprovar a aplicabilidade da formulação posicional aplicada aos problemas de instabilidade linear e não-linear.

\subsection{Organização da Tese}

Além deste capítulo, onde são apresentadas as considerações gerais sobre a pesquisa, constam mais oito capítulos descritos resumidamente a seguir:

Capitulo 2: Apresenta-se uma breve revisão bibliográfica relacionadas aos trabalhos que mais influenciaram e contribuíram para a compreensão e o desenvolvimento desta pesquisa. Destaca-se no capítulo duas linhas fundamentais de pesquisa, quais são: os aspectos puramente teóricos relacionados a evolução analítica do assunto e os métodos computacionais aplicados na análise da instabilidade das estruturas via ferramentas numéricas avançadas. Apresenta-se também o estado da arte acerca dos trabalhos com a formulação posicional desenvolvidos no departamento de estruturas.

Capítulo 3: Apresentam-se os fundamentos da análise não-linear geométrica e os princípios da mecânica dos sólidos deformáveis utilizados no desenvolvimento da formulação geral do método dos elementos finitos posicional. 
Capítulo 4: Apresentam-se os métodos numéricos empregados nas análises, tais como: a metodologia de geração das funções interpoladoras de ordem qualquer, as técnicas de quadraturas usada nas integrações numéricas, os procedimentos de solução do sistema não linear e o algoritmo utilizado no cálculo dos autovalores e autovetores.

Capítulo 5: Apresentam-se as definições e os fundamentos utilizados no desenvolvimento da teoria geral da instabilidade elásticas. Apresenta-se a metodologia de decomposição da matriz Hessiana utilizada na teoria linear de instabilidade do método dos elementos finitos posicional.

Capítulo 6: Apresenta-se a formulação do elemento finito de barra simples utilizado na análise de instabilidade de treliças tridimensionais. Determinam-se os pontos críticos na trajetória de equilíbrio utilizando-se algoritmos do tipo path-following, como o método do arclength. Comparam-se os resultados com as respostas obtidas com os algoritmos de NewtonRaphson com controle de força e controle de deslocamentos. Apresenta-se também as aplicações da metodologia de decomposição da matriz Hessiana empregando-se o algoritmo de Lanczos na identificação dos pontos críticos.

Capítulo 7: Apresenta-se a formulação posicional do elemento finito de casca não linear geométrico no referencial Lagrangiano total e lei constitutiva tridimensional completa. Apresentam-se exemplos empregando-se a estratégia de decomposição da matriz Hessiana para o cálculo de cargas e modos de flambagem. Avaliam-se também as trajetórias de equilíbrio em grandes deslocamentos introduzindo-se defeitos nas peças.

Capítulo 8: Apresenta-se o mapeamento tridimensional do elemento finito posicional de barra geral não-linear geométrico e seus aprimoramentos. Apresenta-se a formulação utilizada na consideração dos enriquecimentos cinemáticos da seção transversal. Introduz-se as mobilidades no plano e fora do plano da seção. Exemplos selecionados são apresentados a fim de comparar as soluções obtidas com o elemento de barra geral e o elemento de casca.

Capítulo 9: Apresentam-se as conclusões da pesquisa, analisando-se as contribuições de cada formulação apresentada na análise do fenômeno de instabilidade. Apresentam-se também as considerações para trabalhos futuros seguindo a mesma linha de pesquisa desta tese.

Ao final, encontram-se a lista de referências e um apêndice que trata da geração dos vetores generalizados utilizados na formulação do elemento de barra geral tridimensional. 
Capítulo 1 - Introdução 


\section{Revisão Bibliográfica}

\subsection{Apresentação do Capítulo}

Neste capítulo examinam-se os aspectos analíticos e computacionais das linhas de pesquisas relacionadas ao fenômeno de instabilidade estrutural. Inicialmente faz-se um breve apanhado histórico mostrando-se a evolução dos conceitos e dos principais métodos teóricos de análise. Posteriormente abordam-se os aspectos computacionais dos métodos numéricos, amplamente utilizados na análise de problemas práticos de instabilidade das estruturas. Finalmente, apresenta-se o estado da arte com relação ao método dos elementos finitos posicional no Departamento de Estruturas da Escola de Engenharia de São Carlos, tendo em vista justificar a presente pesquisa no contexto da análise de instabilidade com o emprego da formulação posicional.

\subsection{Instabilidade Estrutural - Aspectos Analíticos}

A primeira abordagem científica a tratar da instabilidade de sistemas mecânicos está escrita nos princípios matemáticos de filosofia natural, de Newton. Porém, (ELISHAKOFF, 2005), destaca que somente com os trabalhos de Leonhard Euler (1707-1783) e Warner Koiter (1914-1997) foi estabelecido, o que atualmente se considera, os paradigmas clássico e moderno da teoria da instabilidade estrutural.

A abordagem clássica, ainda utilizada no dimensionamento de colunas esbeltas, foi investigada por (EULER, 1744) apud (TIMOSHENKO e GERE, 1961) com base no cálculo variacional e no conceito de raio de curvatura, originalmente investigo por Jacob Bernoulli. Euler determinou a carga crítica de flambagem de colunas esbeltas simplesmente apoiadas, sob a ação de forças compressivas. Em notação atual, a carga crítica obtida por Euler é escrita como:

$$
P_{c r}=\frac{\pi^{2} E I}{L^{2}}
$$

Para (TIMOSHENKO, 1953) merece destaque também as investigações experimentais de Musschenbroek, cujas conclusões também apontavam para a proporcionalidade inversa entre a carga de flambagem e o quadrado do comprimento da coluna.

Em (TIMOSHENKO, 1953) há também menção aos estudos realizados por Lagrange, $\underline{\text { que foi quem introduziu a abordagem energética, a partir do conceito escalar da função }}$ 
Lagrangiana do sistema mecânico. Lagrange aplicou o método variacional no estudo dos critérios de equilíbrio e estabilidade de sistemas com um número finito de graus de liberdade. As contribuições de Lagrange incluem também a determinação das cargas de bifurcação para diferentes modos de flambagem.

A partir da teoria geral da flexão proposta por Navier, a carga crítica de flambagem pode ser determinada empregando-se a equação diferencial de equilíbrio. Sob a hipótese de pequenas deflexões e material elástico linear, Navier estabeleceu a proporcionalidade do carregamento em relação a rigidez a flexão.

A partir da solução da equação diferencial (2.2), se passou a determinar analiticamente o valor da carga crítica de colunas esbeltas.

$$
w^{\prime \prime}+\frac{P}{E I} w=0
$$

Um aperfeiçoamento na cinemática de Navier considera a utilização da expressão completa da curvatura eliminando a hipótese de pequenas deflexões.

Ao admitir essas considerações a equação diferencial toma a forma:

$$
w^{\prime \prime}+\frac{P}{E I} w\left[1+\left(w^{\prime}\right)^{2}\right]^{3 / 2}=0
$$

A solução da equação (2.3) foi realizada com sucesso nos trabalhos de (KIRCHHOFF, 1859) apud (BAžANT, 2003) e (KÁRMÁN, DUNN e TSIEN, 1940), onde são considerados os casos para grandes deflexões, empregando-se integrais elípticas.

Porém, ainda havia uma incompatibilidade da teoria quando se aplicavam a colunas robustas. Barras não esbeltas possuem baixa rigidez ao cisalhamento produzindo deformações que diminuem substancialmente o valor da carga crítica. A constatação dessa relação só veio a ser esclarecida com o trabalho de (ENGESSER, 1889) apud (BAžANT, 2003) e posteriormente resolvidas em (TIMOSHENKO, 1921), o qual propôs uma extensão cinemática da teoria de flexão, em que os efeitos das distorções e rotação da seção transversal são considerados.

Embora grande parte dos trabalhos sobre a instabilidade estrutural tenham se originado como base na teoria de Euler, esta, fora intensamente criticada por seus contemporâneos devido a não reprodutibilidade dos experimentos com os materiais disponíveis na época (madeira e 
rocha). (TODHUNTER, 1893) informa sobre a não relevância prática da teoria para os projetistas e construtores da época, pois os elementos estruturais utilizados eram providos de grandes dimensões. $\mathrm{O}$ autor afirma que nenhuma aplicação prática dessa teoria pode ser verificada por mais de um século.

De acordo com (ELISHAKOFF, 2000) a teoria de Euler permaneceu abandonada até meados da revolução industrial, período em que o aumento significativo por estruturas de aço, especialmente em aplicações na indústria da construção civil e ferroviária, fez com que as teorias da instabilidade de estruturas delgadas fossem constatadas na prática.

Mas o fenômeno de instabilidade não se limita a análise de colunas sob compressão, como destaca (BAžANT, 2003). O campo teórico se estende a outras áreas do conhecimento como pode ser constatado em inúmeros trabalhos publicados no final do século XIX e início do século XX, período em que a fundamentação teórica se consolidou. Dentre os trabalhos desse período merece destaque o estudo realizados por (POICARÉ, 1885) sobre o movimento de rotação de fluidos onde, pela primeira vez, foi utilizado o conceito de ponto de bifurcação.

(POICARÉ, 1885) empregou o conceito para designar o ponto onde ocorre a intersecção de dois ramos na trajetória de equilíbrio devido a um mesmo nível de solicitação. Poicaré estabeleceu que a mudança na natureza do equilíbrio determina a existência de pontos de bifurcação emergindo de uma trajetória fundamental estável.

(BRYAN, 1888) mostrou pela primeira vez na teoria geral da estabilidade elástica que o equilíbrio de um sistema é governado por um mínimo valor na energia potencial total, sendo necessário, reter e analisar apenas os termos lineares da expressão da energia. Matematicamente a teoria de Bryan era incompleta, pois não apresentava formalmente os conceitos de estabilidade ou instabilidade do equilíbrio. Somente (LYAPUNOV, 1892) deu excepcional profundidade e precisão as definições, aplicando-as na análise de sistemas dinâmicos. Com esse trabalho Lyapunov obteve seu doutoramento e uma série de novos trabalhos introduziram substanciais contribuições para a compreensão do fenômeno (SMIRNOV, 1992).

O embasamento teórico da publicação de Lyapunov permitiu que diversas contribuições pudessem se fundamentar nos teoremas gerais enunciados em sua tese, dentre as quais destacase o trabalho de (SOUTHWELL, 1913). Nesse trabalho, o autor investiga as consequências do equilíbrio após a ação de uma perturbação finita no deslocamento ou na velocidade crítica do 
sistema mecânico, introduzindo o conceito de equilíbrio neutro ou indiferente. As conclusões do autor são a base da teoria do equilíbrio adjacente.

Na década de 1930 uma abordagem de caráter estritamente matemático ganhava notoriedade. No trabalho de (ANDRONOV e PONTRYAGIN, 1937) apud (KUZNETSOV, 2004) aparece, pela primeira vez, a noção de instabilidade de variedades topológicas em sistemas dinâmicos. Essa abordagem foi o cerne do que viria a ser a teoria da catástrofe introduzida por (THOM, 1972) apud (STEWART, 1981). A teoria da catástrofe de Thom estuda os aspectos qualitativos de uma equação diferencial, que levam ao aparecimento repentino de uma solução súbita após se variar suavemente as condições de um determinado parâmetro.

Em (STEWART, 1981) há uma vasta revisão das principais aplicações da teoria da catástrofe, com destaque para os exemplos de instabilidade de sistemas mecânicos. O autor também destaca a habilidade da engenharia em tratar o fenômeno, sem recorrer explicitamente ao formalismo da teoria e afirma, que os desenvolvimentos da teoria geral da instabilidade levam às mesmas conclusões da teoria de Thom. Dentre os trabalhos com essas características, o autor destaca as publicações de (THOMPSON e HUNT, 1973) e (SEWELL, 1976).

Apesar de todo o rigor introduzido nas definições e teoremas, as pesquisas citadas até o momento, fundamentam-se na determinação e caracterização dos pontos críticos e na ação que promove a súbita mudança de comportamento do sistema. Em meados do século $\mathrm{XX}$, havia o interesse em se elucidar alguns resultados inesperados em experimentos realizados com cascas esféricas e cilíndricas.

A primeira investigação sistemática a respeito desse assunto está descrita em (KÁRMÁN e TSIEN, 1941). Neste artigo os autores demostram que em estruturas de cascas finas, a falha ocorre a um nível de carga crítica bem menor que o previsto analiticamente pela teoria clássica. Os autores justificam o fato devido a presença de imperfeições geométricas que amplificam o efeito da não-linearidade (BAžANT, 2000).

A aplicação de um critério consistente para descrever o comportamento pós-crítico dessas estruturas foi descrita com sucesso em (KOITER, 1967) apud (ELISHAKOFF, 2000). Publicada em língua inglesa, vinte e sete anos após sua versão original ter sido publicada em holandês, Koiter desenvolve nesse trabalho a teoria geral da instabilidade descrevendo o 
comportamento assintótico da energia num caminho de equilíbrio pós-crítico, a partir de uma lei de sensibilidade as imperfeições (BAžANT e CEDOLIN, 2010).

Koiter introduziu a ideia de espaço multidimensional cujas coordenadas são os carregamentos e as amplitudes dos deslocamentos, são os modos de flambagem da estrutura. Ele mostrou como os diferentes tipos de caminhos de equilíbrio podem ser obtidos a partir da expressão de energia potencial, não limitando a análise aos termos de primeira e segunda, mas expandindo a série até as derivadas de ordem superior.

A contribuição mais relevante do trabalho de Koiter consiste nas conclusões obtidas com o método assintótico. Os resultados da teoria apontam a natureza do equilíbrio pos-crítico a partir do que ocorre no ponto de bifurcação, ou seja, se nesse ponto o sistema exibe uma configuração estável então em sua vizinhança a posição de equilíbrio só poderá existir para carregamentos superiores que o crítico e estas posições também são estáveis. Caso contrário, se no ponto de bifurcação se caracterizar um estado instável de equilíbrio, o equilíbrio nas imediações desse ponto só existirá para cargas menores que a crítica e o tipo de equilíbrio será instável também.

Outra importante conclusão do trabalho de Koiter se refere a influência das imperfeições com relação a capacidade de carga das estruturas. Nesse trabalho o autor estabelece que, se a posição de equilíbrio de uma estrutura sem imperfeições, no ponto de bifurcação é instável, então, a carga crítica das estruturas imperfeitas é menor do que a da estrutura perfeita em decorrência dessas imperfeições.

Como comentado em (PASCOTE, 1993), as aplicações da teoria de Koiter são utilizadas com sucesso na investigação da instabilidade de casos particulares de sistemas estruturais contínuos, formados por cascas cilíndricas, esféricas, placas e elementos lineares de parede fina, e destaca, as contribuições do trabalho de (THOMPSON, 1963) no desenvolvimento da teoria instabilidade elástica de sistemas discretos. (ELISHAKOFF, 2000) reafirma a relevância da teoria assintótica de Koiter na determinação do caminho pós-crítico de sistemas discretos e enfatiza a relevância desse trabalho como um paradigma moderno para a compreensão geral da teoria da instabilidade elástica.

Nesta seção, cabe destacar as contribuições de (THOMPSON, 1963), (BUDIASKY e HUTCHINSON, 1964) e (SEWELL, 1969) à teoria geral da instabilidade elástica. Esses 
trabalhos, aplicados ao estudo do fenômeno em sistemas discretos, fundamentam a abordagem moderna dos métodos numéricos, assunto tratado na próxima seção.

\subsection{Instabilidade Estrutural - Aspectos Numéricos}

Os métodos numéricos de previsão e determinação de cargas críticas são de grande interesse para a engenharia. É a partir das previsões numéricas que um determinado projeto está fadado ao sucesso ou ao fracasso. Quando os resultados dessas previsões levam inevitavelmente a uma situação de fracasso, cabe ao analista propor soluções que viabilizem o empreendimento, conferindo-lhe segurança.

Uma das técnicas numéricas bastante difundida e empregada na análise de instabilidade, sem dúvida é o método dos elementos finitos. A versatilidade do método permite que inúmeras funcionalidades possam ser incorporadas em análise dessa natureza (BAžANT e CEDOLIN, 2010). Os autores destacam a simplicidade em se formular o problema de instabilidade empregando o método dos elementos finitos tanto em análises lineares como não-lineares.

Dentre as estratégias usadas com o método dos elementos finitos (RIKS, 2004) destaca as atuais formulações não-lineares, com base em algoritmos capazes de traçar todo o caminho de equilíbrio da estrutura identificando os pontos críticos ao longo de suas trajetória (RISK, 1972). O autor destaca também o crescimento no número de trabalhos científicos com base nas técnicas assintóticas provenientes da teoria de Kioter. A esse respeito é de notório destaque os trabalhos de (CASCIARO, SALERNO e LANZO, 1992), (GARCEA, MADEO e CASCIARO, 2012) e inúmeras contribuições empregando o elemento finito corrotacional na análise assintótica, oriundos do grupo de pesquisas do Dipartimento di Strutture dell'Università della Calabria.

No contexto das análises de instabilidade das estruturas com perfis de parede delgada destacam-se as estratégias mais difundidas na literatura, comumente associadas a teoria generalizada de vigas (Generalized Beam Theory - GBT) (SILVESTRE, CAMOTIM e SILVA, 2011), o método das faixas finitas (Finite Strip Metod - FSM) (SCHAFER e ÁDÁNY, 2006).

A GBT originalmente desenvolvida por (SCHARDT, 1994) é uma teoria de barras gerais com base na hipótese clássica de Vlasov capaz de descrever as deformações da seção transversal de membros prismáticos submetidos à flexão e a torção. Qualquer deformação do elemento estrutural pode ser descrita como uma combinação linear de modos de instabilidade 
isolados. O método é também capaz de fornecer a contribuição de cada modo para a configuração final ajudando a compreender o comportamento da estrutura (NEDELCU, 2010).

Atualmente modificações na formulação GBT contribuíram com uma variedade de melhoramentos na formulação, tais como, a consideração de seções abertas ramificadas (DINIS, CAMOTIM e SILVESTRE, 2006), seções arbitrárias (GONÇALVES, DINIS e CAMOTIM, 2009) e seções abertas variáveis (NEDELCU, 2010). Aprimoramentos como a análise com carregamento vibratório em membros não homogêneos de parede fina (SILVESTRE e CAMOTIM, 2006 a), análise do comportamento pós-crítico, com base na análise não linear geométrica (SILVESTRE e CAMOTIM, 2006 b) fazem parte desses avanços. Recentemente, devido ao extenso desenvolvimento realizado pela equipe de pesquisa liderada por Silvestre e Camotim no Instituto Superior Técnico da Universidade de Lisboa, foi criado o (GBTUL, 1.0), um programa computacional que permite realizar análise linear de instabilidade utilizando a GBT.

O GBTUL é um programa com base na associação entre a teoria generalizada de vigas e o método dos elementos fintos (DINIS, CAMOTIM e SILVESTRE, 2006). Nesse programa, barras simplesmente apoiadas são tratadas de maneira analítica, enquanto que barras com outros tipos de vinculações são avaliadas via método dos elementos finitos. O programa exibe como resultado os valores dos carregamentos críticos e as formas de instabilidade correspondentes a uma análise linearizada.

Outro método especializado na decomposição modal e bastante difundido na literatura é o método das faixas finitas, originalmente desenvolvido por (ÁDÁNY e SCHAFER, 2006 a) e (ÁDÁNY e SCHAFER, 2006 b). O método convencional, também chamado semi-analítico da FSM fornece uma ampla abordagem utilizada na análise da instabilidade de estruturas elásticas com perfis de parede fina. Basicamente o FSM é uma variação do FEM, onde, substituem-se os elementos da seção transversal por uma série de faixas longitudinais descritas por funções de forma que representam os campos de deslocamento nas direções transversais (LI e SCHAFER, 2010 a).

Uma variação do FSM chamada de Método das Faixas Finitas Confinado (cFSM constrained Finite Strip Method) criado por (ÁDÁNY e SCHAFER, 2008) utiliza as hipóteses da GBT com a finalidade de aprimorar o FSM clássico. No cFSM as funções de forma utilizadas na descrição das faixas na direção transversal são as mesmas utilizadas no FEM com os 
elementos clássicos de vigas, enquanto que as funções de forma na direção longitudinal empregam relações trigonométricas (SCHAFER e ÁDÁNY, 2006).

O cFSM está implementado em um código computacional desenvolvido por Schafer juntamente com o grupo de pesquisa da Universidade Johns Hopkins, chamado (CUFSM, 4.05). O CUFSM é um programa com base no método das faixas finitas capaz de determinar os carregamentos críticos no regime elástico, assim como as formas de instabilidade dos perfis estruturais esbeltos. Nesse programa ainda existem algumas limitações, como por exemplo: só é possível se realizar as análises de instabilidade de barras prismáticas isoladas sem restrição ao empenamento (LI e SCHAFER, 2010 b). Devido a base do programa ser o método das faixas finitas, existem ainda outras restrições na para as análises. A formulação somente admite que as seções extremas das barras possam ser divididas em elementos. O método das faixas finitas confinadas supre essa deficiência sendo permitida a criação de nós intermediários ao longo do eixo longitudinal da barra. A versão mais recente do CUFSM já admite esses aprimoramentos na análise.

Uma alternativa para a análise de instabilidade de estruturas de parede fina é a modelagem direta com elementos finitos de casca (ÁDÁNY, 2012).

Elementos como os de barra geral proposto por (CODA, 2009), (CODA e PACCOLA, 2010) e (CODA e PACCOLA, 2011) e de casca não linear geométrico (CODA e PACCOLA, 2008) e (CODA e PACCOLA, 2009) são altamente eficientes para a análise dessas estruturas. Os aprimoramentos introduzidos pelos autores nesses tipos de elementos tornam o uso do FEM um método bastante atrativo. Dentre as generalidades dessa formulação destacam-se a consideração do cisalhamento na energia de deformação, a generalidade na geometria das seções transversais, o modo de empenamento introduzido com base na teoria da torção livre, a medida variável de deformação na espessura da seção, além da análise dinâmica, nãolinearidade física e geométrica e carregamentos não conservativos são consideradas.

O presente trabalho estuda o elemento finito de barra geral e tem como objetivo agregar a cinemática do elemento a consideração das mudanças de forma, no plano e fora do plano da seção transversal. Além dos aprimoramentos no elemento de barra geral, a utilização dos elementos finitos de barra simples nas análises em grandes deslocamentos de treliças, a partir de estratégias do tipo path-following mostram-se promissoras. 
Tão promissora quanto, consiste a proposta original de decomposição da matriz hessiana utilizada na formulação linear de instabilidade com os elementos finitos posicional.

Nos capítulos seguintes apresenta-se a formulação desses elementos, e a contribuição da presente pesquisa ao atual de estágio de desenvolvimento do fenômeno de instabilidade via métodos computacionais

\subsection{Formulação Posicional: Estado da arte no Departamento de Estruturas}

O programa de pós-graduação do Departamento de Estruturas (SET) originou-se após a departamentalização das secretarias da Universidade de São Paulo na década de 1970. Desde então, exercem diversas atividades, nas quais incluem a formação strictu sensu nos níveis de mestrado e doutorado das grandes áreas da engenharia de estruturas, sendo uma delas a de métodos numéricos.

$\mathrm{Na}$ área de métodos numéricos destacam-se os trabalhos do Grupo de Mecânica Computacional (GMEC) envolvidos com a formulação e aprimoramentos do elemento finito posicional. A formulação posicional consiste no emprego das coordenadas nodais (posições) para descrever os elementos finitos. Atualmente as publicações nesse assunto são importantes referências no cenário científico nacional e internacional.

Cabe ressaltar que desde 2007 o programa de pós-graduação em Engenharia de Estruturas do SET é avaliado com o conceito máximo pela Coordenação de Aperfeiçoamento de Pessoal de Nível Superior (CAPES).

No SET a utilização dos elementos finitos posicional se iniciou a partir da publicação da tese de doutoramento de (GRECO, 2004), sob orientação do Professor Humberto Breves Coda, idealizador da metodologia. Nesta tese, o autor trata da formulação posicional e dos algoritmos numéricos aplicados a análise não-linear geométricas de estruturas reticuladas, considerando o contato e o impacto em anteparos rígidos. Ainda nesse trabalho o autor aborda as formulações estática e dinâmica empregando os algoritmos numéricos de Newton-Rapshon e Newmark. Com base nessa metodologia diversas pesquisas foram desenvolvidas no SET demostrando a aplicabilidade da técnica.

A seguir descrevem-se as contribuições dos pesquisadores que passaram pelo programa de pós-graduação do Departamento de Estruturas e que trabalharam com a formulação do 
elemento finito posicional em diversas aplicações. Essas pesquisas dão subsídio para que a proposta da presente tese venha a contemplar um tópico crucial do estudo da mecânica dos materiais e dos métodos numéricos, que é o fenômeno de instabilidade estrutural.

No trabalho de (MARQUES, 2006) é apresentada a continuidade do estudo de contato e impacto empregando o elemento finito bidimensional de chapa, aplicado a análise não-linear geométrica com base no elemento finito posicional bidimensional. $\mathrm{O}$ autor utiliza o integrador temporal de Newmark modificado, com a intensão de proferir estabilidade ao algoritmo.

(SANCHES, 2006) realiza o acoplamento das descrições Euleriana e Lagrangiana para a análise da iteração fluido-estrutura com o emprego de elementos finitos bidimensionais. (SANCHES, 2011) amplia a capacidade do código computacional fluidodinâmico, inserindo a solução numérica da equação de Navier-Stokes para escoamento compressíveis, por meio da descrição Lagrangiana-Euleriana arbitrária e a iteração fluido-casca. O autor destaca a eficácia e robustez da formulação posicional para a análise de problemas dinâmicos, sobretudo, da iteração fluido estrutura.

(SANTOS, 2008) apresenta o aprimoramento do elemento finito de barra tridimensional introduzindo o modo de empenamento de barras através da solução numérica do problema da torção livre de Saint-Venant. A autora verifica que os problemas de torção e flexo-torção apresentam boas soluções com o emprego da descrição em posições e destaca a originalidade do cálculo do centro de cisalhamento a partir do método dos elementos finitos.

O elemento de barra tridimensional estudado por (SANTOS, 2008) emprega novos parâmetros nodais chamados vetores generalizados. Esses vetores quando utilizados na descrição cinemática do elemento, confere flexibilidade ao cisalhamento para as barra tridimensionais, semelhante a cinemática da viga de Timoshenko.

$\mathrm{Na}$ presente tese emprega-se a estrutura desse elemento de barra tridimensional e se propõem novos aprimoramentos para o elemento, tendo em vista considerar as deformações no plano e fora do plano das seções transversais. A descrição detalhada desses aprimoramentos será contemplada no capítulo 8 .

(MACIEL, 2008) apresenta a formulação posicional para a análises de pórticos bidimensionais estático e dinâmico, assim como as considerações acerca do contato em anteparo rígido de sólidos tridimensionais modelados com elementos tetraédricos de 
aproximação cúbica. Utiliza também o elemento de casca com base em posições para modelar estruturas esbeltas constata a necessidade de se aprimorar esses elementos para captar as especificidades, como por exemplo: as cargas críticas, de estruturas de parede fina.

(PASCON, 2008) implementa os modelos constitutivos hiperelásticos não lineares para o elemento de casca não linear geométrico no referencial. (PASCON, 2012) utiliza a mesma metodologia para implementar os modelos constitutivos com gradação funcional em regime de grandes deslocamentos e elevadas deformações em sólidos tridimensionais. $\mathrm{O}$ autor emprega os elementos finitos hexaédricos e tetraédrico com qualquer ordem de aproximação num referencial Lagrangiano total e destaca que somente com a paralelização dos algoritmos foi possível se perceber ganhos significativos na resposta estrutural dos modelos elastoplástico, pois com isso, pode recorrer a malhas mais refinadas durante as análises.

(MINSKI, 2008) retoma o problema de contato e impacto em anteparos rígidos utilizando a formulação posicional com a introdução das considerações acerca do atrito. $\mathrm{O}$ autor utiliza as técnicas dos multiplicadores de Lagrange e das penalidades, concluindo sobre a equivalência de ambas para a representação do contato. No sentido de apresentar uma formulação termodinamicamente consistente sobre o impacto, (CARRAZEDO, 2009) realiza análises empregando o potencial de energia livre de Helmotz e as leis da termodinâmica na avaliação do impacto de estruturas com comportamento termoelástico e termoplástico. Para efetuar as análises o autor utiliza o elemento finito posicional bidimensional.

(SILVA, 2010) emprega o acoplamento da formulação de pórticos bidimensionais posicional ao método dos elementos de contorno, para proceder a análise da iteração soloestrutura. (SILVA, 2014) propõem a utilização da formulação material, considerando todas as partes componentes de edifícios altos, incluindo as ligações entre o núcleo, as lajes, o solo e as fundações. $\mathrm{O}$ autor modela as lajes via elemento de casca e acopla a matriz de rigidez desses elementos ao de barra tridimensional usados na descrição de vigas e pilares. Em suas conclusões, o autor relata a boa adequação do acoplamento para captar os efeitos da interação núcleo-pavimento, e do empenamento do núcleo na rigidez global do edifício.

(RIGOBELLO, 2011) emprega o elemento de barra geral no estudo de estruturas aporticadas de aço quando expostas a ação térmica decorrentes de incêndios. $\mathrm{O}$ autor realiza análises térmicas transientes considerando o critério tridimensional de plasticidade com a finalidade de determinar os campos de temperatura nas seções transversais dos elementos sob 
ação do fogo. O autor destaca a boa representatividade do elemento finito posicional devido a natureza não linear geométrica da formulação e relata o caráter mais realista dos resultados para estruturas em situação de incêndio.

Empregando o elemento de pórtico e treliça no plano, (REIS, 2012) apresenta um aprimoramento capaz de considerar as ligações semirrígidas elastoplásticas nas barras. (CARDOSO, 2013) utiliza o elemento de treliça não linear geométrico para mostrar a eficácia em simular o comportamento de cabos isolados de pontes estaiadas.

(SANCHEZ, 2013) aplica o elemento posicional de barra bidimensional para obter a resposta estática e dinâmica de estruturas offshore em contato com o leito do mar. O autor modela os deslocamentos severos no topo do raisers a partir de três técnicas: a redução progressiva da rigidez da estrutura, a penalização dos deslocamentos nodais e a redução progressiva da massa e do amortecimento. O fundo do leito do mar é modelado com um modelo de molas distribuídas para o solo. A solicitações decorrentes da flutuação, correntes marítimas, e peso próprio são inseridas no modelo. $\mathrm{O}$ autor destaca a adequação dos resultados quando comparados com as referências presentes na literatura.

(SAMPAIO, 2014) apresenta o acoplamento entre os elementos finitos curvilíneos tridimensional (fibra) e o elemento de casca (matriz) para simular o comportamento estrutural de materiais compósitos. A autora desenvolve uma formulação de casca laminada anisotrópicas com não linearidade geométrica que conserva o número de graus de liberdade do sistema. A autora destaca também que esta alternativa se mostra bastante promissora tendo em vista a não necessidade de se utilizar técnicas de homogeneização para representar as propriedades elásticas do meio, sobretudo se tratando de uma distribuição aleatória de fibras.

Recentemente, (NOGUEIRA, 2015) apresenta um aprimoramento no elemento finito de barra bidimensional, com a finalidade de considerar diferentes camadas ao longo da espessura do elemento de acordo com a teoria de Layerwise. Com essa formulação o autor propõe a modelagem de compósitos laminados considerando a continuidade das tensões na interface entre as lâminas. Outra aplicação recente é apresentada por (MOURA, 2015), que considera o acoplamento multifásico na simulação de materiais compósitos particulados. A autora avalia a influência de propriedades como: geometria, tamanho, fração volumétrica e propriedades mecânicas das partículas, no comportamento estrutural dos meios heterogêneos. Em abas 
aplicações é verificado a boa representatividade do elemento posicional na descrição de materiais compósitos.

O presente levantamento das pesquisas desenvolvidas com o elemento finito posicional no Departamento de estruturas tem como objetivo mostrar a abrangência da metodologia. É possível constatar a evolução das aplicações em um intervalo de tempo, relativamente curto. Porém, verifica-se que existe ainda uma lacuna quanto ao estudo específico do fenômeno de instabilidade modeladas com essa formulação.

Nesta tese o fenômeno de instabilidade estrutural é abordado à luz do método dos elementos finitos posicional. A vantagem de se empregar a metodologia consiste em se utilizar uma formulação geometricamente exata onde a descrição da instabilidade a partir da trajetória de equilíbrio em grandes deslocamentos é intrínseca ao método. Destaca-se ainda a originalidade da proposta, não só com relação aos trabalhos desenvolvidos no Departamento de Estruturas, como também com relação as principais fontes de referência sobre o tema.

\subsection{Fechamento}

Neste capítulo foram apresentadas as principais referências bibliográficas consultadas durante a pesquisa. $\mathrm{O}$ objetivo em expor essas referências foi apresentar uma síntese dos desenvolvimentos analíticos e numéricos do fenômeno de instabilidade estrutural. Foram apresentados também todos os trabalhos desenvolvidos no departamento de estruturas que utilizaram a formulação posicional para se justificar a necessidade de se realizar um estudo sobre a aplicabilidade do método na análise de problemas relacionados a instabilidade estrutural. 



\section{Fundamentos da Análise Não - Linear Geométrica}

\subsection{Apresentação do Capítulo}

Na engenharia estrutural recorrer-se a hipótese de linearidade geométrica quando se admite proporcionalidade entre causa e efeito, como no caso das análises em níveis de pequenos ou moderados deslocamentos. Ao se adotar a hipótese de linearidade geométrica o analista deverá estar ciente de algumas limitações do modelo, sobretudo em problemas envolvendo instabilidade estrutural. Problemas envolvendo a análise de instabilidade é imprescindível que se tome em mãos teorias geometricamente não-lineares, cuja fundamentação sustenta-se na mecânica dos sólidos deformáveis.

Neste capítulo apresentam-se a formulação não linear geométrica dos sólidos deformáveis empregada na geração dos elementos finitos posicional utilizados nesta tese. A partir do princípio da conservação da energia mecânica deduz-se o princípio da estacionariedade da energia potencial.

\subsection{Formulação Não - Linear Geométrica dos Sólidos Deformáveis}

O objetivo da análise não linear geométrica dos sólidos deformáveis consiste em avaliar o equilíbrio do sólido na sua configuração atual, ou seja, depois de ocorridos deslocamentos e deformações devido a ação de carregamentos externos. Nesse tipo de formulação admite-se a situação de pequenas deformações e grandes deslocamentos, de modo que as configurações inicial e atual sejam tratadas de maneira completamente distintas.

Na mecânica do contínuo duas representações são comumente utilizadas para descrever o movimento das partículas, a saber: a descrição Lagrangiana (também chamada Material) e a descrição Euleriana (ou Espacial) (HOLZAPFEL, 2000).

De acordo com (OGDEN, 1997), na descrição Lagrangiana o referencial do movimento acompanha o deslocamento das partículas no espaço. (COIMBRA, 1978), afirma que a descrição Lagrangiana é a mais adequada para quantificar as deformações que ocorrem nos sólidos deformáveis. Na descrição Euleriana, o referencial é imutável e o interesse está em se saber o que ocorre em um ponto fixo do espaço em cada intervalo do movimento. (COIMBRA, 1978) comenta também que este tipo de descrição é adequada para representar fluidos em movimento. 
Para familiarização com os conceitos de mecânica clássica é de interesse consultar (SYMON, 1960) e (BUTKOV, 1973). Nesta seção são apresentados apenas os conceitos essências a formulação do elemento finito.

\subsubsection{Cinemática dos Sólidos Deformáveis}

A cinemática dos sólidos deformáveis trata da descrição do movimento de um corpo sem levar em consideração suas causas. A principal hipótese adotada no estudo da cinemática consiste em se admitir a ideia de meio contínuo. Nesse meio o sólido é tratado como um conjunto contínuo de pontos materiais cujas grandezas: posição, velocidade e aceleração são expressas por meio de funções contínuas.

Definir uma função contínua para descrever as grandezas dos pontos materiais consiste em associar a cada instante do movimento, o lugar geométrico dos pontos do sólido descritos por meio de suas coordenadas geométricas, em relação a um referencial do espaço, neste caso, o espaço Euclidiano tridimensional.

O espaço euclidiano tridimensional deverá formar uma base ortonormal dextrogira, tal que as relações, $\hat{e}_{i} \cdot \hat{e}_{j}=\delta_{i j}$ e $\hat{e}_{i} \times \hat{e}_{j}=\hat{e}_{k} \varepsilon_{i j k}$ sejam válidas (BUTKOV, 1973). Sendo, $\hat{e}_{i}$ as componentes cartesianas da base ortonormal, $\delta_{i j}$, o símbolo de Kroneker, e $\varepsilon_{i j k}$, o símbolo cíclico de Levi-Civita.

De posse dessas propriedades e da hipótese do contínuo, considere-se um corpo $\mathcal{B}$ com $P \in \mathcal{B}$ imerso no espaço Euclidiano tridimensional, como ilustrado na Figura 3.

A partir dessa representação definem-se os seguintes conceitos. 


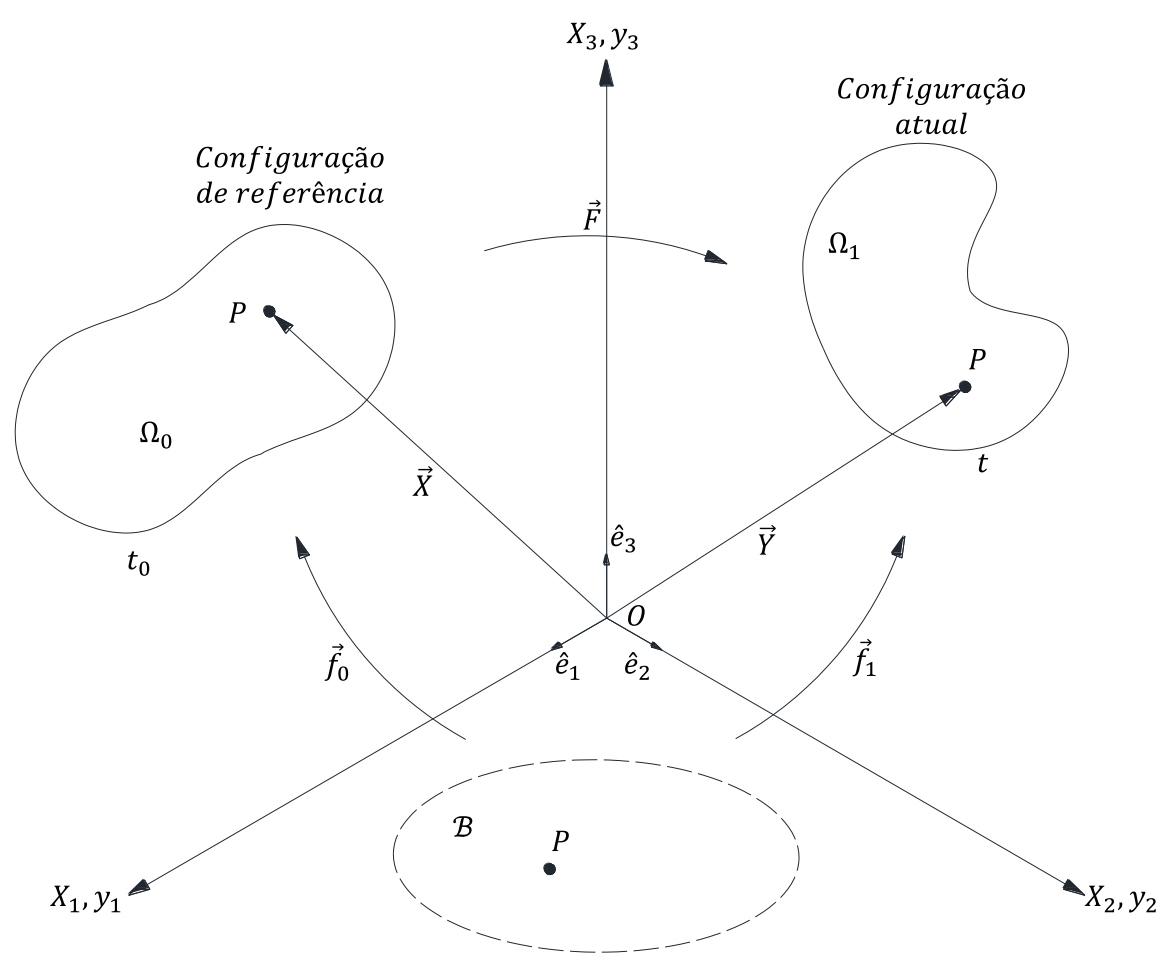

Figura 3: Mudança de configuração de um sólido deformável

\subsubsection{Configuração de Referência}

A configuração de referência é definida supondo-se conhecida a posição de qualquer ponto material $P$, em um determinado instante $t_{0}$, no espaço de coordenadas Euclidiano. A posição desses pontos é representada pelo vetor $\vec{X}$.

No instante $t_{0}$, os pontos materiais ocupam a região $\Omega_{0}$. A essa região dá-se o nome de configuração de referência.

\subsubsection{Configuração Atual}

Decorrido um determinado tempo $t$, a região ocupada pelo sólido passa a ocupar a configuração $\Omega_{1}$, denominada configuração atual, ou configuração deformada, cujas posições dos pontos materiais são definidas pelo vetor $\vec{Y}$.

A partir dessas definições é possível quantificar o movimento do sólido utilizando o conceito de mapeamento cinemático e função mudança de configuração, apresentados a seguir. 


\subsubsection{Transformação dos Sólidos Deformáveis}

Todo sólido deformável sujeito a ações mecânicas, muda de forma ou configuração (OGDEN, 1997). Na Figura 3, o campo vetorial $\vec{F}$ é a transformação ou função mudança de configuração, definida com base na relação entre o mapeamento do sólido na configuração de referência $\vec{f}_{0}$ e a configuração atual $\vec{f}_{1}$, por meio da composição:

$$
\vec{F}=\vec{f}_{1} \circ\left(\vec{f}_{0}\right)^{-1}
$$

A transformação $\vec{F}$ geralmente é desconhecida, porém essa função pode ser calculada a partir dos mapeamentos nas configurações de referência e deformada, como descrito na equação (3.1). O mapeamento fica unicamente determinado calculando-se a configuração deformada $\Omega_{1}$, a partir das configurações de referência $\Omega_{0}$ e configuração auxiliar $\mathcal{B}$, ambas conhecidas.

$\mathrm{Na}$ passagem da formulação analítica para o método dos elementos finitos, a configuração auxiliar $\mathcal{B}$ será tomada como o espaço de coordenadas adimensionais que caracteriza o tipo de elemento finito empregado na discretização do problema. Nos capítulos seguintes, o espaço de configuração auxiliar é definido para cada tipo de elemento finito proposto.

A fim de descrever onde se processam os eventos na mecânica dos sólidos deformáveis, é necessário se definir o tipo de descrição empregada para caracterizar o movimento. Nesse trabalho adota-se a descrição Lagrangiana total.

\subsubsection{Descrição Lagrangiana do Movimento}

Quando a configuração de referência é a própria configuração inicial, o movimento é descrito por suas coordenadas materiais e a região $\Omega_{0}$ representa a configuração indeformada do sólido. Como visto, nesse contexto, diz-se que o movimento se processa segundo a descrição Lagrangiana. Quando $t_{0}=0$, a transformação $\vec{F}$ representa a descrição Lagrangiana total, caso $t_{0}=t$, diz-se que $\vec{F}$ representa a descrição Lagrangiana atualizada do movimento. 


\subsubsection{Gradiente da Transformação}

O gradiente da transformação $\boldsymbol{A}$ fornece as informações acerca da variação da função $\vec{F}$, em relação às coordenadas materiais. O gradiente da transformação é um tensor de segunda ordem e representa a maneira como $\vec{f}_{0}$ se transforma em $\vec{f}_{1}$, após a deformação. O gradiente da transformação é calculado como:

$$
\boldsymbol{A}=\boldsymbol{A}_{1} \cdot\left(\boldsymbol{A}_{0}\right)^{-1}
$$

Sendo $\boldsymbol{A}_{0}=\frac{\partial \vec{f}_{0}}{\partial \vec{X}}$ e $\boldsymbol{A}_{1}=\frac{\partial \vec{f}_{1}}{\partial \vec{X}}$ os gradientes da transformação na configuração inicial e atual, respectivamente.

Da Equação (3.2) é possível se estabelecer uma condição fundamental da mecânica do contínuo, a condição local de impenetrabilidade. Essa condição estabelece que para o material não penetrar em si mesmo e não se aniquilar, o jacobiano da transformação, $J=\operatorname{det}(\boldsymbol{A})$, deverá ser positivo em qualquer ponto material de $\Omega_{1}$.

Com a definição do gradiente da função mudança de configuração é possível se definir uma série de medidas de deformações. Neste trabalho emprega-se a medida de deformação de Green-Lagrange em função do tensor dos estiramentos de uma fibra.

\subsubsection{Tensor dos Estiramentos à Direita de Cauchy-Green}

O tensor dos estiramentos quadráticos ou tensor a direita de Cauchy-Green é comum a uma família de medidas de deformação e representa o estiramento quadrático de uma fibra do sólido na configuração atual. O tensor dos estiramentos é obtido como:

$$
\boldsymbol{C}=\boldsymbol{A}^{t} \boldsymbol{A}
$$

O tensor dos estiramentos de Cauchy-Green, além de ser uma medida positiva definida é simétrico e representa a medida Lagrangiana do alongamento de uma fibra do sólido.De posse dessa medida é possível estabelecer vária medidas de deformação. 


\subsubsection{Tensor das Deformações de Green-Lagrange}

Na maioria dos problemas da mecânica dos sólidos deformáveis, sob não linearidade geométrica, o tensor das deformações de Green-Lagrange satisfaz as aplicações da engenharia estrutural. $\mathrm{O}$ tensor de deformação de Green-Lagrange é a medida não linear mais simples extraída do tensor de Cauchy-Green (CRISFIELD, 1991), calculada como:

$$
\boldsymbol{E}=\frac{1}{2}(\boldsymbol{C}-\boldsymbol{I})
$$

Sendo $\boldsymbol{I}$ o tensor identidade de segunda ordem.

A deformação de Green-Lagrange é uma medida de deformação válida quando o sólido experimenta uma mudança de configuração que envolva grandes deslocamentos e pequenas deformações. Além disso, $\boldsymbol{E}$ é uma medida objetiva, ou seja, ela é invariante em relação ao sistema de coordenadas e em relação aos movimentos de corpo rígido.

Para se descrever o comportamento do material adotado necessita-se da medida de tensão energeticamente conjugada a deformação de Green-Lagrange, porém, essa medida não admite uma interpretação física em termos de força de superfície. Dessa forma, apresenta-se a seguir a lei constitutiva utilizada nesse trabalho para em seguida decrever a medida de tensão energeticamente conjugada.

\subsubsection{Lei Constitutiva de Saint Venant-Kirchhoff}

O estudo de leis constitutivas não lineares é extremamente amplo, como destaca (PASCON, 2012). Neste trabalho dar-se ênfase ao comportamento não linear geométrico das estruturas. Portanto, considera-se neste trabalho um modelo constitutivo para materiais elásticos lineares tridimensionais e isotrópicos, na qual a energia específica de deformação é função da deformação de Green-Lagrange, calculada como:

$$
u_{e}=\frac{1}{2}(\boldsymbol{E}: \mathbb{C}: \boldsymbol{E})
$$

Sendo $\mathbb{C}$ o tensor de quarta ordem denominado módulo de rigidez elástica, definido a partir da seguinte relação: 


$$
\mathbb{C}=\frac{2 G v}{1-2 v} \boldsymbol{I} \otimes \boldsymbol{I}+G \mathbb{I}
$$

Sendo $\mathbb{I}$, o tensor identidade de quarta ordem, $G=\frac{E}{2(1+v)}$ o módulo de rigidez transversal, $E$ o módulo de rigidez longitudinal e $v$ o coeficiente de Poisson.

\subsubsection{Tensor de Tensão de Piola-Kirchhoff Segunda Espécie}

Em situações gerais recorre-se ao conceito de conjugado energético das deformações para se descrever o comportamento exato do material a partir de sua lei constitutiva. A tensão energeticamente conjugada ao tensor das deformações de Green-Lagrange é o tensor das tensões de Piola-Kirchhoff segunda espécie.

$$
\frac{\partial u_{e}}{\partial \boldsymbol{E}}=\boldsymbol{S}=\mathbb{C}: \boldsymbol{E}
$$

O tensor $\boldsymbol{S}$ não admite uma interpretação física em termos de força de superfície, porém, ele é bastante utilizado na mecânica computacional e na formulação da lei constitutiva de sólidos deformáveis.

Matematicamente o tensor de Piola-Kirchhoff segunda espécie se relaciona com a medida de tensão de Cauchy $\sigma$, também designada como medida de tensão verdadeira, por meio da seguinte equação:

$$
\boldsymbol{S}=J\left(\boldsymbol{A}^{-1} \boldsymbol{\sigma} \boldsymbol{A}^{-t}\right)
$$

Sendo $J$ o jacobiano da transformação.

\subsection{Princípios Fundamentais da Mecânica dos Sólidos}

A seguir, apresentam-se dois princípios essenciais da mecânica ao equacionamento do equilíbrio dos sólidos deformáveis, são eles: o princípio da conservação da energia mecânica e o princípio de mínima ação. 


\subsubsection{Princípio da Conservação da Energia Mecânica}

O princípio da conservação da energia mecânica estabelece que em um sistema físico fechado, no caso, o sólido, sob a ação apenas de forças conservativas, a energia mecânica total do sistema permanece constante.

Esse enunciado expressa a energia mecânica como a soma da energia cinética e energia potencial total do sistema. Como neste trabalho adota-se o regime quase estático de aplicação do carregamento, a energia mecânica do sistema é calculada apenas a partir da contribuição da energia potencial total, expressa pela soma das parcelas da energia potencial das deformações armazenadas no sólido e da energia potencial das ações externas, representadas pela equação:

$$
\Pi=U_{e}+P
$$

A energia potencial das deformações em termos das quantidades Lagrangianas é calculada sobre o volume inicial, da seguinte maneira:

$$
U_{e}=\int_{\Omega_{0}} u_{e} d V_{0}
$$

A energia potencial das forças externas é calculada a partir do trabalho realizado pela resultante das forças na configuração atual, dado por:

$$
P=-\vec{F}_{\text {ext }} \cdot \vec{Y}
$$

O sinal de subtração indica que as ações externas são responsáveis por diminuir a capacidade do sólido elástico armazenar energia potencial de deformação a medida que se aumenta a intensidade do carregamento. De fato, essa condição pode ser mentalmente visualizada com o modelo de uma mola sob forças compressivas.

\subsubsection{Princípio da Mínima Ação}

O princípio da mínima ação estabelece que a evolução do sistema da configuração $\Omega_{0}$ para a configuração $\Omega_{1}$ é tal que a ação é um mínimo (SYMON, 1960).

Dos fundamentos da mecânica clássica, a ação será um mínimo, se e somente se: 


$$
\frac{\partial \mathcal{L}}{\partial \vec{q}}=0
$$

A equação (3.12) é denominada equação de Euler-Lagrange independente do tempo. A equação de Euler-Lagrange é a base da formulação Lagrangiana e ela informa como o sistema evolui da configuração de referência para a configuração atual. A quantidade $\vec{q}$ é chamada de vetor de coordenadas generalizadas.

Para se utilizar a equação (3.12) é preciso se conhecer a Lagrangiana $\mathcal{L}$ do sistema. A Lagrangiana é uma quantidade escalar dada pela diferença entre a energia cinética e a energia potencial total. Como a energia cinética em regime estático de carregamento é desprezada, a Lagrangiana é a própria energia potencial e a equação (3.12) indica que a energia potencial do sólido é estacionária em relação as coordenadas generalizadas do sistema.

Substituindo a energia potencial total obtida na equação (3.12), obtém-se:

$$
\frac{\partial \mathcal{L}}{\partial \vec{q}}=-\frac{\partial}{\partial \vec{q}}\left(U_{e}+P\right)=0
$$

Apresentado dessa maneira, o princípio da mínima ação é também denominado, princípio da estacionariedade da energia potencial total.

É interessante destacar que a equação (3.13) representa o resultado da segunda lei de Newton para um sistema de forças conservativo em equilíbrio estático.

Substituindo (3.11) em (3.13) e admitindo que as coordenadas generalizadas estão definidas no espaço euclidiano, ver Figura 3, tem-se que o vetor de coordenadas generalizadas são as posições das partículas na descrição Lagrangiana, resultando:

$$
\frac{\partial U_{e}}{\partial \vec{Y}}-\vec{F}_{e x t}=0
$$

O resultado da equação (3.14) representa um corolário da lei da ação e reação, ou seja, para o sistema se manter equilibrado, o conjugado energético das posições deve representar as forças internas que surgem no sólido.

Porém, o equilíbrio só é satisfeito se o resultado obtido em (3.14) for garantido. Para isso, é necessário se resolver a seguinte equação: 


$$
F_{i}^{e x t}=\frac{\partial U_{e}}{\partial \vec{Y}}\left(Y_{i}\right)=F_{i}^{i n t}
$$

Como se observa na equação (3.15), a energia potencial das deformações é uma função não-linear das posições. Portanto, é necessário se recorrer a estratégias de solução de sistemas não-lineares para se alcançar o equilíbrio das estruturas.

No próximo capítulo, são apresentados os principais métodos de solução de sistemas não-lineares empregados nesta pesquisa.

Na sequência apresenta-se o procedimento geral da formulação não linear geométrica do método dos elementos finitos. Generaliza-se a montagem do vetor de forças internas e da matriz de rigidez das estruturas.

\subsection{Método dos Elementos Finitos Posicional}

Quando o método dos elementos finitos é utilizado na solução de problemas da mecânica dos sólidos sob regime não-linear geométrico, três formulações podem ser consideradas para descrever o movimento. Pode-se empregar a descrição Lagrangiana total, a formulação Lagrangiana atualizada e a descrição co-rotacional (BELYTSCHKO e GLAUM, 1979).

Neste trabalho, emprega-se o referencial Lagrangiano total para formular o elemento de barra simples (ou barra rígida), o elemento de casca e o elemento de barra geral (ou barra flexível). Cada elemento é apresentado em capítulos independentes, porém todo o desenvolvimento tem como base a determinação da energia potencial total escrita em termos das posições do elemento (elemento finito posicional), como apresentado por (CODA e GRECO, 2004).

A fim de uniformizar a nomenclarura, nexte texto, os parâmetros nodais são chamados de graus de liberdade generalizados (GDOF, acrônimo de Generalized Degree Of Freedom), já que as medidas nodais se diferenciam de grandezas clássicas de deslocamentos e rotações.

\subsubsection{Energia Potencial das Deformações}

No método dos elementos finitos o sólido deformável é representado por entes matemáticos discretos com as mesmas propriedades físicas do meio contínuo. 
A energia potencial das deformações é computada considerando-se a contribuição de cada elemento na energia do sistema, obtida a partir da equação:

$$
U_{e}=\int_{\Omega_{0}} u_{e} d V_{0}
$$

Com o auxílio das coordenadas do espaço adimensional $\mathcal{B}$, Figura 3 , é possível se processar as integrações numéricas de maneira imediata. Portanto, é conveniente se realizar uma mudança de coordenada resultando no seguinte cálculo da energia potencial:

$$
U_{e}=\int_{\xi_{1}} \int_{\xi_{2}} \int_{\xi_{3}} u_{e}\left(\xi_{1}, \xi_{2}, \xi_{3}\right) J_{0}\left(\xi_{1}, \xi_{2}, \xi_{3}\right) d \xi_{1} d \xi_{2} d \xi_{3}
$$

Sendo $J_{0}\left(\xi_{1}, \xi_{2}, \xi_{3}\right)$ o jacobiano da transformação na configuração inicial.

Neste trabalho empregam-se as técnicas de quadratura numérica para se realizar essas integrações. Logo, a forma discreta da equação (3.17) é numericamente calculada como:

$$
U_{e}=\sum_{i} \sum_{j} \sum_{k} u_{e}\left(\xi_{i}, \xi_{j}, \xi_{k}\right) J_{0}\left(\xi_{i}, \xi_{j}, \xi_{k}\right) \omega_{i} \omega_{j} \omega_{k}
$$

Sendo $i, j$ e $k$ os índices que representam a soma sobre todos os pontos de integração $\xi$ e pesos $\omega$.

No próximo capítulo faz-se uma explanação sobre os critérios de integração empregados para obter a energia potencial de deformação do sólido.

Para construir a formulação do método dos elementos finitos é necessário inserir as aproximações usadas no mapeamento do elemento e calcular sua contribuição na energia potencial das deformações. Esse procedimento inicia-se com o cálculo do vetor de forças internas e da matriz Hessiana dos elementos, assim, apresenta-se o procedimento geral para o cálculo dessas quantidades.

\subsubsection{Cálculo do Vetor de Forças Internas}

Para se calcular o vetor de forças internas primeiramente é necessário se proceder as derivadas da energia específica de deformação: 


$$
u_{e}=u_{e} \circ \boldsymbol{E} \circ \boldsymbol{C}(\vec{Y})
$$

A equação (3.19) é uma função composta em relação as posições, cuja derivada é obtida fazendo-se:

$$
\frac{\partial u_{e}}{\partial Y_{\alpha \beta}}=\frac{\partial u_{e}}{\partial E_{k \ell}} \frac{\partial E_{k \ell}}{\partial C_{m n}} \frac{\partial C_{m n}}{\partial Y_{\alpha \beta}}
$$

Empregando-se o conceito de conjugado energético, obtém-se:

$$
\frac{\partial u_{e}}{\partial Y_{\alpha \beta}}=\frac{1}{2} S_{k \ell} \delta_{k m} \delta_{\ell n}=\frac{1}{2} S_{m n} \frac{\partial C_{m n}}{\partial Y_{\alpha \beta}}
$$

Sendo, $S_{m n}=\frac{\partial u_{e}}{\partial E_{m n}}$, o conjugado das deformações de Green-Lagrange, denominado tensor das tensões de Piola-Kirchhoff segunda espécie.

A derivada do alongamento à direita de Cauchy-Green, em função dos gradientes da transformação é obtida fazendo-se:

$$
\frac{\partial C_{m n}}{\partial Y_{\alpha \beta}}=\left(A_{m p}^{0}\right)^{-t}\left(\frac{\partial A_{p q}^{1}}{\partial Y_{\alpha \beta}}\right)^{t}\left(A_{q k}^{1}\right)\left(A_{k n}^{0}\right)^{-1}+\left(A_{m p}^{0}\right)^{-t}\left(A_{p q}^{1}\right)^{t}\left(\frac{\partial A_{q k}^{1}}{\partial Y_{\alpha \beta}}\right)\left(A_{k n}^{0}\right)^{-1}
$$

De posse dessas equações, para qualquer elemento finito, o vetor de forças internas é obtido procedendo-se as integrações numéricas:

$$
F_{\alpha \beta}^{\mathrm{int}}=\frac{\partial U_{e}}{\partial Y_{\alpha \beta}}=\sum_{i} \sum_{j} \sum_{k} \frac{\partial u_{e}}{\partial Y_{\alpha \beta}}\left(\xi_{i}, \xi_{j}, \xi_{k}\right) J_{0}\left(\xi_{i}, \xi_{j}, \xi_{k}\right) \omega_{i} \omega_{j} \omega_{k}
$$

\subsubsection{Cálculo da Matriz Hessiana}

Tendo em vista a não linearidade da função energia específica de deformação é necessário se recorrer a técnicas de linearização da equação de equilíbrio por meio de um processo iterativo. Esses métodos são abordados com mais detalhes no próximo capítulo. Mas, para que se complete a descrição da metodologia usada na formulação do método dos elementos finitos, adianta-se que a técnica de linearização resulta na obtenção da segunda variação da energia específica de deformação. 
A matriz Hessiana do elemento é uma forma quadrática positivo-definida, determinada a partir da segunda variação da energia de deformação em relação as posições ou coordenadas generalizadas, resultando:

$$
\frac{\partial^{2} u_{e}}{\partial Y_{\alpha \beta} \partial Y_{\gamma \delta}}=\frac{\partial}{\partial Y_{\alpha \beta}}\left(\frac{1}{2} S_{m n} \frac{\partial C_{m n}}{\partial Y_{\gamma \delta}}\right)=\frac{1}{4} D_{m n p q} \frac{\partial C_{p q}}{\partial Y_{\alpha \beta}} \frac{\partial C_{m n}}{\partial Y_{\gamma \delta}}+\frac{1}{2} S_{m n} \frac{\partial^{2} C_{m n}}{\partial Y_{\alpha \beta} \partial Y_{\gamma \delta}}
$$

Sendo, $D_{\text {mирq }}$ o tensor de quarta ordem denominado módulo de rigidez elástica.

Os termos não nulos da segunda derivada do tensor de Cauchy-Green resultam:

$$
\frac{\partial^{2} C_{m n}}{\partial Y_{\alpha \beta} \partial Y_{\gamma \delta}}=\left(A_{m p}^{0}\right)^{-t}\left(\frac{\partial A_{p q}^{1}}{\partial Y_{\alpha \beta}}\right)^{t}\left(\frac{\partial A_{q k}^{1}}{\partial Y_{\gamma \delta}}\right)\left(A_{k n}^{0}\right)^{-1}+\left(A_{m p}^{0}\right)^{-t}\left(\frac{\partial A_{p q}^{1}}{\partial Y_{\gamma \delta}}\right)^{t}\left(\frac{\partial A_{q k}^{1}}{\partial Y_{\alpha \beta}}\right)\left(A_{k n}^{0}\right)^{-1}
$$

Os termos que compõem a matriz Hessiana são calculados procedendo-se as seguintes integrações numéricas:

$$
H_{\alpha \beta \gamma \delta}=\frac{\partial^{2} U_{e}}{\partial Y_{\alpha \beta} \partial Y_{\gamma \delta}}=\sum_{i} \sum_{j} \sum_{k} \frac{\partial^{2} u_{e}}{\partial Y_{\alpha \beta} \partial Y_{\gamma \delta}}\left(\xi_{i}, \xi_{j}, \xi_{k}\right) J_{0}\left(\xi_{i}, \xi_{j}, \xi_{k}\right) \omega_{i} \omega_{j} \omega_{k}
$$

Após a obtenção das expressões gerais para o cálculo do vetor de força interna e da matriz Hessiana, a solução da equação de equilíbrio será realizada a partir das técnicas de solução numérica de sistemas não-lineares. No próximo capítulo essas expressões são retomadas fazendo-se a conexão entre a formulação do método dos elementos finitos e as técnicas da análise numérica.

\subsection{Fechamento}

Nesse capítulo foram abordados os conceitos e expressões fundamentais da mecânica dos sólidos deformáveis. Esse aparato teórico é fundamental para mostrar a transição entre os princípios gerais da mecânica e o desenvolvimento dos métodos numéricos com base na formulação posicional a partir do critério de conservação da energia. Pretende-se com esse capítulo esclarecer os fundamentos empregados na geração dos elementos de barra simples, barra geral e de casca não linear geométrico que serão apresentados posteriormente. 



\section{Métodos Numéricos para Análise Não - Linear de Estruturas}

\subsection{Apresentação do Capítulo}

Neste capítulo apresentam-se os métodos necessários para se proceder as análises numéricas deste trabalho. Inicialmente apresenta-se o procedimento empregado na obtenção das funções interpoladoras de ordem qualquer. Em seguida descrevem-se as quadraturas utilizadas nas integrações numéricas para determinação dos termos do vetor de forças internas e da matriz Hessiana. Apresentam-se também os procedimentos de solução do sistema não linear via método de Newton-Raphson e arc-length. Por fim, descreve-se o algoritmo de Lanczos utilizado no cálculo dos autovalores e autovetores de matrizes esparsas.

\subsection{Interpolação Polinomial: Funções de Forma de Ordem Qualquer}

A primeira decisão do analista estrutural ao desenvolver um código computacional consiste na escolha do tipo de elemento utilizado na análise. O elemento escolhido deverá satisfazer as condições mecânicas do problema, como por exemplo, representar satisfatoriamente os campos de deslocamentos, deformações e tensões.

Tomando-se como exemplo o caso de uma barra de treliça espacial, a escolha do elemento unidimensional com aproximação linear irá atender adequadamente as necessidades do problema mecânico, uma vez que a ação predominante é um esforço normal constante na barra. No entanto, se o modelo consiste em representar a ação do momento fletor em um problema de pórtico espacial, a melhor representação para o campo dos deslocamentos é obtida a partir de polinômios quadráticos.

Essa discussão é importante para elucidar que a escolha do tipo de elemento não é um procedimento aleatório e exige do analista um real entendimento do problema.

Rotinas mais sofisticadas permitem que se utilizem diferentes elementos em uma mesma análise, ou que se represente o mesmo problema empregando-se diferentes elementos, cada qual para efetuar uma análise específica.

Com a finalidade de proporcionar um leque de opções para implementação de métodos de análise estrutural, o presente capítulo trata da metodologia de geração dos elementos uni e bidimensionais com aproximação polinomial com qualquer ordem de aproximação. 
De acordo com o teorema de Weierstrass (PISKOUNOV, 2000), qualquer função contínua sobre um intervalo fechado pode ser representada por um polinômio, a menos de um erro, tão pequeno, quanto maior a ordem do polinômio.

Partindo-se desse teorema, convém descrever as variáveis de um domínio físico complexo conhecendo-se apenas suas propriedades e geometria em pontos específicos desse domínio, para em seguida, se realizar interpolações e extrapolações polinomiais e se obter as informações da geometria e grandezas físicas em qualquer ponto desse domínio.

Essa é a ideia principal do método dos elementos finitos, representar o domínio físico empregando-se entes matemáticos discretos onde as propriedades físicas e geométricas são determinadas a partir de valores nodais e funções interpoladoras.

Permitir a utilização de aproximações polinomiais de qualquer ordem em uma análise, proporciona maior flexibilidade durante a decisão e escolha do tipo de interpolação. Com essas ferramentas é possível, inclusive, se avaliar a convergência da solução utilizando enriquecimentos no grau de aproximação das variáveis.

No entanto, (CHEN, HE e ZHANG, 2013) informa que no método dos elementos finitos interpolações de ordem elevada podem apresentar erros significativos devido ao mal condicionamento numérico da função polinomial. Esse fenômeno provoca oscilações nas extremidades do intervalo devido ao fenômeno conhecido como efeito Runge.

A seguir, apresentam-se as rotinas de cálculo das funções de forma adotadas na descrição de elementos finitos unidimensionais (retos e curvos) e bidimensionais (triangulares e retangulares). O procedimento utiliza a partição da unidade em conjunto com o cálculo da matriz dos coeficientes de Vandermonde.

\subsubsection{Funções de Forma Unidimensionais}

Neste trabalho, as funções de forma unidimensionais são aplicadas na descrição da cinemática do eixo de referência dos elementos de barra rígida e de barra geral, descritos em detalhes futuramente em capítulos específicos.

As coordenadas geradoras desses elementos são tomadas no espaço adimensional, coincidente com a base utilizado na quadratura de Gauss-Legendre. Neste caso, o conjunto de 
pontos no intervalo de -1 à +1 , igualmente espaçados e dependentes do grau utilizado na aproximação.

A partição do intervalo pode ser calculada a partir da seguinte progressão aritmética, (pontos igualmente espaçados):

$$
\xi_{p}=\xi_{1}+(k-1) r
$$

Sendo $p=1,2, \ldots,(n+1)$, os pontos da partição; $n$ o grau da aproximação; $\xi_{1}=-1$ o limite inferior do intervalo e $r=2 / n$ a razão da progressão. Na Figura 4 apresenta-se a partição do intervalo adimensional adotada na geração das funções de forma linear, quadrática e cúbica.

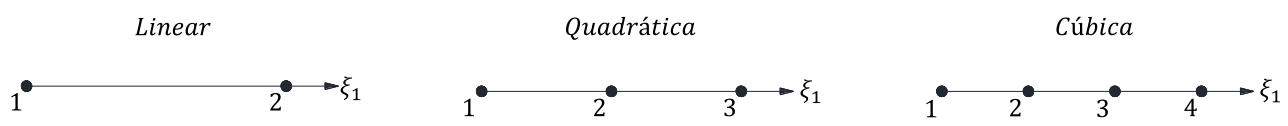

Figura 4: Partição do intervalo para o elemento finito unidimensional

Os polinômios interpoladores são calculados por meio da equação geral:

$$
\varphi_{k}(\xi)=\sum_{j=1}^{n+1} a_{k j} \xi^{(j-1)}, \operatorname{com} k=1,2, \ldots, p
$$

Sendo $a_{k j}$ os coeficientes dos polinômios.

Substituindo os valores $\xi_{p}$ na equação (4.2) e utilizando a propriedade da partição da unidade, onde $\varphi_{i}\left(\xi_{p}\right)=1$ para $i=p$ e $\varphi_{i}\left(\xi_{p}\right)=0$ para $i \neq p$, é possível escrever:

$$
\varphi_{i}\left(\xi_{p}\right)=a_{i 1} \xi_{p}^{0}+a_{i 2} \xi_{p}^{1}+\ldots+a_{i(n+1)} \xi_{p}^{n}=\delta_{i p}
$$

Expandindo (4.3), resulta no seguinte sistema de equações:

$$
\left[\begin{array}{cccc}
a_{11} & a_{12} & \ldots & a_{1(n+1)} \\
a_{21} & a_{22} & \ldots & a_{2(n+1)} \\
\vdots & \vdots & \ddots & \vdots \\
a_{p 1} & a_{p 2} & \ldots & a_{p(n+1)}
\end{array}\right]\left[\begin{array}{cccc}
1 & 1 & \ldots & 1 \\
\xi_{1} & \xi_{2} & \ldots & \xi_{p} \\
\vdots & \vdots & \ddots & \vdots \\
\xi_{1}^{n} & \xi_{2}^{n} & \ldots & \xi_{p}^{n}
\end{array}\right]=\left[\begin{array}{cccc}
1 & 0 & \ldots & 0 \\
0 & 1 & \ldots & 0 \\
\vdots & \vdots & \ddots & \vdots \\
0 & 0 & \ldots & 1
\end{array}\right]
$$


Em representação matricial, $M V=I$, sendo $V$ a matriz com as potências das coordenadas adimensionais, denominada matriz de Vandermonde; I a matriz identidade. Dessa forma, os coeficientes dos polinômios são obtidos fazendo-se $M=V^{-1}$.

Com os coeficientes do polinômio determinam-se as expressões das funções de forma, a partir da equação (4.2)

Com a finalidade de ilustrar a geração dos polinômios interpoladores apresenta-se o procedimento para o cálculo do polinômio unidimensional quadrático.

Passo 1: Cálculo dos pontos na base adimensional.

Para $n=2, k=1,2,3$. A razão da progressão é $r=2 / n=1$. Logo, os pontos no espaço adimensional são $\xi_{1}=-1, \xi_{2}=0$ e $\xi_{3}=+1$.

Passo 2: Cálculo da matriz de Vandermonde

$$
V_{i k}=\xi_{k}^{i-1}, \operatorname{com} i=k=1,2,3 \text {. Assim, } V=\left[\begin{array}{lll}
1 & 1 & 1 \\
\xi_{1} & \xi_{2} & \xi_{3} \\
\xi_{1}^{2} & \xi_{2}^{2} & \xi_{3}^{2}
\end{array}\right]=\left[\begin{array}{ccc}
1 & 1 & 1 \\
-1 & 0 & 1 \\
1 & 0 & 1
\end{array}\right] \text {. }
$$

Passo 3: Cálculo da matriz dos coeficientes

A matriz dos coeficiente é obtida fazendo-se $M_{i j}=V_{i j}^{-1}$.

Portanto, $M=\left[\begin{array}{lll}a_{11} & a_{12} & a_{13} \\ a_{21} & a_{22} & a_{23} \\ a_{31} & a_{32} & a_{33}\end{array}\right]=\left[\begin{array}{ccc}0 & -1 / 2 & 1 / 2 \\ 1 & 0 & -1 \\ 0 & 1 / 2 & 1 / 2\end{array}\right]$.

Passo 4: Cálculo das funções de forma

$$
\begin{aligned}
& \varphi_{1}(\xi)=a_{11}+a_{12} \xi+a_{13} \xi^{2}=\frac{1}{2} \xi(\xi-1) \\
& \varphi_{2}(\xi)=a_{21}+a_{22} \xi+a_{23} \xi^{2}=1-\xi^{2} \\
& \varphi_{3}(\xi)=a_{31}+a_{32} \xi+a_{33} \xi^{2}=\frac{1}{2} \xi(\xi+1)
\end{aligned}
$$

Passo 5: Cálculo das derivadas das funções de forma 


$$
\begin{aligned}
& \varphi_{1}(\xi)=0+a_{11}+2 a_{12} \xi=-\frac{1}{2}+\xi \\
& \varphi_{2}(\xi)=0+a_{21}+2 a_{22} \xi=-2 \xi \\
& \varphi_{3}(\xi)=0+a_{31}+2 a_{32} \xi=\frac{1}{2}+\xi
\end{aligned}
$$

A seguir, disponibiliza-se a rotina de geração automática das funções de forma e suas derivadas de primeira ordem.

Os parâmetros de entrada da rotina são: o grau de aproximação e a coordenada adimensional. Os parâmetros de saída são os valores da função de forma e sua primeira derivada, avaliadas no ponto de coordenada adimensional.

Quadro 1: Sub-rotina de geração das funções de forma do elemento unidimensional de ordem qualquer

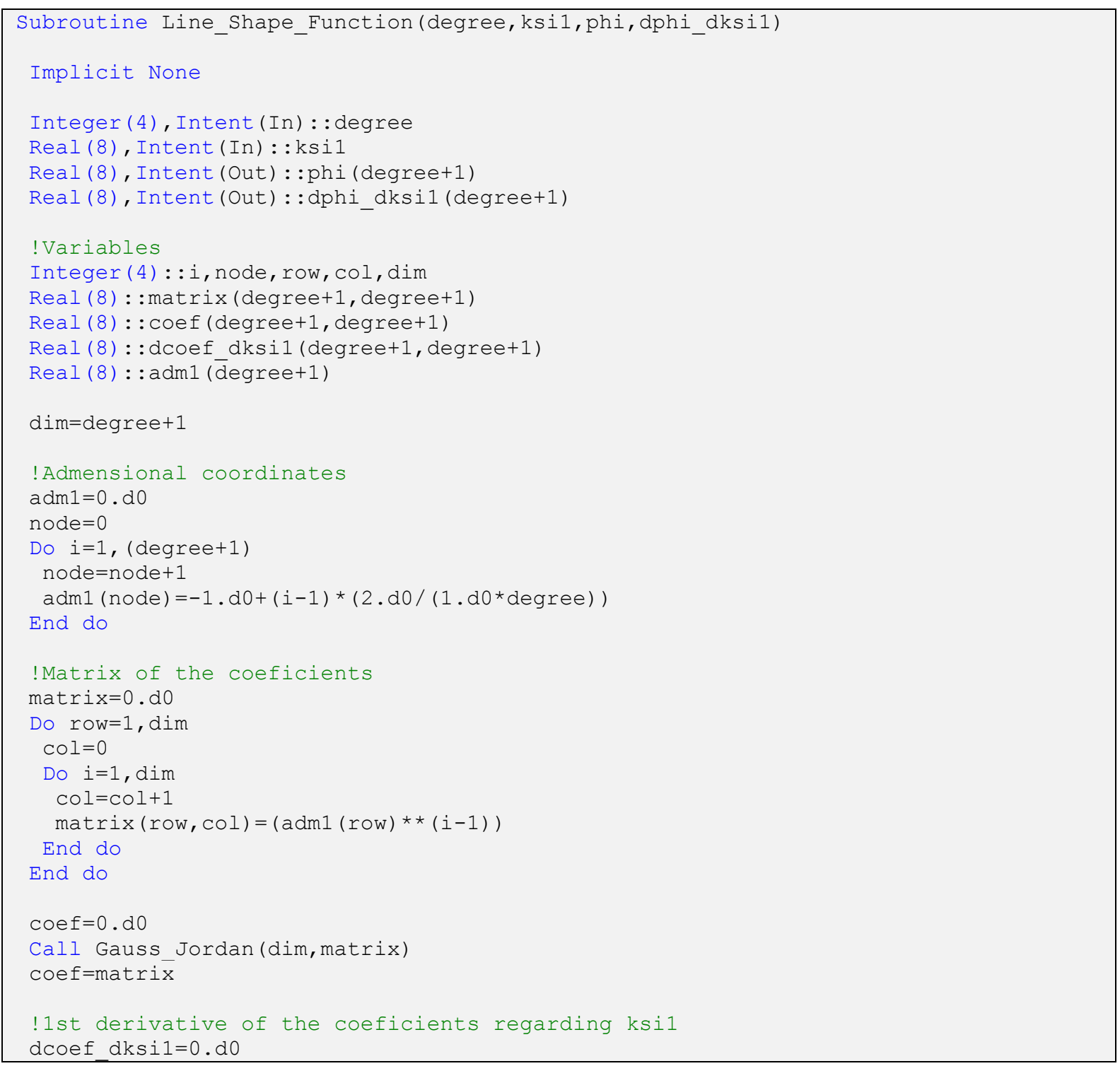




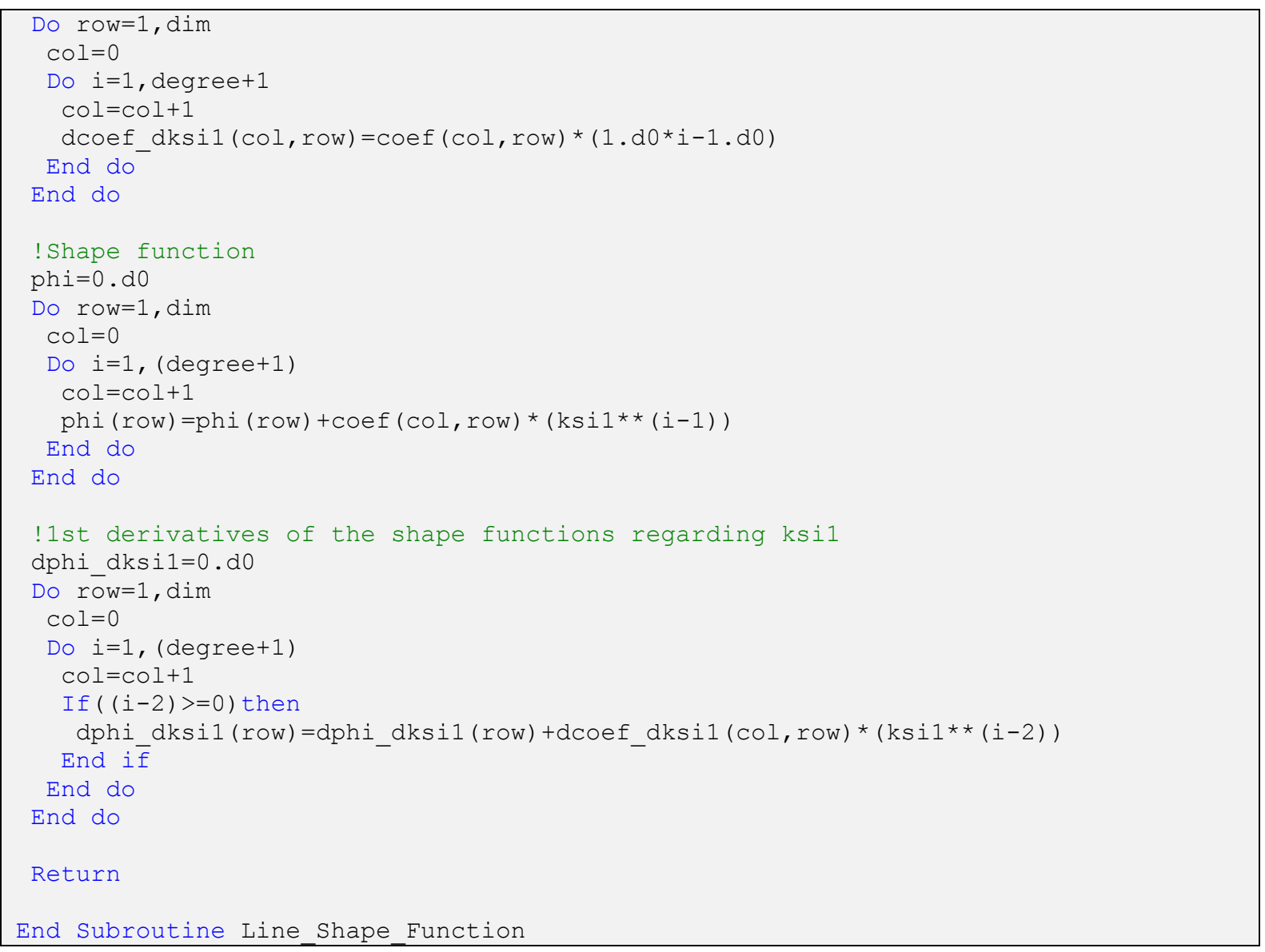

$\mathrm{Na}$ próxima seção apresentam-se as funções de forma bidimensionais usadas na interpolação da seção transversal do elemento de barra geral e na superfície de referência do elemento de casca.

\subsubsection{Funções de Forma Bidimensionais Triangulares}

De maneira semelhante ao procedimento descrito para o elemento unidimensional, a metodologia de geração das funções de forma do elemento triangular, se diferencia apenas quanto a forma do polinômio interpolador e a partição do intervalo adimensional.

Os limites inferiores do domínio são, $\xi_{1}=0$ e $\eta_{1}=0$, enquanto os limites superiores são $\xi_{p}=1$ e $\eta_{p}=1$, sendo $p=(n+1)(n+2) / 2$ o número de nós que define o elemento.

O polinômio interpolador completo é calculado como:

$$
\vartheta_{k}(\xi, \eta)=\sum_{j=n+1}^{1} \sum_{i=1}^{i} a_{k j} \xi^{(i-j)} \eta^{(j-1)}, \text { com } k=1,2, \ldots p
$$


$\mathrm{Na}$ Figura 5 ilustram-se as partições do domínio triangular empregando-se as aproximações lineares, quadráticas e cúbicas.
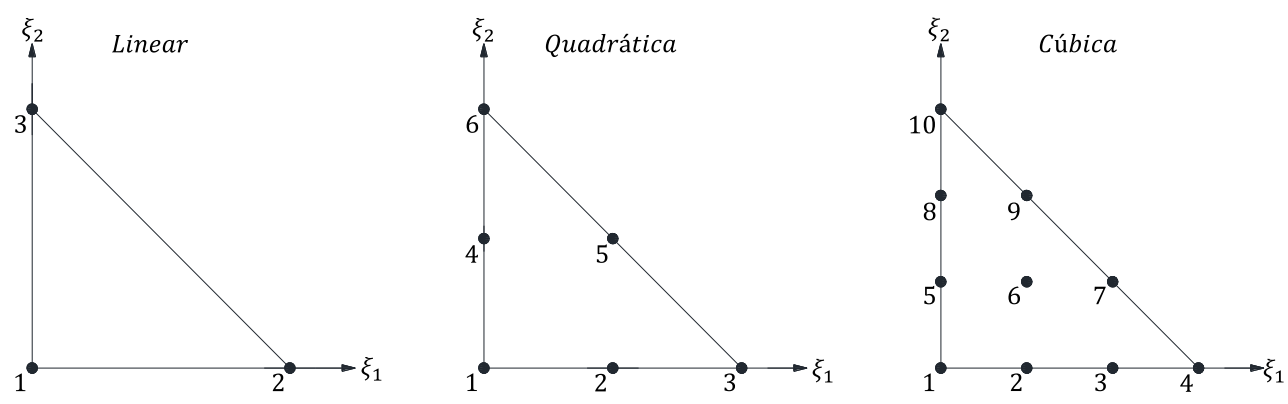

Figura 5: Partição do intervalo para o elemento finito bidimensional triangular

No Quadro 2 disponibiliza-se o código computacional empregado na geração das funções de forma e as primeiras derivadas do elemento finito triangular de ordem qualquer.

Quadro 2: Sub-rotina de geração das funções de forma do elemento bidimensional triangular de ordem qualquer

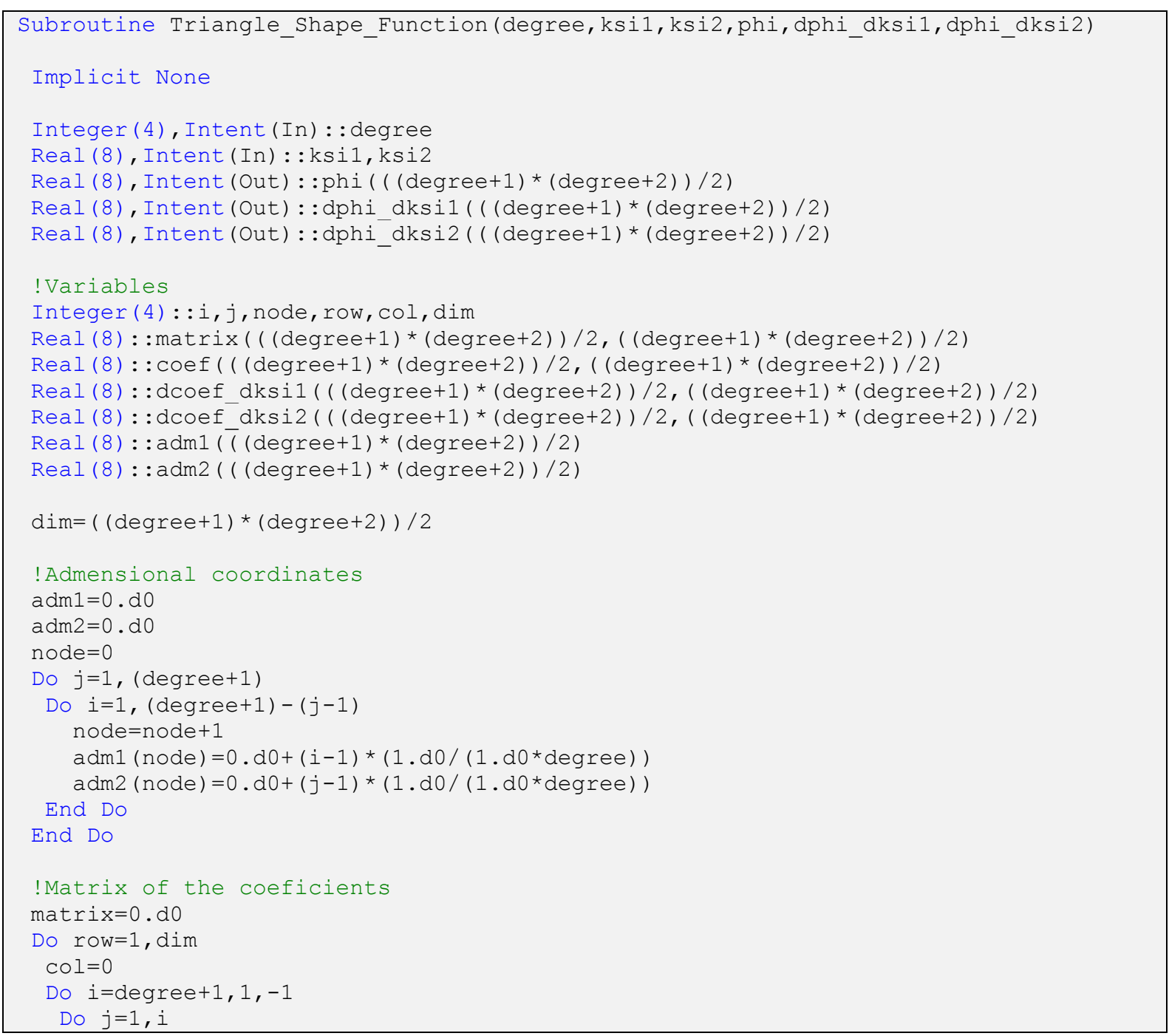




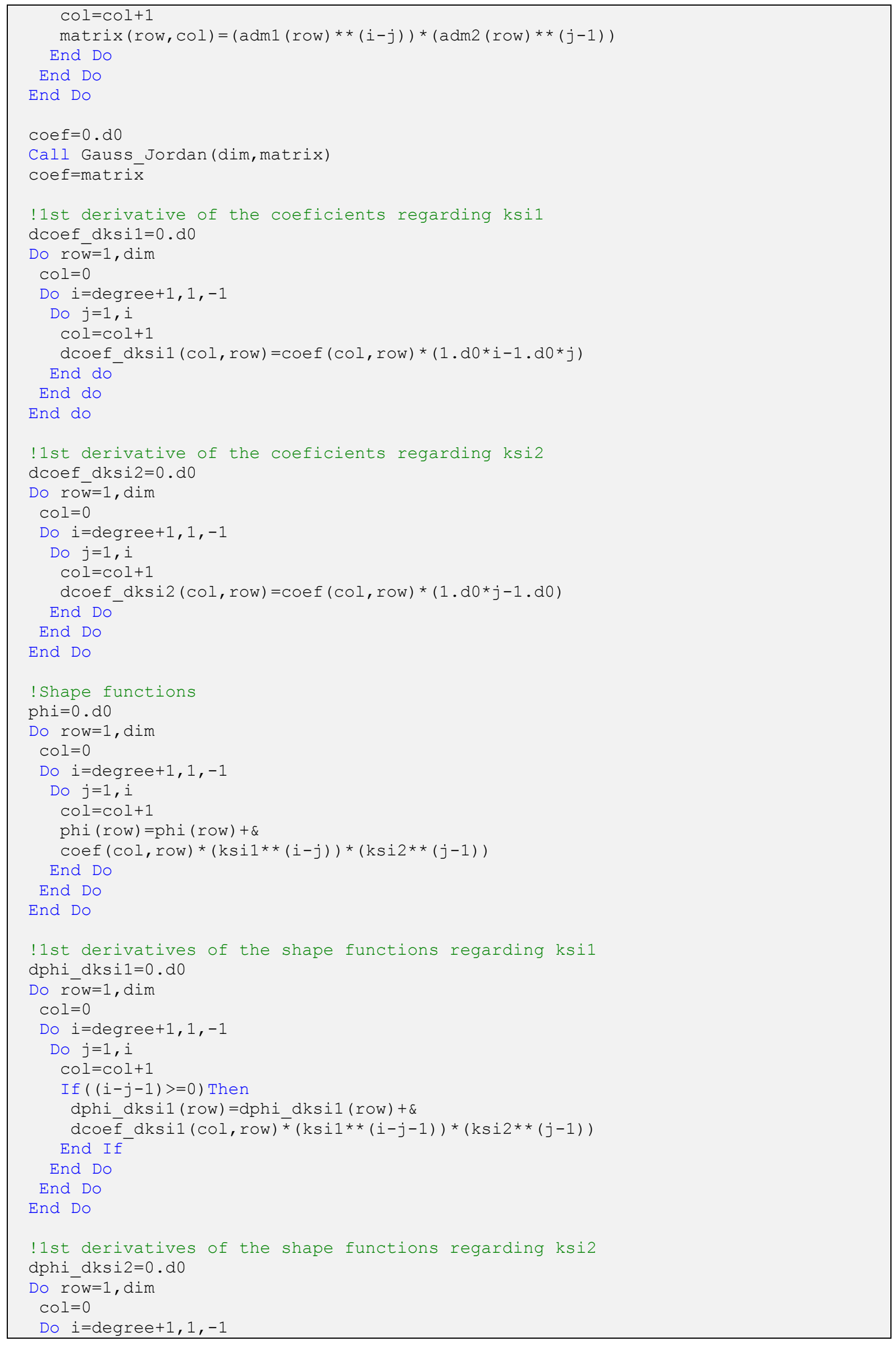




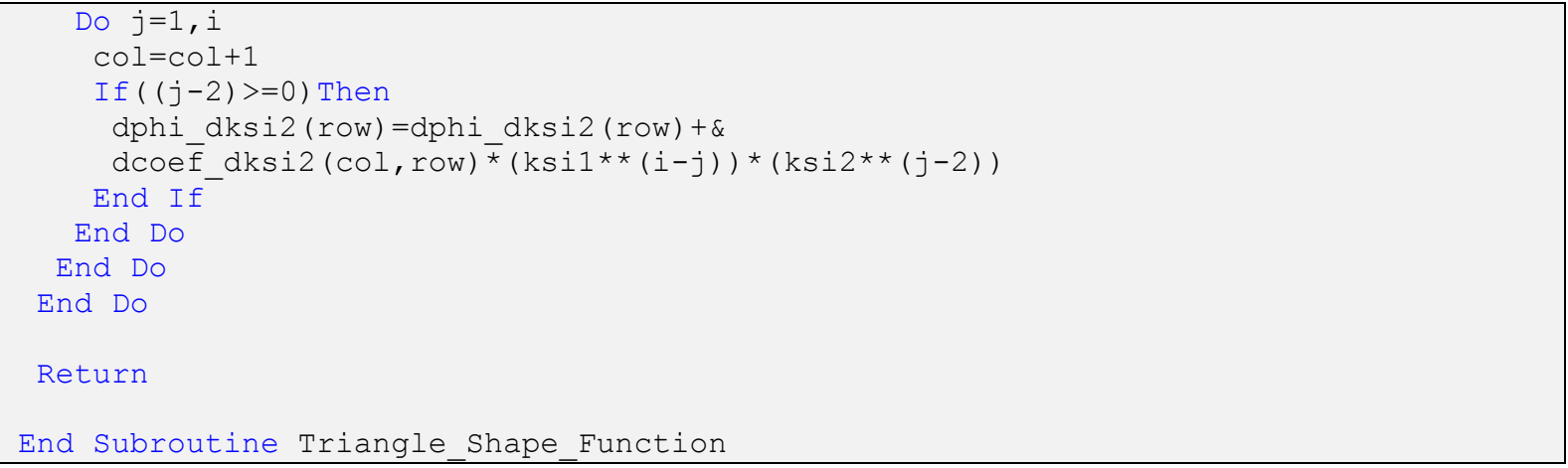

\subsubsection{Funções de Forma Bidimensionais Quadrilaterais}

A partição do elemento quadrilateral segue a mesma metodologia definida para o elemento unidimensional. Porém, a progressão aritmética é definida em ambos os eixos adimensionais. As coordenadas adimensionais são obtidas calculando-se o produto cartesiano $\xi_{i} \times \eta_{j}$, cujo resultado gera $p=(n+1)^{2}$ pontos no plano.

Sendo $\xi_{i}$ conjunto de pontos gerado pela partição do eixo $\xi$, obtido empregando-se a progressão aritmética:

$$
\xi_{i}=\xi_{1}+(i-1) r
$$

Para o eixo $\eta$, o conjunto de pontos é calculado da mesma forma:

$$
\eta_{j}=\eta_{1}+(j-1) r
$$

Sendo $i=j=1,2, \ldots,(n+1)$, os índices que definem os conjuntos de pontos da partição e $n$ o grau da aproximação.

Os valores dos limites do intervalo são definidos de acordo a regra de quadrataura utilizada na integração numérica. Para o elemento quadrilateral adota-se a quadratura de GaussLegendre, cujos valores dos limites inferiores dos eixos adimensionais são: $\xi_{1}=-1$ e $\eta_{1}=-1$. A razão da progressão é calculada da mesma maneira, obtida como: $r=2 / n$.

$\mathrm{Na}$ Figura 4 apresentam-se as partições do intervalo adimensional usadas na geração das funções de forma linear, quadrática e cúbica do elemento quadrilateral de ordem qualquer. 

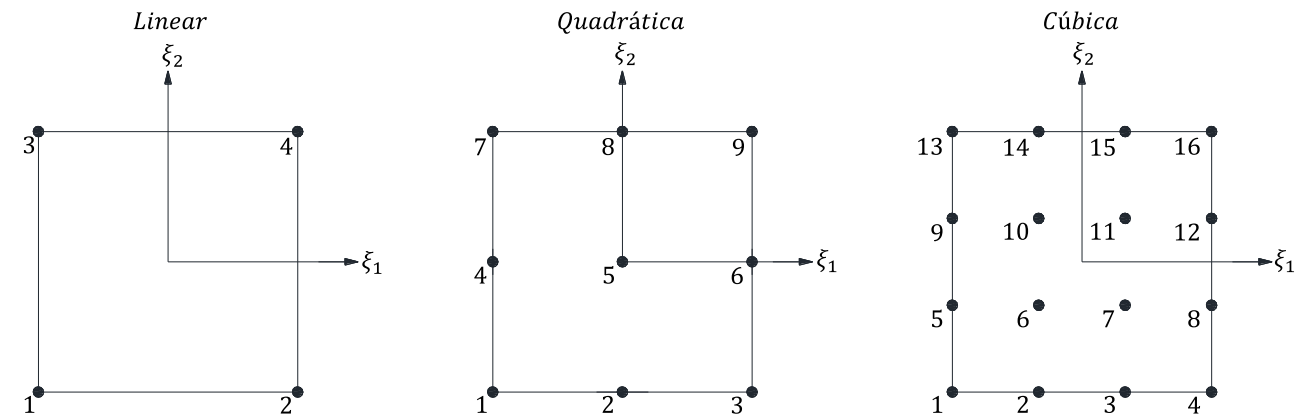

Figura 6: Partição do intervalo para o elemento finito bidimensional quadrilateral

O polinômio interpolador completo é calculado como:

$$
\vartheta_{k}(\xi, \eta)=\sum_{j=1}^{n+1} \sum_{i=1}^{n+1} a_{k j} \xi^{(i-1)} \eta^{(j-1)}
$$

No Quadro 3 é fornecida a sub-rotina para a geração das funções de forma e suas primeiras derivadas.

Quadro 3: Sub-rotina das funções de forma do elemento bidimensional quadrilateral de ordem qualquer

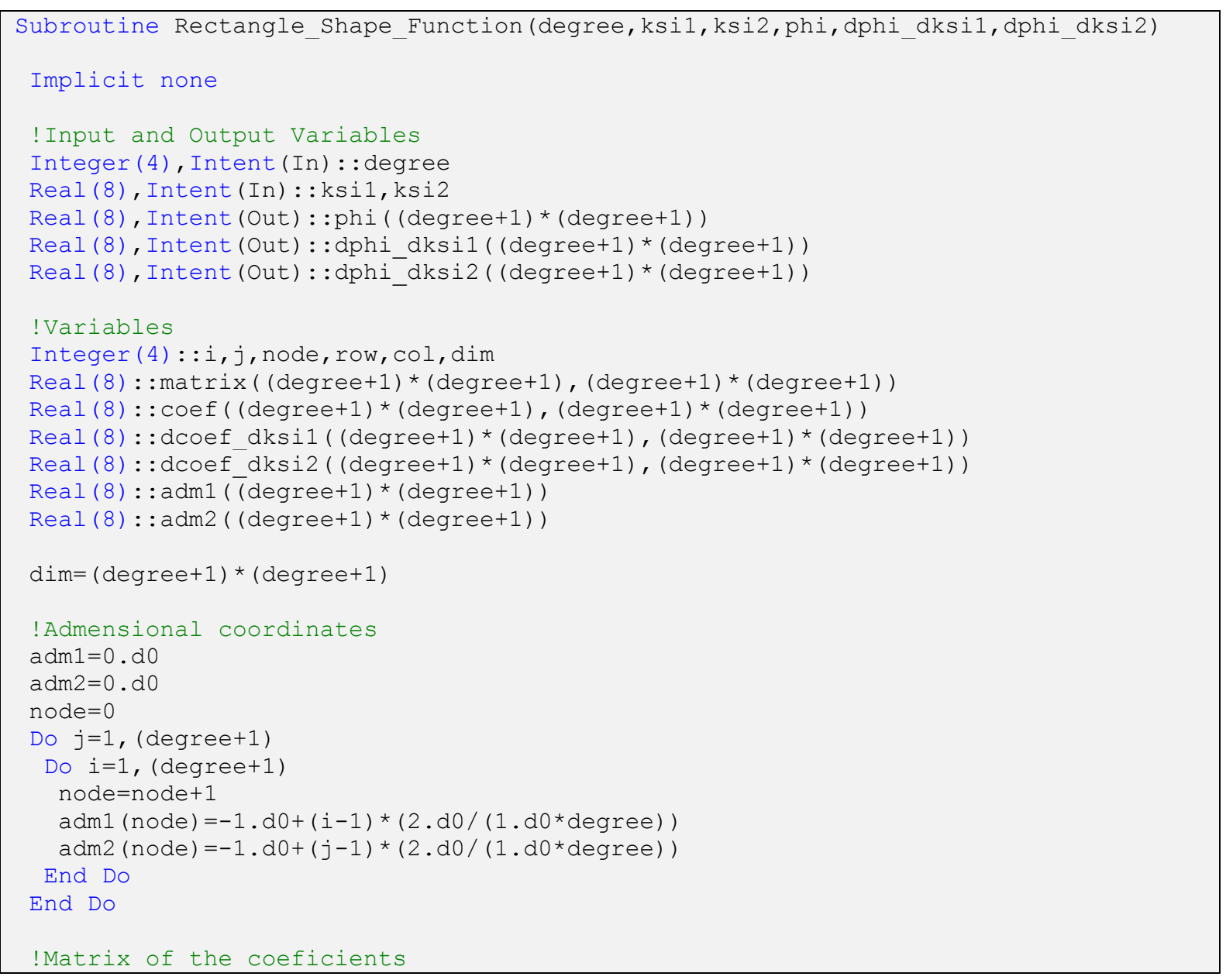




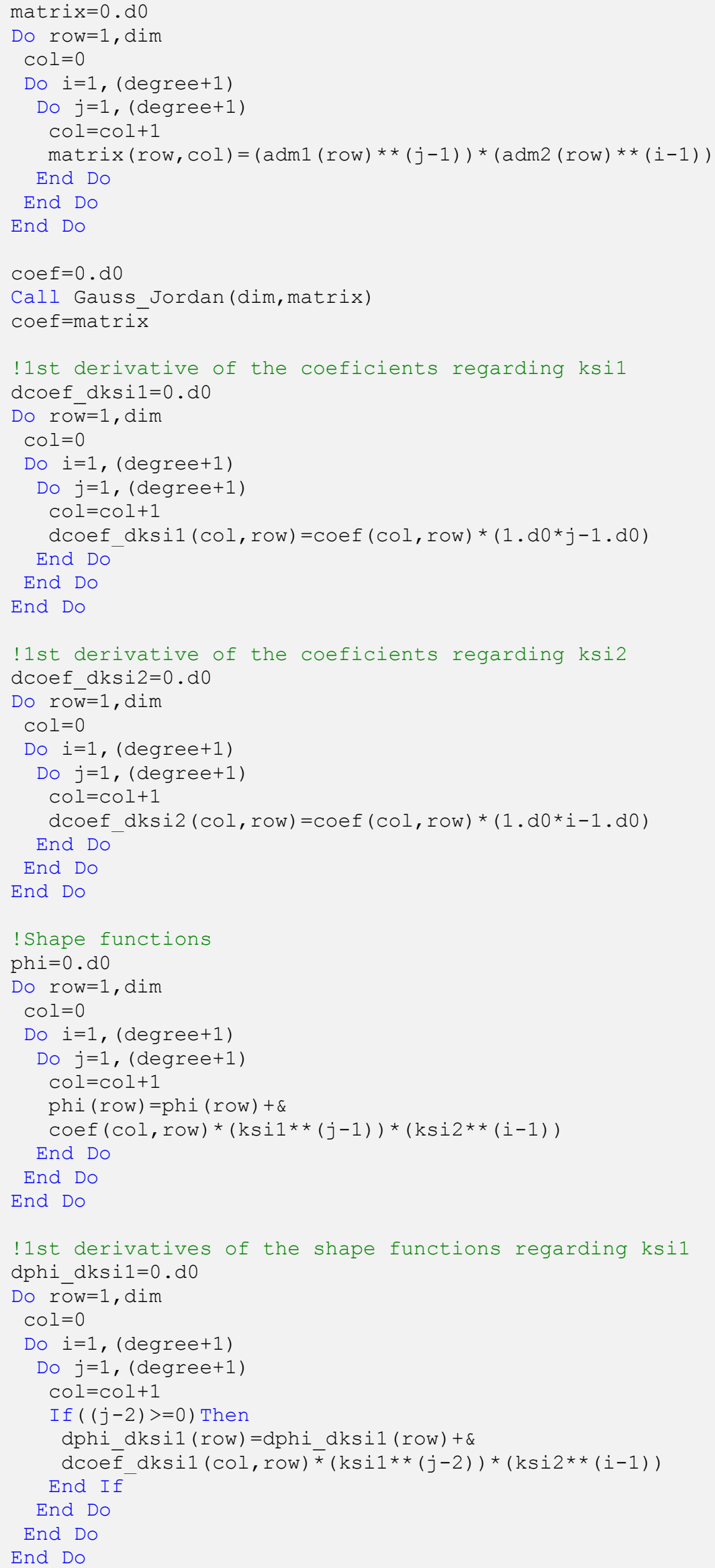




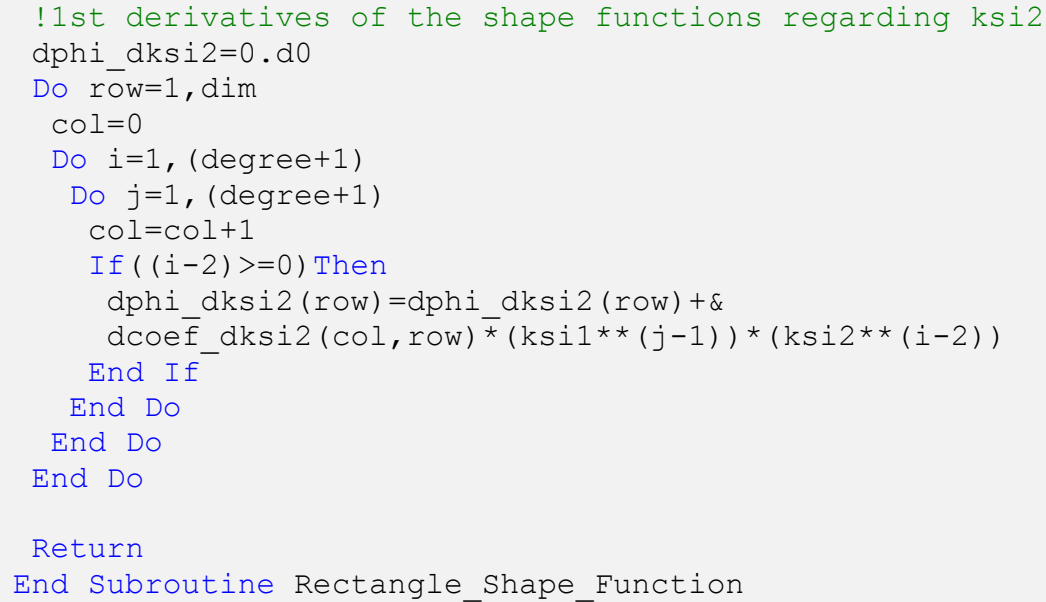

\subsection{Integração Numérica}

Quando se utilizam elementos finitos isoparamétricos com qualquer ordem de aproximação, a geometria do elemento é definida pelas mesmas funções interpoladoras que descrevem as grandezas físicas (REDDY, 2005). Realizar as integrações analíticas do vetor de forças internas e da matriz Hessiana para os elementos com qualquer ordem de aproximação se torna impraticável, devendo-se recorre a procedimentos numéricos de integração, como as regras de quadratura.

Como comentado no capítulo anterior, as regras de integração adotadas neste trabalho dependem do tipo de elemento empregado na análise, em razão exclusivamente da coincidência entre o domínio adimensional das funções de forma e o intervalo de geração das quadraturas.

Neste trabalho, as integrações com base na quadratura de Gauss-Legendre são efetuadas nas seguintes situações: a) sobre o eixo de referência dos elementos unidimensionais de barra simples e barra geral; b) sobre a seção transversal do elemento de barra geral empregando-se elementos quadrilaterais; c) sobre a superfície de referência do elemento de casca quadrilateral e d) ao longo da espessura dos elementos de casca independentemente do tipo de elemento.

A quadratura de Hammer é empregada quando se utilizar funções de forma com domínios triangulares nos seguintes casos: a) a seção transversal do elemento de barra geral discretizada com elementos triangulares ou b) sobre a superfície de referência dos elementos de casca triangulares.

De maneira geral, as técnicas de quadratura numérica consistem em se determinar o valor aproximado da integral de $f(x)$ fazendo-se: 


$$
\int_{a}^{b} w(x) f(x) d x \simeq \sum_{i=1}^{n} A_{i}(x) f_{i}(x)
$$

Sendo, $A_{i}=\int_{a}^{b} w(x) \varphi_{i}(x) d x$, com $w(x)$ a função ponderadora e $\varphi_{i}(x)$ os polinômios interpoladores.

Os métodos de quadratura utilizam as raízes de polinômios ortogonais para efetuar a interpolação polinomial e calcular $\varphi_{i}(x)$. Os polinômios ortogonais são classificados de acordo com a definição da função ponderadora e dão nome as técnicas de quadraturas Gaussianas. Por exemplo: se $w(x)=1$ com $a=-1$ e $b=1$, tem-se os polinômios ortogonais de Legendre, $\operatorname{logo}$ a quadratura utilizada é a de Gauss-Legendre. Para $w(x)=1 / \sqrt{1-x^{2}}$ com $a=-1$ e $b=1$, se definem os polinômios de Tchebyshev, se $w(x)=e^{-x^{2}}$ em $a=-\infty$ e $b=\infty$, se tem os polinômios de Hermite. No presente trabalho empregam-se apenas as raízes dos polinômios de Legendre e Hammer.

\subsubsection{Quadratura de Gauss-Legendre}

$\mathrm{Na}$ quadratura de Gauss-Legendre as integrações apresentam valores exatos ao se integrar os polinômios de ordem $g \leq 2 n-1$. Sendo $g$ o grau do polinômio e $n$ o número de pontos de integração.

A partir dessa expressão é possível constatar o seguinte: se os integrandos são polinômios lineares, basta um ponto de integração para calcular a integral exatamente. Caso o polinômio seja quadrático são necessários $n \geq 3 / 2$, ou seja, dois pontos de Gauss para se efetuar a integral exatamente, e assim por diante.

Tendo em vista essa propriedade, basta definir um número finto de pontos para se proceder satisfatoriamente as integrações das funções, sem se recorrer a esquemas de integração reduzida. No Quadro 4 é fornecida a sub-rotina utilizada para obtenção dos pontos e pesos da quadratura de Gauss-Legendre.

\section{Quadro 4: Pontos e pesos da quadratura de Gauss-Legendre}




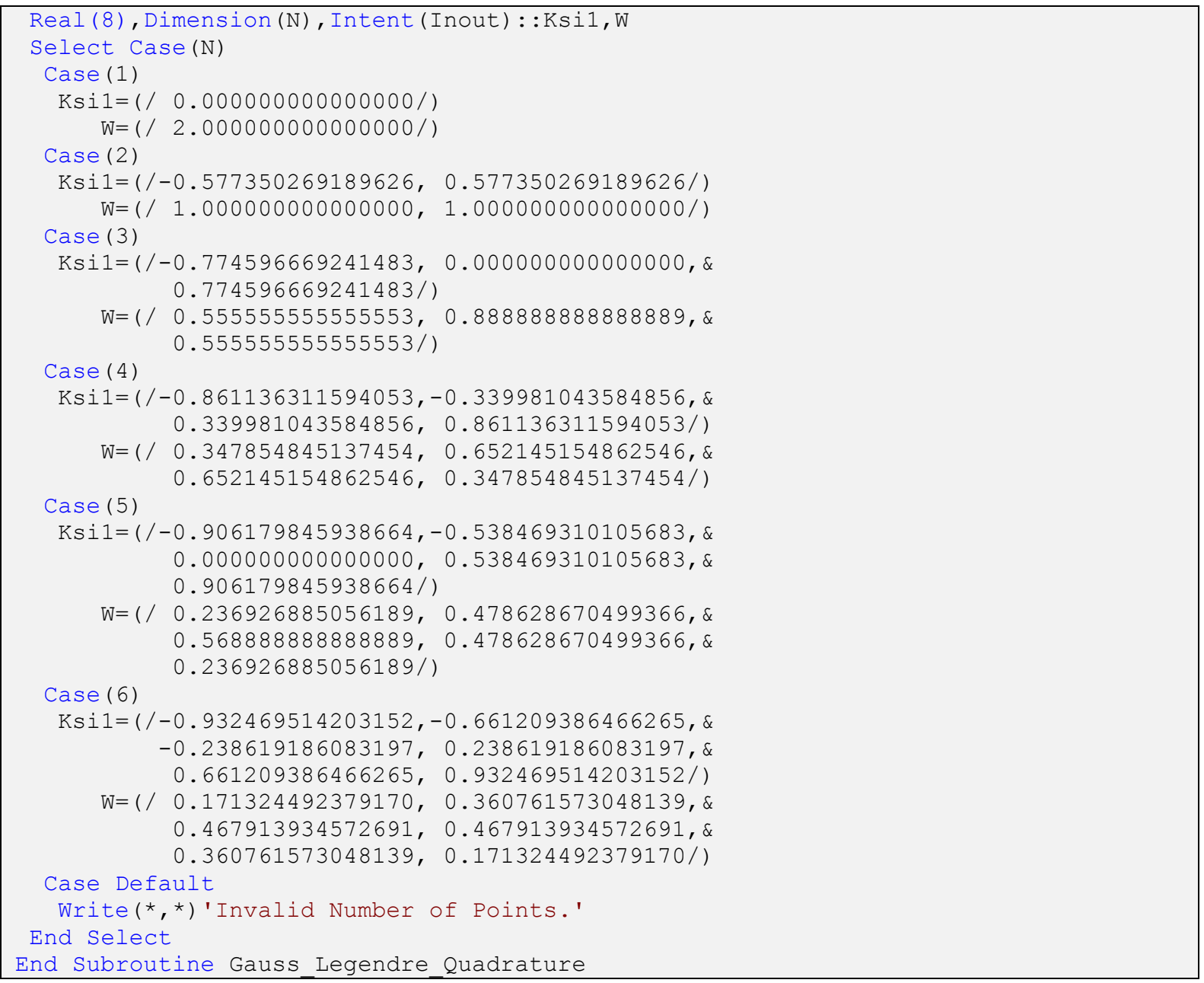

Ao se empregar elementos bidimensionais quadrilaterais a quadratura de GaussLegendre é efetuada em cada uma das variáveis, independentemente. Com isso, basta se proceder o produto cartesiano entre os conjuntos de pontos, um a um, sobre os eixos adimensionais. A rotina apresentada no Quadro 4 pode ser utilizada também para se obter os pontos e pesos usados na integração do elemento quadrilateral.

\subsubsection{Quadratura de Hammer}

O procedimento para obtenção dos pontos e pesos da quadratura de Hammer é semelhante ao apresentado na seção anterior. A diferença é que o procedimento se aplica a domínios bidimensionais triangulares. No Quadro 5 estão dispostos os valores dos pontos e pesos utilizados na integração de domínios triangulares.

Quadro 5: Pontos e pesos da integração de Hammer

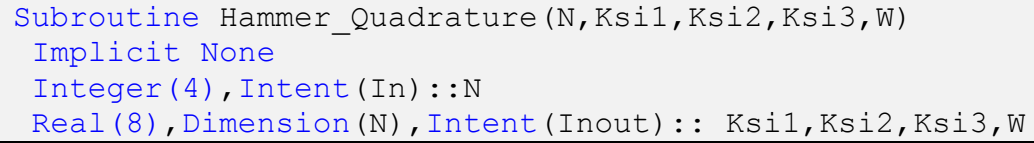




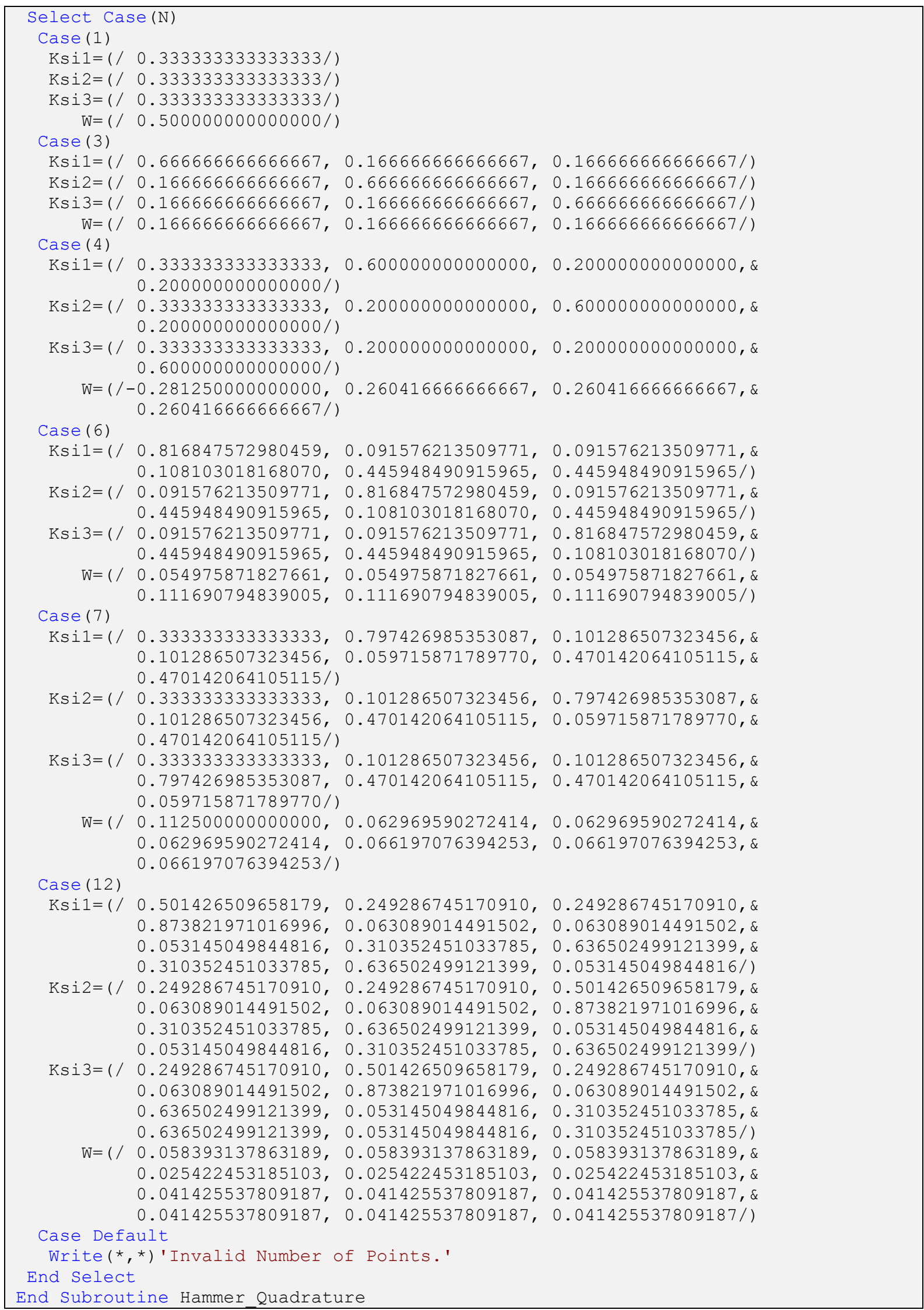

No que segue, apresentam-se as técnicas numéricas de solução dos sistemas de equações não-lineares resultante do método dos elementos finitos posicional. 


\subsection{Método de Newton-Raphson}

De acordo com (FRANCO, 2006) o método de Newton-Raphson é uma das técnicas mais populares empregadas na análise numérica. A metodologia consiste em se determinar as raízes de equações ou sistema de equações não-lineares, a partir de um processo iterativo com base nas etapas de previsão linear e correção não linear, seguida de um teste de parada. $O$ procedimento iterativo tem a finalidade de buscar uma solução tão próxima da solução real, a menos de uma tolerância pré-fixada.

$\mathrm{Na}$ análise de problemas estruturais com não-linearidade geométrica, o critério de parada é aquele em que o sólido atinge a configuração de equilíbrio. Como visto no capítulo anterior, o equilíbrio é estabelecido a partir do princípio da estacionariedade da energia potencial total, resultando numa equação com a seguinte forma:

$$
F_{i}^{\text {int }}\left(Y_{j}\right)-\lambda F_{i}^{\mathrm{ext}}=0
$$

Sendo, $F_{i}^{\text {int }}\left(Y_{j}\right)=\frac{\partial}{\partial Y_{i}}\left\{U_{e}\left(Y_{j}\right)\right\}$, o vetor de forças internas e $\lambda$, um fator de carregamento que define o nível de força aplicado na estrutura.

Na fase de previsão é atribuída uma solução tentativa $Y_{j}^{k-1}$ para um determinado passo de carga $\lambda^{\ell-1}$. Caso o equilíbrio não seja satisfeito, define-se o vetor de forças residuais ou vetor desbalanceamento, expresso por:

$$
F_{i}^{\mathrm{int}}\left(Y_{j}^{k-1}\right)-\lambda^{\ell-1} F_{i}^{\mathrm{ext}}=g_{i}\left(Y_{j}^{k-1}, \lambda^{\ell-1}\right)
$$

Uma vez atendida a equação de equilíbrio (4.10) para o passo de carregamento $\lambda^{\ell-1}$, incrementa-se a força externa fazendo-se:

$$
\lambda^{\ell} F_{i}^{\mathrm{ext}}=\lambda^{\ell-1} F_{i}^{\mathrm{ext}}+\Delta \lambda^{\ell} F_{i}^{\mathrm{ext}}
$$

Ou de forma equivalente, trabalha-se apenas com os incrementos no parâmetro de carregamento, escrito da seguinte maneira:

$$
\lambda^{\ell}=\lambda^{\ell-1}+\Delta \lambda^{\ell}
$$


Aplicando-se o novo incremento de força, o vetor de coordenadas generalizadas no passo de carga atualizado é definido da seguinte maneira:

$$
Y_{j}^{k}=Y_{j}^{k-1}+\Delta Y_{j}^{k}
$$

Sendo $\Delta Y_{j}^{k}$, o incremento adicionado as coordenadas generalizadas e a nova variável do problema.

Devido a natureza não-linear do vetor de forças interna, o vetor desbalanceamento também será uma quantidade não-linear dos parâmetros nodais de coordenadas generalizadas.

Para se resolver a equação não-linear pelo método de Newton-Raphson, emprega-se uma estratégia de linearização do resíduo a partir da expansão em série de Taylor da equação (4.11). Assim, é possível se analisar o que ocorre com o equilíbrio do sistema nas vizinhanças da solução tentativa. Expandindo-se o vetor desbalanceamento em torno dessas coordenadas e desprezando-se os termos de ordem superiores, a linearização do resíduo produz como resposta a equação:

$$
g_{i}\left(Y_{j}^{k}, \lambda^{\ell-1}\right)=g_{i}\left(Y_{j}^{k-1}, \lambda^{\ell-1}\right)+\frac{\partial g_{i}}{\partial Y_{j}}\left(Y_{j}^{k}, \lambda^{\ell-1}\right) \Delta Y_{j}^{k}
$$

A variável $\Delta Y_{j}^{k}$ representa à correção que deverá ser adicionada as coordenadas tentativas a fim de se obter a configuração de equilíbrio. Após a linearização admite-se que a nova solução anule o resíduo.

A nova condição de equilíbrio é satisfeita fazendo-se:

$$
g_{i}\left(Y_{j}^{k-1}, \lambda^{\ell-1}\right)+\frac{\partial g_{i}}{\partial Y_{j}}\left(Y_{j}^{k}, \lambda^{\ell-1}\right) \Delta Y_{j}^{k}=0
$$

O gradiente do resíduo avaliado na solução tentativa é a chamado de matriz de rigidez tangente e é matematicamente equivalente a matriz Hessiana da estrutura.

O vetor correção será obtido fazendo-se:

$$
\Delta Y_{j}^{k}=-H_{i j}^{-1}\left(Y_{j}^{k}, \lambda^{\ell-1}\right) g_{i}\left(Y_{j}^{k-1}, \lambda^{\ell-1}\right)
$$


A nova configuração de equilíbrio é encontrada atualizando-se à solução tentativa expressa na equação (4.14) e o processo iterativo continua até que o vetor desbalanceamento seja tão pequeno quanto uma tolerância pré-fixada.

Neste trabalho, a tolerância é tomada como a medida da distância relativa entre as soluções tentativa consecutivas, ou seja, um vetor correção, cuja referência é a posição indeformada. Essa norma é dada por:

$$
\left|\Delta Y_{j}^{k}\right| \leq \operatorname{tol}\left|Y_{j}^{0}\right|
$$

Numa análise, meramente iterativa, o nível de força é mantido constante e $\lambda^{\ell}=1$. Essa condição significa que o carregamento é aplicado de uma só vez e caracteriza os procedimentos de solução denominados quase-Newton. Porém, dividindo-se o carregamento em passos cumulativos é possível se iniciar o processo iterativo próximo ao resultado desejado, reduzindose assim o número de iterações em cada passo de carregamento. Nessa situação tem-se o chamado processo incremental-iterativo.

Uma crítica em relação ao método incremental-iterativo com o controle de carga ou deslocamento (entenda-se coordenadas generalizadas), consiste na dificuldade do processo em transpor os pontos críticos comumente encontrados na análise de instabilidade estrutural. É necessário se recorre a procedimentos capazes de tratar o incremento de carga ou de posições de forma paramétrica. Na próxima seção, o parâmetro de carregamento não é mais constante e sim uma restrição caracterizada por uma equação no espaço de configurações.

\subsection{Método do Arc-Length}

Como comentado anteriormente, na análise de instabilidade uma característica importante, e que dita a eficiência do método de solução, consiste na capacidade do algoritmo em ultrapassar os pontos críticos na trajetória de equilíbrio da estrutura.

Os algoritmos de Newton-Raphson não possuem a capacidade contornar esses pontos, haja visto o parâmetro de carga ser mantido constante durante a fase corretora do ciclo de iterações. Essa característica leva a um mal condicionamento na matriz de rigidez tangente que acaba por se tornar singular nesses pontos (CRISFIELD, 1997). 
Para se determinar completamente a trajetória de equilíbrio é necessário se introduzir um parâmetro de carga variável, simultaneamente ao incremento das coordenadas. Em (RISK, 1972) são apresentados alguns tratamentos adicionais ao método de Newton-Raphson com a finalidade de introduzir equações de restrições e eliminar o mal condicionamento da matriz de rigidez tangente.

O objetivo do processo de solução com o método do comprimento de arco (arc-length) consiste em encontrar uma solução tentativa para determinado nível de força, desconhecido e sujeito a uma equação de restrição do tipo:

$$
\Delta L^{2}=\Delta Y_{j} \cdot \Delta Y_{j}+\psi^{2} \Delta \lambda^{2}\left(F_{i}^{e x t} \cdot F_{i}^{e x t}\right)
$$

Sendo $\Delta L$ a norma da restrição, obtida de maneira incremental a partir de um valor tentativa para $\Delta \lambda$. O valor de $\psi$ é um ponderador utilizado para homogeneizar as dimensões do parâmetro de carregamento no espaço de configurações.

O método do comprimento de arco é resolvido de maneira semelhante ao método de Newton-Rapson, porém devendo-se atender a equação de restrição num processo com $n+1$ equações. O sistema de equações resultante fica expresso como:

$$
\left\{\begin{array}{l}
g\left(Y_{j}, \lambda\right)=F_{i}^{\mathrm{int}}\left(Y_{j}\right)-\lambda F_{i}^{\mathrm{ext}} \\
\Delta Y_{j} \cdot \Delta Y_{j}+\psi^{2} \Delta \lambda^{2}\left(F_{i}^{e x t} \cdot F_{i}^{e x t}\right)-\Delta L^{2}=0
\end{array}\right.
$$

Sendo $i=1, n$ o número de graus de liberdade do sistema.

Nesse trabalho adota-se o método do comprimento de arco para se traçar a trajetória de equilíbrio do elemento de treliça não-linear geométrico. Admite-se a restrição hiperesférica proposta por (CRISFIELD, 1981), no qual o valor de $\psi=1$.

A solução do sistema de equações (4.20) irá gerar um novo ponto na trajetória de equilíbrio e definirá a origem e o raio do arco para o k-ésimo incremento, caracterizando a etapa chamada de previsão. Essa solução é obtida fazendo-se:

$$
\left\{\begin{array}{l}
Y_{j}^{k}=Y_{j}^{k-1}+\Delta Y_{j}^{k} \\
\lambda^{k}=\lambda^{k-1}+\Delta \lambda^{k}
\end{array}\right.
$$


Até este ponto, o processo de solução é puramente incremental e pode ser combinado com iterações dentro de cada incremento corrigindo-se o par $\left(\Delta Y_{j}^{k}, \Delta \lambda^{k}\right)$. A próxima etapa consiste em determinar uma nova estimativa que anule o resíduo e atenda a equação de restrição.

Em correspondência ao novo par de soluções tentativas, há um desbalanceamento na equação de equilíbrio que pode ser determinado de maneira semelhante ao processo de linearização adotada no método de Newton-Raphson. Porém, a expansão em série deverá atender a equação do resíduo, sujeita a restrição hiperesférica. Essa condição é obtida admitindo-se continuidade da função resíduo e suas primeiras derivadas em relação ao parâmetro de carregamento e coordenadas.

Desenvolvendo-se o resíduo em série de Taylor em torno da solução tentativa, dada por $Y_{j}^{m+1}=Y_{j}^{m}+\Delta Y_{j}^{m}+\delta Y_{j}^{m}$, e sujeito a restrição $\lambda^{m+1}=\lambda^{m}+\Delta \lambda^{m}+\delta \lambda^{m}$, o sistema de equação (4.20) resulta:

$$
\left\{\begin{array}{l}
g_{i}\left(Y_{j}^{m+1}, \lambda^{m+1}\right)=g_{i}\left(Y_{j}^{m}+\Delta Y_{j}^{m}, \lambda^{m}+\Delta \lambda^{m}\right) \\
+\frac{\partial g_{i}}{\partial Y_{j}}\left(Y_{j}^{m}+\Delta Y_{j}^{m}\right) \delta Y_{j}^{m}+\frac{\partial g_{i}}{\partial \lambda}\left(\lambda^{m}+\Delta \lambda^{m}\right) \delta \lambda^{m}=0 \\
\left(\Delta Y_{j}^{m}+\delta Y_{j}^{m}\right) \cdot\left(\Delta Y_{j}^{m}+\delta Y_{j}^{m}\right)+\left(\Delta \lambda^{m}+\delta \lambda^{m}\right)^{2}\left(F_{i}^{e x t} \cdot F_{i}^{e x t}\right)-\Delta L^{2}=0
\end{array}\right.
$$

Sendo $\left(\delta Y_{j}^{m}, \delta \lambda^{m}\right)$ as variações adicionadas aos incrementos na etapa de correção.

Do sistema (4.22) resultam as seguintes condições:

$$
\left\{\begin{array}{l}
g_{i}\left(Y_{j}^{m}+\Delta Y_{j}^{m}, \lambda^{m}+\Delta \lambda^{m}\right)+H_{i j}\left(Y_{j}^{m}+\Delta Y_{j}^{m}\right) \delta Y_{j}^{m}-\delta \lambda^{m} F_{i}^{\mathrm{ext}}=0 \\
\left(\Delta Y_{j}^{m}+\delta Y_{j}^{m}\right) \cdot\left(\Delta Y_{j}^{m}+\delta Y_{j}^{m}\right)+\left(\Delta \lambda^{m}+\delta \lambda^{m}\right)^{2}\left(F_{i}^{e x t} \cdot F_{i}^{e x t}\right)= \\
\Delta Y_{j}^{m} \cdot \Delta Y_{j}^{m}+\left(\Delta \lambda^{m}\right)^{2}\left(F_{i}^{e x t} \cdot F_{i}^{e x t}\right)
\end{array}\right.
$$

Com um pouco de álgebra é possível isolar $\delta Y_{j}^{m}$ e encontrar o valor de $\delta \lambda^{m}$ resolvendose o sistema (4.23) que resulta na equação do segundo grau:

$$
a_{1}\left(\delta \lambda^{m}\right)^{2}+a_{2} \delta \lambda^{m}+a_{3}=0
$$


Sendo:

$$
\begin{aligned}
& a_{1}=\bar{Y}_{j}^{m} \bar{Y}_{j}^{m}+F_{i}^{e x t} F_{i}^{e x t}, \\
& a_{2}=2 \Delta Y_{j}^{m} \bar{Y}_{j}^{m}-2 \bar{Y}_{j}^{m} \delta \bar{Y}_{j}^{m}+2 \Delta \lambda^{m} F_{j}^{e x t} F_{j}^{e x t}, \\
& a_{3}=\delta \bar{Y}_{j}^{m} \delta \bar{Y}_{j}^{m}-2 \Delta Y_{j}^{m} \delta \bar{Y}_{j}^{m} . \\
& \text { O valor } \bar{Y}_{j}^{m}=H_{i j}^{-1}\left(Y_{j}^{m}+\Delta Y_{j}^{m}\right) F_{i}^{e x t} \text { é denominado incremento de retorno e surge }
\end{aligned}
$$
naturalmente na expressão para ajustar a intensidade do carregamento de modo a satisfazer a condição de restrição da hiperesfera. $\mathrm{O}$ valor $\delta \bar{Y}_{j}^{m}=H_{i j}^{-1}\left(Y_{j}^{m}+\Delta Y_{j}^{m}\right) g_{i}\left(Y_{j}^{m}+\Delta Y_{j}^{m}, \lambda^{m}+\Delta \lambda^{m}\right)$ é o incremento da componente residual do método de Newton-Raphson.

De posse das raízes da equação (4.24) é necessário se definir qual delas é a mais adequada para descrever a trajetória de equilíbrio. De acordo com (CRISFIELD, 1997) existem várias propostas de verificação, sendo este um tema ainda em discussão.

A solução considerada neste trabalho é aquela que evita com que o processo de solução retorne pela trajetória de equilíbrio iniciando um descarregamento indesejado da estrutura. Consegue-se essa condição fazendo com que os incrementos consecutivos nas coordenadas generalizadas sejam sempre positivos para uma das raízes.

Essa condição é expressa como:

$$
\Delta Y_{j}^{m+1} \Delta Y_{j}^{m}>0
$$

Caso as duas raízes satisfaçam a condição, opta-se pela solução que mais se aproxime da resposta linear dada por $\delta \lambda^{m}=-a_{3} / a_{2}$.

Para se concluir o processo é necessário se estimar os valores dos incrementos na etapa de previsão. Uma maneira simples de se obter esses valores é por meio de uma extrapolação nos incrementos do parâmetro de carga e coordenadas generalizadas.

Essa extrapolação é feita empregando-se uma relação linear do tipo: 


$$
\begin{aligned}
& \Delta Y_{j}^{m+1}=\zeta \Delta Y_{j}^{m} \\
& \Delta \lambda^{m+1}=\zeta \Delta \lambda^{m}
\end{aligned}
$$

Sendo $\zeta$ um fator de escala utilizado para se estimar a magnitude da hiperesfera. $\mathrm{O}$ valor desse fator é obtido de acordo com a expressão apresentada por (NETO e FENG, 1999), calculada como:

$$
\zeta=\Delta L^{m-1}\left(\frac{i_{m}}{i_{m-1}}\right)
$$

Sendo $\Delta L^{m-1}$ o raio do arco no passo anterior, $i_{m}$ o número de iterações máximas desejadas no passo atual e $i_{m-1}$ o número de iterações do passo anterior. Essa condição acaba por fornecer raios pequenos em situações de forte não-linearidade e raios grandes para respostas aproximadamente lineares.

A crítica que se faz ao procedimento consiste no fato da grandeza $\psi$ ser introduzida para se corrigir a restrição do raio do arco que não possui significado geométrico bem definido. Uma interpretação admissível para esse procedimento consiste em expressar o parâmetro de carregamento como um multiplicador de Lagrange, de variação contínua em relação a um hiperplano com origem na solução tentativa. Fora essa interpretação a norma da hiperesfera não pode ser considerado como uma medida de comprimento, como é comumente referenciada na literatura por comprimento do arco.

Para finalizar o capítulo na próxima seção apresentam-se os fundamentos do algoritmo de Lanczos para a análise de autovalores e autovetores. Destaque é dado para as bibliotecas numéricas, altamente eficientes, disponibilizadas por vários grupos de analistas numéricos.

\subsection{Autovalores e Autovetores: Método de Lanczos}

A determinação dos autovalores e autovetores é um problema comum em várias áreas das ciências. Na engenharia, uma série de aplicações, como por exemplo: o cálculo dos modos de vibração e a determinação das cargas críticas das estruturas, podem ser resolvidas simplesmente a partir do cálculo dos autovalores e autovetores. 
O conhecimento dessas quantidades para a análise e dimensionamento estrutural é de fundamental importância, pois com esses valores o analista definirá os níveis de carregamentos para o qual nenhuma situação de estados limite será atingida.

Em razão da importância desse campo, uma série de pesquisas são realizadas com a finalidade de desenvolver algoritmos cada vez mais eficientes e robustos para o cálculo dos valores e vetores próprios. Uma dessas vertentes dedica-se aos aprimoramentos do método de (LANCZOS, 1950) apud (CULLUM e WILLOUGHBY, 1985).

O método de Lanczos consiste na determinação de valores e vetores próprios de matrizes simétricas esparsas, a partir de uma base de vetores ortogonais e uma submatriz tridiagonal. De acordo com (PARLETT e OMID, 1989), devido a instabilidade numérica originalmente verificada nesse procedimento, o método foi completamente ignorado pelos analistas numéricos por um longo período, sendo utilizado somente para se determinar formas tridiagonais de matrizes simétricas.

Porém, um pequeno grupo de engenheiros verificou que esse método poderia ser aplicado satisfatoriamente ao cálculo de um número restrito de autovalores, em particular, os menores autovalores.

(PAIGE, 1976) apud (PARLETT e OMID, 1989) explica como os erros de aritmética de ponto flutuante perturbam o algoritmo, durante o processo de ortogonalização dos autovetores. $\mathrm{O}$ autor propõem um processo denominado de reortogonalização para garantir que a cada iteração os autovetores semantenham ortogonais e com isso, se elimine os resquício decorrente de aproximações numérica. Com esse procedimento, o método de Lanczos tornouse uma poderosa ferramenta em aplicações de cunho científico e tecnológico.

Em (GOLUBA e VAN DER VORST, 2000) é apresentada uma revisão histórica dos principais métodos de cálculo de autovalores e autovetores de matrizes simétricas. Os autores referenciam também as principais bibliotecas disponibilizadas por algumas das melhores equipes de analistas numéricos e destaca as seguintes páginas da internet para acesso ao conteúdo dessas bibliotecas:
a) http://www.hsl.rl.ac.uk/catalogue/;
b) http://www.caam.rice.edu/software/ARPACK/;
c) http://www.netlib.org/lapack/; 
d) http://slepc.upv.es/e

e) http://www.ecs.umass.edu/ polizzi/feast/index.htm.

Neste trabalho foram utilizadas as rotinas da biblioteca ARPACK, disponíveis para FORTRAN e C++, nas versões sequencial e paralela.

A biblioteca ARPACK é uma coleção de rotinas baseada no algoritmo de Arnoldi, chamado Implicitly Restarted Arnoldi Method (IRAM) empregado para tratar de problemas de autovalores e autovetores de matrizes esparsas de grande escala. Quando a matriz, além de esparsa, se reduz a uma forma simétrica, como é caso dos elementos finitos tratados neste trabalho, a biblioteca se reduz a uma variação do algoritmo de Lanczos, chamado Implicitly Restarted Lanczos Method (IRLM)

Nesta seção, apresenta-se sucintamente a metodologia utilizada pelo algoritmo de Lanczos, o qual será utilizado nas análises lineares de instabilidade.

O método de Lanczos, como originalmente formulado, é aplicado a resolução do problema de autovalor expresso pela equação geral:

$$
A \Lambda=\lambda I \Lambda
$$

Sendo $A$ uma matriz real simétrica de dimensão $n \times n, I$ é a matriz identidade com a mesma dimensão que $A$. As quantidades $\lambda$ e $\Lambda$ representam os autovalores e autovetores da matriz.

Essencialmente, o método consiste em determinar uma matriz $Q$ capaz de transformar a $A$ em a uma forma tridiagonal $T$ a partir da seguinte projeção de $Q$ sobre $A$ :

$$
T=Q^{t} A Q
$$

As componentes da matriz $Q$ são tomadas de maneira a formar uma base de vetores ortogonais.

A determinação direta dos autovalores e autovetores da forma tridiagonal, consequentemente da própria matriz $A$, produzem os erros de arredondamento comentados anteriormente. 
Uma maneira de contornar o problema consiste em se proceder um número de passos tomando-se a matriz de um passo $j$, como uma submatriz do passo $j+1$. A cada novo passo resolve-se um problema de autovalor e autovetor de dimensões reduzidas.

O algoritmo é constituído de duas etapas fundamentais: Na primeira etapa define-se a base de vetores ortogonais construindo-se uma coluna da matriz de transformação $Q$, ao mesmo tempo que se incrementa a matriz de transformação $T$ em uma linha e uma coluna.

Em cada passo resolve-se o problema de autovalores e autovetores na sua forma reduzida, expressa pela equação:

$$
\left(T_{j}-\psi I_{j}\right) \Psi=0
$$

Sendo, $\psi$ e $\Psi$, o autovalor e o autovetor correspondente ao passo $j$.

Na segunda etapa determinam-se os autovetores da matriz $A$ a partir de uma combinação linear com a base de vetores ortogonais, por meio da relação:

$$
\Lambda=Q \Psi
$$

Os algoritmos iterativos para o cálculo dos autovalores podem ser encontrados em vários artigos de referência. Neste trabalho forma consultadas as obras de (SAAD, 1992), (SORENSEN, 1995) e (BAZÁN, 2003) que fornecem os algoritmos de solução.

\subsection{Fechamento}

Neste capítulo foram apresentados os principais métodos numéricos utilizados durante o desenvolvimento e coleta dos resultados da presente pesquisa. A intensão ao se idealizar o capítulo é informar ao leitor sobre as principais ferramentas numéricas necessárias para se atingir o objetivo da pesquisa. Ao longo do capítulo são indicadas as principais referências bibliográficas onde é possível se consultar com mais profundidade cada tópico de análise numérica apresentado. 



\section{$5 \quad$ Fundamentos da Estabilidade Estrutural}

\subsection{Apresentação do Capítulo}

Neste capítulo são apresentadas as principais definições utilizada na teoria geral da instabilidade estrutural. Em seguida demonstra-se a metodologia de análise linear de instabilidade empregando-se a decomposição da matriz Hessiana do elemento finito posicional não-linear geométrico. A partir dessa estratégia é possível se identificar pontos críticos na trajetória de equilíbrio por meio da análise linearizada de instabilidade.

\subsection{Instabilidade Estrutural: Definições}

Define-se perda de estabilidade ou instabilidade estrutural como a transição entre configurações de equilíbrio devido a ação de uma perturbação no sistema. As configurações de equilíbrio podem ser do tipo estáveis ou instáveis. Se uma configuração de equilíbrio deixa de ser estável, diz-se que o limite de instabilidade foi alcançado e o ponto que encerra a sucessão de configurações é denominado ponto crítico, assim vale se aconfiguração deixa de ser instável e passa a ser estável.

O equilíbrio é estável, quando pequenas perturbações no sistema produzem configurações equilibradas, tão próximas das configurações anteriores, quanto menor a intensidade das perturbações, caso contrário diz-se que o equilíbrio é instável.

Para se descrever a estabilidade ou instabilidade do sistema recorre-se a noção de configuração de equilíbrio ou trajetória de equilíbrio.

As análises com o intuito de descrever a trajetória de equilíbrio da estrutura, identificando seus possíveis pontos críticos, são denominadas de análise do tipo path-following. Essas estratégias são amplamente estudadas na literatura, como por exemplo os algoritimos de continuação do arc-length, (CRISFIELD, 1981). Análises desse tipo são de grande importância em problemas com forte não-linearidade geométrica.

O termo flambagem, ainda empregado nos textos da mecânica dos sólidos, está associada a uma condição idealizada. Nesse caso, a estrutura é isenta de qualquer imperfeição e o ponto crítico, denominado ponto de bifurcação caracteriza o tipo de instabilidade do sistema. 
Aproveita-se a oportunidade para esclarecer que neste texto emprega-se a denominação instabilidade para se referir a perda de estabilidade no sentido mais amplo da terminologia. Limita-se a utilização do termo flambagem, apenas ao se tratar do problema clássico de bifurcação do equilíbrio, ou flambagem de Euler.

Como mencionado, a instabilidade da uma estrutura é caracterizada pela transição entre configurações de equilíbrio estável e instável. Essa classificação está associada a espécie dos problemas e que podem ser classificados como:

a) Problemas de primeira espécie: também chamados de problemas de autovalor, ou instabilidade bifurcacional, tratam da instabilidade de estruturas isenta de imperfeições físicas ou geométricas. Na iminência de se atingir a carga crítica, qualquer solicitação provocará a instabilidade da estrutura. Como exemplo, cita-se o problema da flambagem de Euler.

b) Problemas de segunda espécie: tratam da instabilidade de estruturas reais com imperfeições física ou geométrica, ou de estruturas ideais com carregamento excêntrico. A trajetória de equilíbrio varia gradualmente até o ponto em que os deslocamentos aumentam consideravelmente após um pequeno acréscimo na carga.

c) Problemas de terceira espécie: também classificados como problemas de ponto limite, ocorre devido a presença de um ponto que encerra uma sucessão de configurações de equilíbrio sem o aparecimento de pontos de bifurcação, ou seja, não ocorre o aparecimento de mais de uma trajetória no caminho de equilíbrio. Após esse ponto, a natureza das configurações altera-se de estáveis para instáveis. Atingido o ponto limite a mudança de equilíbrio ocorre de forma abrupta, caracterizando-se o fenômeno de snap-trhought.

A análise também pode ser definida de acordo com as hipóteses cinemáticas consideradas. De acordo com (RACHID e MORI, 2006) é possível classifica-las como:

a) Análise de primeira ordem: o equilíbrio da estrutura é determinado na configuração indeslocada, considerando-se a hipótese de pequenos deslocamentos.

b) Análise de segunda ordem: o cálculo do equilíbrio é determinado na configuração deslocada, porém, ainda sob a condição de pequenos deslocamentos. 
c) Análise de terceira ordem: o equilíbrio da estrutura é considerado na configuração deslocada. Não se admite simplificações cinemáticas introduzidas pela hipótese de pequenos deslocamentos.

Em (REIS e CAMOTIM, 2001), os autores argumentam que numa análise em terceira ordem, a instabilidade do sistema estrutural depende da complexidade introduzida pela não linearidade. Nesses casos, o traçado da trajetória de equilíbrio se reduz a um número limitado de problemas elementares e soluções mais gerais devem ser tratadas a luz das análises aproximadas, como pelo método de Galerkin, Rayleigh-Ritz ou o método dos elementos finitos.

As hipóteses introduzidas nas equações de equilíbrio diferenciam os tipos de instabilidade e podem conduzir a relações cinemática. De acordo com (REIS e CAMOTIM, 2001) definem-se dois tipos de análises, quais são:

a) Análise Linear de Instabilidade: consiste na determinação das cargas críticas e dos modos associados a perda de estabilidade em decorrência de um ponto de bifurcação na trajetória de equilíbrio. Nesse tipo de análise o interesse prioritário é se determinar o fator pelo qual deve-se combinar o carregamento externo de modo a se obter a magnitude da carga crítica, a partir de um problema geral de valores e vetores próprios. Os modos representam as configurações que a estrutura assume quando atingidas essas cargas, porém, os modos não representam os valores reais dos deslocamentos, pois fornecem apenas os dados qualitativos da maneira como se processam as deformações.

b) Análise Não Linear de Instabilidade: ao contrário do que ocorre na análise linear de estabilidade, os valores dos modos representam os deslocamentos que ocorrem na estrutura e as análises são levadas além do ponto de bifurcação. Na análise não linear de instabilidade considera-se também a influência das imperfeições.

Neste trabalho a não linearidade geométrica é intrínseca a formulação dos elementos finitos, pois a cinemática dos modelos considera o equilíbrio da estrutura na configuração deslocada. Devido essa generalidade é possível se analisar a trajetória de equilíbrio inclusive em grandes deslocamentos e rotações.

O que se pretende nesse capítulo é utilizar os conceitos e terminologias para se apresentar uma metodologia que considera a formulação não linear geométrica em uma análise 
linear de estabilidade, ou seja, determinar os valores dos carregamento e modos críticos de estruturas considerando-se as relações cinemáticas exatas.

Para isso mais algumas definições são imprescindíveis, como por exemplo a caracterização dos pontos críticos.

Acompanhar a trajetória de equilíbrio não-linear das estruturas é uma maneira eficiente de identificar a ocorrência de pontos críticos. Variando-se o parâmetro de carregamento é possível quantificar o nível de solicitação capaz de produzir um estado crítico.

Os pontos críticos quando ocorrem nessa trajetória limitam a natureza do equilíbrio, e de acordo com suas características são classificados em pontos de bifurcação ou pontos limite. Esses pontos identificam tipos de instabilidade, denominados respectivamente: instabilidade bifurcacional ou instabilidade de primeira espécie (ou simplesmente flambagem) e a instabilidade por ponto limite ou instabilidade de segunda espécie.

No ponto de bifurcação as configurações de equilíbrio estáveis deixam de ser únicas. Para além do ponto de bifurcação as possíveis configurações de equilíbrio passam a ser de natureza estável ou instável e a esse ponto associa-se um valor denominado, carga crítica.

A instabilidade por ponto limite ocorre devido a presença de um ponto que encerra uma sucessão de configurações de equilíbrio sem o aparecimento de pontos de bifurcação. Para além desse ponto, a natureza das configurações altera-se de estáveis para instáveis.

$\mathrm{Na}$ Figura 7 ilustram-se pontos críticos na trajetória fundamental de equilíbrio, caracterizando-se também a estabilidade das trajetórias pós-críticas. 


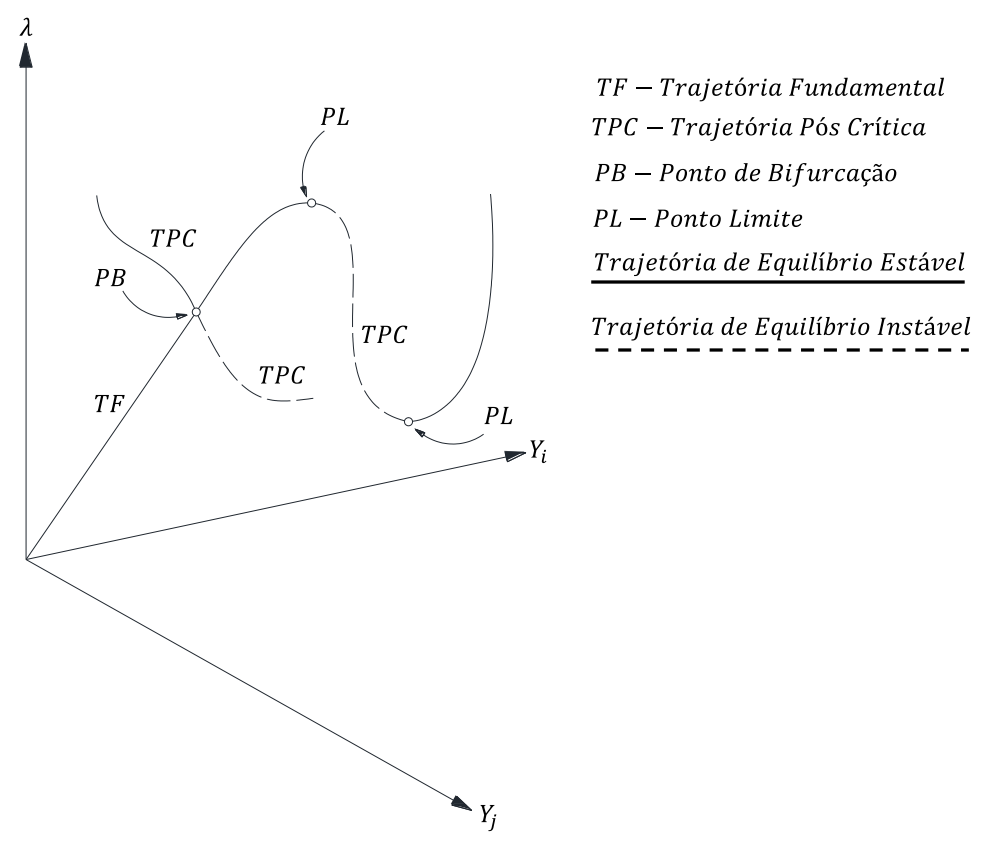

Figura 7: Trajetórias de equilíbrio da estrutura

A proposta de se realizar uma análise linear de instabilidade empregando-se a formulação Lagrangiana total do elemento finito posicional é uma metodologia inédita e precisa que algumas considerações sejam feitas antes do cálculo dos valores e vetores próprios da estrutura.

A fim de se chegar na formulação comentada, apresentam-se nas próximas seções os fundamentos que permitem que análises nesse sentido sejam realizadas.

\subsection{Teoria Geral da Estabilidade Elástica}

De acordo com (LYAPUNOV, 1892), a conceituação geral do fenômeno de instabilidade requer a consideração dinâmica das forças conservativas. Porém, se as ações atuam a partir de pequenos incrementos de carga, é possível determinar a resposta estrutural em regime quase-estático sem perda de generalidade. Os autores (SIMITSES e HODGES, 2006) informam que o fenômeno de instabilidade pode ser formulado a partir de diferentes abordagens, empregando-se as equações de equilíbrio (abordagem vetorial), ou através do critério da energia potencial estacionária (formulação escalar).

Neste texto, estuda-se o problema de instabilidade considerando-se o regime quaseestático de resposta estrutural, formulado a partir de critérios energéticos. 
O critério energético fundamenta-se no teorema de Lagrange-Dirichlet (BAžANT e CEDOLIN, 2010) e estabelece uma condição geral de estabilidade para o sistema mecânico, cuja interpretação é a seguinte:

Sendo a energia potencial total uma função contínua de suas coordenadas generalizadas, com um mínimo relativo em alguma posição de equilíbrio, então essa posição é dita de equilíbrio estável.

O enunciado do teorema é um corolário do princípio da estacionariedade da energia potencial total apresentado no capítulo anterior, e estabelece quais configuração de equilíbrio levam a um aumento da energia do sistema. A partir desse enunciado é possível unificar as condições de equilíbrio e estabilidade em um único critério.

Para ilustrar essa condição, recorre-se a análise de um sistema mecânico elementar, representado por uma esfera sujeita a ação gravitacional e restrita a vínculos de natureza puramente cinemática, como mostrado na Figura 8.

$$
y(x)=-x^{2}
$$

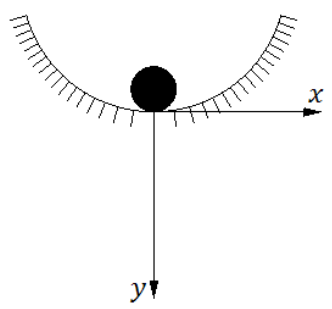

(a)Eq.estável

$$
y(x)=0
$$

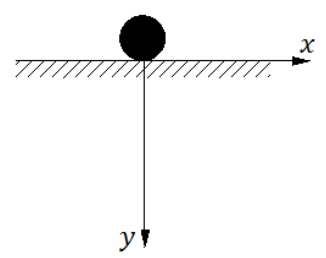

(b)Eq.indiferente $y(x)=x^{2}$

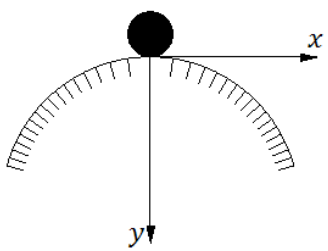

(c)Eq.instável

\section{Figura 8: Instabilidade do equilíbrio}

De maneira intuitiva nota-se que o equilíbrio do sistema é dito estável, caso a esfera consiga regressas à sua posição inicial após cessada a perturbação. Essa condição é satisfeita pelo vínculo com superfície côncava, Figura 8 (a). O equilíbrio é neutro ou indiferente, se a esfera alcançar uma nova configuração de equilíbrio, mínimo local, em uma posição diferente da inicial, como na Figura 8 (b). Intuitivamente, a condição de equilíbrio instável é aquela em que a esfera não consegue retornar à nenhuma configuração de equilíbrio, mesmo cessada a perturbação. Essa situação pode ser verificada com o vínculo de superfície convexa na Figura 8 (c). 
A energia potencial total pode ser avaliadas da seguinte maneira:

$$
\begin{aligned}
& \Pi_{(a)}=-P y(x)=m g x^{2} \\
& \Pi_{(b)}=-P y(x)=0 \\
& \Pi_{(c)}=-P y(x)=-m g x^{2}
\end{aligned}
$$

Sendo $m$ a massa da esfera e $g$ a aceleração da gravidade.

O sinal negativo na equação (5.3) indica que a esfera, ao se afastar da posição de referência, no sentido negativo do eixo $y$, aumenta seu potencial gravitacional, consequentemente, a capacidade da força peso realizar trabalho é maior.

As primeiras derivadas da energia em relação à posição da esfera resultam:

$$
\begin{aligned}
& \frac{d \Pi_{(a)}}{d x}=2 m g x=0 \Leftrightarrow x=0 \\
& \frac{d \Pi_{(b)}}{d x}=0, \forall x \\
& \frac{d \Pi_{(c)}}{d x}=-2 m g x=0 \Leftrightarrow x=0
\end{aligned}
$$

Verifica-se que $x=0$ é um ponto crítico, sendo um máximo ou mínimo local, a depender do sinal da segunda variação da energia. Logo, analisando-se o sinal da segunda derivada, tem-se:

$$
\begin{aligned}
& \frac{d^{2} \Pi_{(a)}}{d x^{2}}=2 m g>0, \forall x \\
& \frac{d^{2} \Pi_{(b)}}{d x^{2}}=0, \forall x \\
& \frac{d^{2} \Pi_{(c)}}{d x^{2}}=-2 m g<0, \forall x
\end{aligned}
$$


Conclui-se que o equilíbrio do sistema mecânico é estável quando representa uma condição de mínimo local, caso (a). O equilíbrio é neutro ou indiferente quando a esfera permanece no trecho horizontal, caso (b). No caso (c) o equilíbrio é instável e a posição da esfera representa um ponto de máximo local na expressão da energia potencial.

Nesta análise o sistema adotado possui apenas um grau de liberdade. A generalização desses conceitos a sistemas estruturais com múltiplos grau de liberdade constitui o principal objetivo da análise geral de estabilidade elástica

Recorrendo-se a condição de equilíbrio da formulação posicional do método dos elementos finitos, mostrou-se que a segunda variação da energia potencial é uma forma quadrática das coordenadas generalizadas, denominada matriz Hessiana. A condição de estabilidade desse sistema é obtida fazendo-se:

$$
\operatorname{det}(\boldsymbol{H}-\lambda \boldsymbol{I})>0
$$

Caso a condição seja verificada diz-se que o equilíbrio é estável, caso contrário, o equilíbrio é instável. Porém, se a forma quadrática é nula, fica caracterizada uma condição de equilíbrio crítico e nada se pode afirmar acerca da estabilidade do equilíbrio, sendo necessário avaliar o sinal dos termos de ordem superior da energia potencial total.

A avaliação dos termos de ordem superior é a principal metodologia empregada por (KOITER, 1967) e se baseia fundamentalmente na análise do incremento de energia potencial total do sistema quando este experimenta uma perturbação em sua condição de equilíbrio. Essa análise configura o que (BAžANT e CEDOLIN, 2010) classificam como teoria não-linear de instabilidade ou análise pós-crítica, como apresentado por (REIS e CAMOTIM, 2001).

O critério apresentado na equação (5.10) é uma ferramenta prática para se avaliar a estabilidade do equilíbrio de sistemas estruturais. Porém, em sistemas com uma quantidade muito grande de graus de liberdade torna-se dispendiosa essa verificação.

Para contornar esse problema é interessante calcular o determinante da matriz hessiana como o produto dos seus autovalores buscando-se a equivalência:

$$
\operatorname{det}(\boldsymbol{H}-\lambda \boldsymbol{I})=\lambda_{1} \cdot \lambda_{2} \cdot \lambda_{3} \ldots \lambda_{n}
$$


Sendo $n$ a ordem da matriz Hessiana e $\lambda_{i}$, os autovalores. É fácil mostrar que essa condição corresponde a diagonalização da matriz e decorre da propriedade de ortogonalidade dos autovetores.

A solução de um problema de instabilidade de estruturas sujeitas a grandes deslocamentos necessita que a positividade da matriz Hessiana seja verificada a cada incremento de carga, o que deve ser executado, não pelo sinal do determinante da matriz, mas sim pelo sinal do menor autovalor.

Cada autovalor expresso na equação (5.11) pode ser interpretado como a rigidez que deve ser retirada, segundo um determinado grau de liberdade, para que a estrutura experimente uma situação de equilíbrio crítico. A ocorrência de autovalores negativos equivale a necessidade de se acrescentar molas desacopladas segundo os graus de liberdade, para que a estrutura retorne a condição de equilíbrio crítico. Dessas expressões pode-se ainda concluir que o número de autovalores negativos indica a quantidade de pontos críticos ultrapassados na trajetória de equilíbrio e que o número de autovalores é igual a ordem do sistema, a menos da multiplicidade desses valores.

No que segue apresenta-se a formulação geral da análise linear de instabilidade (problema de autovalor e autovetor) aplicada a linearização da matriz Hessiana do elemento finito posicional.

\subsection{Análise Linear de Estabilidade}

Para sistemas estruturais com carregamento conservativo verifica-se que a matriz Hessiana é uma forma quadrática positivo-definida. Considerando-se ainda a hipótese de comportamento elástico-linear do material, a Hessiana torna-se simétrica.

A análise linear de estabilidade consiste na determinação do parâmetro de carga para o qual a estrutura ou elemento estrutural perde estabilidade devido a ocorrência de pontos de bifurcação na trajetória de equilíbrio. O cálculo desse parâmetro é obtido, de maneira geral, a partir de um problema generalizado de autovalores, dado por:

$$
\left(\boldsymbol{K}_{T}-\lambda \boldsymbol{K}_{G}\right) \Lambda=0
$$


Sendo $\boldsymbol{K}_{T}$, a matriz de rigidez tangente numa configuração de equilíbrio estável. Quando esta configuração é tomada em relação ao estado inicial da estrutura descarregada sem imperfeições na geometria e no material, diz-se que a condição de instabilidade é denominada de análise de Euler, (MEIRELLES e PIMENTA, 1995) e a matriz de rigidez tangente é semelhante a matriz de rigidez linear $K_{L}$.

A matriz $\boldsymbol{K}_{G}$, é a matriz de rigidez geométrica obtida assumindo-se a condição de pequenos deslocamentos proporcionais ao carregamento.

A condição limite de estabilidade corresponde a determinação do menor fator de carga $\lambda$ capaz de produzir deslocamentos indeterminados na estrutura. Essa condição é equivalente ao cálculo do menor autovalor $\lambda$ de (5.12). Os valores $\Lambda$ correspondem as configurações deslocadas da estrutura calculadas por meio dos autovetores do problema.

Esse procedimento limita o campo de aplicação e reduz a teoria da instabilidade a estrutura sob a hipóteses de pequenos deslocamentos. Isso ocorre porque na teoria em grandes deslocamentos, um novo termo associado a rigidez geométrica surge na análise. Nessas condições o valor da carga crítica produzirá resultados maiores que o esperado e um procedimento de correção deverá ser utilizado. Nesse caso a metodologia está fora do escopo da análise de Euler, tratando-se de uma análise incremental-iterativa, não-linear de instabilidade.

Para a condição de pequenas cargas e pequenos deslocamentos, a carga crítica é obtida por meio da combinação:

$$
\vec{F}_{c r_{i}}=\lambda_{i} \vec{F}_{e x t}
$$

Sendo $\vec{F}_{c r_{i}}$, o vetor com as cargas críticas correspondente a cada autovalor $\lambda_{i}$. O vetor $\vec{F}_{e x t}$ é o carregamento de referência, sendo a própria carga que atua na estrutura.

Como destacado, a originalidade deste trabalho consiste em se utilizar adequadamente a metodologia de linearização em conjunto com o elemento finito posicional não-linear geométrico. Na próxima seção apresenta-se a metodologia de decomposição da matriz Hessiana utilizada para se realizar satisfatoriamente esse processo. 


\subsubsection{Decomposição da Matriz Hessiana dos Elementos Finitos Posicional}

O procedimento que permite que a matriz Hessiana seja decompostas nas parcelas de rigidez linear e geométrica advêm do cálculo da segunda derivada da energia específica de deformação.

Reescrevendo-se essa equação, observam-se as seguintes propriedades:

$$
\frac{\partial^{2} u_{e}}{\partial Y_{\alpha \beta} \partial Y_{\gamma \delta}}=\frac{1}{4} D_{m n p q} \frac{\partial C_{p q}}{\partial Y_{\alpha \beta}} \frac{\partial C_{m n}}{\partial Y_{\gamma \delta}}+\frac{1}{2} S_{m n} \frac{\partial^{2} C_{m n}}{\partial Y_{\alpha \beta} \partial Y_{\gamma \delta}}
$$

Sob a hipótese de pequenos carregamentos, a primeira parcela da equação (5.14) se aproxima da matriz de rigidez linear, enquanto a segunda parcela se aproxima da matriz de rigidez geométrica.

Essa observação é crucial para se adequar a formulação do elemento finito posicional nas análises envolvendo a instabilidade linear de instabilidade.

Observa-se na equação (5.14) o tensor de tensões $S_{m n}$ que surge em decorrência da ação do carregamento sobre a estrutura. Desse modo, o tensor de Piola-Kirchhoff é proporcional a carga $S_{m n}=P \bar{S}_{m n}$. Ao substituir esse resultado na equação (5.14) resulta:

$$
h_{m n p q}=\frac{1}{4} D_{m n p q} \frac{\partial C_{p q}}{\partial Y_{\alpha \beta}} \frac{\partial C_{m n}}{\partial Y_{\gamma \delta}}+\frac{1}{2} P \bar{S}_{m n} \frac{\partial^{2} C_{m n}}{\partial Y_{\alpha \beta} \partial Y_{\gamma \delta}}=h_{m n p q}^{L}+P h_{m n p q}^{G}
$$

Ao se integrar as parcelas $h_{m n p q}^{L}$ e $h_{m n p q}^{G}$ no volume inicial total, daí a formulação Lagrangiana total, e substituindo-se o carregamento equivalente pelo parâmetro de carga, observa-se formas equivalentes a matriz linear e geométrica da análise clássica do problema de autovalores. Sendo assim, a metodologia de decomposição da matriz Hessiana sob o regime de pequenas cargas e pequenos deslocamentos pode ser enquadrado nos moldes da análise geral de autovalores e autovetores.

Levando-se em conta que o equilíbrio da estrutura é garantido após se realizar um número suficiente de iterações, o cálculo da carga crítica é determinado de acordo com o problema: 


$$
\left(H_{m n p q}^{L}+\lambda H_{m n p q}^{G}\right) \Lambda_{p q}=0
$$

$\mathrm{Na}$ equação (5.16) o valor de $\lambda$ é o autovalor ao qual se deve multiplicar o carregamento para que a estrutura encontre seus modos críticos. O menor desses valores determina a carga crítica da estrutura.

O procedimento é geral e não se restringe a um tipo específico de elemento finito. Neste trabalho, essa metodologia é utilizada na análise de instabilidade dos elementos de barra simples, casca e barra geral.

Como são empregados elementos com diferentes características, a natureza do fenômeno dependerá do tipo de elemento usado na análise. Em problemas modelados com o elemento de barra simples só é possível se determinar a perda de equilíbrio global da estrutura. Para problemas modelados com o elemento de barra geral, a perda de estabilidade global da estrutura pode ser ocasionada devido a instabilidade de um de seus componentes. $\mathrm{O}$ aprimoramento da seção transversal devido a introdução das mobilidades no plano e fora do plano, proporcionará que flexibilidade suficiente a seção para que possa ocorre instabilidade local de chapa, se ativada durante a análise.

Na maioria dos textos sobre estabilidade estrutural é comum a utilização do termo, modo de instabilidade. Essa denominação não deve ser confundida com os resultados da análise de vibração em dinâmica das estruturas. Deve-se deixar claro que qualquer referência aos modos de instabilidade não se está associando as formas de instabilidade dos modos de vibração na análise de frequências, e sim a determinação de um problema de valores e vetores próprios semelhantes ao da dinâmica das estruturas. A configuração deformada da estrutura ou dos elementos estruturais resultante desse tipo de análise é referida na literatura especializada como modo de instabilidade.

\subsubsection{Modos de Instabilidade}

Embora o fenômeno de instabilidade ocorra com a interação entre diferentes modos é possível caracteriza-lo adequadamente para se avaliar a eficiência da estrutura, propondo-se medidas a fim de evita-los. 
A forma como se manifestam os modos de instabilidade dependem de fatores como: vinculação, geometria da seção e comprimento da peça. De maneira geral, classifica-se a instabilidade como de natureza global quando ocorre a perda de estabilidade da estrutura.

Em elementos estruturais de chapa delgada, as formas globais estão associadas aos chamados modos de flexão, modos de torção e modos de flexotorção.

Os modos globais se caracterizam por não apresentarem deformações significativas da seção transversal, deformando-se quase que exclusivamente devido a movimentos de corpo rígido da estrutura.

Comum a instabilidade global, pode-se caracterizar a instabilidade global de um elemento estrutural como sendo as deformações devido à instabilidade que ocorrem sobretudo no eixo longitudinal da peça que compõem a estrutura. As deformações da seção transversal, nesse caso, podem ser consideradas desprezíveis.

Por sua vez, as formas de instabilidade local estão associadas as deformações locais e distorcionais das chapas. Nesse caso, a seção transversal se deforma sem apresentar deslocamentos significativos no eixo da barra (GONÇALVES, DINIS e CAMOTIM, 2009) e as chapas podem apresentar deformações tanto no plano como fora do plano da seção transversal.

Nos exemplos apresentados nos próximos capítulos, mostram-se como os elementos de barra simples manifestam, sobretudo os modos de instabilidade global da estrutura. Essa característica decorre do fato de se restringir a rigidez a flexão para essas barras. Nos elementos de barra geral constatam-se os modos de instabilidade no elemento estrutural sendo de natureza global ou mesmo local, devido aos aprimoramentos introduzidos na cinemática da seção transversal do elemento.

Da mesma forma que o elemento de barra geral, os elementos de casca manifestam os modos globais no elemento, porém, com maior relevância as deformações locais das placas e nos flanges devido ao efeito de membrana.

Tendo essas definições e toda a metodologia necessária para se proceder a análise linear de estabilidade a partir dos elementos finitos não linear geométricos. Nos próximos capítulos 
descrevem-se com detalhes a formulação Lagrangiana total usada no desenvolvimento e aprimoramento dos elementos finitos posicional.

\subsection{Fechamento}

Neste capitulo foram apresentados os conceitos chaves utilizados na teoria geral de instabilidade elástica para se propor uma metodologia capaz de identificar os pontos críticos da trajetória de equilíbrio para os elementos finitos posicional, não-linear geométricos que ainda serão desenvolvidos e validados nesta tese. 


\section{Elemento Finito de Barra Simples}

\subsection{Apresentação do Capítulo}

Neste capítulo apresenta-se a formulação dos elementos de barra simples a partir do elemento curvilíneo tridimensional. A originalidade da formulação consiste em se adotar aproximações de ordem qualquer e uma lei constitutiva elástico linear empregando-se as medidas de deformações de Hill e seus respectivos conjugados energéticos (OGDEN, 1997). Na sequência, particulariza-se a geometria a fim de se desenvolver o elemento de treliça não linear geométrico com lei material de Saint-Venant-Kirchhoff.

O sistema de equações não linear é resolvido empregando-se as estratégias de solução com base nos algoritmos de previsão e correção dos métodos de Newton-Raphson e comprimento de arco - Arc-Length (CRISFIELD, 1981). Empregando-se esses algoritmos avaliam-se a natureza do equilíbrio a partir de estratégias do tipo path-following. Apresentamse exemplos com a finalidade de demonstrar as potencialidades de cada abordagem.

A outra metodologia, originalmente apresentada neste trabalho, consiste na decomposição da matriz Hessiana e controle dos autovalores. Esse processo é utilizado para se identificar dos pontos de bifurcação por meio de uma análise linear de estabilidade empregando-se o algoritmo de Lanczos. Mostra-se que a metodologia é equivale a decomposição da matriz de rigidez linear e geométrica.

Ao final do capítulo apresentam-se exemplos com o objetivo de validar a metodologia proposta.

\subsection{Elemento Finito Curvilíneo}

Considere-se o elemento finito curvilíneo sujeito a uma transformação $\vec{F}$ no espaço tridimensional. Representa-se por $\boldsymbol{A}$ o gradiente dessa transformação.

Na Figura 9 ilustram-se as transformações do elemento finito da configuração inicial, $f_{i}^{0}$ para a configuração atual, $f_{i}^{1}$. 


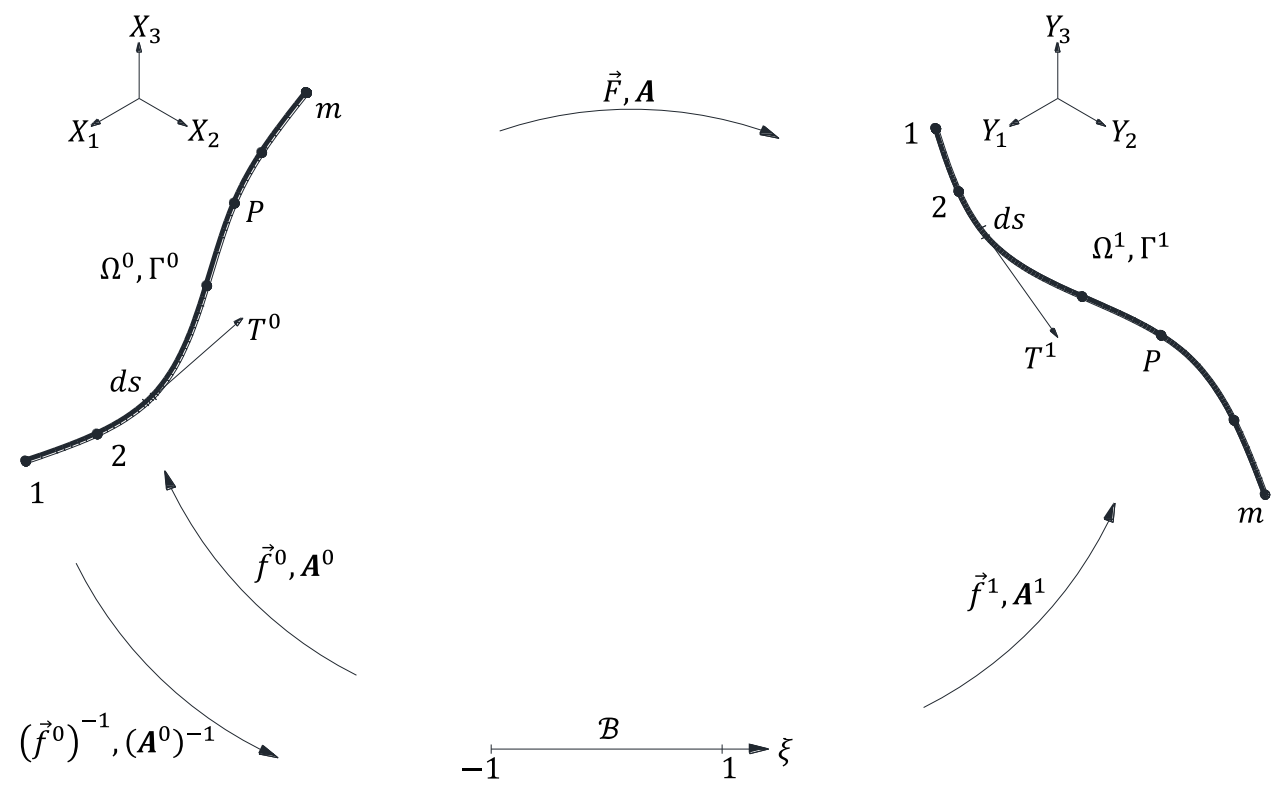

Figura 9: Elemento unidimensional curvilíneo

Qualquer ponto material $P$ sobre esse elemento pode ser determinado a partir das transformações:

a) Na configuração inicial:

$$
f_{i}^{0}=X_{i}(P)=\varphi_{j}(\xi) x_{i j}
$$

b) Na configuração atual:

$$
f_{i}^{1}=Y_{i}(P)=\varphi_{j}(\xi) y_{i j}
$$

Sendo, $x_{i j}$ e $y_{i j}$ as coordenadas cartesianas $i=1,2,3$, dos nós $j=1, \ldots, m$. As funções $\varphi_{j}(\xi)$ relacionam as coordenadas adimensionais $\xi$ do espaço de coordenadas auxiliar às coordenadas do espaço físico de configurações.

Ao se utilizar uma formulação com base nas posições nodais do elemento evita-se o emprego de matrizes de rotação para escreve as grandezas físicas no sistema de referência global.

Na Figura 9 identifica-se também um conjunto de coordenadas curvilíneas $\Gamma_{0}$ de comprimento infinitesimal $d s^{0}$ na configuração inicial e $\Gamma^{1}, d s^{1}$, na configuração atual. 
O comprimento do elemento curvilíneo é calculado com o auxílio do conjunto de coordenadas adimensionais, tal que:

a) Na configuração inicial, o comprimento do elemento é calculado como:

$$
L^{0}=\int_{\Gamma^{0}} d s=\int_{-1}^{+1} J^{0}(\xi) d \xi
$$

b) Na configuração atual, o comprimento do elemento é calculado como:

$$
L^{1}=\int_{\Gamma^{1}} d s=\int_{-1}^{+1} J^{1}(\xi) d \xi
$$

Sendo, $J^{0}(\xi)$ e $J^{1}(\xi)$ o Jacobiano das transformações nas configurações inicial e atual, respectivamente.

Cabe salientar que o valor numérico do Jacobiano é equivalente ao comprimento do vetor tangente avaliados nos nós do elemento, por sua vez, semelhante a norma do gradiente da transformação. Dessa forma, o Jacobiano pode ser apresentado da seguinte maneira:

a) Na configuração inicial:

$$
J^{0}(\xi)=\left|T^{0}\right|=\left|A_{i \xi}^{0}\right|=\sqrt{\left(f_{1, \xi}^{0}\right)^{2}+\left(f_{2, \xi}^{0}\right)^{2}+\left(f_{3, \xi}^{0}\right)^{2}}
$$

b) Na configuração atual:

$$
J^{1}(\xi)=\left|T^{1}\right|=\left|A_{i \xi}^{1}\right|=\sqrt{\left(f_{1, \xi}^{1}\right)^{2}+\left(f_{2, \xi}^{1}\right)^{2}+\left(f_{3, \xi}^{1}\right)^{2}}
$$

Sendo, $f_{i, \xi}^{0}=\frac{\partial \varphi_{j}}{\partial \xi}(\xi) x_{i j}=A_{i \xi}^{0}$ e $f_{i, \xi}^{1}=\frac{\partial \varphi_{j}}{\partial \xi}(\xi) y_{i j}=A_{i \xi}^{1}$ as componentes do vetor gradiente da transformação na configuração inicial e atual, respectivamente.

Admite-se que o comportamento mecânico do material seja linear elástico, cuja lei material adotada tenha a seguinte forma geral:

$$
\sigma(\varepsilon)=\mathbb{E} \varepsilon
$$


Sendo, $\varepsilon$ as medidas de deformações de Hill para o caso unidimensional; $\sigma(\varepsilon)$, as tensões energeticamente conjugadas as deformações de Hill. $\mathbb{E}$ é a constante de proporcionalidade ou módulo de rigidez elástica tangente.

De acordo com (HOLZAPFEL, 2000) as medidas de deformação de Hill unidimensionais são calculadas da seguinte maneira:

$$
\varepsilon_{p}=\left\{\begin{array}{r}
\frac{1}{p}\left(\lambda^{p}-1\right), p \neq 0 \\
\ln (\lambda), p=0
\end{array}\right.
$$

Sendo, $\lambda=\frac{L^{1}}{L^{0}}$ o estiramento linear de Cauchy-Green.

Como apresentado anteriormente, o objetivo da formulação em posições consiste em escrever os graus de liberdade do elemento em termos das coordenadas generalizadas dos nós.

Com a finalidade de se aplicar o princípio da estacionariedade da energia potencial, primeiramente determina-se a energia específica de deformação do elemento. No caso de elementos com rigidez axial, a energia específica de deformação é dada pela equação:

$$
u_{e}=\int_{0}^{\varepsilon_{p}} \sigma(\varepsilon) d \varepsilon=\int_{0}^{\varepsilon_{p}} \mathbb{E} \varepsilon d \varepsilon=\frac{1}{2} \mathbb{E} \varepsilon_{p}^{2}
$$

Sendo, $\varepsilon_{p}$ as medidas de deformações de Hill, cujos casos particulares mais comuns são: $p=-2$, para a medida de deformação de Almansi; $p=-1$ para a deformação hiperbólica ou de Reiner; $p=0$ para a medida de deformação natural, logarítmica ou deformação de Henky; $p=1$ para a medida de deformação linear, de Biot ou de engenharia e $p=2$ para a medida de deformação quadrática ou de Green-Lagrange.

Devido a proporcionalidade entre as medidas de tensão e deformação é possível se determinar as respectivas medidas de tensão, energeticamente conjugadas. Destaca-se neste trabalho a tensão nominal ou de engenharia associada a deformação de Biot e a tesão de PiolaKirchhoff segunda espécie conjugada da deformação de Green-Lagrange. 
Cabe destacar que para na hipótese de pequenas deformações, ou seja, $\left|\varepsilon_{1}\right|<1 \%$, a tensão de engenharia se confunde com a tensão verdadeira, também denominada tensão de Cauchy e o erro ao se empregar qualquer medida de deformação com $|p| \leq 2$ é da ordem de 0,5\%. (OGDEN, 1997).

A energia específica pode ser escrita de forma equivalente ao caso geral do capítulo 3, a pertir da função composta:

$$
u_{e}=u_{e} \circ \varepsilon_{p} \circ \lambda\left(y_{k \ell}\right)
$$

Sendo, $\varepsilon_{p}$ e $\lambda$ as variáveis relacionadas a deformação e ao estiramento unidimensionais, respectivamente. O símbolo "。” representa a composição de funções, indicando a dependência entre as variáveis.

A partir da energia específica é possível determinar a equação material da energia potencial das deformações, calculada como:

$$
U_{e}=\int_{V^{0}} u_{e} d V=\frac{1}{2} \mathbb{E} \varepsilon_{p}^{2} A L^{0}
$$

O equilíbrio do sistema é estabelecido a partir do princípio da estacionariedade da energia potencial total, sendo o vetor de forças internas calculado a partir do gradiente da energia de deformação.

O vetor de forças internas é dado por:

$$
F_{k \ell}^{\mathrm{int}}=\frac{\partial U_{e}}{\partial y_{k \ell}}=\frac{1}{2} \mathbb{E} A L^{0} \frac{\partial}{\partial y_{k \ell}}\left(\varepsilon_{p}^{2}\right)
$$

Para se efetuar as derivadas das deformações em relação aos parâmetros nodais emprega-se a regra da derivada da função composta, tal como:

$$
\frac{\partial}{\partial y_{k \ell}}\left(\varepsilon_{p}^{2}\right)=2 \varepsilon_{p} \frac{\partial \varepsilon_{p}}{\partial \lambda} \frac{\partial \lambda}{\partial L^{1}} \frac{\partial L^{1}}{\partial y_{k \ell}}
$$


Sendo, $\frac{\partial}{\partial \varepsilon_{p}}\left(\varepsilon_{p}^{2}\right)=2 \varepsilon_{p} ; \frac{\partial \varepsilon_{p}}{\partial \lambda}=\lambda^{p-1}, \forall p ; \frac{\partial \lambda}{\partial L^{1}}=\frac{1}{L^{0}}$.

Substituindo esses valores na equação (6.13), encontra-se a equação simplificada para o cálculo do vetor de forças internas:

$$
F_{k \ell}^{\mathrm{int}}=\mathbb{E} A \varepsilon_{p} \lambda^{p-1} \frac{\partial L^{1}}{\partial y_{k \ell}}
$$

Da equação (6.4) o gradiente do comprimento atual é dado por: $\frac{\partial L^{1}}{\partial y_{k \ell}}=\int_{-1}^{+1} \frac{\partial J^{1}}{\partial y_{k \ell}}(\xi) d \xi$.

Reescrevendo-se o Jacobiano a partir do produto interno:

$$
J^{1}(\xi)=\left[\left(\varphi_{j, \xi}(\xi) y_{i j}\right)\left(\varphi_{r, \xi}(\xi) y_{i r}\right)\right]^{\frac{1}{2}}
$$

A derivada resulta:

$$
\frac{\partial J^{1}}{\partial y_{k \ell}}(\xi)=\left[J^{1}(\xi)\right]^{-1}\left[\varphi_{j, \xi}(\xi) y_{k j}\right] \varphi_{\ell, \xi}(\xi)
$$

Nota-se que $\varphi_{j, \xi}(\xi) y_{k j}=A_{k \xi}^{1}(\xi)$ é o gradiente da transformação, logo:

$$
\frac{\partial L^{1}}{\partial y_{k \ell}}=\int_{-1}^{+1}\left[J^{1}(\xi)\right]^{-1} A_{k \xi}^{1}(\xi) \varphi_{\ell, \xi}(\xi) d \xi
$$

Finalmente, o vetor de força interna é calculado a partir da equação:

$$
F_{k \ell}^{\mathrm{int}}=\mathbb{E} A \varepsilon_{p} \lambda^{p-1} \int_{-1}^{+1}\left[J^{1}(\xi)\right]^{-1} A_{k \xi}^{1}(\xi) \varphi_{\ell, \xi}(\xi) d \xi
$$

A solução numérica do equilíbrio tem como base a linearização da função desbalanceamento, como visto no capítulo 4. Esse procedimento requer a avaliação do gradiente do resíduo, calculado a partir da segunda variação da energia potencial total. Esse resultado é equivalente ao Laplaciano da energia de deformação ou matriz Hessiana do sistema. Nos cálculos a seguir, apresentam-se os desenvolvimentos para determinação dessa quantidade. 
A Hessiana do sistema é dada por:

$$
H_{m n k \ell}=\frac{\partial^{2} U_{e}}{\partial y_{m n} \partial y_{k \ell}}=\frac{\partial F_{k \ell}^{\mathrm{int}}}{\partial y_{m n}}
$$

Substituindo a equação (6.14) em (6.19), obtém-se:

$$
H_{m n k \ell}=\mathbb{E} A \frac{\partial}{\partial y_{m n}}\left(\varepsilon_{p} \lambda^{p-1} \frac{\partial L^{1}}{\partial y_{k \ell}}\right)
$$

Aplicando-se derivada do produto, resulta:

$$
H_{m n k \ell}=\mathbb{E} A\left[\frac{\partial}{\partial y_{m n}}\left(\varepsilon_{p}\right) \lambda^{p-1} \frac{\partial L^{1}}{\partial y_{k \ell}}+\varepsilon_{p} \frac{\partial}{\partial y_{m n}}\left(\lambda^{p-1}\right) \frac{\partial L^{1}}{\partial y_{k \ell}}+\varepsilon_{p} \lambda^{p-1} \frac{\partial}{\partial y_{m n}}\left(\frac{\partial L^{1}}{\partial y_{k \ell}}\right)\right]
$$

Cujas parcelas são calculadas da seguinte maneira:

$$
\begin{gathered}
\frac{\partial}{\partial y_{m n}}\left(\varepsilon_{p}\right)=\frac{\partial \varepsilon_{p}}{\partial \lambda} \frac{\partial \lambda}{\partial L^{1}} \frac{\partial L^{1}}{\partial y_{m n}}=\lambda^{p-1} \frac{1}{L^{0}} \frac{\partial L^{1}}{\partial y_{m n}} \\
\frac{\partial}{\partial y_{m n}}\left(\lambda^{p-1}\right)=\frac{\partial}{\partial \lambda}\left(\lambda^{p-1}\right) \frac{\partial \lambda}{\partial L^{1}} \frac{\partial L^{1}}{\partial y_{m n}}=(p-1) \lambda^{p-2} \frac{1}{L^{0}} \frac{\partial L^{1}}{\partial y_{m n}}
\end{gathered}
$$

O cálculo da segunda variação do comprimento atual é um pouco mais extenso. A seguir descreve-se o procedimento para a obtenção desse resultado.

Considere-se o Laplaciano: $\frac{\partial^{2} L^{1}}{\partial y_{m n} \partial y_{k \ell}}=\int_{-1}^{+1} \frac{\partial}{\partial y_{m n}}\left\{\left[J^{1}(\xi)\right]^{-1} A_{k \xi}^{1}(\xi) \varphi_{\ell, \xi}(\xi) d \xi\right\}$

Aplicando-se a regra do produto é possível se escrever a derivada como: $\frac{\partial^{2} L^{1}}{\partial y_{m n} \partial y_{k \ell}}=\int_{-1}^{+1}\left[\frac{\partial}{\partial y_{m n}}\left\{\left[J^{1}(\xi)\right]^{-1}\right\} A_{k \xi}^{1}(\xi)+\left[J^{1}(\xi)\right]^{-1} \frac{\partial}{\partial y_{m n}}\left\{A_{k \xi}^{1}(\xi)\right\}\right] \varphi_{\ell, \xi}(\xi) d \xi$

Realizando as derivadas, obtém-se: $\frac{\partial}{\partial y_{m n}}\left\{\left[J^{1}(\xi)\right]^{-1}\right\}=-\left[J^{1}(\xi)\right]^{-2} \frac{\partial J^{1}}{\partial y_{m n}}(\xi)$

Sendo: $\frac{\partial J^{1}}{\partial y_{m n}}(\xi)=\left[J^{1}(\xi)\right]^{-1} A_{m \xi}^{1}(\xi) \varphi_{n, \xi}(\xi)$. 
Cujo resultado é dado por: $\frac{\partial}{\partial y_{m n}}\left\{\left[J^{1}(\xi)\right]^{-1}\right\}=-\left[J^{1}(\xi)\right]^{-3} A_{m \xi}^{1}(\xi) \varphi_{n, \xi}(\xi)$.

A derivada do gradiente fica: $\frac{\partial}{\partial y_{m n}}\left\{A_{k \xi}^{1}(\xi)\right\}=\frac{\partial}{\partial y_{m n}}\left\{\varphi_{j, \xi}(\xi) y_{k j}\right\}=\varphi_{j, \xi}(\xi) \delta_{k m} \delta_{j n}$.

Resultando: $\frac{\partial A_{k \xi}^{1}}{\partial y_{m n}}(\xi)=\varphi_{n, \xi}(\xi) \delta_{k m}$

O gradiente do comprimento atual, fica: $\frac{\partial L^{1}}{\partial y_{m n}}=\int_{-1}^{+1}\left[J^{1}(\xi)\right]^{-1} A_{m \xi}^{1}(\xi) \varphi_{n, \xi}(\xi) d \xi$

Logo, a segunda derivada é calculada da seguinte maneira:

$$
\begin{aligned}
& \frac{\partial^{2} L^{1}}{\partial y_{m n} \partial y_{k \ell}}=-\int_{-1}^{+1}\left[J^{1}(\xi)\right]^{-3} A_{m \xi}^{1}(\xi) \varphi_{n, \xi}(\xi) A_{k \xi}^{1}(\xi) \varphi_{\ell, \xi}(\xi) d \xi+ \\
& \int_{-1}^{+1}\left[J^{1}(\xi)\right]^{-1} \varphi_{n, \xi}(\xi) \delta_{k m} \varphi_{\ell, \xi}(\xi) d \xi
\end{aligned}
$$

Com os resultados encontrados nas equações (6.22), (6.23) e (6.24), substitui-se na equação (6.21) para se obter a Hessiana do sistema, calculada como:

$$
H_{m n k \ell}=\mathbb{E} A\left[\begin{array}{l}
\lambda^{2(p-1)} \frac{1}{L^{0}} \frac{\partial L^{1}}{\partial y_{k \ell}} \frac{\partial L^{1}}{\partial y_{m n}}+ \\
(p-1) \varepsilon_{p} \lambda^{p-2} \frac{1}{L^{0}} \frac{\partial L^{1}}{\partial y_{m n}} \frac{\partial L^{1}}{\partial y_{k \ell}}+ \\
\varepsilon_{p} \lambda^{p-1} \frac{\partial^{2} L^{1}}{\partial y_{m n} \partial y_{k \ell}}
\end{array}\right]
$$

Com esse procedimento permite-se calcular o vetor de forças internas e a matriz Hessiana dos elementos unidimensionais curvilíneos empregando-se polinômios de Lagrange de qualquer ordem e relação constitutiva elástica linear com as medidas de deformação de Hill.

A aplicação dos elementos curvilíneos com qualquer ordem de aproximação é de grande interesse em diversas áreas da mecânica dos materiais, como na análise de materiais compósitos considerando-se o acoplamento matriz-fibra (CODA, PACCOLA e SAMPAIO, 2013) e (SAMPAIO, PACCOLA e CODA, 2015). Nesses trabalhos o êxito da formulação foi possível 
graças ao acoplamento entre os elementos curvilíneos (fibras) e as coordenadas do meio (matriz). Outra aplicação possível para esses elementos consiste em utiliza-lo em estruturas flexíveis como cabos, empregando-se molas nodais fictícias aos nós intermediários afim de se evitar a singularidades na matriz Hessiana. Nessa aplicação é possível se encontrar a s equilíbrio penalizando-se a rigidez dessas molas. Por fim, outra aplicação desse elemento, consiste na penalização da energia do meio contínuo, empregando-o como um elemento de trinca. Esses assuntos não estão contemplados no presente texto, mas sugere-se como propostas a utilização do elemento curvilíneo nas aplicações citadas anteriormente.

Com a finalidade de utilizar esse elemento na análise estrutural de estruturas de barra rígida, particulariza-se a geometria do elemento considerando-se apenas dois nós em cada barra. Com essa aproximação é possível realizar as análises de treliças bi e tridimensionais.

Na próxima seção apresentam-se o vetor de forças internas e a matriz Hessiana considerando-se essa simplificação no grau de aproximação e na geometria do elemento.

\subsection{Elemento Finito de Barra Reta}

Considere-se o elemento retilíneo a seguir:
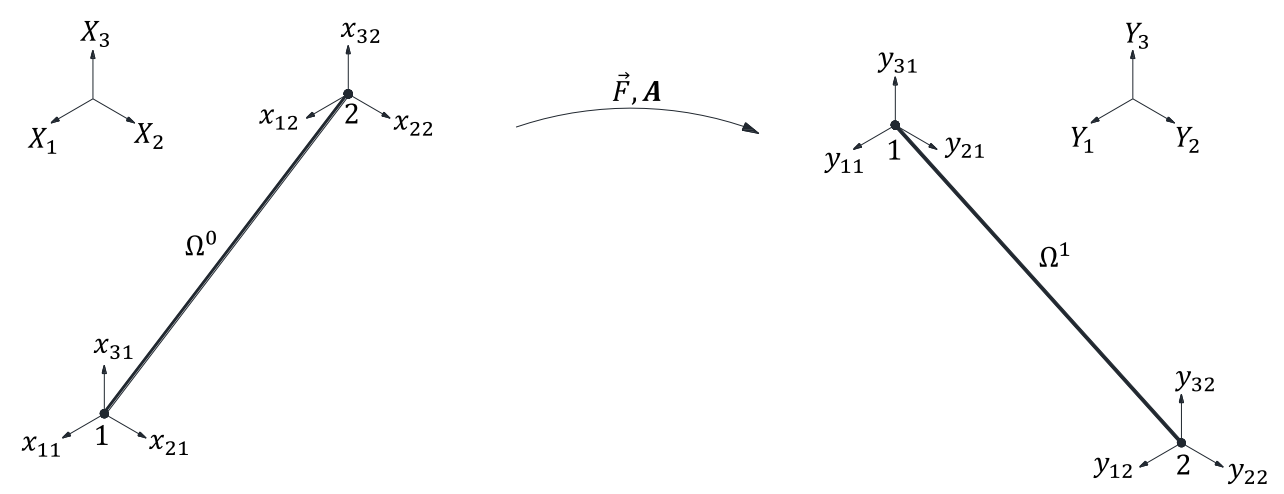

Figura 10: Elemento finito de barra simples

A Figura 10 ilustra as posições nodais do elemento finito no espaço de coordenadas tridimensional nas configurações inicial $\Omega_{0}$ e atual $\Omega_{1}$.

Os cálculos apresentados anteriormente são simplificados considerando-se $p=2$ para as deformações de Green-Lagrange e elemento finito com dois nós. Esses parâmetros são parte dos dados de entrada do código e podem ser modificados pelo analista. 
Ao se adotar a medida de deformação de Green-Lagrange acaba-se por se utilizar a medida quadrática da deformação. Caso se deseje utilizar a medida de deformação não linear de engenharia basta considerar $p=1$ e assim por diante. Com esta formulação qualquer medida de deformação pode ser ativadas na análise, basta fazer $p \in \mathfrak{R}$.

O vetor de forças internas é calculado com a equação (6.14), fazendo-se $\varepsilon_{2}=E$, para as deformações de Green-Lagrange e $\lambda=\frac{L^{1}}{L^{0}}$ para o estiramento de Cauchy-Green, sendo, $\left(L^{0}\right)^{2}=\left(x_{11}-x_{12}\right)^{2}+\left(x_{21}-x_{22}\right)^{2}+\left(x_{31}-x_{32}\right)^{2}$ e $\left(L^{1}\right)^{2}=\left(y_{11}-y_{12}\right)^{2}+\left(y_{21}-y_{22}\right)^{2}+\left(y_{31}-y_{32}\right)^{2}$.

Por simplicidade, emprega-se a variável auxiliar $\Delta=\left(L^{1}\right)^{2}$, tal que:

$$
\frac{\partial L^{1}}{\partial y_{k \ell}}=\frac{\partial}{\partial y_{k \ell}}\left(\Delta^{1 / 2}\right)=\frac{1}{2} \Delta^{-1 / 2} \frac{\partial \Delta}{\partial y_{k \ell}}=\frac{1}{2} \frac{1}{L} \frac{\partial \Delta}{\partial y_{k \ell}}
$$

Escrevendo-se o vetor de forças internas em termos dessa variável, tem-se:

$$
F_{k \ell}^{\text {int }}=\frac{1}{2} \frac{\mathbb{E} A E}{L^{0}} \frac{\partial \Delta}{\partial y_{k \ell}}
$$

Sendo, $\quad \frac{\partial \Delta}{\partial y_{k \ell}}=2(-1)^{\ell}\left(y_{k 2}-y_{k 1}\right), \quad k=1,2,3$, as coordenadas nodais do espaço tridimensional e $\ell=1,2$, o número de nós do elemento.

A matriz Hessiana é obtida com a equação (6.25) considerando-se também, $\varepsilon_{2}=E$; $\lambda=\frac{L^{1}}{L^{0}} ; \frac{\partial L^{1}}{\partial y_{k \ell}}=\frac{1}{2} \frac{1}{L^{1}} \frac{\partial \Delta}{\partial y_{k \ell}}$ e $\frac{\partial \Delta}{\partial y_{k \ell}}=2(-1)^{\ell}\left(y_{k 2}-y_{k 1}\right)$.

A matriz Hessiana é dada por:

$$
H_{m n k \ell}=\frac{\mathbb{E} A}{L^{0}}\left[\frac{1}{4}\left(\frac{1}{L^{0}}\right)^{2} \frac{\partial \Delta}{\partial y_{m n}} \frac{\partial \Delta}{\partial y_{k \ell}}+\frac{1}{2} E \frac{\partial^{2} \Delta}{\partial y_{k \ell} \partial y_{m n}}\right] .
$$


Sendo, $\quad \frac{\partial \Delta}{\partial y_{m n}}=2(-1)^{n}\left(y_{m 2}-y_{m 1}\right) ; \quad \frac{\partial^{2} \Delta}{\partial y_{k \ell} \partial y_{m n}}=2(-1)^{\ell}(-1)^{n} \delta_{k m} ; \quad m=1,2,3, \quad$ as coordenadas nodais do espaço tridimensional e $n=1,2$, o número de nós do elemento.

De posse das equações (6.27) e (6.28) é possível constatar que o vetor de forças internas e a matriz Hessiana ficam completamente definidas conhecendo-se os termos em destaque:

a) Vetor de forças internas:

$$
\begin{aligned}
& \boldsymbol{F}_{\mathbf{1 1}}^{\text {int }}=\frac{\mathbb{E} A E}{L^{0}}\left(y_{11}-y_{12}\right) \\
& \boldsymbol{F}_{\mathbf{2 1}}^{\text {int }}=\frac{\mathbb{E} A E}{L^{0}}\left(y_{21}-y_{22}\right) \\
& \boldsymbol{F}_{\mathbf{3 1}}^{\text {int }}=\frac{\mathbb{E} A E}{L^{0}}\left(y_{31}-y_{32}\right) \\
& F_{12}^{\text {int }}=-F_{11}^{\text {int }} \\
& F_{22}^{\text {int }}=-F_{21}^{\text {int }} \\
& F_{32}^{\text {int }}=-F_{31}^{\text {int }}
\end{aligned}
$$

b) Matriz Hessiana:

$$
H_{m n k \ell}=\left[\begin{array}{cccccc}
\boldsymbol{H}_{1111} & \boldsymbol{H}_{\mathbf{1 1 2 1}} & \boldsymbol{H}_{\mathbf{1 1 3 1}} & -H_{1111} & -H_{1121} & -H_{1131} \\
H_{1121} & \boldsymbol{H}_{2121} & \boldsymbol{H}_{\mathbf{2 1 3 1}} & -H_{1121} & -H_{2121} & -H_{2131} \\
H_{1131} & H_{2131} & \boldsymbol{H}_{\mathbf{3 1 3 1}} & -H_{1131} & -H_{2131} & -H_{33} \\
-H_{1111} & -H_{1121} & -H_{1131} & H_{1111} & H_{1121} & H_{1131} \\
-H_{1121} & -H_{2121} & -H_{2131} & H_{1121} & H_{2121} & H_{2131} \\
-H_{1131} & -H_{2131} & -H_{3131} & H_{1131} & H_{2131} & H_{3131}
\end{array}\right]
$$

Os termos da matriz são calculados como:

$$
\begin{aligned}
& H_{1111}=\frac{\mathbb{E} A}{L^{0}}\left[\left(\frac{y_{11}-y_{12}}{L^{0}}\right)^{2}+E\right] . H_{1121}=\frac{\mathbb{E} A}{L^{0}}\left(\frac{y_{11}-y_{12}}{L^{0}}\right)\left(\frac{y_{21}-y_{22}}{L^{0}}\right) \\
& H_{1131}=\frac{\mathbb{E} A}{L^{0}}\left(\frac{y_{11}-y_{12}}{L^{0}}\right)\left(\frac{y_{31}-y_{32}}{L^{0}}\right) . H_{2121}=\frac{\mathbb{E} A}{L^{0}}\left[\left(\frac{y_{21}-y_{22}}{L^{0}}\right)^{2}+E\right]
\end{aligned}
$$




$$
H_{2131}=\frac{\mathbb{E} A}{L^{0}}\left(\frac{y_{21}-y_{22}}{L^{0}}\right)\left(\frac{y_{31}-y_{32}}{L^{0}}\right) \cdot H_{3131}=\frac{\mathbb{E} A}{L^{0}}\left[\left(\frac{y_{31}-y_{32}}{L^{0}}\right)^{2}+E\right]
$$

\subsection{Exemplos}

Nesta seção apresentam-se os exemplos com a finalidade de se verificar as potencialidades do elemento posicional de barra rígida não linear geométrico. Especial atenção é dada aos problemas de instabilidade global de estruturas reticuladas. Apesar de elementar, estes exemplos são fundamentais para se explorar as principais características do fenômeno de instabilidade estrutural

\subsubsection{Treliça de Von Mises}

O primeiro exemplo a ser estudado consiste na treliça de Von Mises. De acordo com (KWASNIEWSKI, 2009), essa estrutura apresenta comportamento não linear na presença de tensões compressivas e está sujeita, essencialmente, a instabilidade por ponto limite. Porém, (PSOTNý e RAVINGER, 2002) apresentam soluções que levam a instabilidade por bifurcação do equilíbrio. Inicia-se a validação dos resultados estudando-se a treliça de Von Mises devido a riqueza e simplicidade da estrutura.

Na Figura 11, ilustra-se a treliça de Von Mises nas configurações inicial e deslocada.

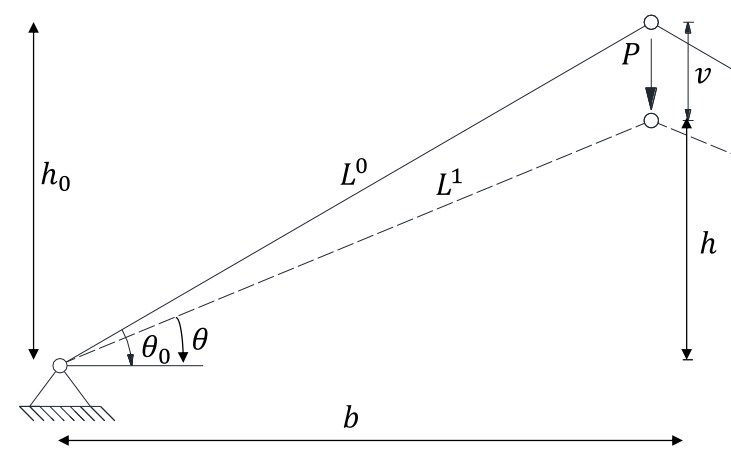

Figura 11: Treliça de Von Mises na configuração inicial e deslocada

No que segue, apresenta-se a solução analítica desse problema a partir do princípio da estacionariedade da energia potencial total levando-se em conta as seguintes hipóteses:

a) Consideram-se as barras deformando-se axialmente. As barras são impedidas de fletir, permanecendo reta durante todo processo de carregamento; 
b) Admite-se também que o sentido da força externa independe da configuração da estrutura, ou seja, atue apenas carregamentos conservativos;

c) Supõem-se que as barras tenham o mesmo comprimento e sejam constituídas de material elástico linear.

Sob essas hipóteses, a energia potencial da estrutura é calculada como:

$$
\Pi=\frac{1}{2} \mathbb{E} A L^{0}\left[\left(\varepsilon_{1}\right)^{2}+\left(\varepsilon_{2}\right)^{2}\right]-P v
$$

Considerando-se $\varepsilon_{1}=\varepsilon_{2}=\varepsilon$, as deformações axiais das barras, calculadas a partir da medida de deformação de Green-Lagrange, tem-se:

$$
\varepsilon=\frac{1}{2\left(L^{0}\right)^{2}}\left[\left(L^{1}\right)^{2}-\left(L^{0}\right)^{2}\right]
$$

Na configuração deslocada o comprimento da barra é calculado como:

$$
\left(L^{1}\right)^{2}=\left(L^{0} \cos \theta_{0}\right)^{2}+\left(L^{0} \operatorname{sen} \theta_{0}-v\right)^{2}
$$

Do princípio da estacionariedade da energia potencial total, a condição de equilíbrio crítico é determinada fazendo-se $\Pi_{, v}=0$, logo:

$$
\Pi_{, v}=\frac{\partial \Pi}{\partial v}=\mathbb{E} A L^{0} \frac{\partial}{\partial v}\left\{\varepsilon^{2}\right\}-P=0
$$

Realizando-se as simplificações necessárias, a trajetória de equilíbrio da estrutura é uma função não linear da carga em relação ao deslocamento vertical, dada pela equação:

$$
P=\frac{\mathbb{E} A}{\left(L^{0}\right)^{3}}\left[v^{3}-3 v^{2} L^{0} \operatorname{sen} \theta_{0}+2 v\left(L^{0}\right)^{2} \operatorname{sen}^{2} \theta_{0}\right]
$$

A estabilidade da trajetória de equilíbrio fundamental é avaliada a partir do sinal da segunda variação da energia em relação ao deslocamento vertical, calculado como:

$$
\Pi_{, v v}=\frac{\partial^{2} \Pi}{\partial v^{2}}=\frac{\mathbb{E} A}{\left(L^{0}\right)^{3}}\left[3 v^{2}-6 v L^{0} \operatorname{sen} \theta_{0}+2\left(L^{0}\right)^{2} \operatorname{sen}^{2} \theta_{0}\right]
$$


Na condição crítica $\Pi_{, v v}=0$, no sistema de coordenadas adimensional fornece as seguintes raízes da equação (6.36): $v_{1}=(1-1 / \sqrt{3}) \operatorname{sen} \theta_{0}$ e $v_{2}=(1+1 / \sqrt{3}) \operatorname{sen} \theta_{0}$. Esses valores correspondem aos deslocamentos mínimo e máximo, respectivamente, ou seja, $v_{1}$ e $v_{2}$ são os pontos limites da trajetória fundamental. Ao se atingir os níveis de carregamento correspondentes a esses deslocamentos, a estrutura irá buscar uma posição de equilíbrio estável, invertendo a inclinação das barras de forma abrupta, assim caracterizado a instabilidade por snap-trhough.

Para se avaliar numericamente os resultados encontrados com a solução analítica apresenta-se a seguir as simulações com o programa da barra simples, mostrando-se a capacidade do elemento finito de treliça posicional em proceder a análise de instabilidade.

Nessa análise, os dados do problema são considerados, por questões puramente didática, como: $E A=1, b=10$ e $\theta=10^{\circ}$. No gráfico da Figura 12 ilustram-se as trajetórias de equilíbrio com as respostas analítica e numérica.

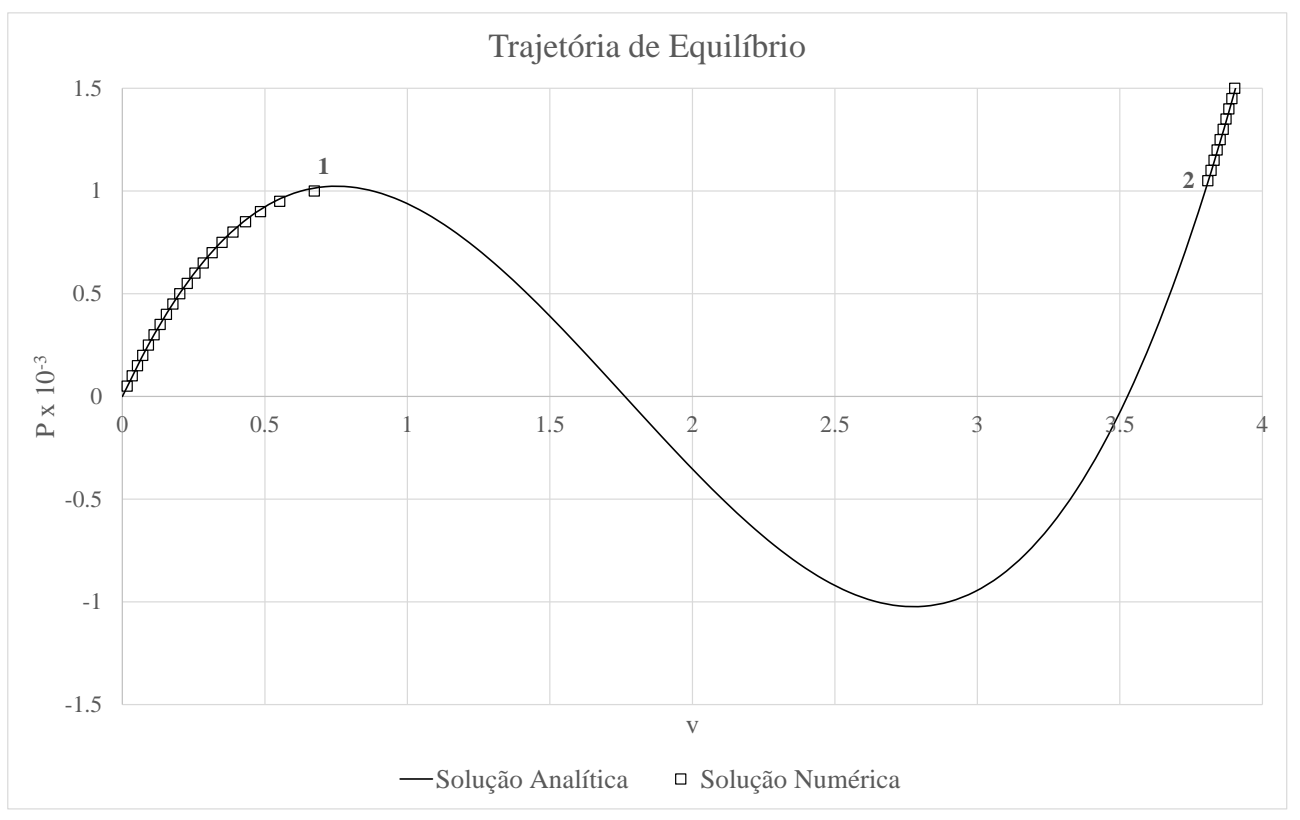

Figura 12: Instabilidade por snap-through

Inicialmente, a solução apresentada na Figura 12, está apresentada somente a resposta com base no método de Newton-Raphson considerando-se o controle de forças.

Fica clara a descontinuidade da solução numérica ao se atingir o ponto crítico da trajetória fundamental, característica da instabilidade por snap-through. O carregamento 
associado a esse ponto é denominado carga limite e representa a força máxima que a estrutura suporta em regime estável de equilíbrio estático. Após o ponto limite, a configuração de equilíbrio é alcançada com a inversão da inclinação da barra. Essa a mudança na configuração ocorre de maneira dinâmica e abrupta.

O ângulo de inclinação da barra na situação limite é dado por $\theta_{\lim }=5,78^{\circ}$, correspondente ao deslocamento $v=0,75$. O parâmetro de carga correspondente a esse deslocamento é $P=1,02$.

Para que estrutura ocupe posições bem definidas no trecho instável é necessário que o algoritmo de solução seja capaz de controlar os deslocamentos do nó onde o carregamento é aplicado. Inserindo essa metodologia no algoritmo de Newton-Raphson obtém-se a resposta com controle de deslocamento. No gráfico da Figura 13 apresenta-se a solução numérica observando-se a capacidade do algoritmo em traçar toda a trajetória de equilíbrio.

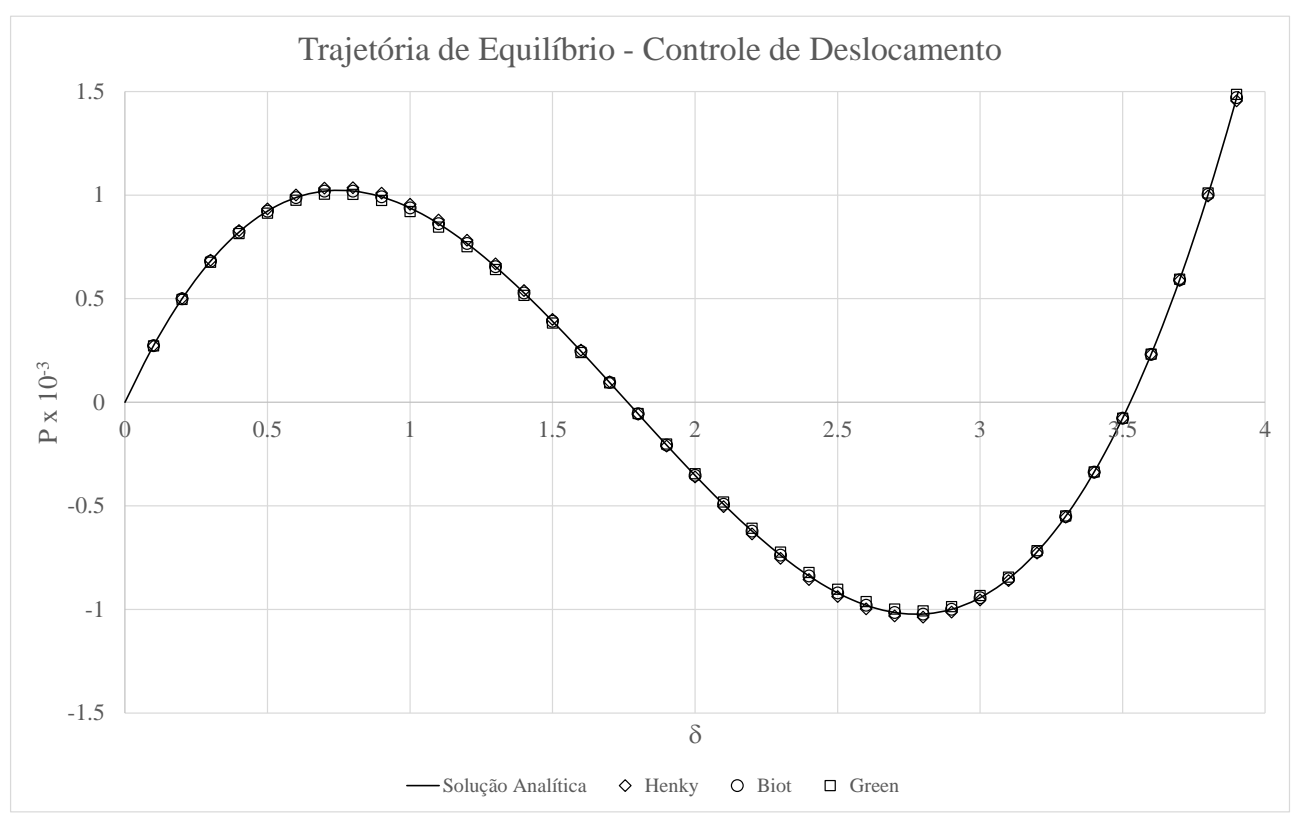

Figura 13: Trajetória de equilíbrio com controle de deslocamento

Nesse mesmo gráfico estão plotados os resultados dos deslocamentos considerando-se três medidas distintas de deformação. Com essa resposta comprova-se que as medidas de deformação da família de Hill, praticamente se confundem para a hipótese de pequenas deformações. 
Dando continuidade as análises, na sequência, apresentam-se mais dois exemplos com o objetivo de se demonstrar a necessidade de se aprimorar o algoritmo de solução, sobretudo, devido a possibilidade de ocorrência do fenômeno de snap-back. A motivação de se apresentar esses exemplos consiste em se proceder uma a análise não-linear com base nas estratégias do tipo path-following.

\subsubsection{Treliça de Von Mises com mola acoplada.}

Outra situação interessante consiste na análise do fenômeno de instabilidade devido quando do aparecimento dos chamados turnings-points na trajetória de equilíbrio. Estes pontos são caracterizados por uma tangente vertical ao caminho dos deslocamentos e afetam, de maneira geral, a performance dos algoritmos de solução não-linear. Mudança de configuração devido os turnings-points denomina-se instabilidade por snap-back.

Como visto no exemplo anterior, os métodos com controle de força são capazes de detectar os pontos limite na trajetória de deslocamento, mas, em geral, não são capazes de ir além desses pontos. Ao se proceder o controle dos deslocamentos verifica-se que para a instabilidade por snap-through, a resposta no trecho instável é bem determinada. Entretanto, em as estruturas que manifestam instabilidade por snap-back é necessário se utilizar algoritmos capazes de detectar os pontos com inversão no sentido dos deslocamentos.

Neste exemplo, apresenta-se a treliça de Von Mises com dois graus de liberdade e uma mola acoplada. O objetivo deste exemplo consiste em comparar as estratégias de solução com o método de Newton-Raphson e o método do arc-length.

Antes de se apresentar a solução numérica do programa de treliça não linear geométrico faz-se um breve estudo da solução analítica, obtida aplicando-se o critério energético de estacionariedade da energia potencial total para a treliça da Figura 14. 


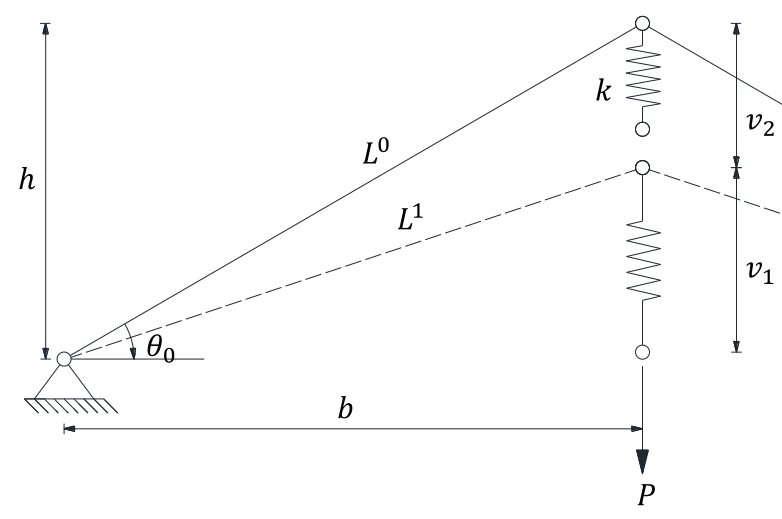

Figura 14: Treliça de Von com dois graus de liberdade.

Escrevendo a energia potencial das deformações, em função da energia de deformação das barras e da mola, é possível se chegar a expressão:

$$
U_{e}=2 U_{\text {barra }}+U_{\text {mola }}
$$

Sendo, $U_{e}$, a energia potencial de deformação elástica do sistema barra-mola.

A energia armazenada em cada barra é calculada com o auxílio da deformação de GreenLagrange, como:

$$
U_{\text {barra }}=\frac{1}{2} \mathbb{E} A L^{0}\left\{\frac{1}{2\left(L^{0}\right)^{2}}\left[\left(L^{1}\right)^{2}-\left(L^{0}\right)^{2}\right]\right\}^{2}
$$

Sendo, $\left(L^{1}\right)^{2}=\left(h-v_{2}\right)^{2}+b^{2}$, o comprimento da barra na configuração deslocada, com $h=L^{0} \operatorname{sen} \theta_{0}$ e $b=L^{0} \cos \theta_{0}$.

A energia armazenada na mola é expressa como:

$$
U_{\text {mola }}=\frac{1}{2} k\left(v_{1}-v_{2}\right)^{2}
$$

A energia potencial total do sistema, levando-se em consideração o trabalho realizado pela força externa, é calculado em função da configuração inicial (formulação Lagrangiana total), expressa pela equação: 


$$
\Pi=\frac{1}{4} \frac{\mathbb{E} A}{\left(L^{0}\right)^{3}}\left[\left(v_{2}\right)^{2}-2 v_{2} L^{0} \operatorname{sen} \theta_{0}\right]^{2}+\frac{1}{2} k\left(v_{1}-v_{2}\right)^{2}-P v_{1}
$$

Aplicando-se o princípio da estacionariedade da energia potencial total, a primeira variação da energia em relação aos graus de liberdade, deve ser nula, resultando no equilíbrio do sistema:

$$
\left\{\begin{array}{l}
\Pi_{, v_{1}}=\frac{\partial \Pi}{\partial v_{1}}=k\left(v_{1}-v_{2}\right)-P=0 \\
\Pi_{, v_{2}}=\frac{\partial \Pi}{\partial v_{2}}=\frac{\mathbb{E} A}{\left(L^{0}\right)^{3}}\left[\left(v_{2}\right)^{2}-2 v_{2} L^{0} \operatorname{sen} \theta_{0}\right]\left(v_{2}-L^{0} \operatorname{sen} \theta_{0}\right)-k\left(v_{1}-v_{2}\right)=0
\end{array}\right.
$$

Resolvendo-se o sistema (6.41), tem-se:

$$
P=\frac{\mathbb{E} A}{\left(L^{0}\right)^{3}}\left[\left(v_{2}\right)^{2}-2 v_{2} L^{0} \operatorname{sen} \theta_{0}\right]\left(v_{2}-L^{0} \operatorname{sen} \theta_{0}\right)
$$

A instabilidade por snap-back ocorre na componente $v_{1}$ do deslocamento. Fisicamente é possível concluir que esse tipo de instabilidade ocorre quando a mola tracionada é novamente comprimida após a inversão na inclinação das barras, ou seja, após snap-through do ápice da treliça.

Da equação (6.41) é possível escrever $v_{2}=v_{1}-P / k$, que ao ser substituído na equação (6.42) fornece a expressão da trajetória de equilíbrio para o ponto de aplicação do carregamento, resultando:

$$
P=\frac{\mathbb{E} A}{\left(L^{0}\right)^{3}}\left[\left(v_{1}-\frac{P}{k}\right)^{2}-2\left(v_{1}-\frac{P}{k}\right) L^{0} \operatorname{sen} \theta_{0}\right]\left(v_{1}-\frac{P}{k}-L^{0} \operatorname{sen} \theta_{0}\right)
$$

A equação (6.43) é uma expressão não linear do carregamento, cuja solução pode ser obtida, por exemplo, pelo método de Newton-Rapshon.

Empregando-se o método dos elementos finitos para solucionar o problema. Utilizamse os algoritimos de Newton-Raphson e Arc-Length para se observar as principais diferenças entre as estratégias de solução. Os dados empregados na análise são: rigidez da barra: $E A=1$, 
rigidez da mola, $k=\frac{E A}{L}=0,02$. Altura da estrutura, $h=5$ e ângulo de inclinação inicial das barras, $\theta_{0}=30^{\circ}$.

Na Figura 15 ilustra-se o gráfico da trajetória de deslocamento do ponto de aplicação da carga. Apresentam-se os resultados do método de Newton-Raphson com controle de força e com controle de deslocamento. Esses resultados são comparados com a trajetória completa obtida com o método do Arc-Length.

Com o controle de força a estrutura alcança um nível de carregamento máximo no qual se torna incapaz de resistir a qualquer incremento de carga, até que ocorra uma mudança repentina na configuração de equilíbrio da estrutura (snap-through). Esse comportamento se caracteriza pela singularidade na matriz de rigidez tangente da estrutura.

Com o controle do passo de deslocamento, a tangente vertical não define um ponto singular, porém, é de grande interesse conhecer esse ponto, pois sua ocorrência afeta, sobretudo, o condicionamento dos métodos de solução.

No gráfico da Figura 15, notam-se as descontinuidades do algoritmo de NewtonRaphson.

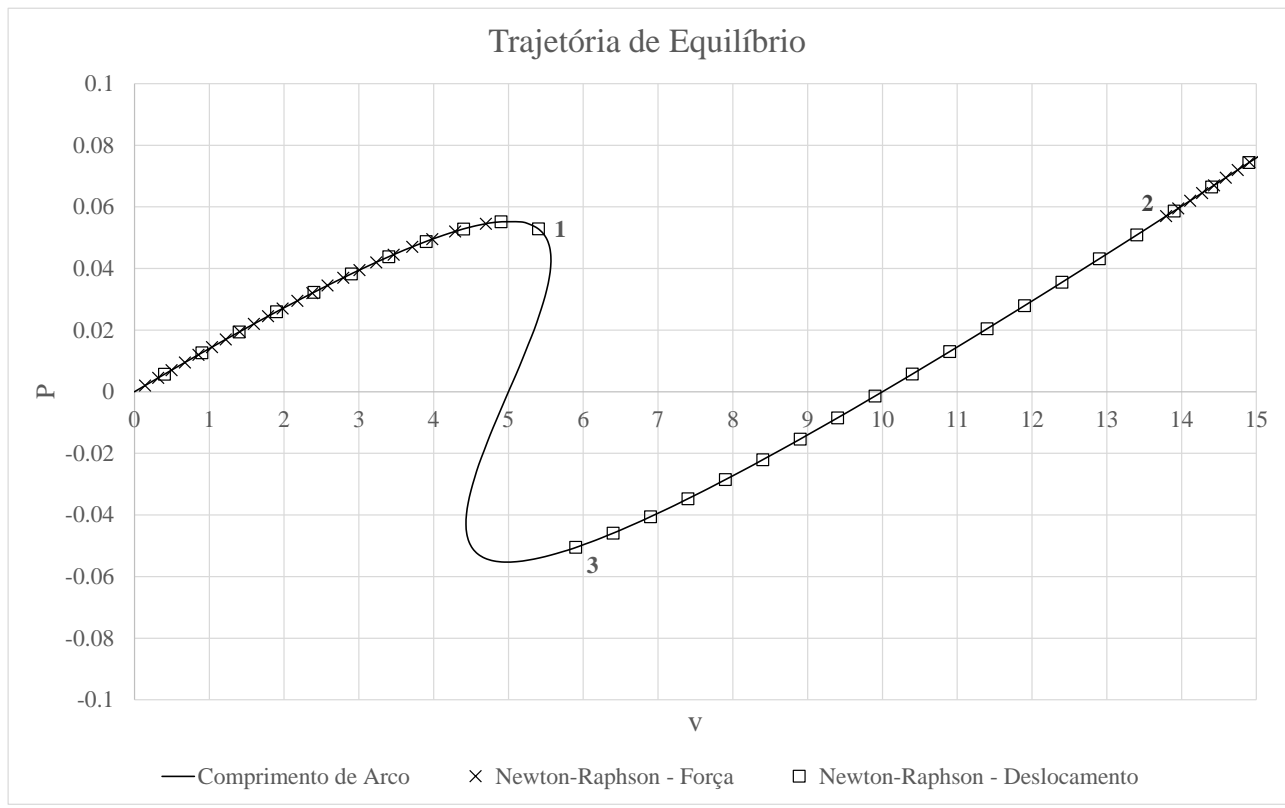

Figura 15: Trajetória de equilíbrio da treliça com dois graus de liberdade 
Utilizando-se o controle do carregamento, isto é, adicionando valores controlados para um carregamento crescente, verifica-se a transição da posição 1 para a posição 2 , a partir de uma variação brusca no deslocamento do ponto de aplicação do carregamento. Realizando-se o controle do deslocamento, ou seja, adicionando incrementos no deslocamento, observa-se que a transição ocorre de 1 para 3 com a carga sendo reduzida subitamente para um mesmo nível de deslocamento. Nessa situação ocorre um alívio na tensão da mola.

A seguir apresenta-se uma série de exemplos analisados exclusivamente com as ferramentas numéricas desenvolvidas nesta pesquisa. A intensão é comprovar a aplicabilidade da formulação do elemento finito posicional empregando-se o método do arc-length na determinação do traçado de equilíbrio estruturas multiestáveis cuja interpretação completa do fenômeno de instabilidade é complexa.

\subsubsection{Domo Tridimensional Hexagonal}

O exemplo a seguir consiste na estrutura proposta por (HANGAI e KAWAMATA, 1972), cuja geometria é a de um domo tridimensional formado por pontos de um hexágono.

Na Figura 16 ilustram-se a geometria e a disposição das 24 barra que compõem o sistema estrutural. As propriedades geométricas das barras e os dados do material utilizados na simulação também constam nessa ilustração.

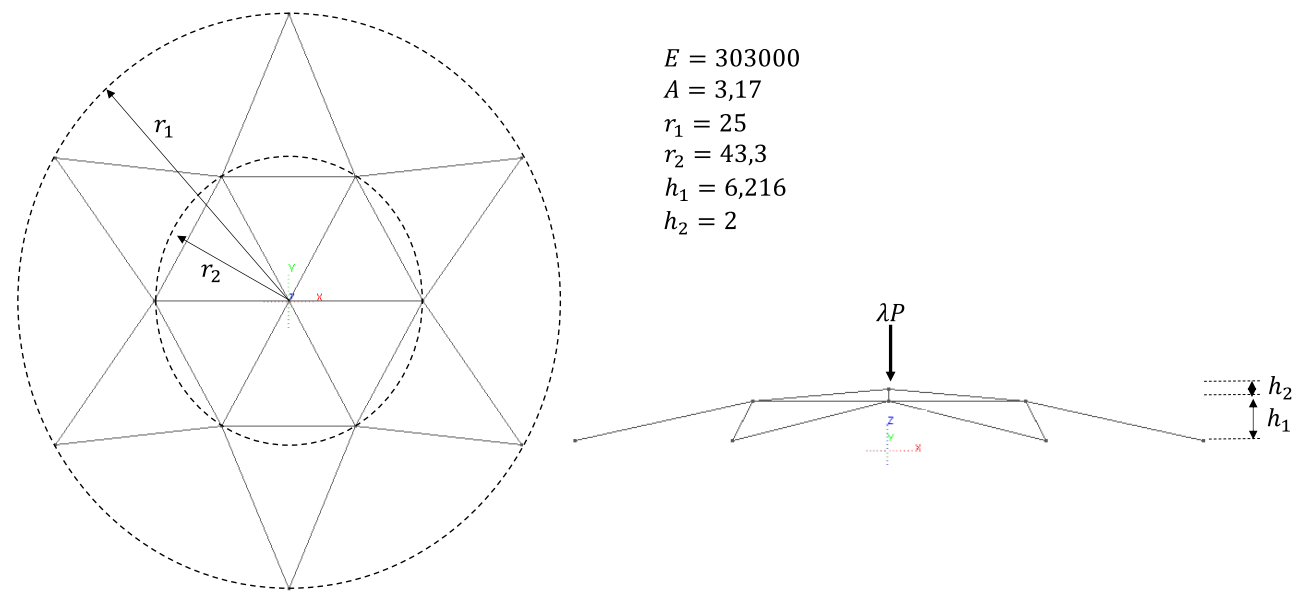

Figura 16: Domo com 24 elementos de barra simples

Na Figura 17 ilustra-se a aplicabilidade do método arc-length em reproduzir completamente a trajetória de equilíbrio da estrutura. 


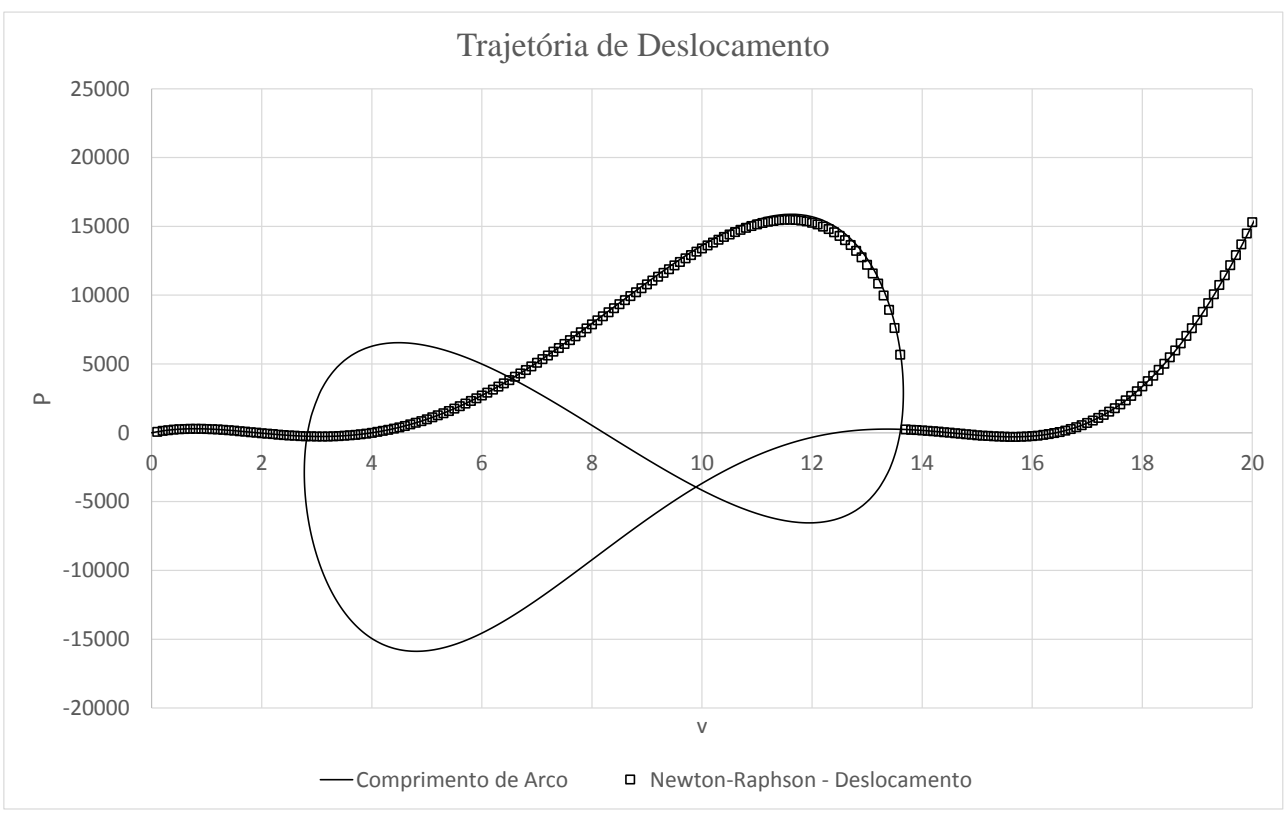

Figura 17: Trajetória de equilíbrio do ponto de aplicação do carregamento

Estão presentes no gráfico as respostas obtidas com o método de Newton-Raphson com controle de deslocamento e o método do arc-length.

Verifica-se que as soluções são coincidentes apenas nos trechos de deslocamento crescente. Quando ocorre a inversão do sentido do deslocamento, caracterizado pela ocorrência de uma tangente vertical à trajetória de equilíbrio, o método de Newton-Raphson mostra-se ineficiente em acompanhar o traçado da curva de equilíbrio.

Como comentado no capítulo anterior, os turning-points não são considerados pontos críticos, pois não produzem singularidades na matriz de rigidez, porém conduzem a instabilidade por snap-back e sua determinação é imprescindível para a avaliação da natureza do equilíbrio.

Uma maneira simples de se verificar os níveis de carga que produzem a instabilidade consiste em se determinar a inclinação do vetor tangente à trajetória de equilíbrio numa etapa de pós-processamento. Essa metodologia não consiste em um procedimento para cálculo de pontos críticos, porém e um eficiente recurso quando se tem a trajetória de equilíbrio bem determinada, como no método do arc-lenght.

De maneira geral é possível se identificar os pontos limites na trajetória procedendo-se um controle dos autovalores da matriz Hessiana a partir da nulidade do determinante próximo ao ponto limite. Essa é uma estratégia de análise dita de instabilidade não-linear. 
A seguir, em uma seção específica, ilustra-se o procedimento de decomposição da matriz Hessiana para o cálculo dos autovalores e autovetores do elemento de barra rígida. Após a apresentação da metodologia retoma-se o exemplo com a finalidade de se identificar a precedência do ponto de bifurcação em relação ao ponto limites que surge na trajetória.

No próximo exemplo apresenta-se uma estrutura cuja trajetória de equilíbrio é bastante complexa com múltiplos pontos de instabilidade. Sem a consideração de métodos mais consistente de solução torna-se impossível se reproduzir a trajetória de equilíbrio completa dessa estrutura.

\subsubsection{Arco Treliçado de Crisfield}

Nesse exemplo, extraído de (CRISFIELD, 1997), analisa-se a trajetória de equilíbrio de um arco treliçado bidimensional modelado com 101 elementos de barras simples. A geometria da estrutura e as propriedades físicas das barras estão ilustradas na Figura 18.

Considere-se a seguinte estrutura:

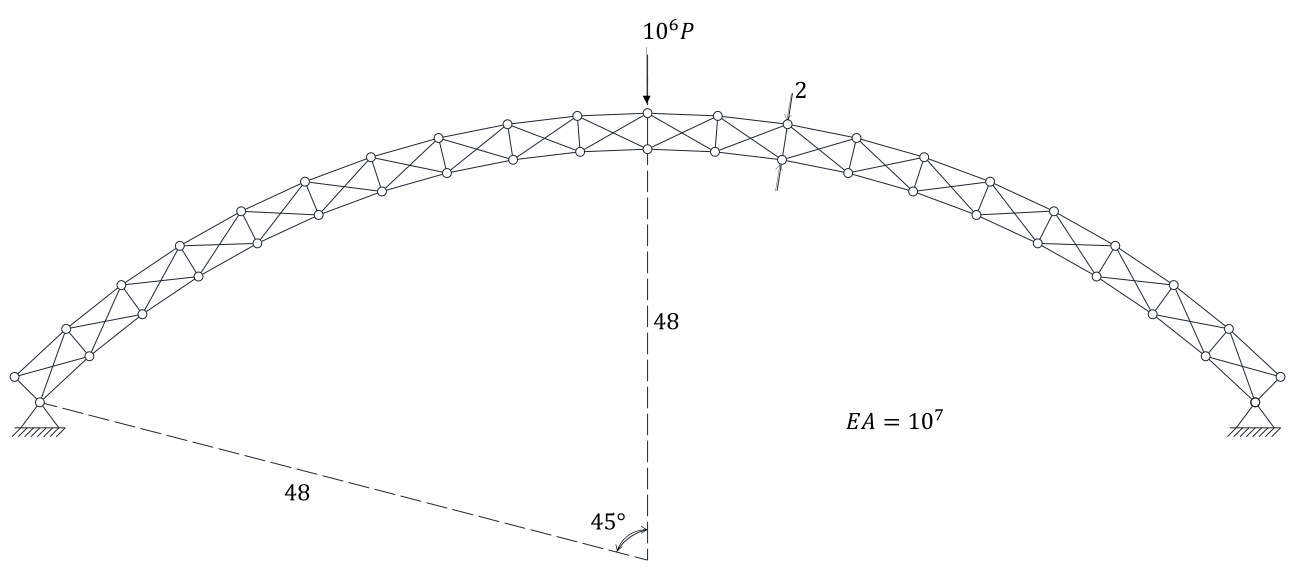

Figura 18: Arco treliçado bidimensional

O resultado da análise empregando-se a estratégia do tipo path-following está ilustrada no gráfico da Figura 19. 


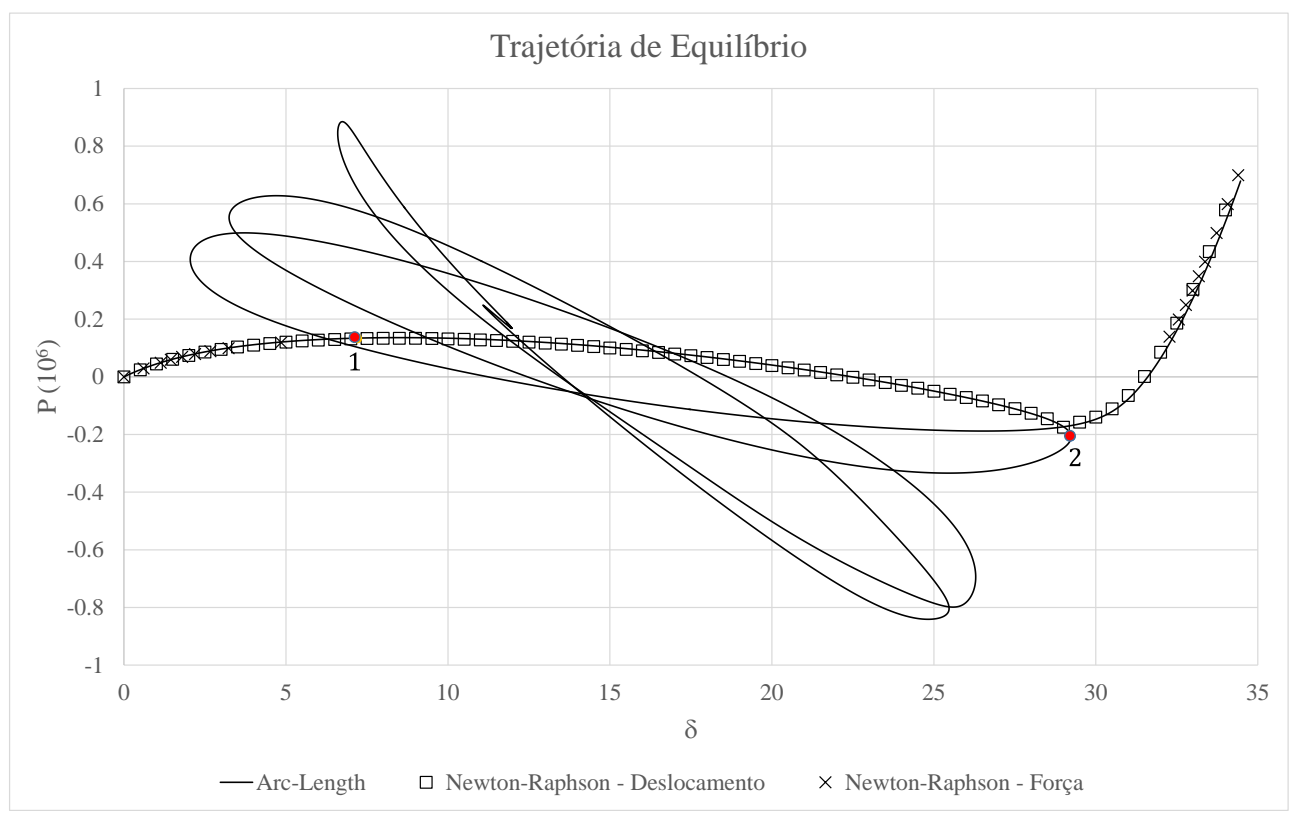

Figura 19: Trajetória de equilíbrio do arco treliçado

Nota-se que as informações quanto a ocorrência de instabilidade por snap-through e snap-back são perdidas ao se adotar o algoritmo de Newton-Raphson com controle de deslocamento e de força. Verifica-se também que o método do comprimento de arco delineou todo o traçado do equilíbrio, ultrapassando os pontos críticos nessa trajetória.

Verifica-se no gráfico que o primeiro ponto limite, ponto 1, surge prematuramente. Nesse caso a energia armazenada nas barras é liberada de forma abrupta caracterizando o fenômeno de snap-trhough. Nesse ponto a trajetória de equilíbrio se torna paralela ao eixo dos deslocamentos.

Do ponto de vista de projeto, a identificação do nível de carregamento nessa situação é de fundamental importância para se ter um controle dos deslocamentos da estrutura. Porém, após esse ponto a estrutura não esgota sua capacidade autoportante e o dimensionamento nesse nível de carga é conservador. Verifica-se que com o método de Newton-Raphson com controle de força é possível se ter apenas uma avaliação desse ponto crítico.

No entanto, ao se ultrapassar o ponto limite impondo-se um controle dos deslocamentos da estrutura, surge no ponto 2, o primeiro turning-point. Para se prosseguir a análise é necessário se adotar a metodologia de solução pelo arc-length de maneira a se captar a inversão no sentido dos deslocamentos. 
Nota-se que ao longo da trajetória, diferentes níveis de carregamento conduzem as situações de instabilidade por snap-trhough e snap-back provando-se a capacidade do elemento de teliça proceder avaliações satisfatórias de estruturas multi-estáveis, desde que se opte por um algoritmo de solução adequado. A seguir apresenta-se a solução do domo de Schwedler.

\subsubsection{Domo de Schwedler}

O domo de Schwedler consiste em uma estrutura treliçada com um número mínimo de diagonais solicitadas apenas por esforço normal de tração (KURRER, 2008). Neste trabalho a estrutura é modelada com 264 barra de treliça, cujas dimensões e propriedades do material estão ilustradas na Figura 20.

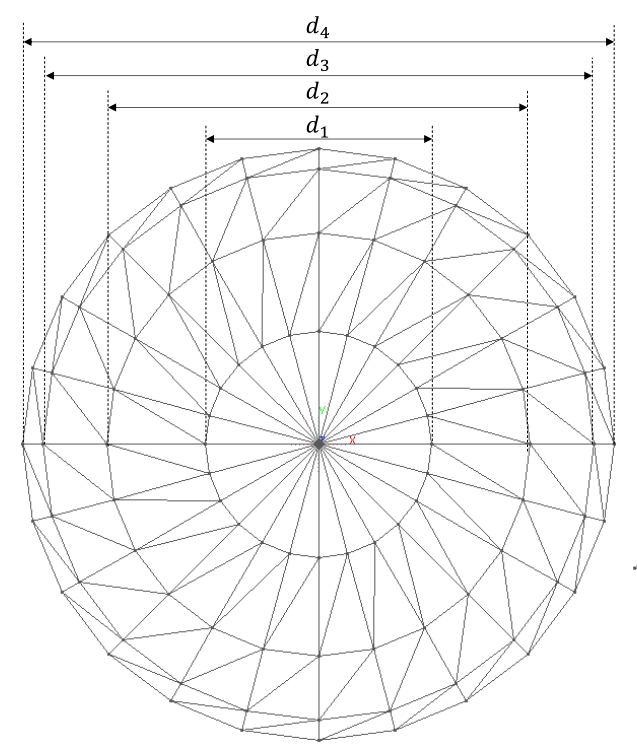

$$
\begin{array}{cl}
E=2 \times 10^{11} \\
A=0,0032 \\
d_{1}=17,56 \quad h_{1}=1,79 \\
d_{2}=32,82 \quad h_{2}=1,47 \\
d_{3}=42,72 \quad h_{3}=1,01 \\
d_{4}=45,80 \quad h_{4}=0,31
\end{array}
$$

Figura 20: Geometria e propriedades dos materiais do domo de Schwedler

Na Figura 21 apresenta-se a trajetória de equilíbrio obtida empregando-se os métodos de Newton-Rapshon com controle de força e controle de deslocamento e o método do arclength. 


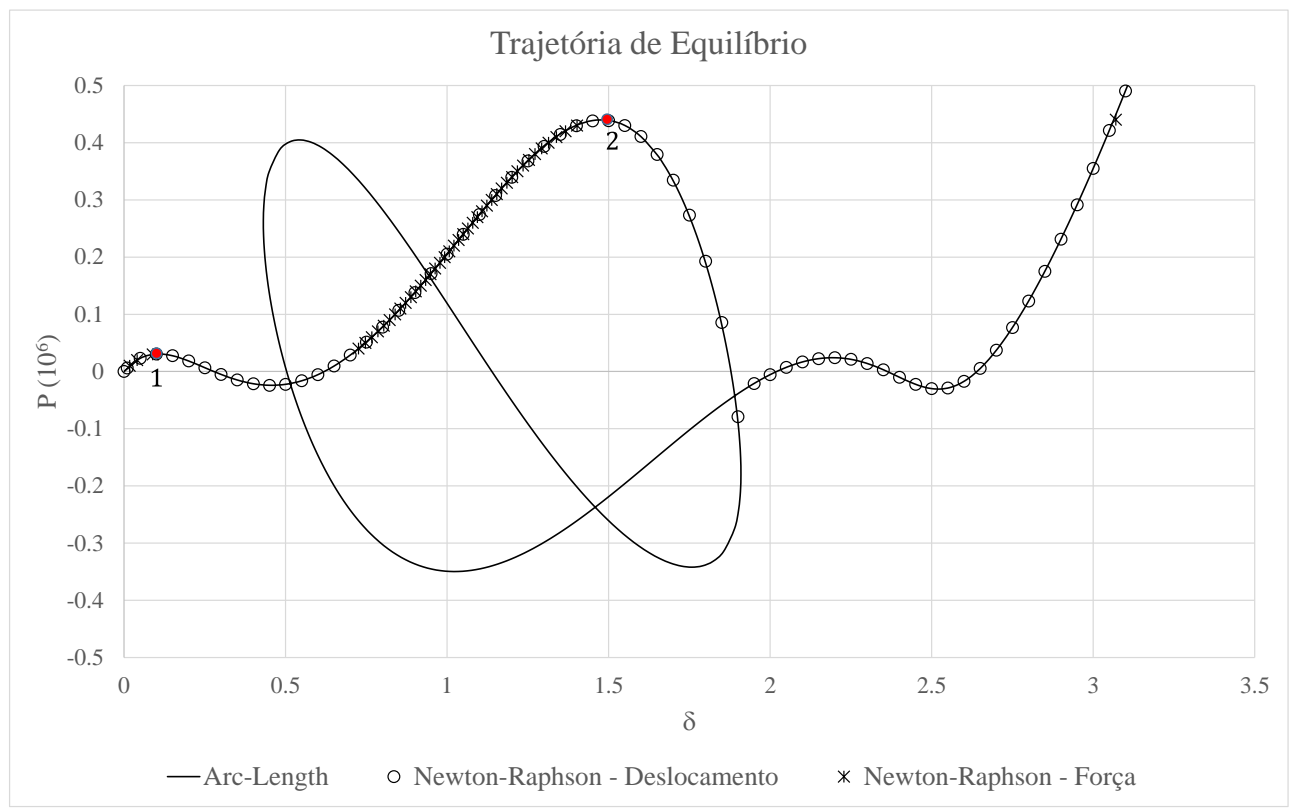

Figura 21: Trajetória de equilíbrio para o domo de Schwedler

Observa-se novamente que no método de Newton-Raphson com controle de força é possível se determinar os valores do carregamento associado ao ponto limite. Ao passo que se avança na trajetória mantendo-se o nível de força controlado, é possível se identificar dois pontos limites, ponto 1 e ponto 2 de instabilidade por snap-trhough, porém não se consegue determinar outros pontos de instabilidade por snap-back.

Controlando-se o deslocamento foi possível ultrapassar os pontos críticos mostrando-se os ramos da curva de equilíbrio instável. Porém, não é possível identificar a mudança de sentido na trajetória de equilíbrio, mesmo com o método de Newton-Raphson com controle dos deslocamentos.

Verifica-se que em todos os exemplos os resultados obtidos são típicos de treliças geometricamente abatidas. No entanto, para treliças não abatidas, a instabilidade por ponto de bifurcação pode preceder a instabilidade por ponto limite. Numa análise mais completa tornase necessário avaliar a condição de instabilidade por ponto de bifurcação dessas estruturas. Um Exemplo desse tipo é avaliados na próxima seção e também no capítulo 8, utilizando-se a análise de autovalores e autovetores para o elemento de barra geral, onde ocorre a flambagem da barra.

Como se admitiu por hipótese, as barras de treliça são rígidas e impedidas de fletir. Nesse caso, a instabilidade por ponto de bifurcação só tem sentido resolvendo-se o problema 
de autovalor com a finalidade de se obter a carga crítica global da estrutura devido a um movimento de corpo rígido.

Para se determinar os autovalores e autovetores para o elemento de treliça é necessário se aplicar a técnica de decomposição da matriz Hessiana apresentada no capítulo 5. Na próxima seção apresenta-se a metodologia demonstrando-se as equações que governa a análise.

\subsection{Análise Linear de Instabilidade do Elemento de Barra Rígida}

Nesta seção apresenta-se a metodologia de decomposição da matriz Hessiana para o elemento de treliça, empregando-se a solução geral do problema de autovalor.

Decompõem-se a matriz de rigidez tangente nas parcelas linear e geométrica. $\mathrm{Na}$ formulação não linear do método dos elementos finitos posicional, essa equivalência é válida para problemas em pequenos deslocamentos.

Aplica-se a decomposição da matriz Hessiana para o elemento reto com deformação de Green-Lagrange. No entanto, a formulação é geral e válida também para o elemento curvilíneo com qualquer medida de deformação.

A equação (6.28), é retomada convenientemente neste ponto, reescrevendo-a da seguinte forma:

$$
H_{m n k \ell}=\frac{1}{4}\left(\frac{1}{L^{0}}\right)^{3} \mathbb{E} A \frac{\partial \Delta}{\partial y_{m n}} \frac{\partial \Delta}{\partial y_{k \ell}}+\frac{1}{2} \frac{1}{L^{0}} S A \frac{\partial^{2} \Delta}{\partial y_{m n} \partial y_{k \ell}}
$$

Sendo, $S=\mathbb{E} E$ a tensão de Piola-Kirchhoff de segunda espécie.

Esse tensor representa o esforço axial da barra devido a ação do carregamento externo. Para o caso de carregamentos com pequena intensidade, a hipótese de pequenas deformações é satisfeita e o segundo termo da equação (6.44) se aproxima da parcela geométrica.

Empregando-se a transformação $\bar{S}=\frac{S}{P}=\frac{\mathbb{E} E}{P}$ a equação (6.44) pode ser escrita como:

$$
H_{m n k \ell}=\frac{1}{4}\left(\frac{1}{L^{0}}\right)^{3} \mathbb{E} A \frac{\partial \Delta}{\partial y_{m n}} \frac{\partial \Delta}{\partial y_{k \ell}}+\frac{1}{2} \frac{1}{L^{0}} P \bar{S} A \frac{\partial^{2} \Delta}{\partial y_{m n} \partial y_{k \ell}}
$$


A condição de instabilidade para um sistema com múltiplos graus de liberdade é determinada por meio da nulidade do determinante da matriz de rigidez tangente. A inversão no sinal da segunda derivada da energia representa a mudança de concavidade da função e a determinação do ponto de inflexão recai no cálculo das raízes do polinômio característico da matriz, ou seja, na obtenção de seus valores e vetores próprios.

De posse desse argumento procura-se a solução não trivial do seguinte sistema:

$$
\left(H_{m n k \ell}^{L}+\lambda H_{m n k \ell}^{G}\right) \Lambda_{m k}=0
$$

Sendo, $\quad H_{m n k \ell}^{L}=\frac{1}{4}\left(\frac{1}{L^{0}}\right)^{3} \mathbb{E} A \frac{\partial \Delta}{\partial y_{m n}} \frac{\partial \Delta}{\partial y_{k \ell}}$ e $H_{m n k \ell}^{G}=\frac{1}{2} \frac{1}{L^{0}} P \bar{S} A \frac{\partial^{2} \Delta}{\partial y_{m n} \partial y_{k \ell}}$ as parcelas da matriz Hessiana equivalentes aos termos linear e geométrico em pequenos deslocamentos.

A nova variável $\lambda$ é usada para representar os autovalores incógnitos do problema e $\Lambda_{m k}$ os autovetores correspondentes.

O menor valor de $\lambda$ que satisfaz a equação (6.46) é a carga crítica linear de instabilidade (REIS e CAMOTIM, 2001).

A solução de (6.46) é obtida pré-multiplicando o sistema pela matriz de rigidez geométrica, resultando:

$$
\left(\bar{H}_{m n k \ell}+\lambda I_{m n k \ell}\right) \Lambda_{m k}=0
$$

Sendo, $\bar{H}_{m n k \ell}=\left(H_{m n k \ell}^{G}\right)^{-1} H_{m n k \ell}^{L}$ e $I_{m n k \ell}$ a matriz identidade de ordem $m n \times k \ell$.

Nota-se que a metodologia é em tudo semelhante a formulação geral apresentada no capítulo anterior. A solução desse sistema é obtida utilizando-se o algoritmo de Lanczos por meio da biblioteca ARPACK.

Com a finalidade de se demonstrar a metodologia, retoma-se o problema do domo em forma de estrela ilustrado na Figura 16 e calcula-se o parâmetro de carga para o qual ocorre um ponto crítico de instabilidade global antes do ponto limite. 


\subsubsection{Análise de Autovalor do Domo Hexagonal}

Diferentemente das condições de contorno utilizadas no exemplo da Figura 16. Para esta análise aplicam-se os carregamentos $P=-0,5 \lambda$ no nó central e $P=-\lambda$ em cada nó inscrito no círculo de raio 25, conforme proposto por (CRISFIELD, 1997). Na Figura 22 ilustra-se o arranjo final da estrutura, considerando-se os nós da base fixos.

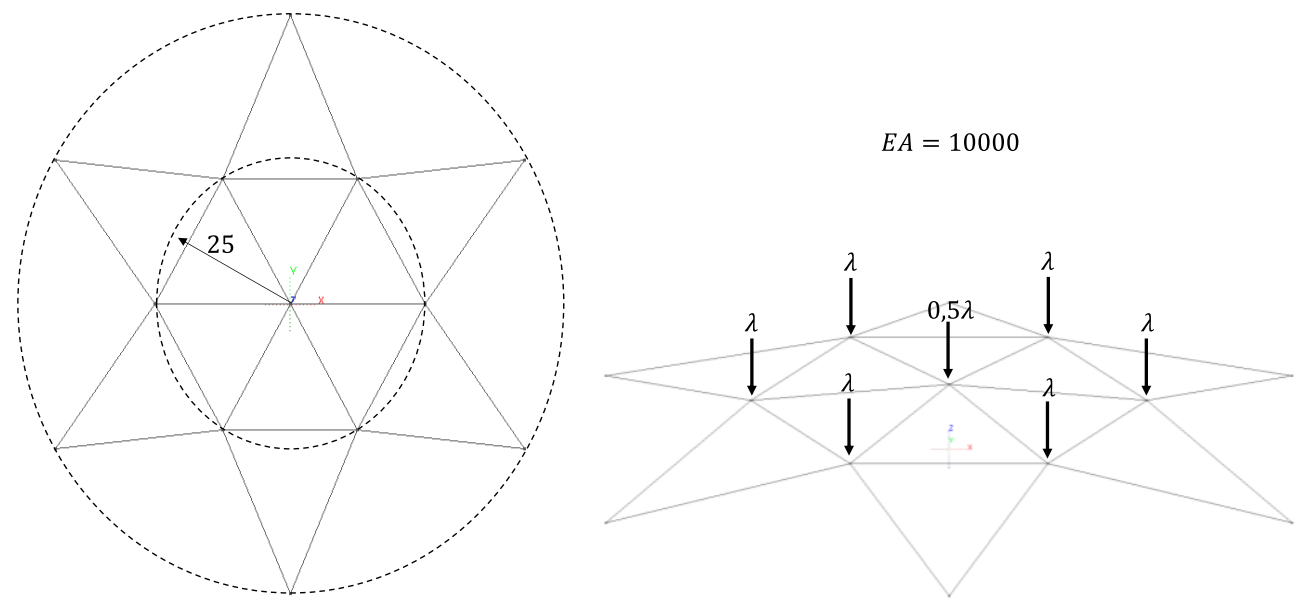

Figura 22: Carregamento considerado para a análise dos autovalores do domo

Em (CRISFIELD, 1997) são apresentadas as estratégias com base na análise assintótica para a obtenção dos pontos e das trajetórias bifurcada da estrutura. Toma-se esse trabalho como referência para se realizarem as comparações necessárias mostrando-se que, diferentemente dos algoritmos propostos pelo autor, é possível se calcular adequadamente os pontos limites e oos pontos de bifurcação, assim como suas respectivas trajetórias de equilíbrio considerando-se apenas a formulação Lagrangiana proposta para o elemento de barra simples, a metodologia de decomposição da matriz Hessiana e o método do arc-lenght.

Por comodidade, na Figura 23 são reproduzidos os resultados apresentados por (CRISFIELD, 1997) para simples conferência das soluções obtidas nesta pesquisa. 


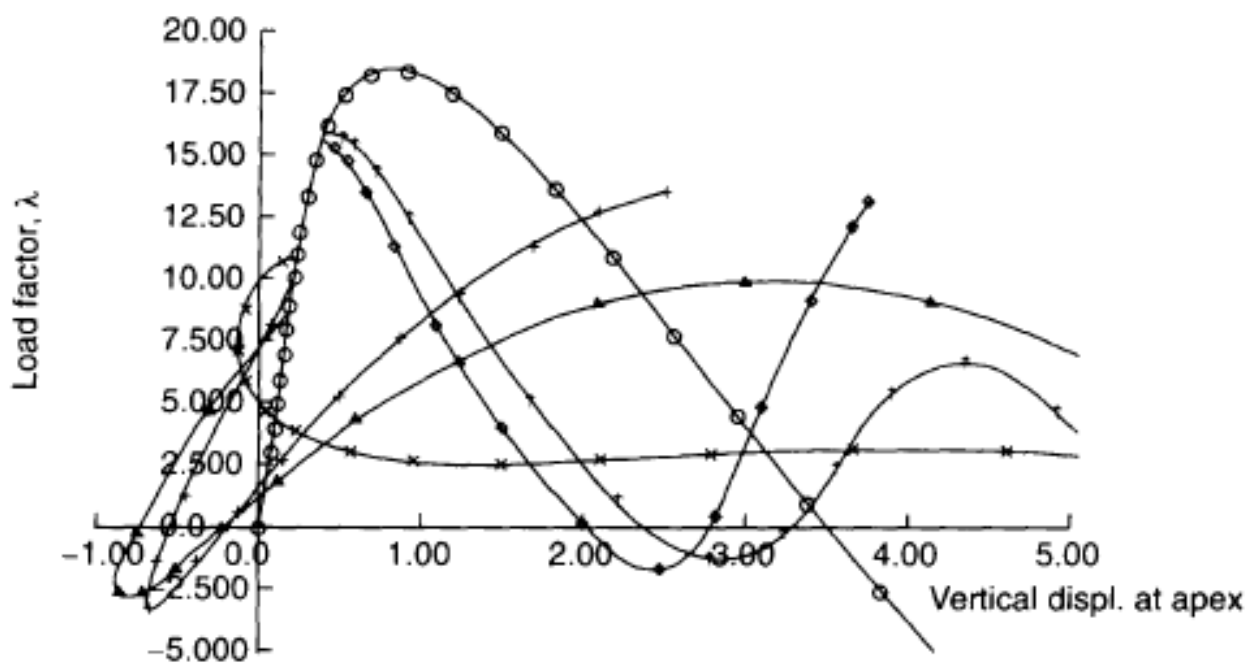

Figura 23: Trajetória de equilíbrio fundamental e bifurcadas para o elemento de treliça. (CRISFIELD, 1997)

A solução obtida a partir da análise de linear de instabilidade do elemento de treliça posicional produziu os seguintes autovalores: $\lambda_{1}=8,26, \lambda_{2}=9,97$ e $\lambda_{3}=15,38$. Esse pontos representam os pontos de bifurcação do equilíbrio, sendo que os parâmetros $\lambda_{2}$ e $\lambda_{3}$, resultaram com multiplicidade dois. De fato, pode-se interpretar esses dados observando-se a Figura 23 de onde verificam-se duas trajetórias de equilíbrio emergindo do segundo o do terceiro ponto de bifurcação. Para além desses pontos obteve-se o parâmetro limite a partir da análise de autovalores da própria matriz Hessiana, resultando: $\lambda_{\lim }=18,35$, para $\operatorname{det}(H)=0,23 \times 10^{-4}$.

Na tabela comparam-se os resultados de (CRISFIELD, 1997), com os autovalores encontrados na presente pesquisa:

Tabela 1: Parâmetros de carregamento correspondentes aos pontos críticos

\begin{tabular}{|c|c|c|c|c|}
\cline { 2 - 5 } \multicolumn{1}{c|}{} & Pt. Bifurcação 1 & Pt. Bifurcação 2 & Pt. Bifurcação 3 & Pt. Limite \\
\hline (CRISFIELD 1997) & 8,68 & 10,26 & 15,67 & 18,40 \\
\hline Treliça Posicional & 8,26 & 9,97 & 15,38 & 18,35 \\
\hline
\end{tabular}

Verifica-se a boa adequação dos parâmetros de carregamento, em relação aos valores apresentados no trabalho de referência.

A cada autovalor está associado um autovetor cuja configuração representa um modo de bifurcação, na Figura 24ilustram-se as configurações deformadas do domo para os cinco primeiros pontos de bifurcação, antes do ponto limite. Verifica-se a multiplicidade de dois 
autovalores, produzindo diferentes configurações. Na Figura 24 ilustram-se a perda de estabilidade global da estrutura e seus respectivos pontos de bifurcação.

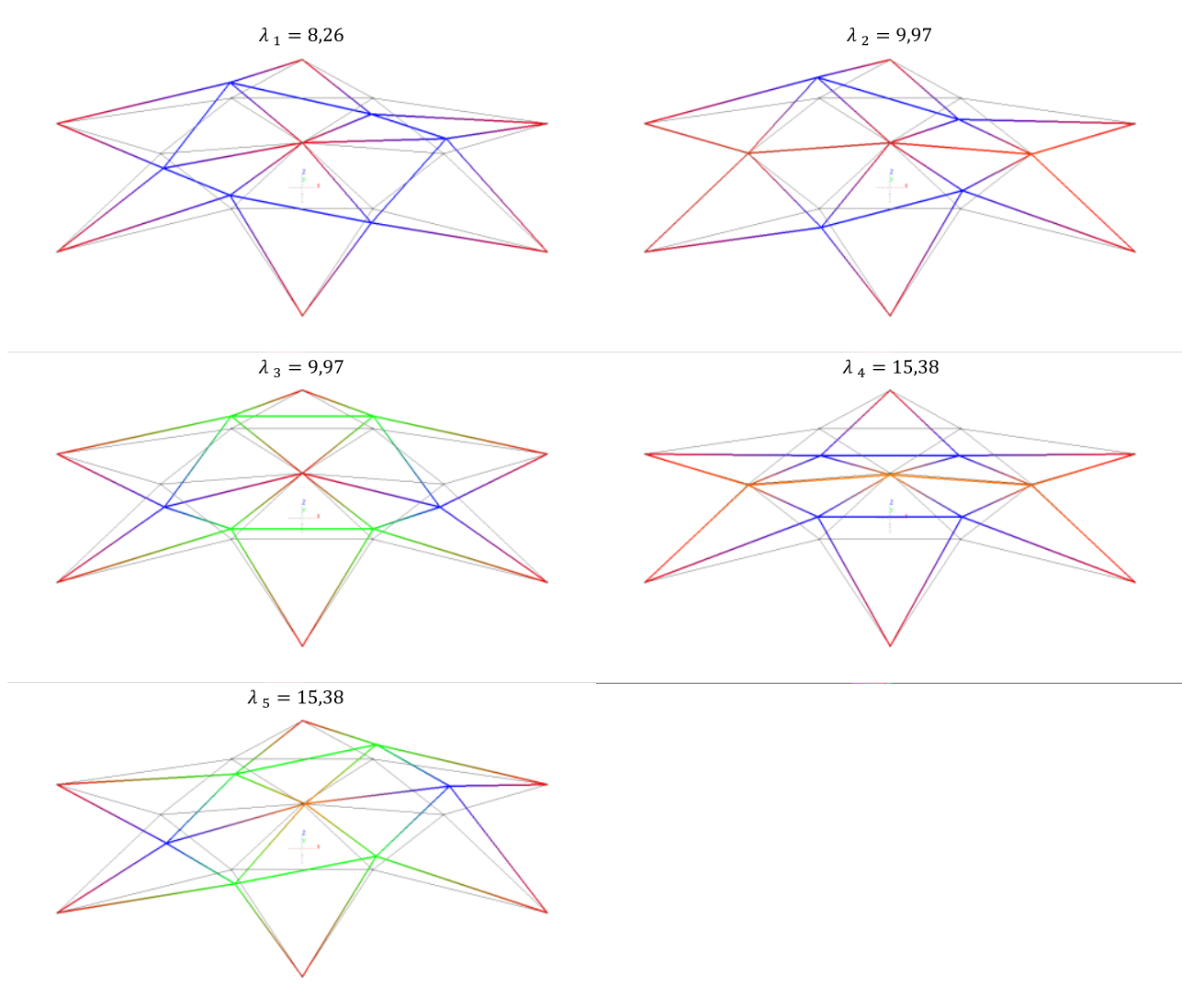

Figura 24: Autovetores dos cinco primeiros parâmetros de bifurcação

Para uma análise das trajetórias bifurcadas, esse autovetores foram tomados como a configuração inicial da estrutura. A partir dessa consideração procedeu-se uma análise nãolinear com o método do arc-length do domo com imperfeição geométrica inicial. Os resultados dessa análise produziram as trajetórias bifurcadas ilustradas na Figura 24.

A menos da trajetória 3, todas as demais trajetórias coincidem com as curvas apresentadas por (CRISFIELD, 1997).

Justifica-se o desvio devido a sensibilidade da análise com relação aos parâmetros de imperfeições iniciais. Procedimentos onde as considerações dos termos de ordem superior na parcela da energia potencial podem suprir essas diferenças nos resultados. 


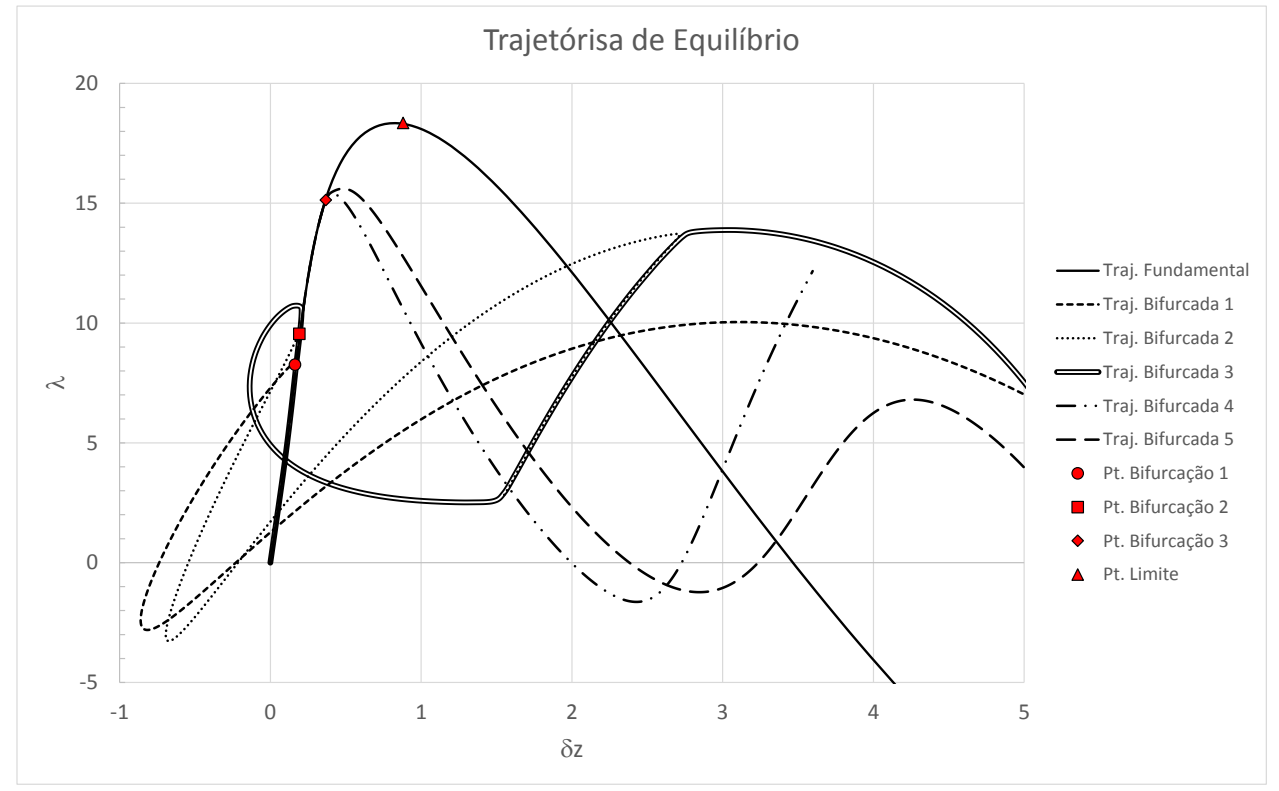

Figura 25: Trajetórias fundamental e bifurcadas obtidas com o elemento de treliça posicional

Os parâmetros de imperfeições iniciais foram introduzidos tomando-se as respostas obtidas com os autovetores. Ou seja, produziram-se configurações imperfeitas de pequena amplitude a partir das configurações geradas pelos autovetores. Essas configurações foram inseridas na análise não-linear do problema original para se produzir as trajetórias bifurcadas.

$\mathrm{Na}$ teoria linear de instabilidade é imprescindível que se conheça com maior exatidão a trajetória fundamental da estrutura. Na Figura 27 ilustra-se a trajetória fundamental e o primeiro ponto limite obtido com a análise de autovalor.

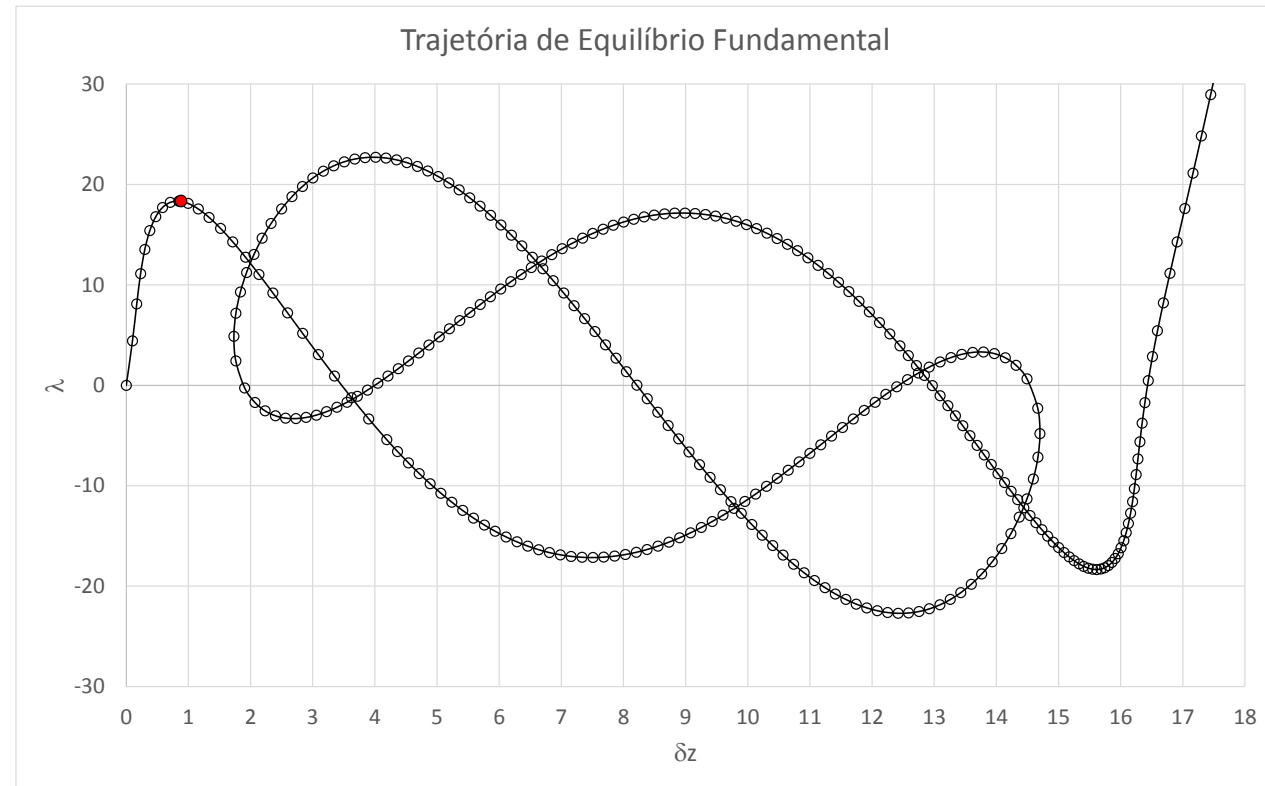


A seguir ilustram-se as trajetórias bifurcadas obtidas considerando-se as imperfeições geométricas iniciais correspondentes ao autovetores.

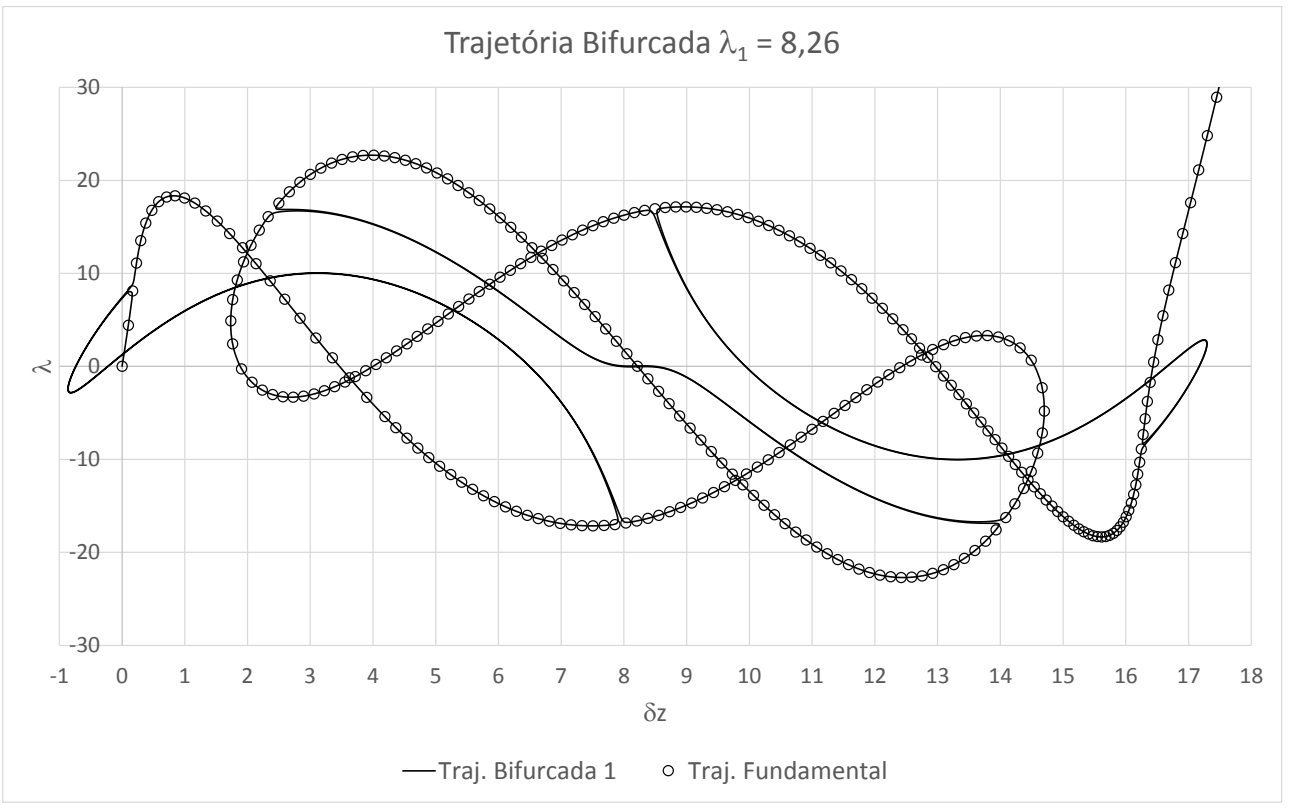

Figura 27: Trajetória bifurcada 1.

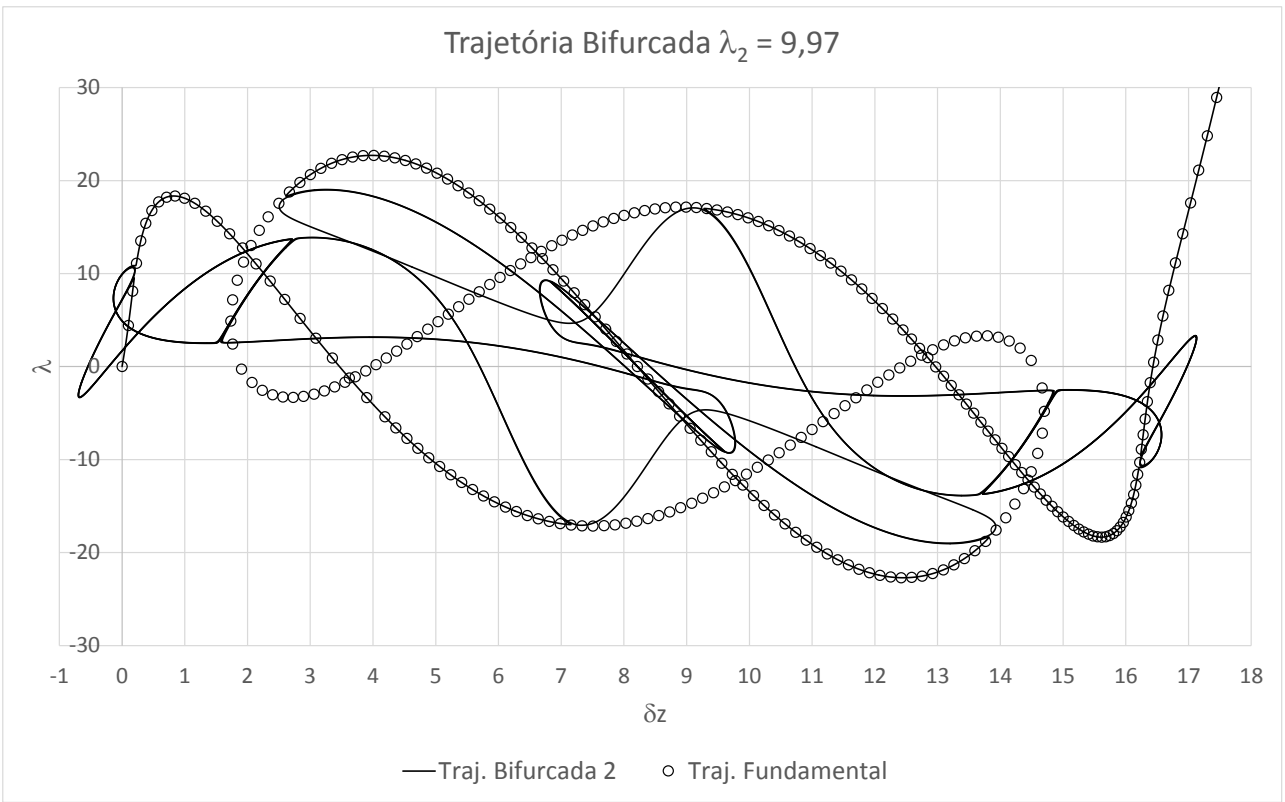

Figura 28: Trajetória bifurcada 2 


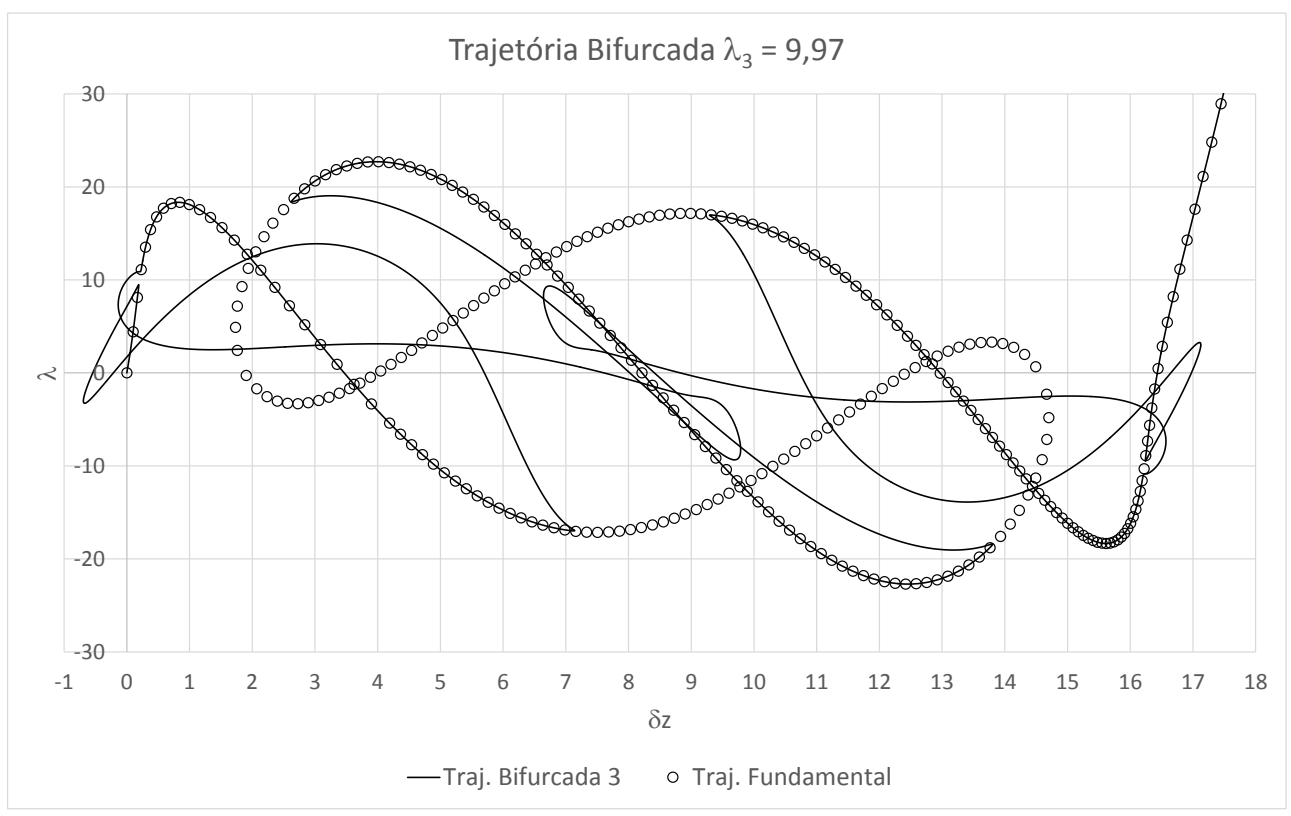

Figura 29: Trajetória bifurcada 3

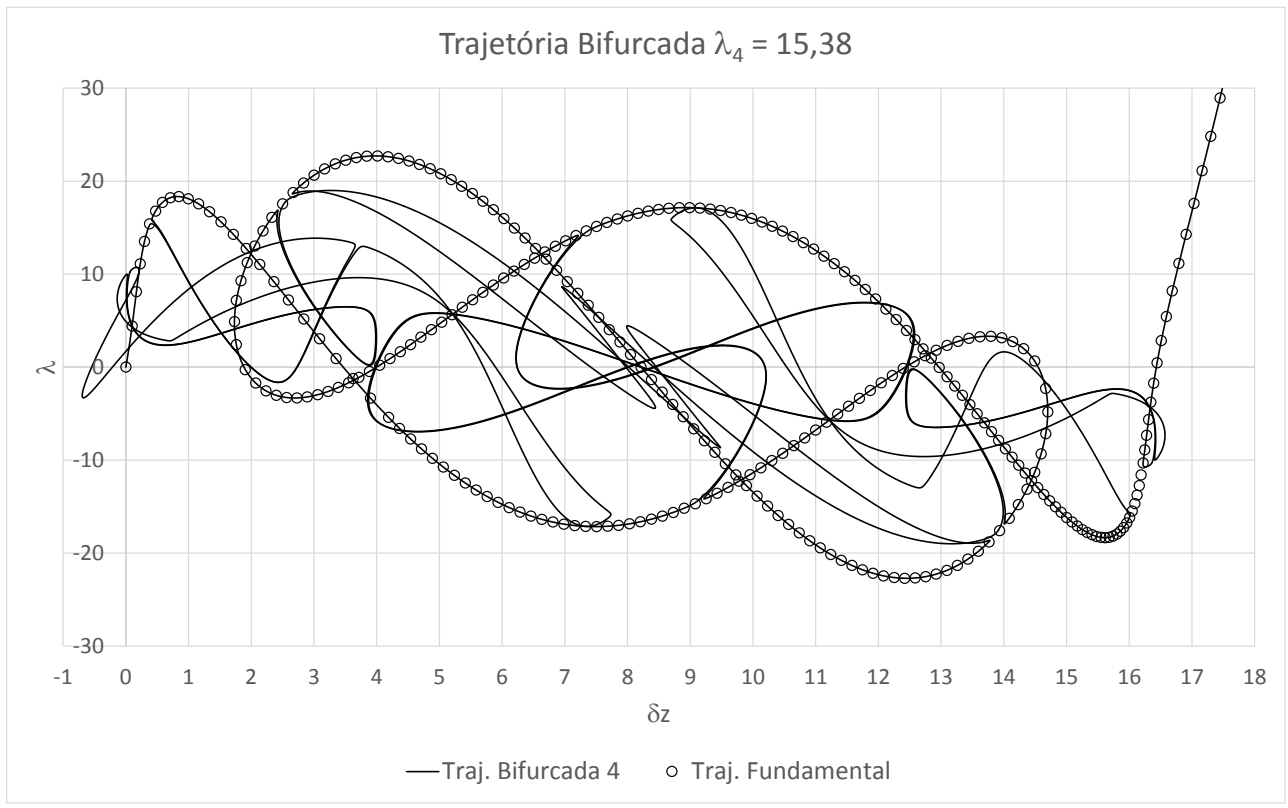

Figura 30: Trajetória bifurcada 4 


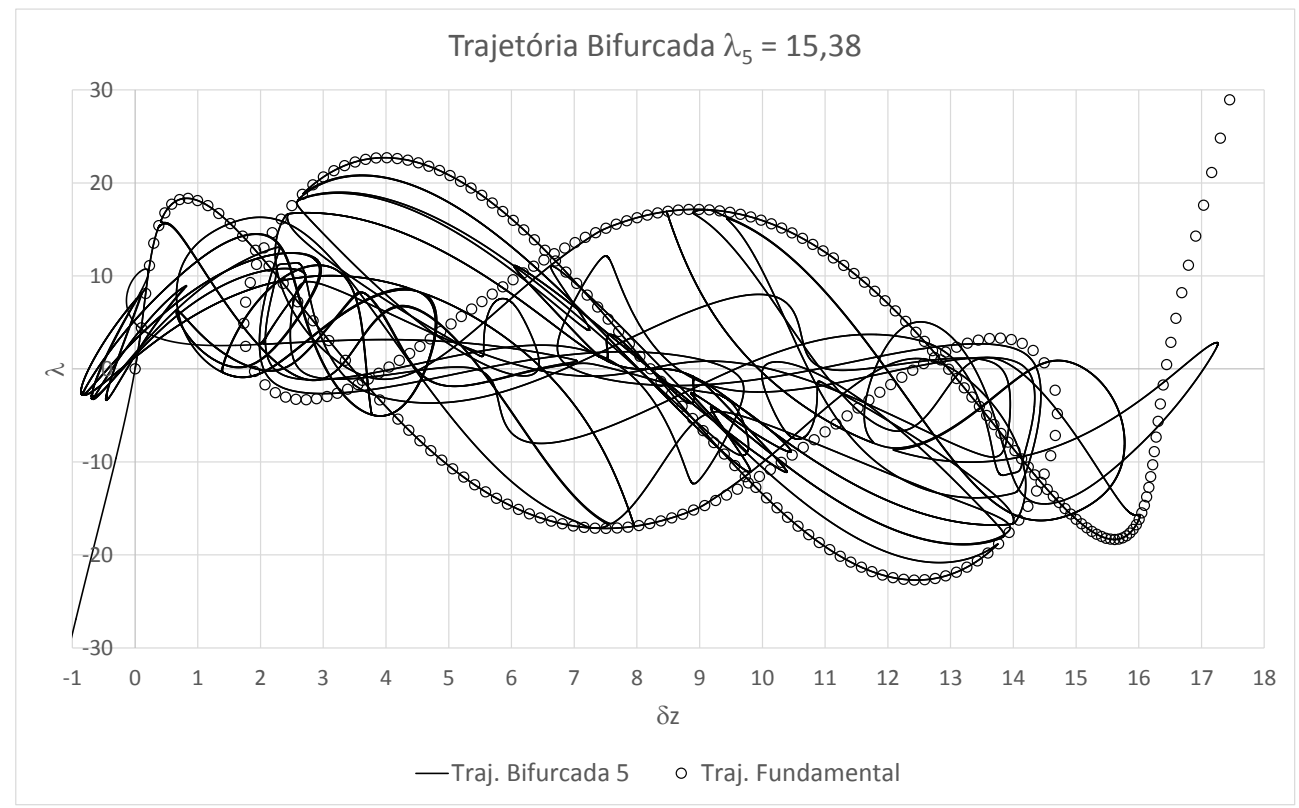

Figura 31: Trajetória bifurcada 5

Apesar de extremamente complexas, as trajetórias bifurcadas não se desviam completamente da trajetória fundamental. Esse comportamento é explicado pelo fato da estrutura buscar uma configuração simétrica de equilíbrio durante a perda de estabilidade. $\mathrm{O}$ ponto de bifurcação em estruturas constituídas por barras rígidas, pode ser entendido como aquele no qual a estrutura perde essa simetria.

Verificando-se com mais detalhe as trajetórias bifurcadas é possível constatar a ocorrência de múltiplos pontos de bifurcação ao longo da trajetória fundamental. Esse fato comprova a hipótese de que a metodologia é eficaz ao se tratar de problemas multiestáveis.

\subsection{Fechamento}

Neste capítulo foram apresentadas as formulações dos elementos curvilíneos com qualquer ordem de aproximação e medida de deformação obtida a partir das deformações de Hill. A formulação do elemento curvilíneo foi adaptada para se obter o elemento de barra reta. Esses elementos foram utilizados no estudo da instabilidade de treliças espaciais via estratégias do tipo path-following. Verificou-se que para se traçar o caminho completo do equilíbrio é necessário se recorrer a procedimentos mais robustos de solução como o método do arc-length. Uma série de exemplos com trajetórias complexas foram solucionadas satisfatoriamente com essa metodologia. 
Por fim, aplicou-se a metodologia de decomposição da matriz Hessiana para o elemento de barra reta com lei constitutiva de Saint-Venant-Kirchhoff, com a finalidade de se identificar os pontos de instabilidade global do equilíbrio. 



\section{$7 \quad$ Elemento Finito de Casca}

\subsection{Apresentação do Capítulo}

Neste capítulo apresenta-se a formulação posicional do elemento finito de casca não linear geométrico. Adota-se o referencial Lagrangiano total e a lei constitutiva tridimensional completa para se descrever uma cinemática aprimorada e livre de travamento. Emprega-se a estratégia de decomposição da matriz Hessiana para se proceder a análise de linear de instabilidade, a fim de avaliar as cargas e modos críticos de estruturas compostas por chapas delgadas. Avaliam-se também as trajetórias de equilíbrio em grandes deslocamentos introduzindo-se defeitos nas peças. Exemplos selecionados comprovam a aplicabilidade da metodologia e a eficiência do modelo para simulação de estruturas com múltiplos modos de instabilidade.

\subsection{Elemento de Casca Não Linear Geométrico}

O elemento finito de casca não linear geométrico proposto por (CODA e PACCOLA, 2007) possui como parâmetros nodais as componentes das posições, dos vetores generalizados e o aprimoramento das deformações ao longo da espessura da casca. O mapeamento dos elementos de casca é realizado em relação as coordenadas nodais da superfície média, ou superfície de referência. Na Figura 32 ilustra-se o elemento finito de casca triangular não linear geométrico. 


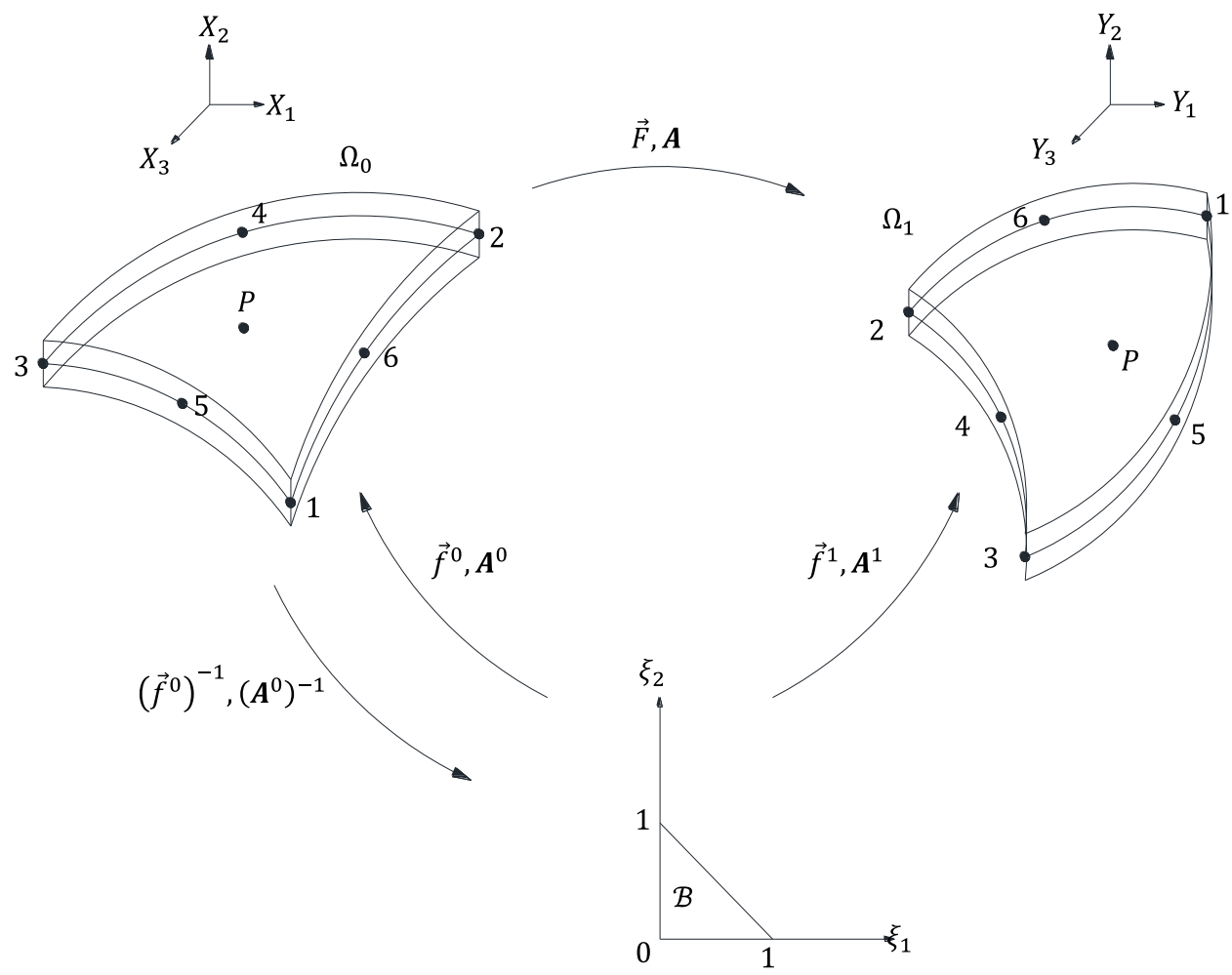

Figura 32: Mapeamento do elemento finito de casca não linear geométrico

Qualquer ponto sobre a superfície média do elemento pode ser determinada, na configuração inicial, a partir da interpolação:

$$
f_{i}^{0}=X_{i}(P)=\phi_{j}\left(\xi_{1}, \xi_{2}\right) x_{i j}
$$

Sendo, $\phi_{j}$ as funções de forma bidimensionais expressas em termos das coordenadas $\left(\xi_{1}, \xi_{2}\right)$ do espaço auxiliar $\mathcal{B}$. Neste trabalho é possível se adotar o espaço adimensional triangular de Hammer ou o espaço quadrilateral de Gauss. Os valores de $x_{i}$ definem as coordenadas nodais do elemento no espaço físico.

Na configuração atual, para se localizar o ponto $P$ sobre a superfície média é necessário se empregar as coordenadas atualizadas $y_{i j}$ do elemento após mudança a mudança de configuração, tal que:

$$
f_{i}^{1}=Y_{i}(P)=\phi_{j}\left(\xi_{1}, \xi_{2}\right) y_{i j}
$$


Por se tratar de um elemento tridimensional, ainda é necessário mapear os pontos fora da superfície média do elemento, porém, dentro da espessura da casca. Esses pontos são identificados a partir do vetor generalizado, conforme ilustrado na Figura 33.

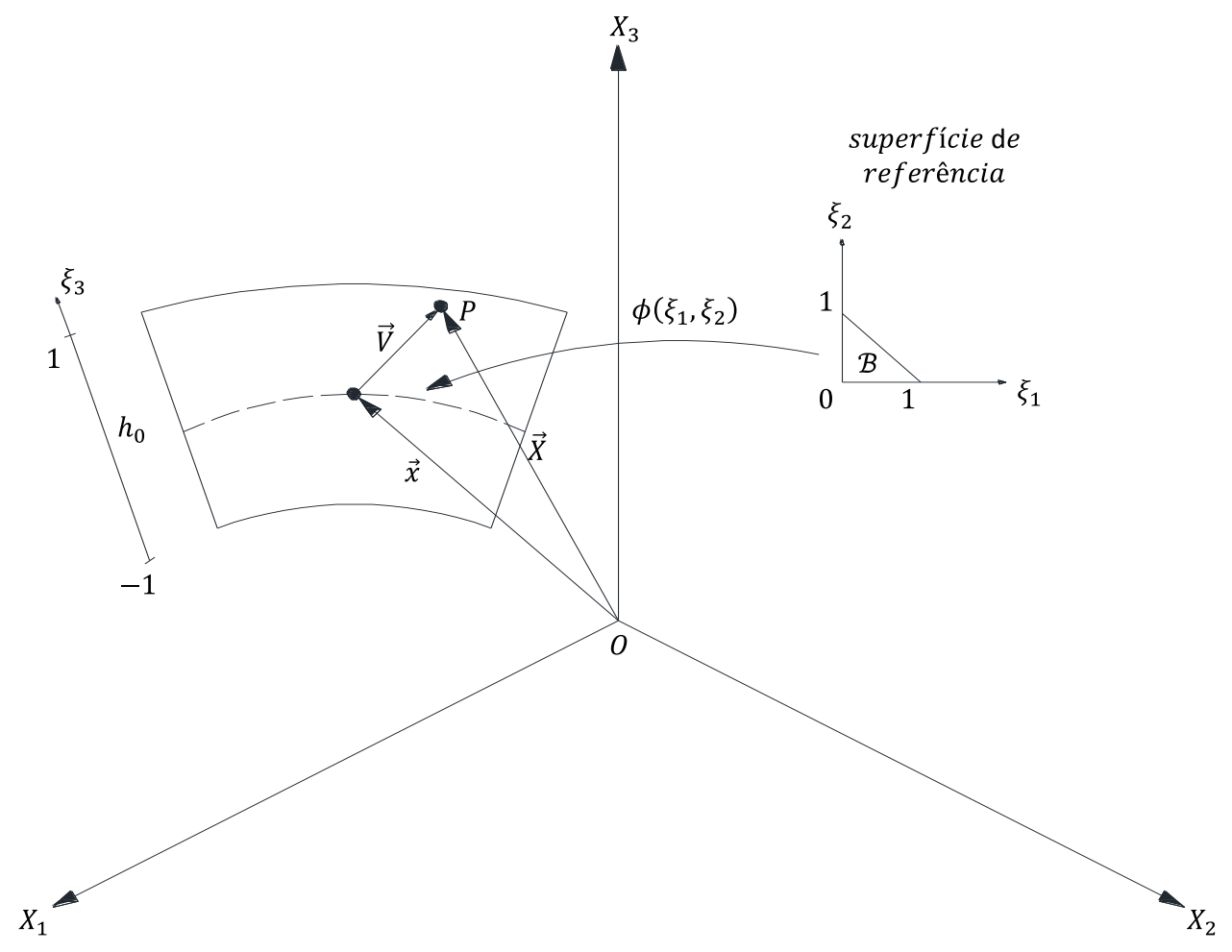

Figura 33: Mapeamento ao longo da espessura do elemento

Apenas por simplicidade, admite-se que, na configuração inicial, o vetor generalizado é ortogonal a superfície de referência e de intensidade unitária. Na configuração atual permite-se que o vetor possa assumir qualquer valor, tratando-o como uma variável do problema. A contribuição do vetor é obtida após a determinação do equilíbrio da casca.

Essa generalidade permite que o vetor tenha mobilidade para se movimentar segundo as deformações provocadas pelas tensões cisalhantes, semelhante ao que ocorre na hipótese cinemática de Reissner-Mindlin para placas e cascas sob flexão.

$\mathrm{Na}$ configuração inicial as posições dos pontos materiais são mapeadas a partir da função:

$$
X_{i}(P)=\phi_{j}\left(\xi_{1}, \xi_{2}\right) x_{i j}+V_{i}
$$

Sendo o vetor $V_{i}=\frac{h_{0}}{2} \xi_{3} \phi_{j}\left(\xi_{1}, \xi_{2}\right) v_{i j}$ unitário e ortogonal a superfície média. 
Nessa formulação, considera-se o elemento com espessura inicial $h_{0}$ constante. Os valores de $v_{i j}$ são as componentes normalizadas do vetor.

Para contornar o problema decorrente do travamento volumétrico, (CODA e PACCOLA, 2007) inserem na cinemática da casca o aprimoramento referente a variação linear das deformações transversais ao longo da espessura. Essa quantidade altera apenas a intensidade do vetor generalizado na configuração deformada de modo que o mapeamento total passa a ser calculado como:

$$
Y_{i}(P)=\phi_{j}\left(\xi_{1}, \xi_{2}\right) y_{i j}+G_{i}
$$

Sendo, $G_{i}=\frac{h_{0}}{2}\left[\xi_{3}+\phi_{\ell}\left(\xi_{1}, \xi_{2}\right) a_{\ell} \xi_{3}^{2}\right] \phi_{j}\left(\xi_{1}, \xi_{2}\right) g_{i j}$ o vetor generalizado atual com componentes $g_{i j}$. O valor de $a_{\ell}$ representa o novo grau de liberdade das deformações.

Nota-se que a coordenada adimensional $\xi_{3}$ é inserida nas transformações com o objetivo de se realizar o mapeamento ao longo da espessura do elemento.

O elemento finito com os aprimoramentos apresenta sete graus de liberdade, assim identificados:

$$
q_{j}=\left\{y_{1 j}, \mathrm{y}_{2 j}, \mathrm{y}_{3 j}, \mathrm{~g}_{1 j}, \mathrm{~g}_{2 j}, \mathrm{~g}_{3 j}, a_{j}\right\}
$$

Sendo, $q_{j}$ o vetor de coordenadas generalizadas, $y_{i j}$ as componentes de posição e $g_{i j}$ as componentes do vetor generalizado, nas direção $i$ do nós $j$. O valor de $a_{j}$ representa a intensidade das deformações transversais na espessura do elemento, tomados na configuração deformada. De posse dos mapeamentos é possível determinar os gradientes desses valores.

\subsection{Gradiente da Transformação}

Da mesma maneira como realizado para o elemento de barra geral, apresentam-se as componentes do gradiente da transformação nas configurações inicial e atual. 


\subsubsection{Gradiente na Configuração Inicial}

Escrevendo-se a forma completa da cinemática na configuração inicial, tem-se:

$$
f_{i}^{0}=\phi_{j}\left(\xi_{1}, \xi_{2}\right) x_{i j}+\frac{h_{0}}{2} \xi_{3} \phi_{j}\left(\xi_{1}, \xi_{2}\right) v_{i j}
$$

O gradiente nessa configuração é calculado como: $A_{i \ell}^{0}=\frac{\partial f_{i}^{0}}{\partial \xi_{\ell}}=f_{i, \ell}^{0}$

Cujas componentes são:

$$
\begin{aligned}
& f_{i, 1}^{0}=\phi_{j, 1}\left(\xi_{1}, \xi_{2}\right) x_{i j}+\frac{h_{0}}{2} \xi_{3} \phi_{j, 1}\left(\xi_{1}, \xi_{2}\right) v_{i j} \\
& f_{i, 2}^{0}=\phi_{j, 2}\left(\xi_{1}, \xi_{2}\right) x_{i j}+\frac{h_{0}}{2} \xi_{3} \phi_{j, 2}\left(\xi_{1}, \xi_{2}\right) v_{i j} \\
& f_{i, 3}^{0}=\frac{h_{0}}{2} \phi_{j}\left(\xi_{1}, \xi_{2}\right) v_{i j}
\end{aligned}
$$

\subsubsection{Gradiente na Configuração Atual}

Na configuração atual o mapeamento é determinado fazendo-se:

$$
f_{i}^{1}=\phi_{j}\left(\xi_{1}, \xi_{2}\right) y_{i j}+\frac{h_{0}}{2}\left[\xi_{3}+\phi_{\ell}\left(\xi_{1}, \xi_{2}\right) a_{\ell} \xi_{3}^{2}\right] \phi_{j}\left(\xi_{1}, \xi_{2}\right) g_{i j}
$$

Para se realizar o cálculo do gradiente de maneira mais didática divide-se a equação (7.8) em duas parcelas:

$$
f_{i}^{1}=B_{i}+C_{i}
$$

Sendo:

$$
\begin{gathered}
B_{i}=\phi_{j}\left(\xi_{1}, \xi_{2}\right) y_{i j} \\
C_{i}=\frac{h_{0}}{2}\left[\xi_{3}+\phi_{\ell}\left(\xi_{1}, \xi_{2}\right) a_{\ell} \xi_{3}^{2}\right] \phi_{j}\left(\xi_{1}, \xi_{2}\right) g_{i j}
\end{gathered}
$$


O gradiente da transformação atual é obtido fazendo-se: $A_{i \ell}^{1}=\frac{\partial}{\partial \xi_{\ell}}\left\{B_{i}+C_{i}\right\}$. Aplicando-se o operador derivada parcial nas duas parcelas, obtém-se:

Para a parcela $B_{i, \ell}$ :

$$
\begin{aligned}
& B_{i, 1}^{1}=\phi_{j, 1}\left(\xi_{1}, \xi_{2}\right) y_{i j} \\
& B_{i, 2}^{1}=\phi_{j, 2}\left(\xi_{1}, \xi_{2}\right) y_{i j} \\
& B_{i, 3}^{1}=0
\end{aligned}
$$

Para a parcela $C_{i, m}$ :

$$
\begin{aligned}
& C_{i, 1}=\frac{h_{0}}{2}\left[\begin{array}{l}
\left(\xi_{3}+\phi_{\ell}\left(\xi_{1}, \xi_{2}\right) a_{\ell} \xi_{3}^{2}\right) \phi_{j, 1}\left(\xi_{1}, \xi_{2}\right) g_{i j}+ \\
\left(\phi_{\ell, 1}\left(\xi_{1}, \xi_{2}\right) a_{\ell} \xi_{3}^{2}\right) \phi_{j}\left(\xi_{1}, \xi_{2}\right) g_{i j}
\end{array}\right] \\
& C_{i, 2}=\frac{h_{0}}{2}\left[\begin{array}{l}
\left(\xi_{3}+\phi_{\ell}\left(\xi_{1}, \xi_{2}\right) a_{\ell} \xi_{3}^{2}\right) \phi_{j, 2}\left(\xi_{1}, \xi_{2}\right) g_{i j}+ \\
\left(\phi_{\ell, 2}\left(\xi_{1}, \xi_{2}\right) a_{\ell} \xi_{3}^{2}\right) \phi_{j}\left(\xi_{1}, \xi_{2}\right) g_{i j}
\end{array}\right] \\
& C_{i, 3}=\frac{h_{0}}{2}\left[1+2 \phi_{\ell}\left(\xi_{1}, \xi_{2}\right) a_{\ell} \xi_{3}\right] \phi_{j}\left(\xi_{1}, \xi_{2}\right) g_{i j}
\end{aligned}
$$

Todos os parâmetros seguem o sistema de referência global evitando-se com isso o uso de esquemas de rotações finitas. Em contrapartida, o cálculo das deformações é realizado seguindo-se as direções principais do tensor de Cauchy-Green, de modo a preservar a isotropia do material, da mesma forma como apresentado por (CODA e PACCOLA, 2007).

Com a cinemática do elemento de casca, o cálculo dos valores e vetores próprios a partir da decomposição da matriz Hessiana são obtidos da maneira geral como apresentado no capítulo 5. A metodologia descrita na seção 5.4 é geral e aplicável tanto ao elemento de casca quanto ao elemento de barra geral, optou-se por deixar o detalhamento da metodologia de decomposição da matriz, apenas no capítulo 5, para não correr o risco da demonstração se tornar repetitiva para ambos os elementos (casca e barra geral).

Posto isso, na próxima seção apresentam-se exemplos que comprovam a aplicabilidade do elemento de casca posicional no estudo da instabilidade de estruturas esbelta. Pretende-se com esses exemplos validar a metodologia de decomposição da matriz Hessiana e utilizar a 
teoria linear de instabilidade no cálculo das cargas de bifurcação, a partir da determinação dos valores próprios.

Nos exemplos avaliam-se também a influência das imperfeições geométricas no comportamento pós-crítico em grandes deslocamentos empregando-se a estratégia do tipo pathfollowing. Na próxima seção apresentam-se os exemplos de referência do capítulo

\subsection{Exemplos}

No primeiro exemplo demonstram-se a eficácia do elemento de cassca posicional em se determinar as cargas de bifurcação e os modos locais de uma chapa simplesmente apoiada sob compressão uniforme. Estuda-se o problema de instabilidade pós-crítica em grandes deslocamentos introduzindo-se uma imperfeição geométrica transversal ao plano da chapa. Ainda neste exemplo, liberam-se gradativamente as bordas descarregadas para que seja verificada a transição dos modos locais para os modos globais. São analisados os elementos de chapa, flange e colunas delgadas.

No segundo exemplo apresentam-se os resultados do cálculo dos autovalores e autovetores de um perfil estrutural de parede fina empregando-se o elemento de casca posicional. Adota-se na análise um perfil do tipo $\mathrm{C}$, que será utilizado como referência para o modelo de barra geral. Neste exemplo estuda-se também a influência das imperfeições iniciais devido a ação de carregamentos combinados. Em conjunto se faz uma avaliação da trajetória pós-crítica da estrutura sob a influência das imperfeições na geometria. $\mathrm{O}$ exemplo é inspirado no trabalho de (GARCEA, 2001) no qual utilizou dois tipos de elementos de casca com base na teoria assintótica de Koiter.

\subsubsection{Flambagem de Chapas, Flanges e Colunas Delgadas}

De acordo com (REIS e CAMOTIM, 2001) a geometria bidimensional da chapa proporciona um acréscimo na capacidade resistente devido ao efeito de membrana. Esse acréscimo promove a redistribuição das tensões às partes mais enrijecidas permitindo que a mesma continue suportando o carregamento, mesmo após a ocorrência de instabilidade local. Esse fenômeno é evidente em chapas delgadas.

As chapas esbeltas submetidas a tensões compressivas perdem estabilidade com valores de carga abaixo do limite de resistência, porém essa condição não implica em esgotamento da 
capacidade resistente e a redistribuição das tensões devido ao efeito de membrana pode ser considerada uma reserva de resistência pós-crítica.

Em (TIMOSHENKO e GERE, 1961) é demonstrada a expressão da energia potencial total para uma chapa simplesmente apoiada e submetida a um carregamento unidirecional aplicado na superfície média.

O valor da energia potencial total é obtida por:

$$
\Pi=\frac{\pi^{4} a b}{8} D \sum_{m=1}^{\infty} \sum_{n=1}^{\infty} A_{m n}\left(\frac{m^{2}}{a^{2}}+\frac{n^{2}}{b^{2}}\right)^{2}-\frac{\pi^{2} b}{8 a} P \sum_{m=1}^{\infty} \sum_{n=1}^{\infty} m^{2} A_{m n}^{2}
$$

Na configuração de equilíbrio a energia potencial total é estácionária e o valor da carga crítica é calculado por meio de um problema geral de autovalor.

A carga crítica em pequenos deslocamentos para materiais isotrópicos e elásticolineares é calculada como:

$$
P_{m n}=D \frac{\pi^{2} a^{2}}{m^{2}}\left(\frac{m^{2}}{a^{2}}+\frac{n^{2}}{b^{2}}\right)^{2}
$$

Sendo, $D=\frac{E t^{3}}{12\left(1-v^{2}\right)}$ a rigidez a flexão; $a, b$ e $t$, a largura, o comprimento e a espessura da chapa, respectivamente.

$\mathrm{Na}$ equação (7.15) o carregamento é uma função das dimensões, das propriedades do material e do número de semi-ondas no plano da chapa. $\mathrm{O}$ valor da carga crítica será aquele no qual as semi-ondas são obtidas para o estado menos energético de deformação. Essa situação ocorre para $n=1$, ou seja, uma única semi-onda na direção transversal da chapa (REIS e CAMOTIM, 2001).

Tendo isso em conta, a equação (7.15) pode ser escrita da seguinte forma:

$$
P_{m}=k \frac{D \pi^{2}}{b^{2}} \text {, sendo } k=\left(\frac{a}{m b}+\frac{m b}{a}\right)^{2}
$$


De acordo com a equação (7.16) o resultado da carga crítica depende de dois fatores, a carga crítica de Euler para uma faixa de largura unitária de comprimento $a$ e da instabilidade de chapa, determinada pelo parâmetro $k$.

É possível verificar para placas longas, $a>4 b$, simplesmente apoiadas que o padrão de instabilidade consiste em semi-ondas quadradas iguais a largura da chapa.

Para chapas com diferentes condições de vínculos e carregamentos é necessário se obter uma nova solução analítica, ou se proceder uma análise via método dos elementos finitos. No que segue, emprega-se o elemento de casca não-linear geométrico posicional, a fim de se verificar a adequação dos resultados em relação a solução analítica.

A carga crítica é obtida empregando-se o algoritmo de Lanczos para o cálculo dos autovalores. Ilustram-se qualitativamente as configurações geradas pelos autovetores para mostrar a concordância com os modos de instabilidade previstos na solução analítica.

Considere-se inicialmente uma placa delgada sob compressão uniforme, com os bordos simplesmente apoiados conforme a Figura 34.

Considerou-se na análise uma malha com 320 elementos quadrilaterais de aproximação quadrática, totalizando 9646 graus de liberdade com o elemento finito posicional de casca.

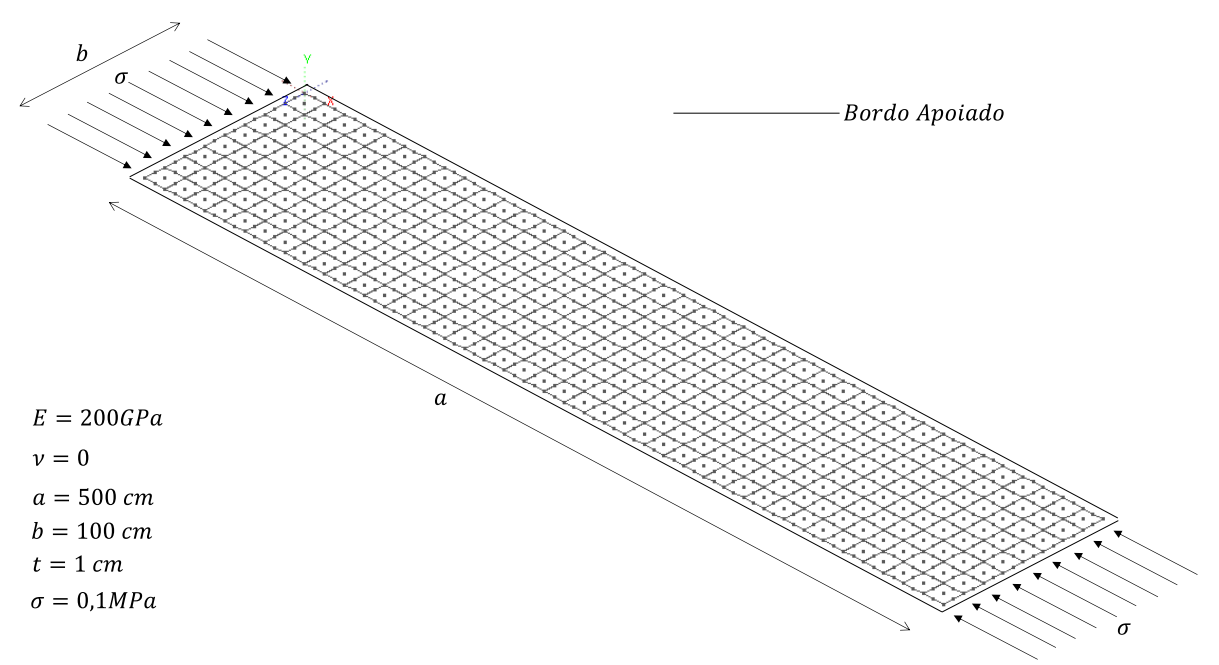

Figura 34: Chapa simplesmente apoiada sob compressão uniforme

Considerou-se na análise uma malha com 320 elementos quadrilaterais de aproximação quadrática, totalizando 9646 graus de liberdade com o elemento finito posicional de casca. 
$\mathrm{Na}$ Tabela 2 apresentam-se os resultados dos seis primeiros pontos críticos:

Tabela 2: Pontos críticos para a chapa simplesmente apoiada

\begin{tabular}{|c|c|c|c|}
\hline Modo & Analítico $(\mathrm{kN})$ & Numérico $(\mathrm{kN})$ & Erro relativo (\%) \\
\hline 1 & 657.97363 & 656.59286 & 0.2099 \\
\hline 2 & 680.08885 & 678.62658 & 0.2150 \\
\hline 3 & 691.28354 & 689.95826 & 0.1917 \\
\hline 4 & 735.31910 & 733.76254 & 0.2117 \\
\hline 5 & 814.34517 & 812.68684 & 0.2036 \\
\hline 6 & 845.13057 & 843.81661 & 0.1555 \\
\hline
\end{tabular}

Os autovetores correspondentes as cargas de flambagem podem ser visualizados na Figura 35.

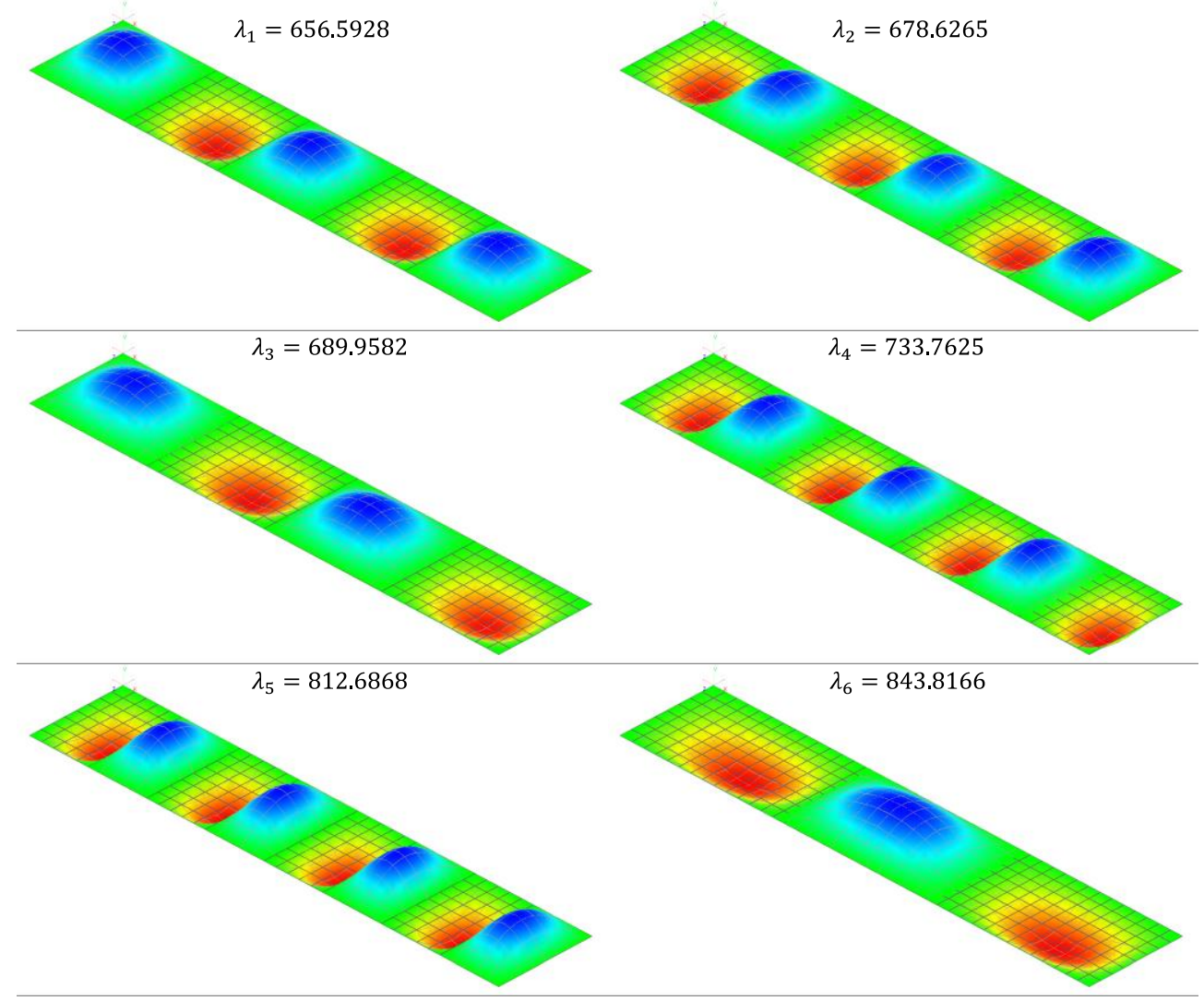

Figura 35: Modos de instabilidade local de chapa

De posse dessas configurações verificasse que os autovalores gerados na análise correspondem aos modos de instabilidade locais ou modos de chapa. Verifica-se também que o modo correspondente a carga crítica é aquela em que as semi-ondas são quadradas e de comprimentos iguais a largura da chapa. Nesse exemplo o modo crítico apresenta cinco semiondas na direção longitudinal, como era de se esperar. 
A medida que os lados da chapa vão sendo liberados verifica-se a transição entre os modos locais para os modos globais conforme a teoria de flambagem de placas.

Liberando-se o apoio de uma das bordas descarregadas, obtém-se a configuração dos chamados flanges, comumente associados as partes enrijecidas dos perfis estruturais (DE SOUZA, 2012). Apesar dos flanges estarem rigidamente ligados as outras partes do perfil, ocorre uma transferência de esforços entre as peças que faz com que o flange perca estabilidade local de maneira forçada.

A solução geral para o problema de instabilidade de flange é apresentada em (TIMOSHENKO e KRIEGER, 1959). A carga crítica é calculada pela equação (7.16), porém, com o valor de $k$ obtido considerando-se uma borda simplesmente apoiada. Esse valor foi derivado por (HUBOLT e STOWEL, 1950) e para placas longas e vale:

$$
k=\frac{1}{6 \pi^{2}}\left[6(1-v)+\left(\frac{m \pi b}{a}\right)^{2}\right]
$$

Na Figura 36 estão apresentadas as seis primeiras cargas críticas para o flange.

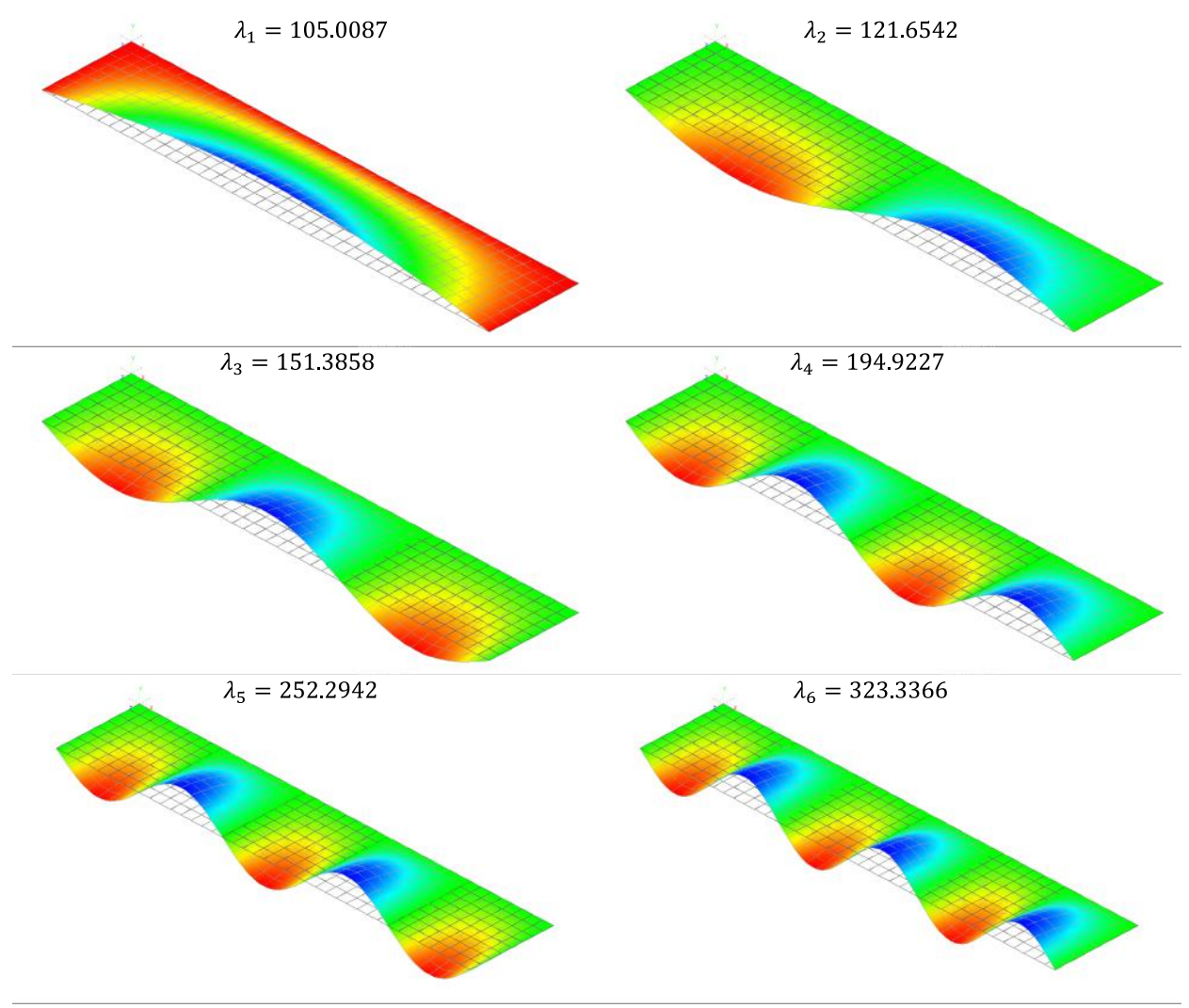


Na Tabela 3 apresentam-se os valores obtidos analítica e numericamente.

Tabela 3: Pontos críticos para o flange simplesmente apoiada

\begin{tabular}{|c|c|c|c|}
\hline Modo & Analítico $(\mathrm{kN})$ & Numérico $(\mathrm{kN})$ & Erro relativo $(\%)$ \\
\hline 1 & 106.57974 & 105.00878 & 1.47397 \\
\hline 2 & 126.31895 & 121.65422 & 3.69281 \\
\hline 3 & 159.21763 & 151.38587 & 4.91890 \\
\hline 4 & 205.27578 & 194.92271 & 5.04349 \\
\hline 5 & 264.49341 & 252.29425 & 4.61227 \\
\hline 6 & 336.87051 & 323.33666 & 4.01752 \\
\hline
\end{tabular}

Liberando-se os dois bordos descarregados tem-se a estrutura denominada de coluna larga, tradução livre de (wide column).

Nesse caso a placa pode ser considerada como uma coluna em que a rigidez a flexão deixa de ser $E I$ e passa a ser calculada pelo produto $D b$, tal que a carga crítica pode ser calculada fazendo-se:

$$
P_{m}=\frac{m^{2} \pi^{2} D b}{a^{2}}
$$

Admitindo-se um coeficiente de Poisson nulo, então $D=E t^{3} / 12$ comprovando que o cálculo da carga de bifurcação pode ser determinado diretamente com a equação de Euler, fazendo-se a inercia da chapa igual a $I=b t^{3} / 12$.

$\mathrm{Na}$ Tabela 4 comparam-se os seis primeiros autovalores obtidos com a biblioteca numérica ARPACK e os calculados com a equação (7.18).

Tabela 4: Cargas de bifurcação da coluna larga

\begin{tabular}{|c|c|c|c|}
\hline Modo & Analítico $(\mathrm{kN})$ & Numérico $(\mathrm{kN})$ & Erro relativo (\%) \\
\hline 1 & 6.5797 & 6.5796 & 0.0021 \\
\hline 2 & 26.3189 & 26.3178 & 0.0044 \\
\hline 3 & 59.2176 & 59.2122 & 0.0092 \\
\hline 4 & 105.2758 & 105.2600 & 0.0150 \\
\hline 5 & 164.4934 & 164.4580 & 0.0215 \\
\hline 6 & 236.8705 & 236.8070 & 0.0268 \\
\hline
\end{tabular}

Na Figura 37 ilustram-se as configurações deformadas (autovetores) e os parâmetros de carga correspondentes (autovalores) para os modos de flexão da coluna. 

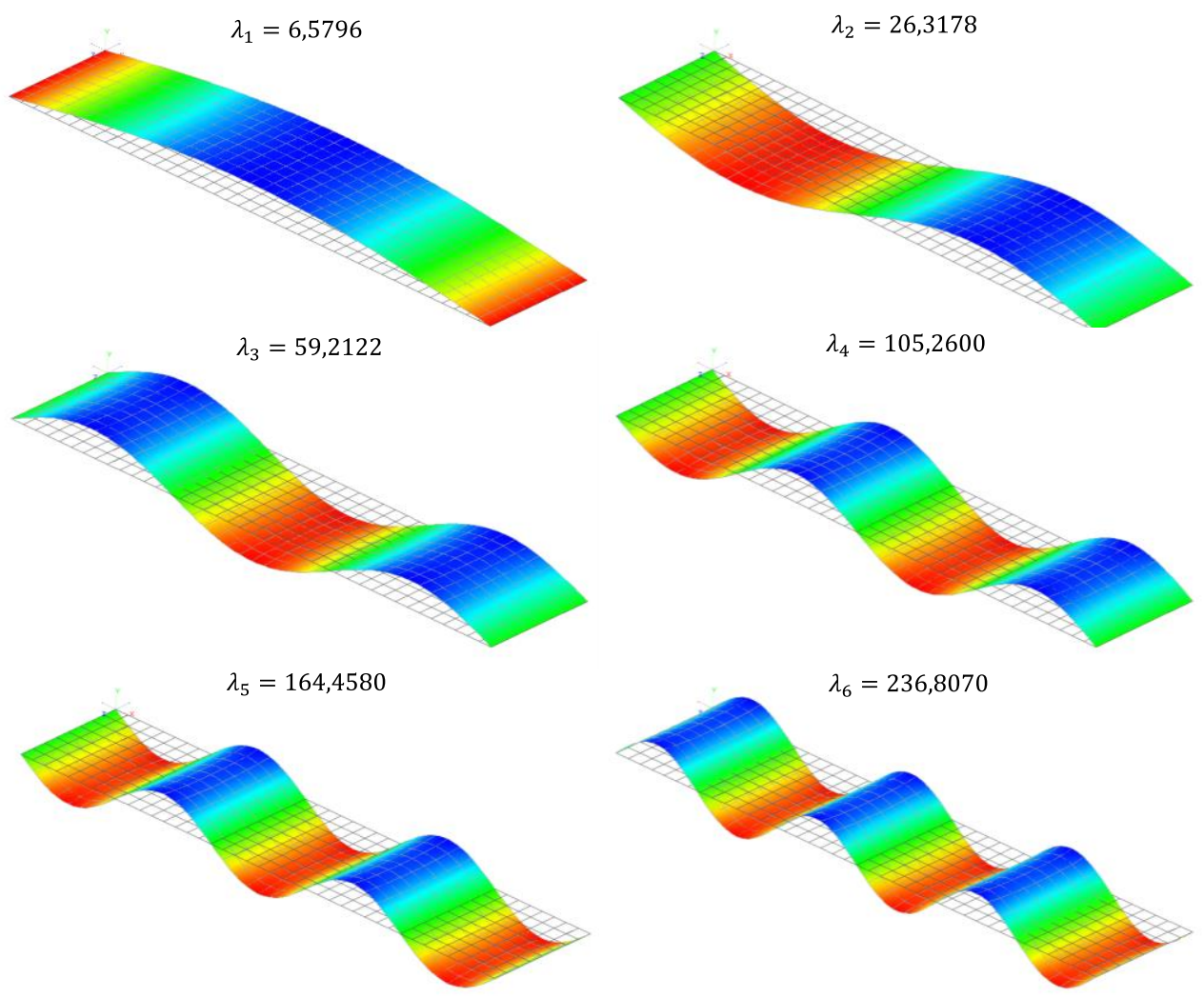

Figura 37: Modos de flambagem a flexão da coluna larga

A trajetória não-linear em grandes deslocamentos é traçada considerando-se uma imperfeição inicial gerada por um carregamento perpendicular ao plano da placa e de intensidade $0,01 \sigma$. As trajetórias de equilíbrio dos deslocamentos em $\mathrm{x}$ do ponto 1 e em y para o ponto 2 estão representadas no gráfico da Figura 38.

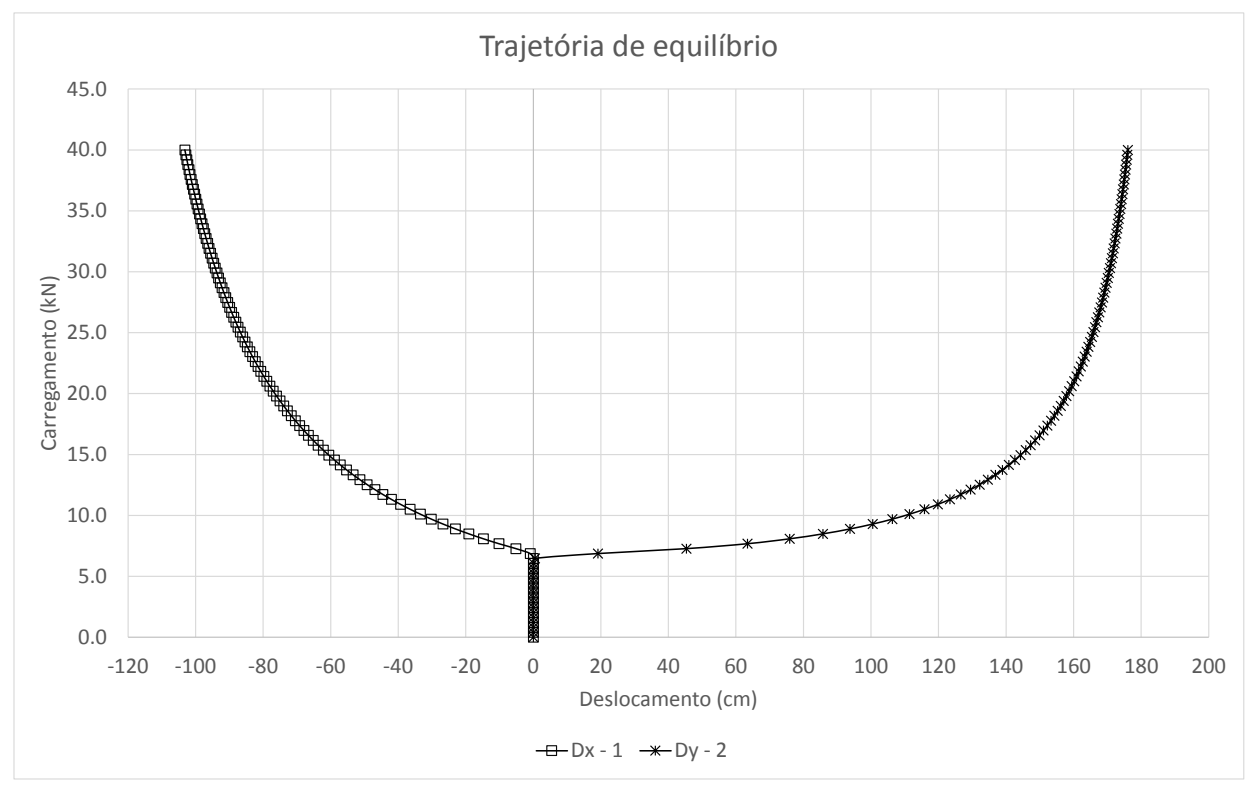


No gráfico da Figura 38 são plotadas as soluções obtidas com o método de NewtonRaphson, com controle de força. Utilizaram-se 100 iterações com passo de carga de $0,4 k N$ e tolerância de $10^{-8}$ para a norma dos deslocamentos.

É possível notar que no ponto de carga crítica $\lambda_{1}=6,5796 \mathrm{kN}$, ambas as curvas apresentam um deslocamento excessivo comprovando a condição de flambagem por flexão, cujas configurações deslocadas no passo final estão ilustradas na Figura 39.

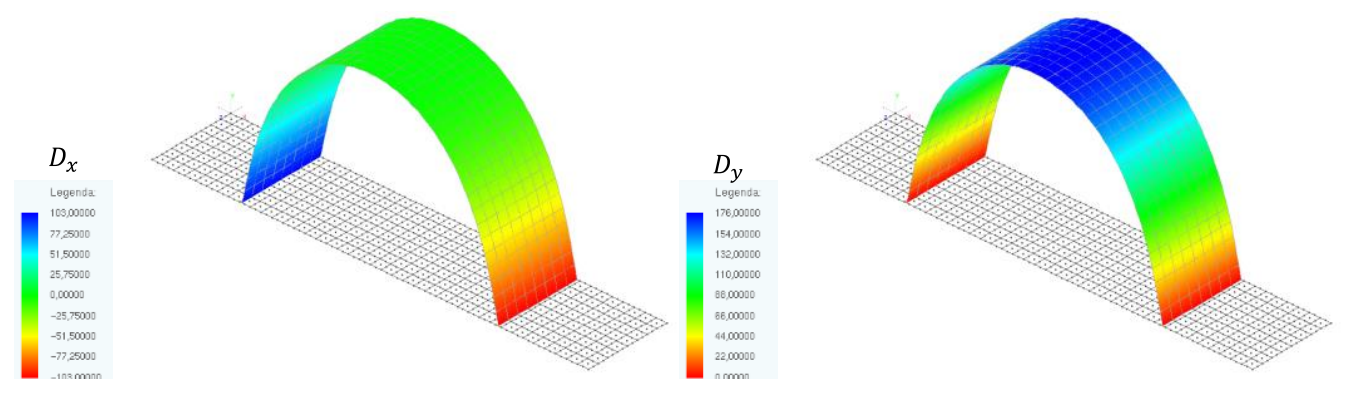

Figura 39: Deslocamentos no passo de carga final para a coluna larga

Nesse exemplo buscou-se mostrar a influência das condições de contorno na transição entre os modos de instabilidade local e global. Essa característica é de grande relevância para o estudo da instabilidade de perfis estruturais de parede fina, uma vez que essas peças são formadas pela composição de chapas delgadas.

No próximo exemplo a metodologia utilizada determinam-se as cargas críticas dos perfis estruturais de parede fina empregando-se a mesma metodologia para o cálculo das cargas críticas com o elemento de casca posicional.

\subsubsection{Instabilidade Estrutural do Perfil C}

Trata-se de um perfil C submetido a compressão uniforme, simplesmente apoiado. No artigo de referência são propostos três tipos de combinações de carregamentos para simular imperfeições geométricas e verificar a influência dessas imperfeições no comportamento pré e pós-crítico da estrutura.

Na Figura 40 ilustra-se as características do modelo. 


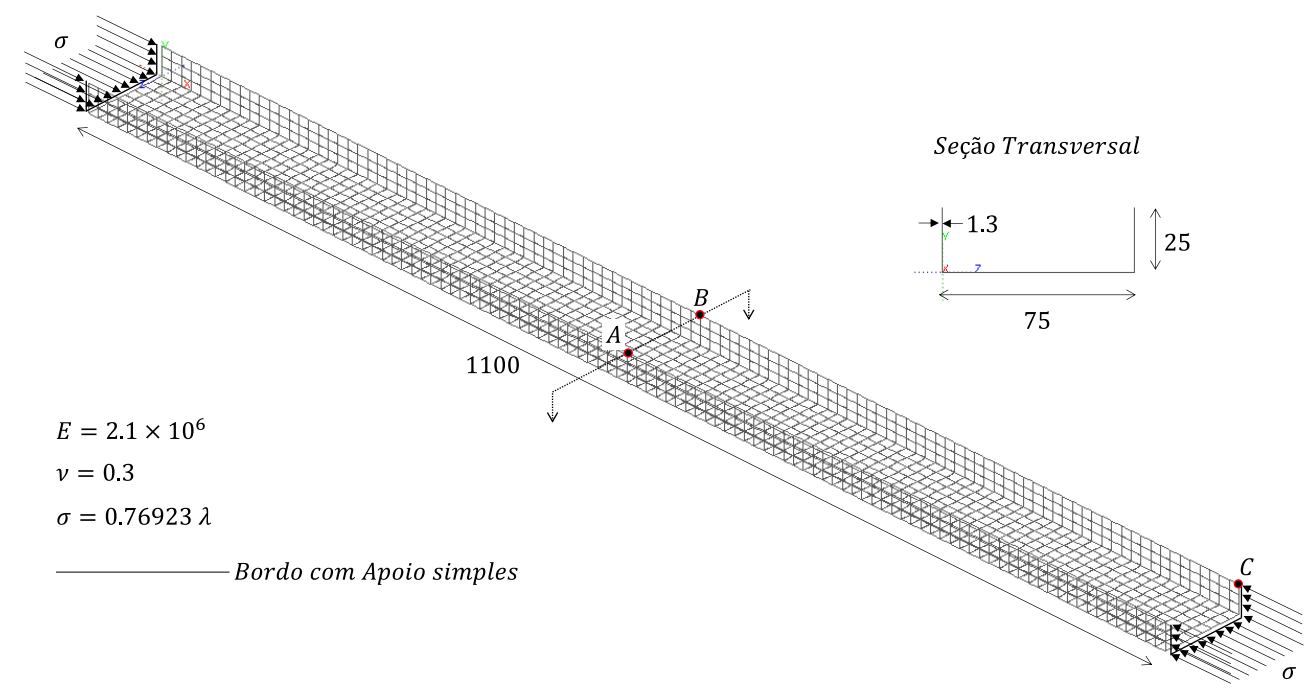

Figura 40: Perfil C sob compressão uniforme

As imperfeições são introduzidas no modelo por meio de uma combinação do carregamento de compressão, com os carregamentos atuando nos flanges do perfil segundo as condições estabelecidas na Figura 41.
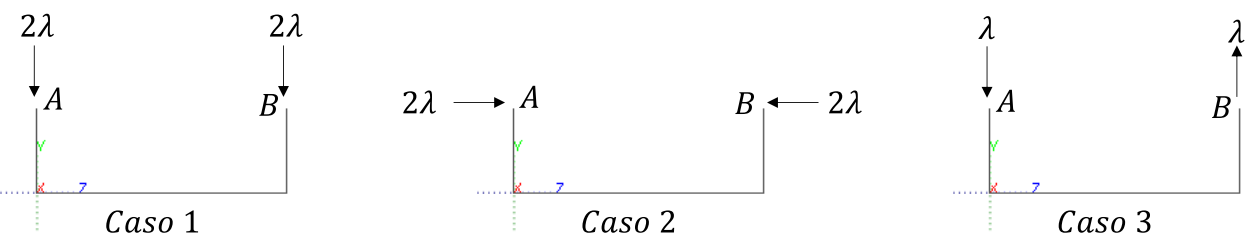

Figura 41: Corte AB. Imperfeições na seção transversal no meio do vão

A seguir apresentam-se as análises para esses casos de carregamentos.

No caso 1 trata-se das imperfeições relativas a flexão. São calculados os autovalores e autovetores do elemento de casca posicional empregando-se a metodologia de decomposição da matriz Hessiana com o algoritmo de Lanczos. Comparam-se os resultados obtidos com a biblioteca ARPACK com a solução apresentada em (GARCEA, 2001) e (GARCEA, MADEO e CASCIARO, 2012). Nos artigos os autores apresentam duas formulações para os elementos de casca segundo a teoria de Koiter e compara os resultados com os valores das simulações realizadas no software NASTRAN.

Esses resultados são reproduzidos na Figura 42, apenas para verificação e comparação, sendo todos os direitos dos resultados atribuídos a (GARCEA, 2001).

Na Figura 42 ilustram-se os resultados de (GARCEA, 2001) para o caso 1. 


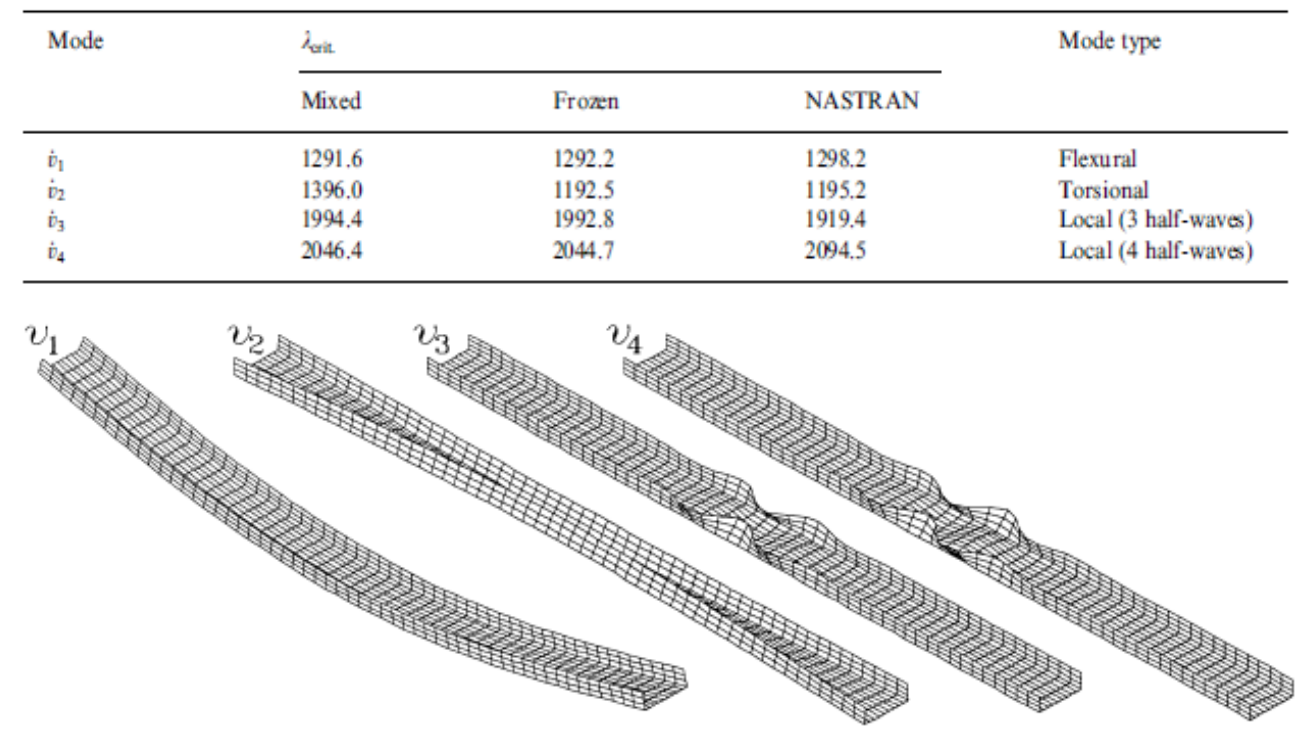

Figura 42: Carga e modos de instabilidade para o caso 1. Fonte: (GARCEA, 2001)

Na Figura 43 ilustram-se os resultados da análise de autovalor e autovetor realizadas com o elemento de casca posicional.

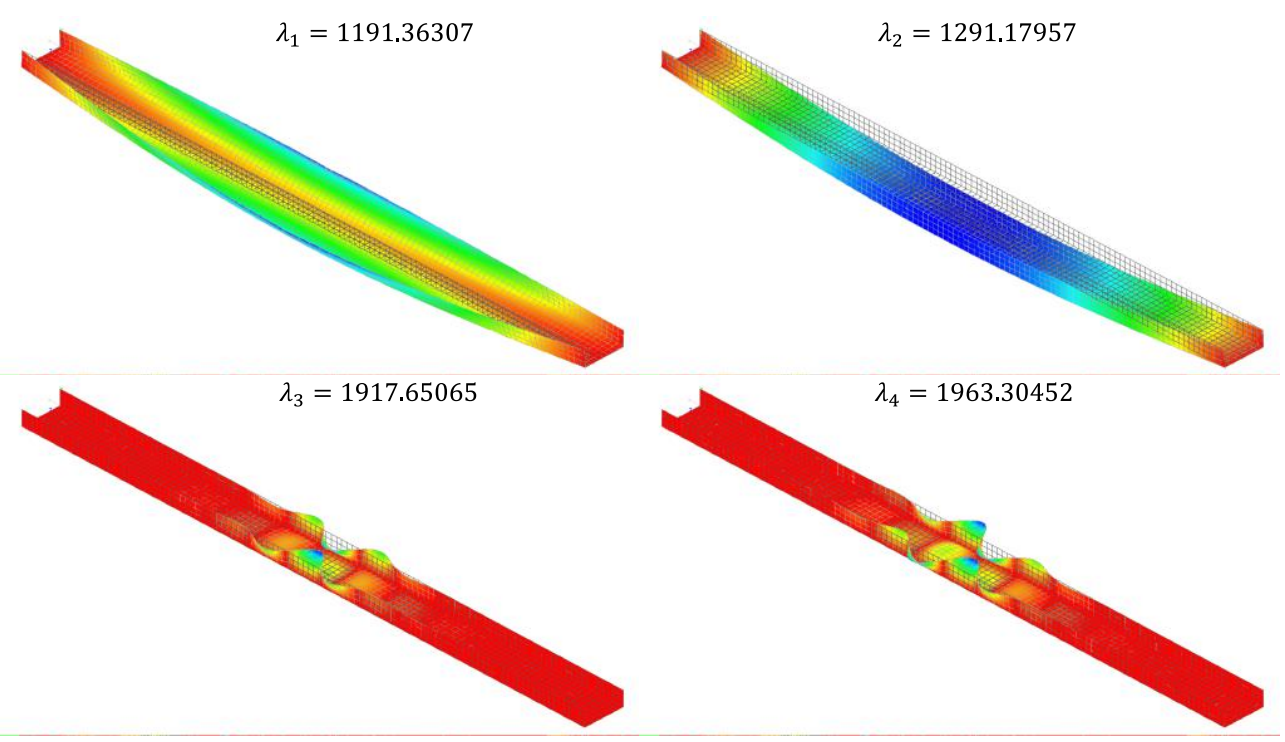

Figura 43: Autovalores e autovetores com elemento de casca posicional, caso 1

Verifica-se que a resposta obtida com a biblioteca ARPACK estão em concordância com os resultados apresentados por (GARCEA, 2001).

Nos gráficos da figura abaixo apresentam-se os resultados da análise pós-crítica em grandes deslocamentos considerando-se a imperfeição inicial indicada no caso 1. Ilustra-se a trajetória de equilíbrio longitudinal do ponto $\mathrm{C}$ obtida com o controle de força do método de Newton-Raphson e os resultados de (GARCEA, 2001) para comparação. 


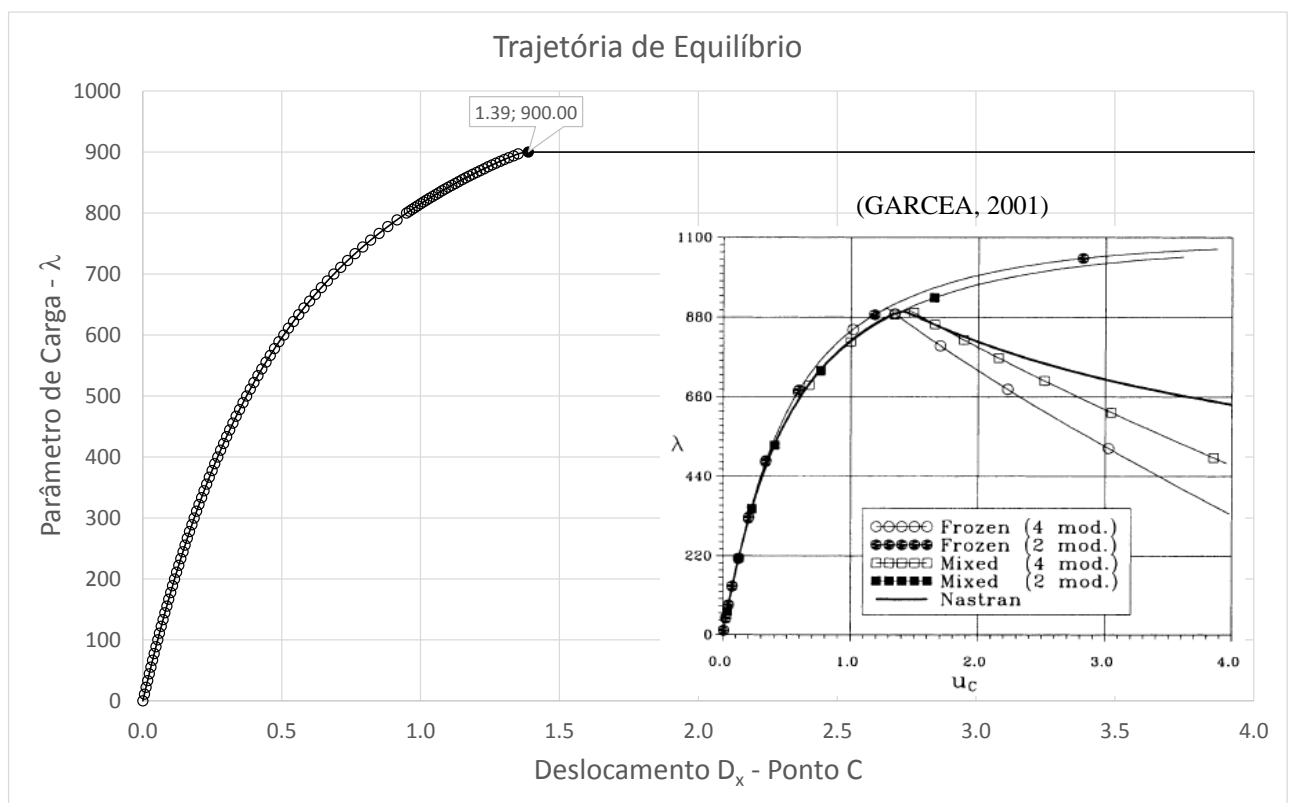

Figura 44: Trajetória de equilíbrio para o caso 1. Resultado da presente pesquisa e de (GARCEA, 2001).

Para se chegara a solução dividiu-se os passos de carregamento em duas etapas. Adotouse esse tipo de estratégia para se chegar o mais próximo possível dos valores representativos do ponto limite, ou seja, os resultados em que matriz Hessiana da estrutura se torna singular. $\mathrm{O}$ valor encontrado para o ponto limite corresponde a $\lambda_{\text {lim }}=900,00$.

Os valores do parâmetro limite de (GARCEA, 2001) estão representados na Figura 45.

\begin{tabular}{lll}
\hline$\lambda_{\max }$ & & \\
\hline Mixed & NASTRAN & Frozen conf. \\
\hline 900.3 & 896.3 & 908.4 \\
\hline
\end{tabular}

Figura 45: Parâmetro de carga limite dos elementos propostos por (GARCEA, 2001). Caso 1

No caso 2 as imperfeições tendem a produzir os modos de instabilidade local de chapa. Os flanges comprimidos são submetidos a um carregamento proporcional fazendo com que ocorra flexão nesses componentes.

Assim como no caso 1, comparam-se as cargas críticas obtidas por (GARCEA, 2001) e a presente pesquisa. A seguir, apresentam-se esses resultados. 


\begin{tabular}{lllll}
\hline \multirow{2}{*}{ Mode } & \multicolumn{2}{l}{} & & Mode type \\
\cline { 2 - 4 } & M & FC & NASTRAN & \\
\hline$\dot{v}_{1}$ & 1293.2 & 1289.9 & 1296.1 & Flexural \\
$\dot{v}_{2}$ & 1409.5 & 1387.7 & 1391.2 & Torsional \\
$\dot{v}_{3}$ & 3150.7 & 3134.3 & 3084.8 & Local (13 half-waves) \\
$\dot{v}_{4}$ & 3150.9 & 3148.6 & 3097.4 & Local (14 half-waves) \\
\hline
\end{tabular}

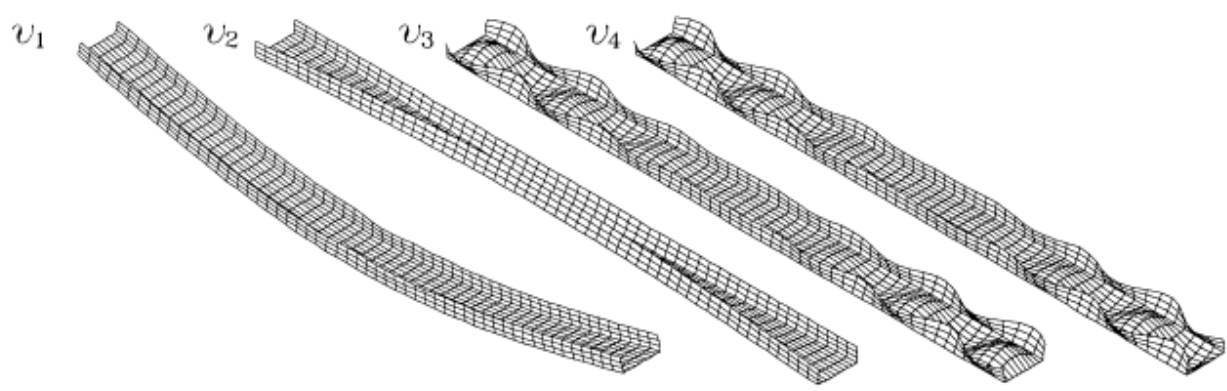

Figura 46: Carga e modos de instabilidade para o caso 2. Fonte: (GARCEA, 2001)

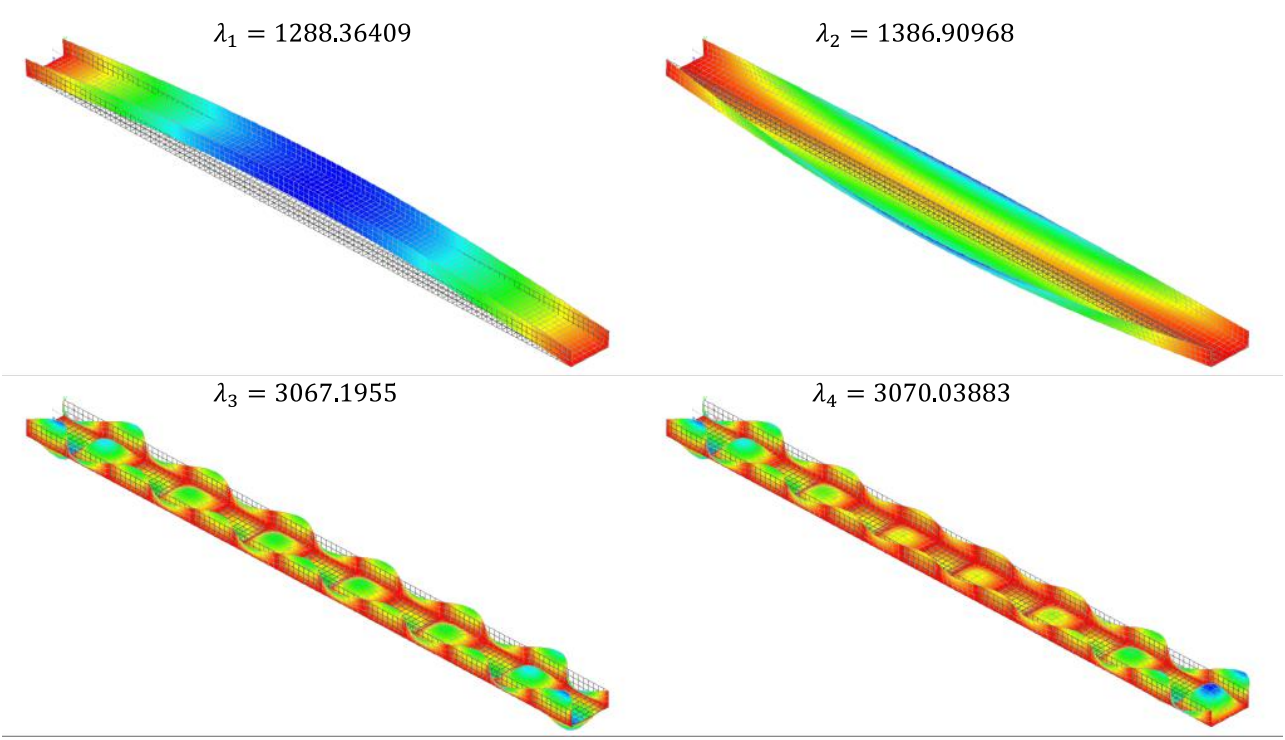

Figura 47: Autovalores e autovetores com elemento de casca posicional. Caso 2

Nota-se que os autovetores da Figura 47 são simétricos em relação aos apresentados na Figura 46. Essa condição não implica em erros nas respostas, pois o autovetor indica apenas a direção da flambagem e independe do sinal encontrado para o autovetor em questão.

Com a análise pós-crítica empregando-se o controle de forças do método de NewtonRaphson, o valor do parâmetro de carregamento limite é apresentado no gráfico da Figura 48. Esse valore corresponde ao parâmetro limite $\lambda_{\text {lim }}=1228,28$. 


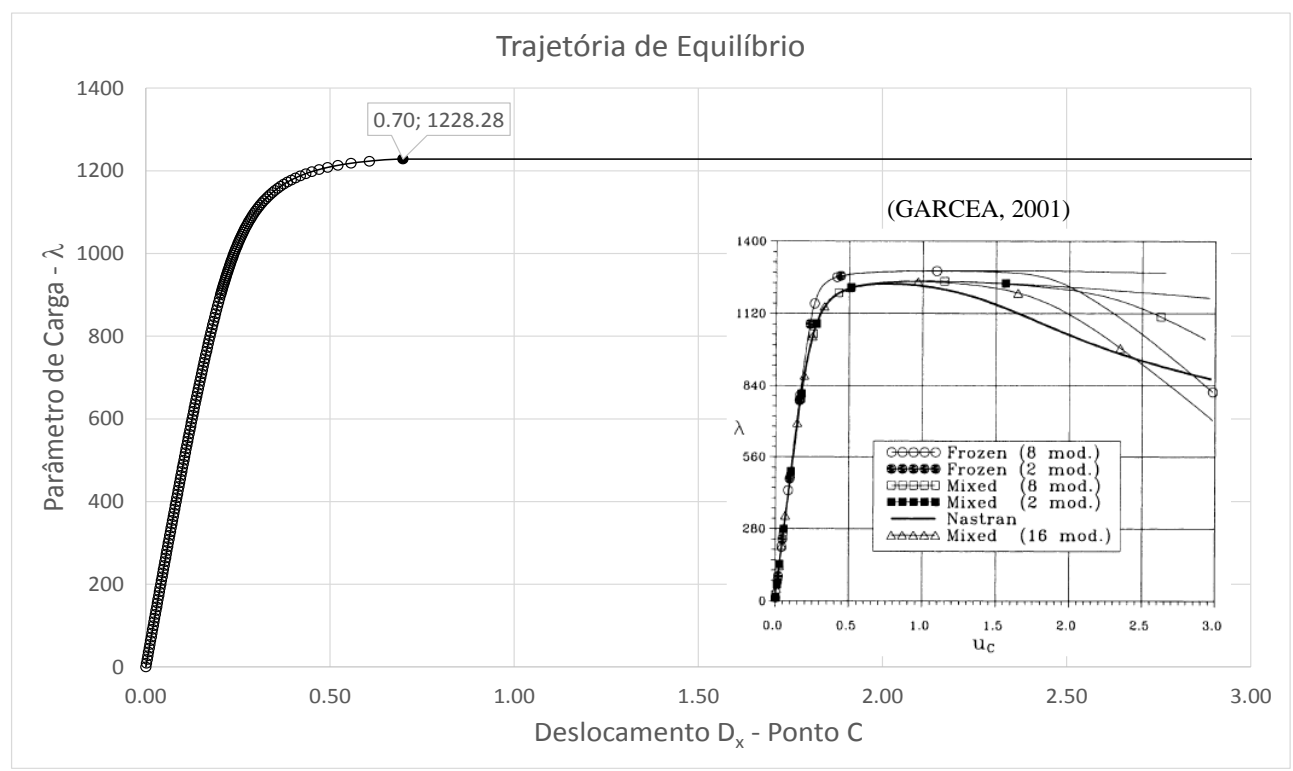

Figura 48: Trajetória de equilíbrio para o caso 2. Resultado da presente pesquisa e de (GARCEA, 2001)

Os resultados obtidos por (GARCEA, 2001) são apresentados na Figura 49:

\begin{tabular}{lll}
\hline$\lambda_{\text {lim }}$ & & \\
\hline $\mathrm{M}$ & $\mathrm{FC}$ & NASTRAN \\
\hline 1246.1 & 1284.8 & 1235.42 \\
\hline
\end{tabular}

Figura 49: Parâmetro de carga limite dos elementos propostos por (GARCEA, 2001). Caso 2

Finalmente, analisando-se o caso 3, em que o carregamento dos flanges induz imperfeições torcionais no perfil. Os resultados apresentados no artigo de referência são resumidos na Figura 50.

\begin{tabular}{lllll}
\hline \multirow{2}{*}{ Mode } & \multicolumn{2}{c}{} & & Mode type \\
\cline { 2 - 4 } & M & FC & NASTRAN & \\
\hline$\dot{v}_{1}$ & 1264.9 & 1289.9 & 1296.0 & \\
$\dot{i}_{2}$ & 1833.9 & 1711.8 & 1715.6 & Flexural \\
$\dot{i}_{3}$ & 2808.5 & 2912.1 & 2842.4 & Torsional \\
$\dot{t}_{4}$ & 2823.9 & 2930.0 & 2863.5 & Local (7 half-waves) \\
\hline
\end{tabular}

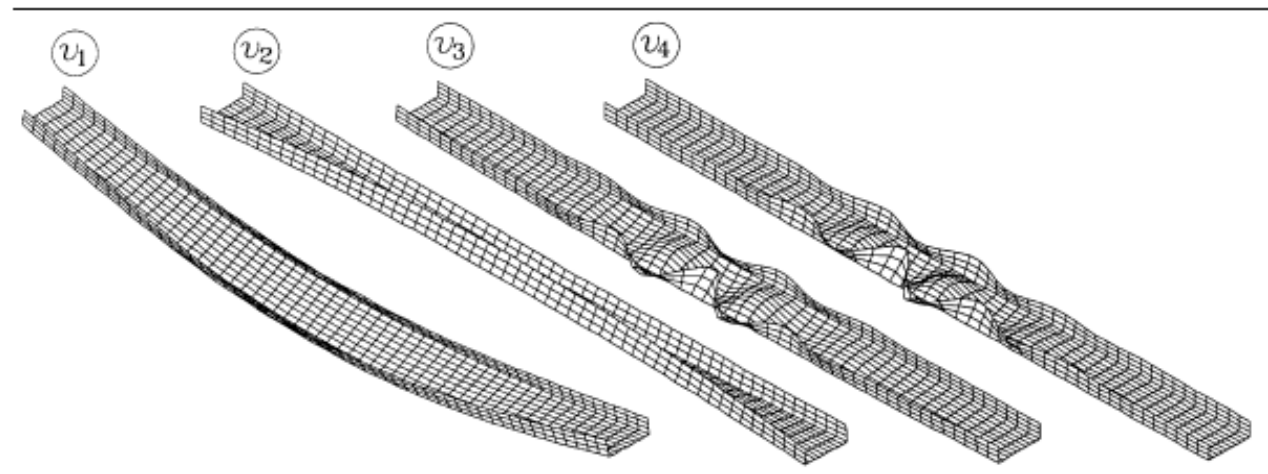


Os valores críticos obtidos na presente pesquisa estão ilustrados na Figura 51.

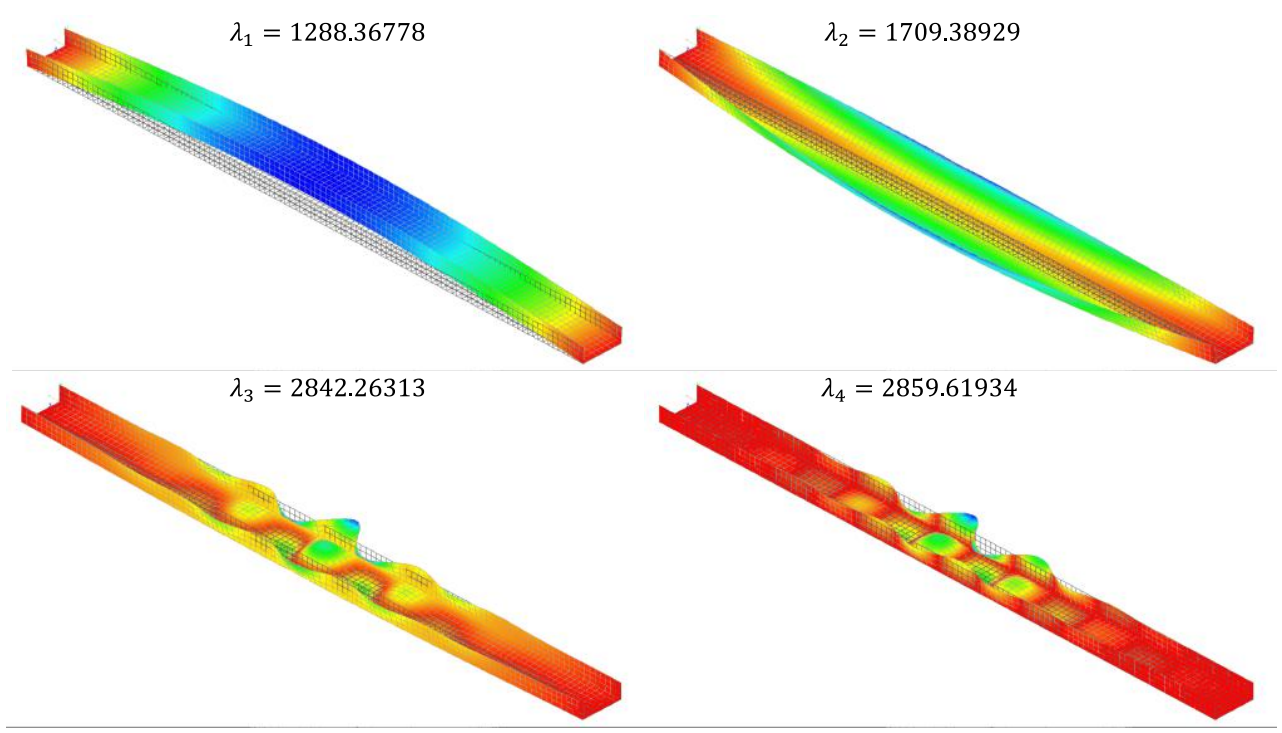

Figura 51: Autovalores e autovetores com elemento de casca posicional. Caso 2

Verifica-se a concordância da formulação posicional, inclusive se comparado os resultados com a simulação no programa NASTRAN, como mostrado nos resultados de (GARCEA, 2001).

$\mathrm{Na}$ análise em grandes deslocamentos o parâmetro de carga é $\lambda_{\text {lim }}=1132,32$, cuja trajetória de equilíbrio e o ponto limite estão ilustrados no gráfico da Figura 52.

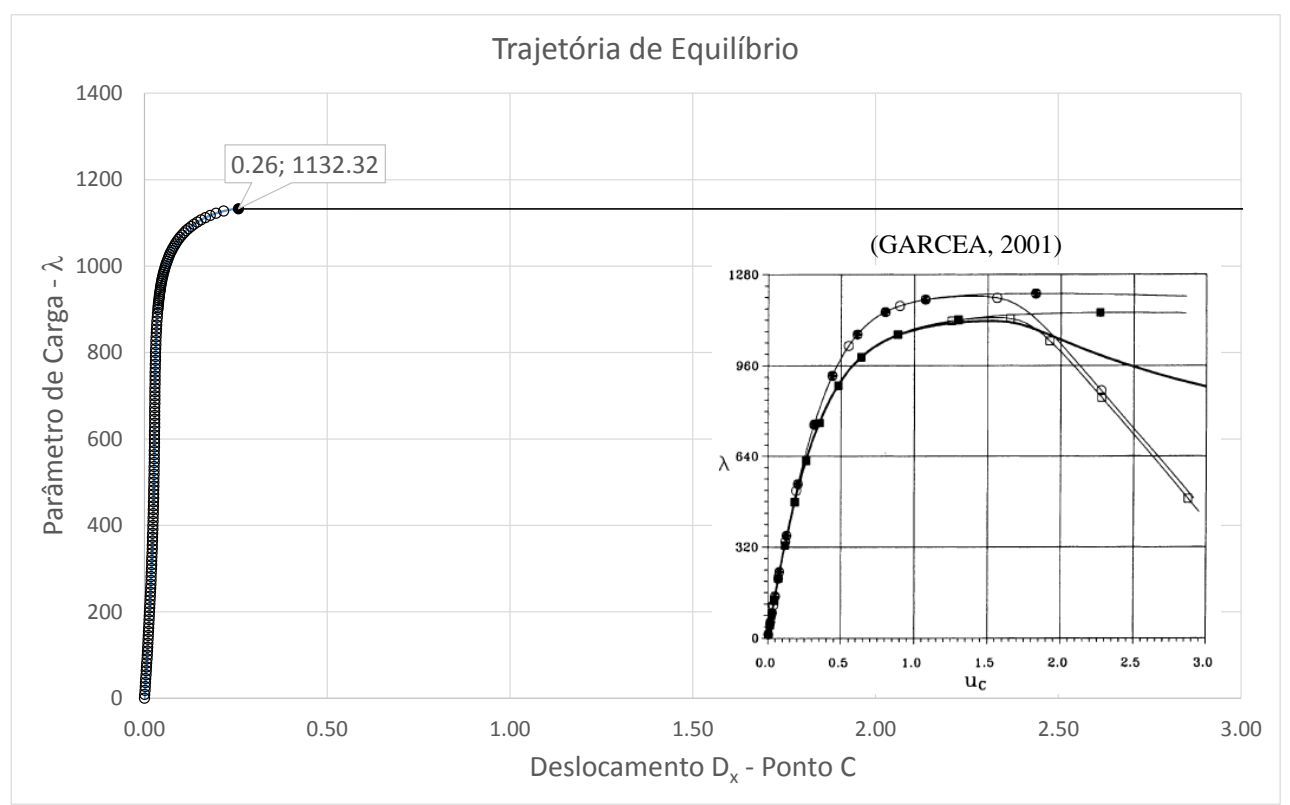

Figura 52: Trajetória de equilíbrio para o caso 3. Resultado da presente pesquisa e de (GARCEA, 2001) 
Os valores do artigo de referência podem ser verificados na Figura 53.

\begin{tabular}{lll}
\hline$\lambda_{\text {lim }}$ & & \\
\hline $\mathrm{M}$ & $\mathrm{FC}$ & NASTRAN \\
\hline 1128.67 & 1204.17 & 1116.96 \\
\hline
\end{tabular}

Figura 53: Parâmetro de carga limite dos elementos propostos por (GARCEA, 2001). Caso 3

Nesse último caso o elemento de casca posicional apresentou trajetória mais rígida do que as respostas apresentadas no artigo de referência, porém, com o valor do parâmetro de carregamento limite, adequadamente próximo.

Observa-se claramente a boa adequação dos resultados da análise de autovalores e autovetores com o elemento de casca posicional. Apesar de se notar pequenas diferenças em relação as respostas do trabalho de referência, justificáveis pelo fato do autor empregar um elemento finito com cinemática completamente diferentes da apresentada neste trabalho, fica evidente a aplicabilidade do elemento de casca posicional em simular problemas de instabilidade linear e no regime pós-critico.

\subsection{Fechamento}

Neste capítulo foi apresentada a formulação cinemática do elemento de casca posicional não-linear geométrico. Utilizou-se esse elemento para se realizar análises lineares de instabilidade de estruturas compostas por chapas tridimensionais. Empregou-se o cálculo dos autovalores e autovetores a partir da metodologia de decomposição da matriz Hessiana para a determinação dos pontos de bifurcação. Adotou-se o controle do determinante da própria matriz Hessiana não linear para se realizar uma análise não linear de instabilidade verificando-se o exato parâmetro de carga limite, para o qual a matriz torna-se singular. Foram realizadas também a nas análises pós-críticas em grandes deslocamentos comparando-se os resultados com soluções analíticas e exemplos extraídos da literatura técnica especializada.

Pode-se concluir, dentro das expectativas das análises propostas, que os resultados obtidos com o elemento de casca posicional atende adequadamente as necessidades do estudo da instabilidade de estruturas tridimensionais. 



\section{Elemento Finito de Barra Geral}

\subsection{Apresentação do Capítulo}

Neste capítulo apresenta-se o mapeamento tridimensional do elemento finito posicional de barra geral não linear geométrico e seus aprimoramentos. Propõem-se um enriquecimento cinemático capaz de considerar as mobilidades no plano e fora do plano da seção transversal, de modo a captar a perda de estabilidade local de perfis estruturais de parede fina.

Realiza-se as análises linear de instabilidade empregando-se a metodologia de decomposição da matriz Hessiana e o cálculo dos autovalores e autovetores. Análises póscríticas em grandes deslocamentos também são efetuadas considerando-se o caminho de equilíbrio das estruturas com imperfeições geométricas.

Exemplos são propostos afim de se comparar os resultados gerados com a teoria linear de instabilidade e o comportamento pós-críticas em grandes deslocamentos.

\subsection{Mapeamento em Posições e Vetores Generalizados}

O mapeamento em posições e vetores generalizados é uma forma alternativa de descrever os pontos materiais dos sólidos tridimensionais. Neste trabalho, os graus de liberdade em posições e vetores generalizados são utilizados com o objetivo de descrever a cinemática de sólidos tridimensional de estruturas e elementos estruturais de barras prismáticas.

Ao se empregar essa representação, nenhuma restrição é feita ao sistema de coordenadas utilizados na descrição do contínuo. Por essa razão, o mapeamento é dito invariante à transformação de coordenadas e por isso é uma medida objetiva da posição e dos vetores generalizados (CODA e GRECO, 2004). Com essas considerações elimina-se a necessidade de se utilizar esquemas de deslocamentos e rotações finitas como na proposta do elemento finito co-rotacional introduzido por (BELYTSCHKO e HSIEH, 1973).

De posse dessa propriedade é possível definir um conjunto de coordenadas generalizadas no espaço de configuração, com um número finito de graus de liberdade (SYMON, 1960). Aqui, o espaço de configurações possui o mesmo significado que a transformação (ou função mudança de configuração) da mecânica dos sólidos deformáveis. 
No trabalho de (CODA, 2009) o elemento finito tridimensional é representado por pontos materiais do meio contínuo mapeados sobre uma linha de referência e uma seção transversal correspondente. A Figura 54 ilustra o mapeamento geométrico do ponto $P$ para o caso particular em que a linha de referência é representada por um elemento finito unidimensional reto com aproximação quadrática e seção transversal com oito elementos finitos triangulares de aproximação linear.

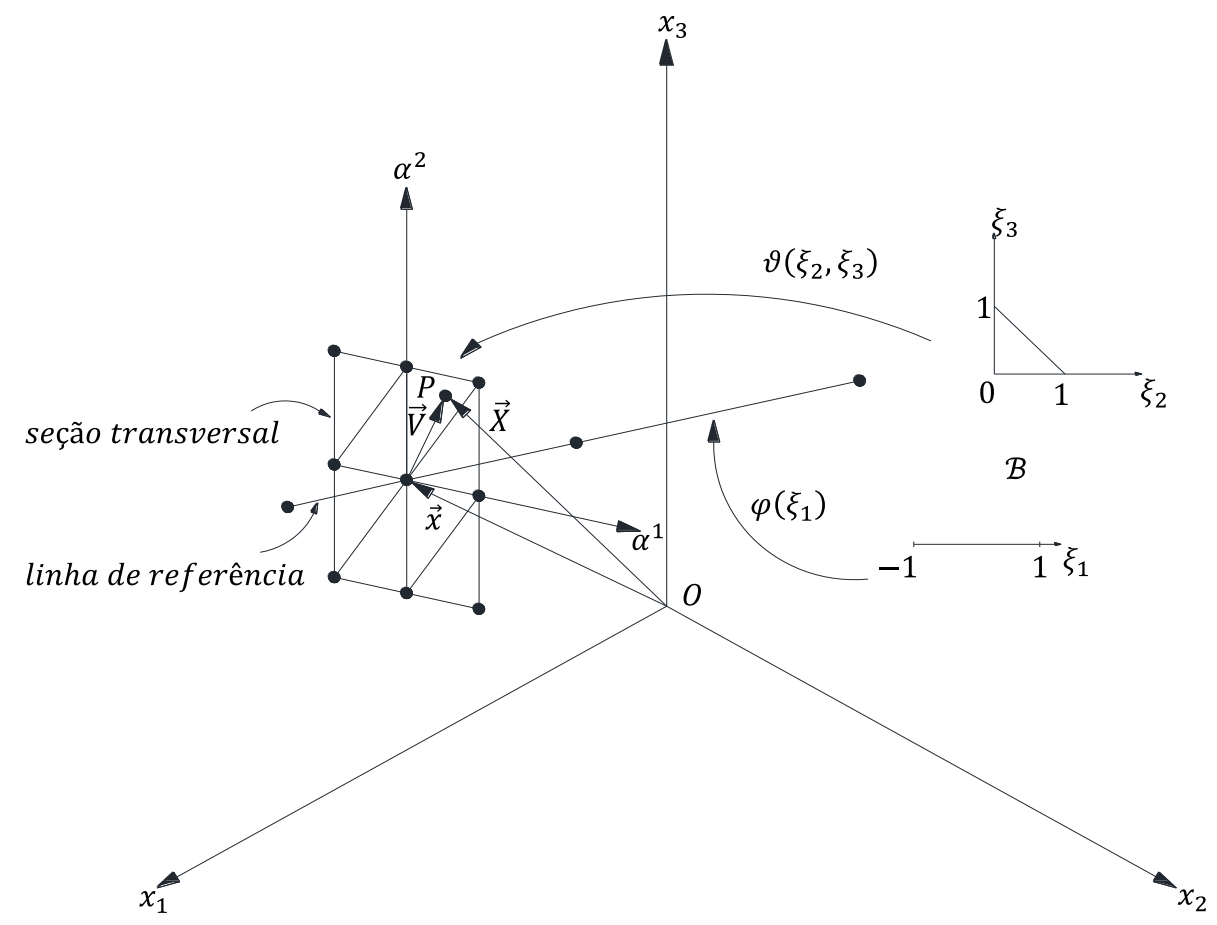

Figura 54: Mapeamento em posições e vetores generalizados

Empregando-se o mapeamento em posição e vetores generalizados qualquer ponto material do sólido pode ser determinado com a equação:

$$
X_{i}(P)=\varphi_{j}\left(\xi_{1}\right) x_{i j}+\left[\vartheta_{k}\left(\xi_{2}, \xi_{3}\right) \alpha_{k}^{1}\right] \varphi_{j}\left(\xi_{1}\right) v_{i j}^{1}+\left[\vartheta_{k}\left(\xi_{2}, \xi_{3}\right) \alpha_{k}^{2}\right] \varphi_{j}\left(\xi_{1}\right) v_{i j}^{2}
$$

Com esse tipo de cinemática é possível considerar a seção transversal com qualquer geometria, além de ser possível empregar a relação constitutiva tridimensional completa.

O primeiro termo da representa o mapeamento da linha de referência através da função de forma $\varphi_{j}\left(\xi_{1}\right)$, sendo $\xi_{1}$ a coordenada do espaço adimensional. Os vetores $v_{i j}^{1}$ e $v_{i j}^{2}$ formam a base do espaço bidimensional empregado na descrição da seção transversal. 
A geometria da seção é representada por meio das coordenadas auxiliares $\alpha_{k}^{1}$ e $\alpha_{k}^{2}$, conhecidas e invariantes durante a deformação, característica da formulação Lagrangiana. As funções de forma bidimensionais $\vartheta_{k}\left(\xi_{2}, \xi_{3}\right)$ são usadas para descrever as coordenadas materiais da seção, sendo $\xi_{2}$ e $\xi_{3}$ as coordenadas adimensionais auxiliares.

Neste trabalho é possível que a linha de referência e a seção transversal sejam aproximadas com elementos finitos de ordem qualquer. No apêndice A apresenta-se a metodologia utilizada na geração das funções de forma de ordem qualquer.

Esta forma de descrever o contínuo resulta em nove graus de liberdade para cada nó da linha de referência, sendo três componentes para as posições da linha de referência, três componentes para cada um dos vetores base que definem a seção trasversal, resultando no seguinte conjunto de graus de liberdade generalizados:

$$
q_{i}=\left\{x_{1}, x_{2}, x_{3}, v_{1}^{1}, v_{2}^{1}, v_{3}^{1}, v_{1}^{2}, v_{2}^{2}, v_{3}^{2}\right\}
$$

Portanto, existem seis graus de liberdade adicionais em relação à formulação clássica. Essas mobilidades proporcionam ao elemento maior flexibilidade cinemática permitindo que a seção transversal se deforme sob a ação das tensões cisalhantes (CODA e PACCOLA, 2010).

Neste ponto é possível notar que os graus de liberdade diferem das grandezas físicas clássicas, como deslocamentos e rotações, sendo grandezas mais gerais e dependentes da posição dos pontos materiais.

É importante destacar que para a configuração indeformada assume-se, por simplicidade, que os vetores generalizados sejam unitários e ortogonais a linha de referência, além de ortogonais entre seus pares. Porém, essa consideração não é imposta na configuração deformada, pois tais vetores são incógnitos ao problema, como será apresentado na próxima seção. No apêndice B é descrita a metodologia de obtenção dos vetores generalizados, justificando a condição de ortonormalidade assumida na configuração inicial.

\subsection{Função Mudança de Configuração}

Como mencionado na seção anterior nenhuma restrição é feita aos vetores na configuração deformada. Nessa configuração, os vetores não são unitários nem ortogonais em 
relação à linha de referência e entre seus pares, daí a denominação vetores generalizados. Esses vetores podem assumir qualquer configuração, o que equivale a tratar a barra por meio da hipótese cinemática de Timoshenko, no qual as tensões de cisalhamento deformam a seção transversal durante a flexão. A Figura 55 ilustra a versão tridimensional do mapeamento do elemento de barra geral equivalente.

A Figura 55 mostra um elemento quadrático na linha de referência e linear na seção transversal. É de interesse salientar que os elementos são de aproximação qualquer, sendo o analista responsável por determinar a ordem de aproximação desejada para os elementos. Na Figura 55 são ilustrados também os elementos finitos que descrevem a linha de referência e a seção transversal nas configurações inicial e deformada.

Ainda com relação a Figura 55, as quantidades $\vec{F}$ e $\boldsymbol{A}$ representam o mapeamento da transformação e seu gradiente, respectivamente. As quantidades $\vec{f}^{0}$ e $\vec{f}^{1}$ representam o mapeamento da transformação na configuração inicial e atual, respectivamente. Análogo para $\boldsymbol{A}^{0}$ e $\boldsymbol{A}^{1}$ que representam os gradientes dessas transformações.

Os índices sobrescritos representam a configuração inicial $(.)^{0}$ e atual $(.)^{1}$.

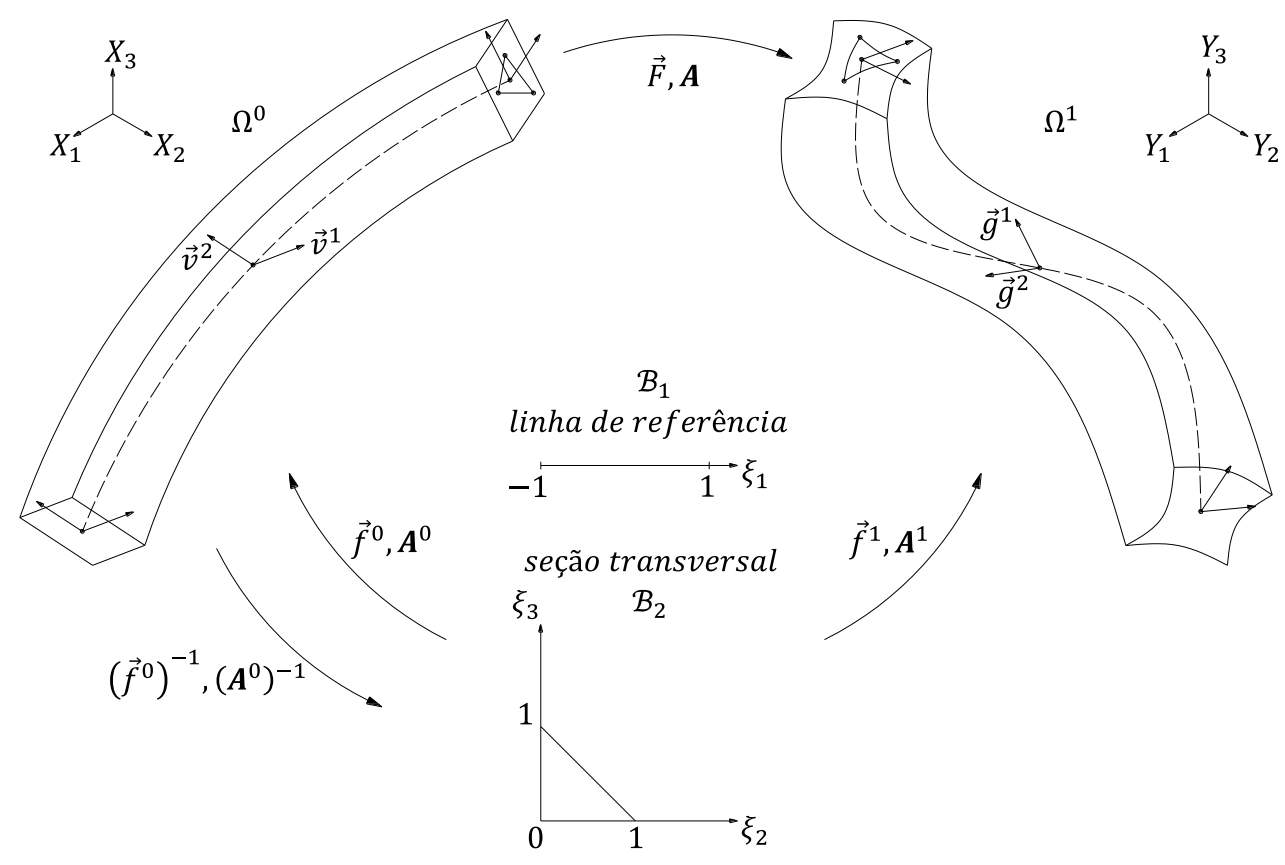

Figura 55: Elemento de barra geral na configuração inicial e atual 
As posições e vetores generalizados passam a ser as novas incógnitas do problema, determinados após o equilíbrio da estrutura:

Na configura corrente o mapeamento dos pontos do contínuo é dado ela equação:

$$
Y_{i}(P)=\varphi_{j}\left(\xi_{1}\right) y_{i j}+\left[\vartheta_{k}\left(\xi_{2}, \xi_{3}\right) \alpha_{k}^{1}\right] \varphi_{j}\left(\xi_{1}\right) g_{i j}^{1}+\left[\vartheta_{k}\left(\xi_{2}, \xi_{3}\right) \alpha_{k}^{2}\right] \varphi_{j}\left(\xi_{1}\right) g_{i j}^{2}
$$

\subsection{Aprimoramentos na Cinemática da Seção Transversal}

Para (BISCHOFF e RAMM, 2000) o travamento volumétrico é produzido pelas tensões de cisalhamento que ocorrem no elemento quando se adotam uma relação constitutiva tridimensional completa e cinemática flexível ao cisalhamento, como na cinemática de barra geral de Timoshenko. Tendo em vista a metodologia em coordenadas generalizadas utilizadas nesse trabalho o mapeamento dos pontos do contínuo se deformam de maneira equivalente a cinemática de Timoshenko, portanto, susceptível ao efeito de travamento volumétrico.

Para (CODA, 2009) o travamento volumétrico ocorre devido à influência do coeficiente de Poisson na relação constitutiva tridimensional devido a diferença entre as aproximações adotadas para as deformações normais e de cisalhamento da seção. Para corrigir esse problema o autor propõe uma variação quadrática dos deslocamentos dos nós da seção.

A fim de elucidar a proposta de aprimoramento, no próximo item, apresenta-se a metodologia desenvolvida por (CODA, 2009).

\subsubsection{Aprimoramento nas Deformações transversais}

É importante ressaltar que esse aprimoramento não muda as dimensões da seção transversal, apenas permite que as deformações transversais variem linearmente a partir da linha de referência em direção as extremidades da seção. Esse aprimoramento implica movimentação quadrática dos pontos e garante um comportamento de meio contínuo para a seção transversal.

A flexibilidade cinemática das deformações transversais é expressas modificando-se a equação (8.3), inserindo-se a variação quadrática das deformações. A nova função passa a ser escrita como: 


$$
\begin{aligned}
& Y_{i}(P)=\varphi_{j}\left(\xi_{1}\right) y_{i j}+ \\
& {\left[\vartheta_{k}\left(\xi_{2}, \xi_{3}\right) \alpha_{k}^{1}\right] \varphi_{j}\left(\xi_{1}\right) g_{i j}^{1}+} \\
& {\left[\vartheta_{k}\left(\xi_{2}, \xi_{3}\right) \alpha_{k}^{2}\right] \varphi_{j}\left(\xi_{1}\right) g_{i j}^{2}+} \\
& \left\{\left[\vartheta_{k}\left(\xi_{2}, \xi_{3}\right) \alpha_{k}^{1}\right]^{2}\left[\varphi_{\ell}\left(\xi_{1}\right) a_{\ell}^{1}\right]\right\} \varphi_{j}\left(\xi_{1}\right) g_{i j}^{1}+ \\
& \left\{\left[\vartheta_{k}\left(\xi_{2}, \xi_{3}\right) \alpha_{k}^{2}\right]^{2}\left[\varphi_{\ell}\left(\xi_{1}\right) a_{\ell}^{2}\right]\right\} \varphi_{j}\left(\xi_{1}\right) g_{i j}^{2}
\end{aligned}
$$

Sendo, $a_{\ell}^{1}$ e $a_{\ell}^{2}$ os parâmetros nodais capazes de medir a intensidade com que variam as deformações transversais da seção. Vale a pena frisar a generalidade do novo parâmetro, o que justifica adotar a denominação graus de liberdade generalizados.

Com a intenção de flexibilizar a seção da barra para deformações fora do plano (CODA e PACCOLA, 2010) propõem o aprimoramento relativo ao modo de empenamento, o qual está descrito na próxima seção.

\subsubsection{Aprimoramento Devido ao Modo de Empenamento}

Barras com seções abertas de parede fina e seções monossimetricas com o centro de torção não coincidente com o centroide sofrem torção quando submetidos a carregamentos transversais. Na teoria clássica de Euler assim como a hipótese de Timoshenko para barras gerais não são suficientes para prever o efeito de empenamento induzido pela torção.

Devido às restrições das deformações fora do plano da seção, a cinemática da equação (8.4) não é totalmente destituída do fenômeno de travamento, principalmente se esta induz o empenamento na seção. Para corrigir essa deficiência, (CODA e PACCOLA, 2010) introduzem uma nova mobilidade no elemento de barra geral, capaz de detectar a intensidade do empenamento.

O modo de empenamento é obtido a partir da teoria da torção livre, ou torção de SaintVenant, calculada para um giro unitário na seção transversal. Apesar da rotação ser limitada a um valor unitário, isso não implica em simplificações na cinemática do elemento, pois o modo de empenamento deve ser entendido um novo grau de liberdade generalizado.

O empenamento da seção transversal $\bar{w}$ é obtido interpolando-se os deslocamentos longitudinais devido o giro unitário de torção, medido em cada nó da seção transversal: 


$$
\bar{w}\left(\xi_{2}, \xi_{3}\right)=\vartheta_{k}\left(\xi_{2}, \xi_{3}\right) w_{k}
$$

Sendo, $w_{k}$ o vetor que contém os deslocamentos dos nós da seção. As direções dos deslocamentos fora do plano, segundo a direção $n_{i}$ são calculadas a partir do produto vetorial:

$$
n_{i}\left(\xi_{1}\right)=\left[\varphi_{a}\left(\xi_{1}\right) g_{a p}^{1}\right]\left[\varphi_{b}\left(\xi_{1}\right) g_{b q}^{2}\right] \varepsilon_{p q i}
$$

Com $\varepsilon_{p q i}$ o símbolo permutador de Levi-Civita.

O empenamento ao longo do eixo de referência do elemento de barra geral é determinado inserindo-se o novo parâmetro nodal $\varpi_{j}$.

$$
\mathrm{W}_{i}\left(\xi_{1}, \xi_{2}, \xi_{3}\right)=\left[\vartheta_{k}\left(\xi_{2}, \xi_{3}\right) w_{k}\right]\left[\varphi_{j}\left(\xi_{1}\right) \varpi_{j}\right] n_{i}\left(\xi_{1}\right)
$$

Esse parâmetro quantifica a intensidade do deslocamento de um ponto material qualquer fora do plano da seção e é capaz de considerar a influência da não linearidade geométrica sobre o empenamento unitário.

A cinemática do elemento de barra geral com a consideração do empenamento é obtida adicionando a contribuição das deformações da seção transversal na cinemática do elemento de barra resultando:

$$
\begin{aligned}
& Y_{i}(P)=\varphi_{j}\left(\xi_{1}\right) y_{i j}+ \\
& {\left[\vartheta_{k}\left(\xi_{2}, \xi_{3}\right) \alpha_{k}^{1}\right] \varphi_{j}\left(\xi_{1}\right) g_{i j}^{1}+} \\
& {\left[\vartheta_{k}\left(\xi_{2}, \xi_{3}\right) \alpha_{k}^{2}\right] \varphi_{j}\left(\xi_{1}\right) g_{i j}^{2}+} \\
& \left\{\left[\vartheta_{k}\left(\xi_{2}, \xi_{3}\right) \alpha_{k}^{1}\right]^{2}\left[\varphi_{\ell}\left(\xi_{1}\right) a_{\ell}^{1}\right]\right\} \varphi_{j}\left(\xi_{1}\right) g_{i j}^{1}+ \\
& \left\{\left[\vartheta_{k}\left(\xi_{2}, \xi_{3}\right) \alpha_{k}^{2}\right]^{2}\left[\varphi_{\ell}\left(\xi_{1}\right) a_{\ell}^{2}\right]\right\} \varphi_{j}\left(\xi_{1}\right) g_{i j}^{2}+ \\
& {\left[\vartheta_{k}\left(\xi_{2}, \xi_{3}\right) w_{k}\right]\left[\varphi_{j}\left(\xi_{1}\right) \varpi_{j}\right]\left[\varphi_{a}\left(\xi_{1}\right) g_{a p}^{1}\right]\left[\varphi_{b}\left(\xi_{1}\right) g_{b q}^{2}\right] \varepsilon_{p q i}}
\end{aligned}
$$

A equação (8.8) representa um mapeamento vetorial objetivo do espaço adimensional de coordenadas, para a configuração atual do corpo, incluindo as taxas de deformações transversais e o empenamento da seção. Essa cinemática resulta em doze graus de liberdade para cada nó do elemento, sendo três translações, seis componentes de vetores generalizados, 
dois graus de liberdade com a intensidade da taxa de deformação transversal da seção e um parâmetro com a intensidade do empenamento. $\mathrm{O}$ vetor de coordenadas generalizadas fica:

$$
q_{i}=\left\{x_{1}, x_{2}, x_{3}, v_{1}^{1}, v_{2}^{1}, v_{3}^{1}, v_{1}^{2}, v_{2}^{2}, v_{3}^{2}, a^{1}, a^{1}, \varpi\right\}
$$

Nas Figura 56 (a) e (b) ilustram-se os aprimoramentos das deformações lineares transversais no plano da seção. Na Figura 56 (c) mostra-se a contribuição conjunta dessas deformações e na Figura 56 (d) ilustra-se as deformações fora do plano da seção devido o modo de empenamento.

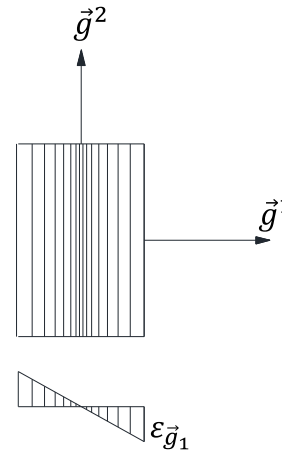

(a)

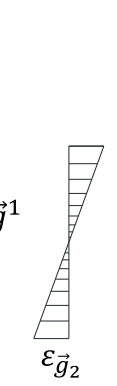

(b)

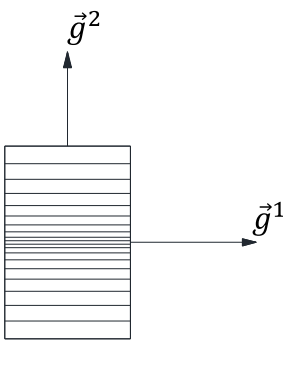

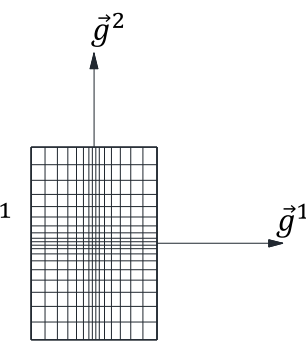

(c)

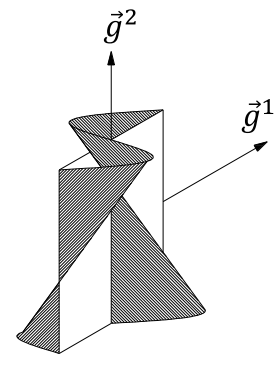

(d)

Figura 56: Aprimoramentos na cinemáticos da seção transversal

Antes de se apresentar a proposta de enriquecimento cinemático demonstra-se a aplicabilidade e eficiência da formulação posicional em conjunto com a metodologia de decomposição da matriz Hessiana, para o cálculo das cargas críticas empregando-se a análise de autovalores e autovetores.

No exemplo a seguir iniciam-se as análises estudando-se o problema clássico da flambagem de Euler. Demonstra-se a concordância entre a solução analítica e o cálculo dos autovalores na obtenção da carga crítica. Apresenta-se também a análise da estrutura com imperfeições geométricas iniciais mostrando-se o traçado da trajetória de equilíbrio pós-crítica em grandes deslocamentos.

\subsection{Primeira Série de Exemplos: Elemento Finito de Barra Geral}

Nessa seção apresentam-se exemplos selecionados com a finalidade de se comprovar a aplicabilidade da formulação do elemento de barra geral no estudo da instabilidade estrutural. 
Estudam-se duas séries de exemplos. Nesta seção são avaliados três exemplos empregando-se a cinemática do elemento de barra geral formulado proposto.

No primeiro exemplo estuda-se o problema clássico da flambagem de Euler, com a finalidade de validar a solução gerada pela análise de autovalor e autovetor do elemento de barra geral. Apresenta-se também a solução não-linear em grandes deslocamentos considerando-se as imperfeições geométricas da estrutura.

No segundo exemplo, estuda-se o problema da treliça de Von Mises apresentada no capítulo 6. Retoma-se esse exemplo com a finalidade de se verificar o fenômeno de instabilidade global, devido a flambagem das barras da estrutura.

Finalizando-se a primeira série de exemplos são apresentados os resultados do estudo de instabilidade lateral de perfis estruturais de parede fina.

\subsubsection{Carga Crítica de Euler}

Neste exemplo considera-se o cálculo da carga crítica de Euler para uma coluna simplesmente apoiada e compressão centrada, conforme ilustrado na Figura 57. Adota-se a hipótese clássica da teoria de flexão onde admite-se que as seções transversais não empenam nem distorcem, permanecendo planas e ortogonais ao eixo da barra.

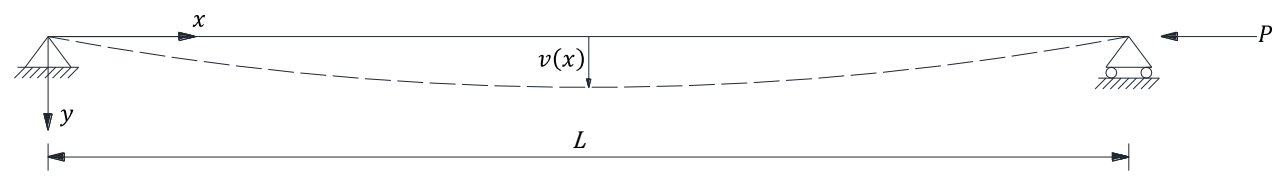

Figura 57: Coluna ideal, flambagem de Euler

Em (TIMOSHENKO e GERE, 1961) é apresentada a equação diferencial em termos dos deslocamentos transversais, reproduzida aqui como:

$$
E I v^{\prime \prime}(x)+P v(x)=0
$$

Em (ALFUTOV, 2000) é demonstrado que a equação (8.10) é o resultado da linearização de um problema de teoria de terceira ordem, cuja solução recai no cálculo de valores e vetores próprios. O autor comenta que é possível demonstrar que problemas de instabilidade de estruturas ideais sempre se recai em análises de autofunções. 
Como nesse exemplo pretende-se apresentar o cálculo da carga crítica a partir da solução dos autovalores, restringe-se a equação da curvatura a teoria de segunda ordem, cujos resultados são perfeitamente admissíveis para uma análise linear de estabilidade. Caso fosse utilizada a teoria de terceira ordem a equação diferencial só teria solução empregando-se funções elípticas, o que tornaria o exemplo bastante dispendioso.

Para uma estrutura com rigidez constante à flexão, a equação (8.10) pode ser representada em termos de uma equação diferencial com coeficiente constante, expressa da seguinte forma:

$$
v^{\prime \prime}(x)+k^{2} v(x)=0
$$

Sendo $k^{2}=P / E I$.

A solução geral dessa equação é determinada fazendo-se:

$$
v(x)=C_{1} \operatorname{sen} k x+C_{2} \cos k x
$$

Cujas condições de contorno homogêneas $v(0)=0$ e $v(L)=0$ satisfazem a equação (8.11). É interessante mencionar que a constante $k$ só será um autovalor do problema se pelo menos uma das constantes $C_{i}$ for não nula. Essa condição equivale a determinar uma solução não trivial do sistema:

$$
\left\{\begin{array}{l}
C_{1} \cdot 0+C_{2} \cdot 1=0 \\
C_{1} \operatorname{sen} k L+C_{2} \cos k L=0
\end{array}\right.
$$

O sistema homogêneo apresenta uma solução diferente da trivial se e somente se o determinante de seus coeficientes for nulo. Essa condição resulta:

$$
\left|\begin{array}{cc}
0 & 1 \\
\operatorname{sen} k L & \cos k L
\end{array}\right|=\operatorname{sen} k L=0
$$

A equação característica (8.14) possui infinitas raízes inteiras e são calculadas a partir da equação trigonométrica, fazendo-se: 


$$
k=\frac{n \pi}{L}, \operatorname{com} n=1,2,3 \ldots
$$

Substituindo-se o valore de $k$ na equação (8.15), obtém-se os valores das forças correspondentes aos modos de flambagem da coluna, comumente denominada de equação de Euler, exepressa da seguinte forma:

$$
P_{n}=\frac{n^{2} \pi^{2} E I}{L^{2}}
$$

De (8.16) é possível afirmar que qualquer valor de $P_{n}$ determina um ponto de bifurcação do equilíbrio. O menor valor, correspondente a $n=1$, é chamado de carga crítica de bifurcação, ou simplesmente carga crítica de Euler. Os autovetores do problema são obtidos utilizando-se a equação da elástica, expressa como:

$$
v(x)=C_{1} \operatorname{sen}\left(\frac{n \pi}{L} x\right)
$$

Em resumo, cada solução é um autovalor da equação diferencial (8.11). É de interesse conhecer o menor dentre esses valores, pois fornecerá a carga crítica de flambagem. A essa carga associa-se um autovetor que representa o modo crítico da linha elástica.

Analisando-se a equação (8.17) verifica-se que a constante $C_{1}$ é indeterminada, o que justifica o argumento apresentado no capítulo 5 que discorre acerca do resultado qualitativo dos modos de instabilidade. A elástica da estrutura só será bem definida se a constante de amplificação do modo for conhecida.

A solução analítica apresentada representa o problema de autovalor e é válida apenas para o cálculo da carga crítica de flambagem de estruturas elásticas ideais.

Na sequência, apresentam-se os resultados da simulação numérica com o algoritmo de Lanczos para o cálculo dos autovalores e autovetores do elemento finito de barra geral.

Para se estudar a estrutura, considere-se os seguintes dados que serão utilizados na determinação das soluções analítica e numérica. Portanto, seja uma coluna com seção retangular $15 \times 30 \mathrm{~cm}$, módulo de elasticidade $E=2476,8 \mathrm{kN} / \mathrm{cm}^{2}$ e coeficiente de Poisson nulo. 
Como comentado anteriormente, em projetos estruturais é de interesse prático se conhecer apenas o primeiro ponto de bifurcação, pois este representa a carga crítica da estrutura. Porém, com a finalidade de validar o programa computacional apresentam-se também as seis primeiras cargas de bifurcação e os modos de instabilidade associados.

De acordo com (REIS e CAMOTIM, 2001) a curva de instabilidade é um dado primordial para se identificar a participação dos modos de flambagem no cálculo da carga crítica, em especial das estruturas com seção aberta e de parede fina. Neste exemplo, porém, convém introduzir a curva de instabilidade a fim de se analisar a influência da esbeltez da peça no resultado da carga crítica. Ilustra-se também o gráfico de convergência dos autovalores em função do número de elementos adotados na simulação do problema.

No gráfico da Figura 58 ilustra-se a variação da carga crítica para incrementos de $50 \mathrm{~cm}$ no comprimento da coluna. Apresentam-se as respostas obtidas com a solução analítica, dada pela equação de Euler, e os valores calculados com a simulação da coluna por meio dos elementos de barra geral.

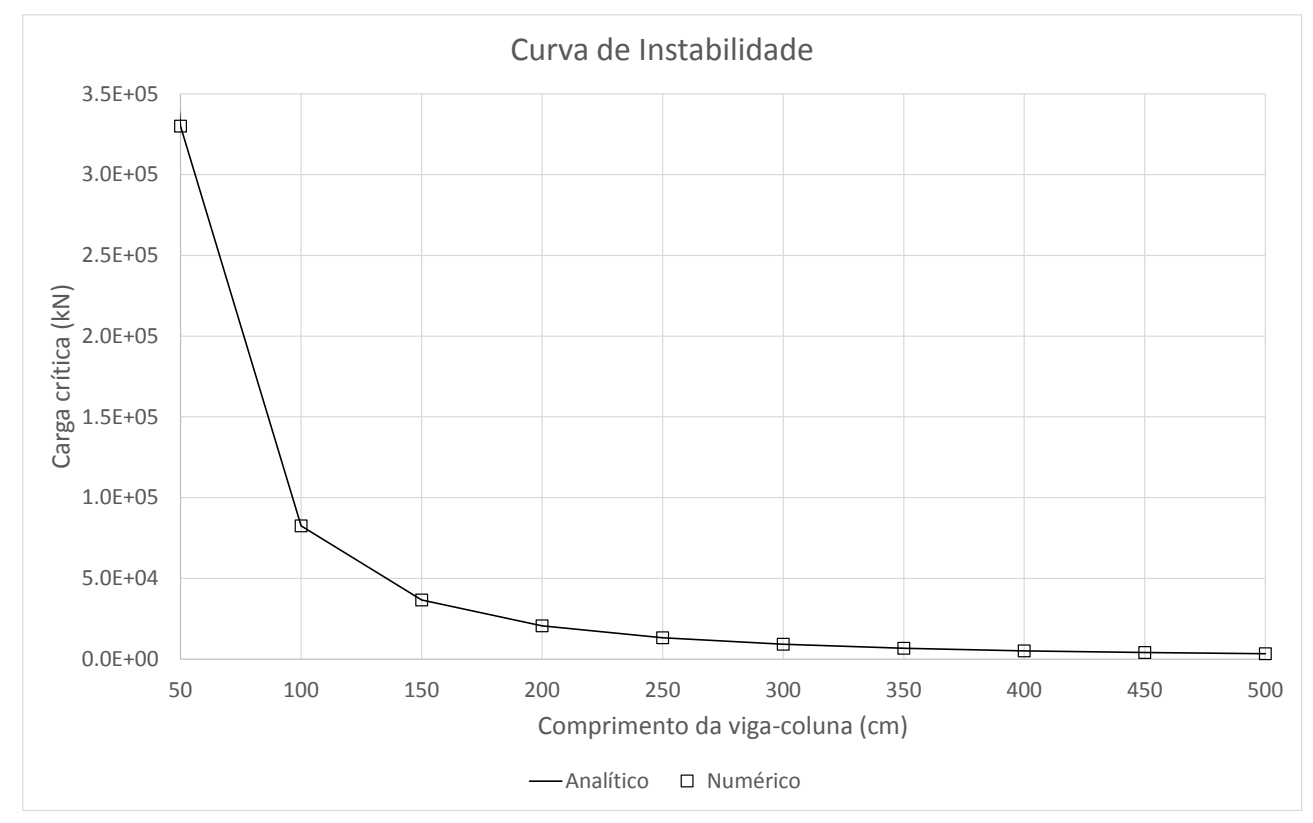

Figura 58: Curva de instabilidade para a viga coluna da Figura 57

Foram utilizados dez elementos com aproximação cúbica para o eixo da seção transversal e nove elementos triangulares com aproximação cúbica para se modelar a seção transversal da peça. Aplicou-se um carregamento compressivo unitário, de modo a se obter diretamente o valor da crítica de flambagem. 
Analisando-se o gráfico da Figura 58 verifica-se a proporcionalidade inversa entre o valor da carga crítica e o comprimento do elemento estrutural mostrando-se que a medida que a esbeltez da peça aumenta, o valor da carga crítica diminui.

Na Tabela 5, comparam-se os cinco primeiros autovalores calculados com a equação de Euler e os resultados obtidos com a biblioteca ARPACK que utiliza o algoritmo de Lanczos.

Ilustram-se apenas os valores para a peça com comprimento $L=500 \mathrm{~cm}$.

Tabela 5: Cargas de bifurcação para a coluna com cinco metros

\begin{tabular}{|c|c|c|c|}
\hline Modo & Analítico $(\mathrm{kN})$ & Numérico $(\mathrm{kN})$ & Erro relativo (\%) \\
\hline 1 & 3300.08 & 3300.08 & 0.00002 \\
\hline 2 & 13200.32 & 13200.35 & 0.00027 \\
\hline 3 & 29700.72 & 29701.12 & 0.00135 \\
\hline 4 & 52801.28 & 52803.52 & 0.00424 \\
\hline 5 & 82502.00 & 82510.49 & 0.01029 \\
\hline
\end{tabular}

Nota-se que o menor erro relativo está associado ao valor da carga crítica. A maior precisão na determinação desse resultado é relevante sob o ponto de vista de projeto, uma vez que a carga crítica é um dado fundamental para o dimensionamento.

Na sequência apresenta-se um gráfico de convergência dos cinco primeiros autovalores da barra de comprimento $L=500 \mathrm{~cm}$. Nessa análise, fixa-se a malha da seção transversal e varia-se a malha do eixo longitudinal da coluna. Considera-se também nessa análise os elementos com aproximação cúbica.

No gráfico da Figura 59, o eixo vertical representa os valores normalizados da carga de bifurcação. É possível constatar que o refinamento da malha não influencia na precisão do primeiro autovalor. De fato, para os pontos de bifurcação de ordem mais elevadas, o algoritmo de Lanczos necessita de um número de iterações maior para convergir. Essa é uma consequência do algoritmo, porém não afetam a aplicabilidade do método. 


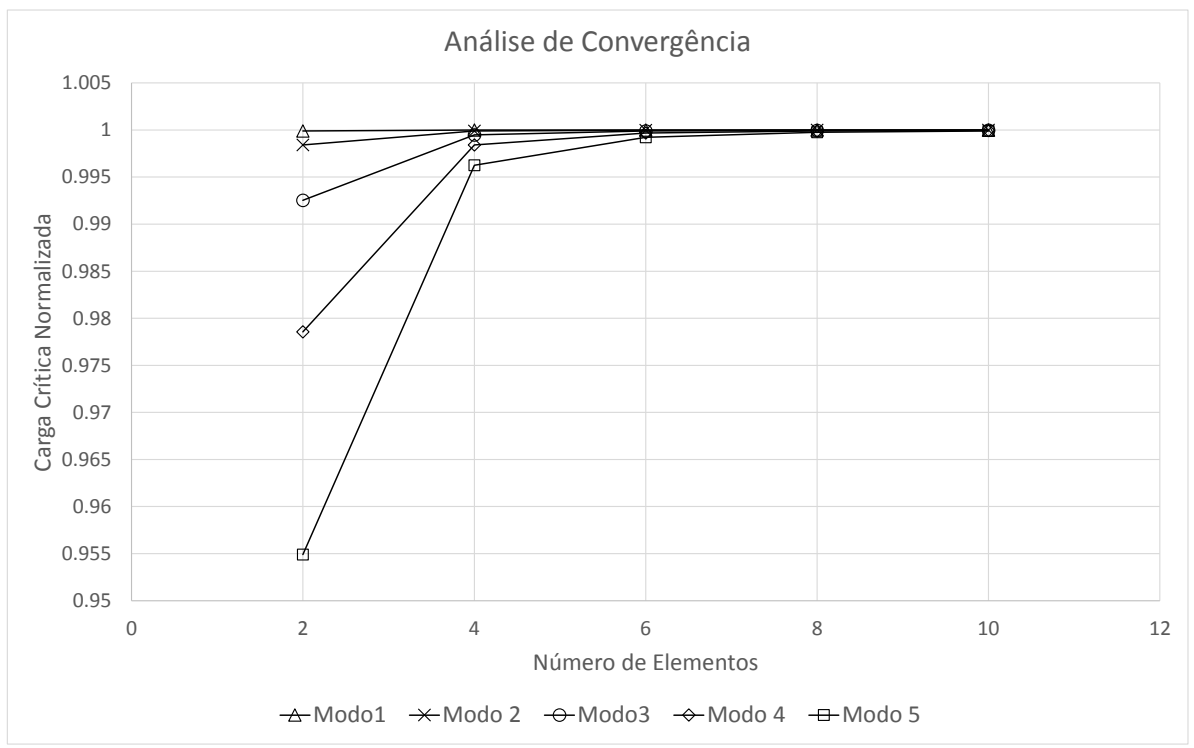

Figura 59: Análise de convergência dos autovalores

Na Figura 60 ilustram-se os autovetores relativos aos quatro modos de flambagem do eixo longitudinal da barra.
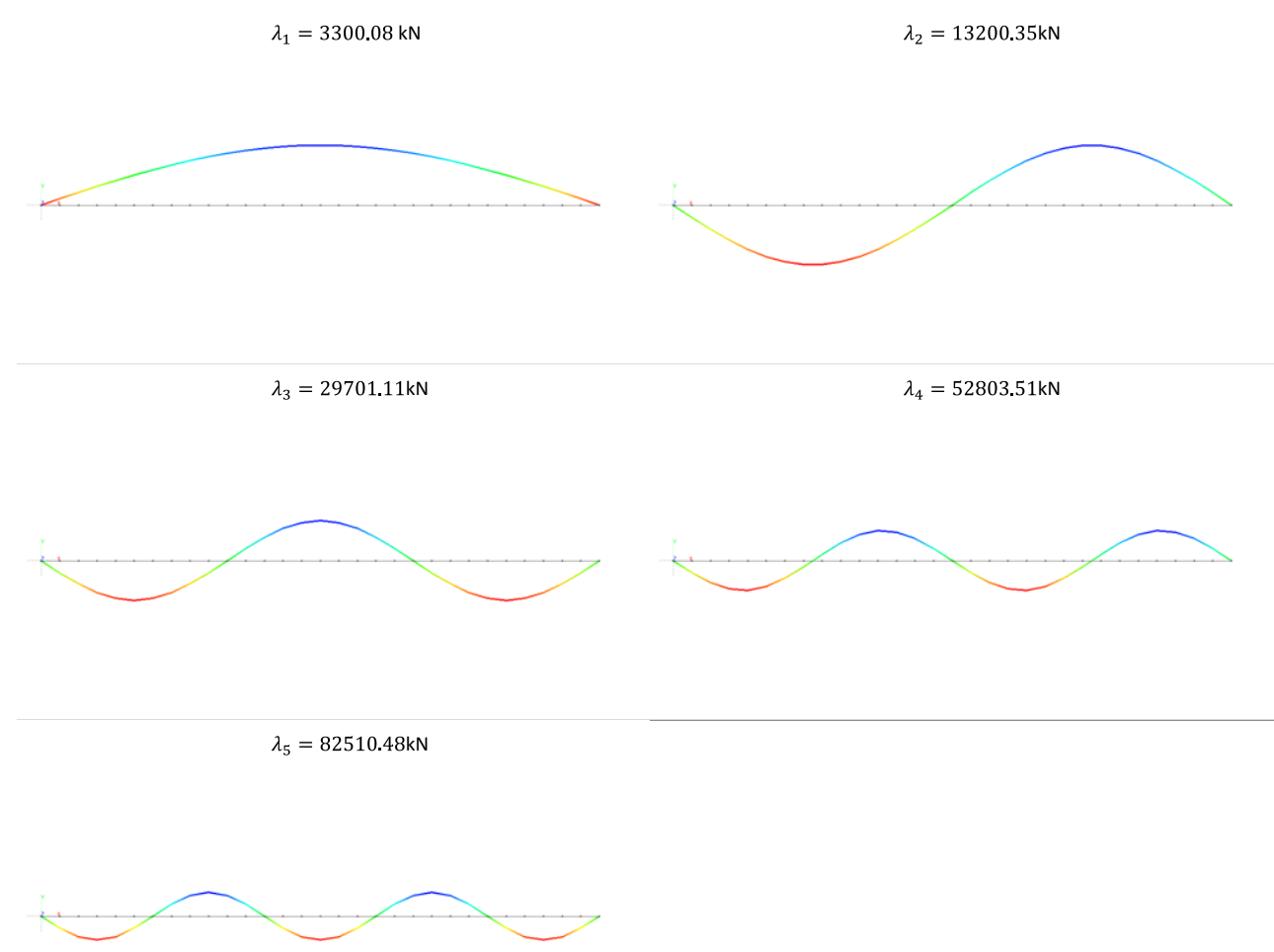

Figura 60: Autovetores referentes aos cinco primeiros modos de instabilidade 
Para finalizar o exemplo, consideram-se as imperfeições iniciais na barra. É possível realizar essa análise levando-se em conta duas situações: a primeira consiste em se inserir a imperfeição nas coordenadas geométricas da barra, desviando sua configuração retilínea a partir dos deslocamentos dos nós da malha. A outra, consiste em se aplicar uma perturbação provocada por um carregamento transversal ao eixo da barra, de pequena intensidade e proporcional ao carregamento de compressão. A seguir consideram-se as duas situações.

Primeiramente se insere uma imperfeição do tipo senoidal às coordenadas dos nós ao longo do eixo da barra, conforme a equação:

$$
y(x)=\delta_{0} \operatorname{sen}\left(\frac{\pi x}{L}\right)
$$

Sendo $\delta_{0}$ a amplitude da imperfeição.

Na segunda situação, aplica-se um fator de escala $\beta=0,01 P$, transversal ao eixo da barra, localizado no meio do vão. Admite a geometria da barra idealmente reta.

No gráfico da Figura 61 apresentam-se as respostas pós-críticas em grandes deslocamentos para as duas situações. Ilustra-se também a trajetória para duas amplitudes de imperfeições, com valores de $\delta_{0}$ igual a 0,05 e 0,01 .

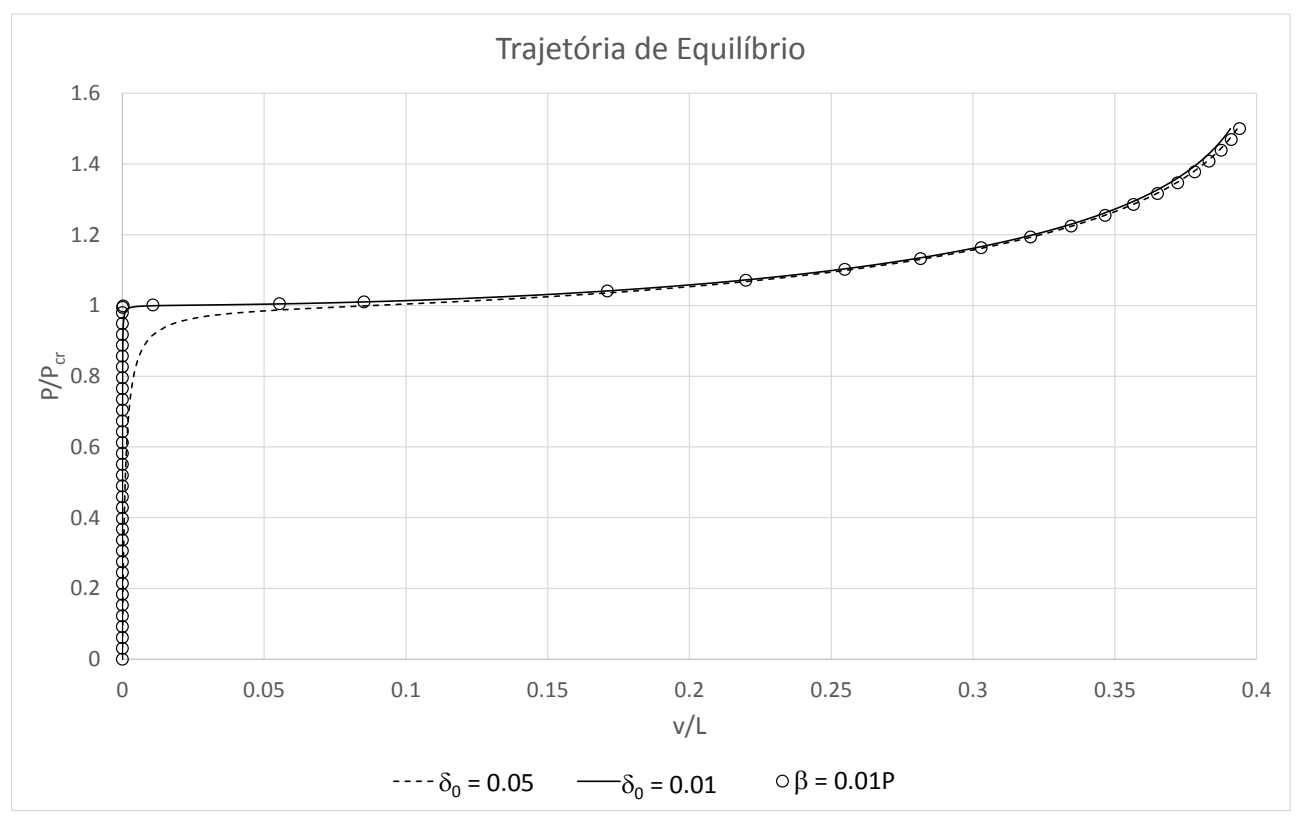

Figura 61: Trajetória de equilíbrio pós-crítica, com imperfeições geométricas 
Nota-se no gráfico da Figura 61 a equivalência entre a imperfeição gerada a partir da lei de variação aplicada nas coordenadas com amplitude $\delta_{0}=0,01$ e a aplicação do carregamento combinado, $\beta=0,1 P$. Em ambas as situações, as trajetórias praticamente coincidem.

Além disso, é possível verificar no ponto de carga uma mudança repentina nos valores dos deslocamentos transversais, característico do comportamento das estruturas com bifurcação simétrica estável. Para valores de força além do ponto de bifurcação, surgem deslocamentos transversais acentuados indicando que a coluna perdeu estabilidade.

Considerando-se a amplitude $\delta_{0}=0,05$, a curva resultante é mais suave próxima ao ponto crítico, porém, ainda é possível verificar a tendência a bifurcação simétrica. Constata-se que próximo ao ponto de bifurcação ocorrem grandes deslocamentos transversais semelhantes aos obtidos com os dois tipos de imperfeições analisadas anteriormente.

A seguir apresentam-se o exemplo do domo com a intenção de se aplicar a decomposição da matriz Hessiana no cálculo da flambagem dos elementos da estrutura.

\subsubsection{Flambagem da Treliça de Von Mises com Elemento de Barra Geral}

Nesta seção, retoma-se o exemplo da treliça de Von Mises apresentado no capítulo 6 com a finalidade de se avaliar a carga crítica de flambagem com a rotina de autovalor e autovetor do elemento de barra geral. A metodologia de apresentação do exemplo segue a proposta apresentada no trabalho de (PSOTNý e RAVINGER, 2002), a qual será tomado como referência.

Os resultados a seguir demonstram que o fenômeno de instabilidade de estruturas lineares modeladas com o elemento de barra geral está condicionado as características geométricas do modelo e o do parâmetro de esbeltez das barras.

A instabilidade por ponto de bifurcação é considerada admitindo-se as barras conectadas por rotulas perfeitas de maneira que as barras sejam solicitadas por um esforço normal perfeitamente centrado. Nessa situação idealizada, admite-se ainda que as barras sejam isentas de qualquer imperfeição material ou geométrica.

Para efeito de comparação, na Figura 62 são reproduzidos os resultados divulgados em (PSOTNý e RAVINGER, 2002), para os quatro primeiros autovalores da estrutura. 

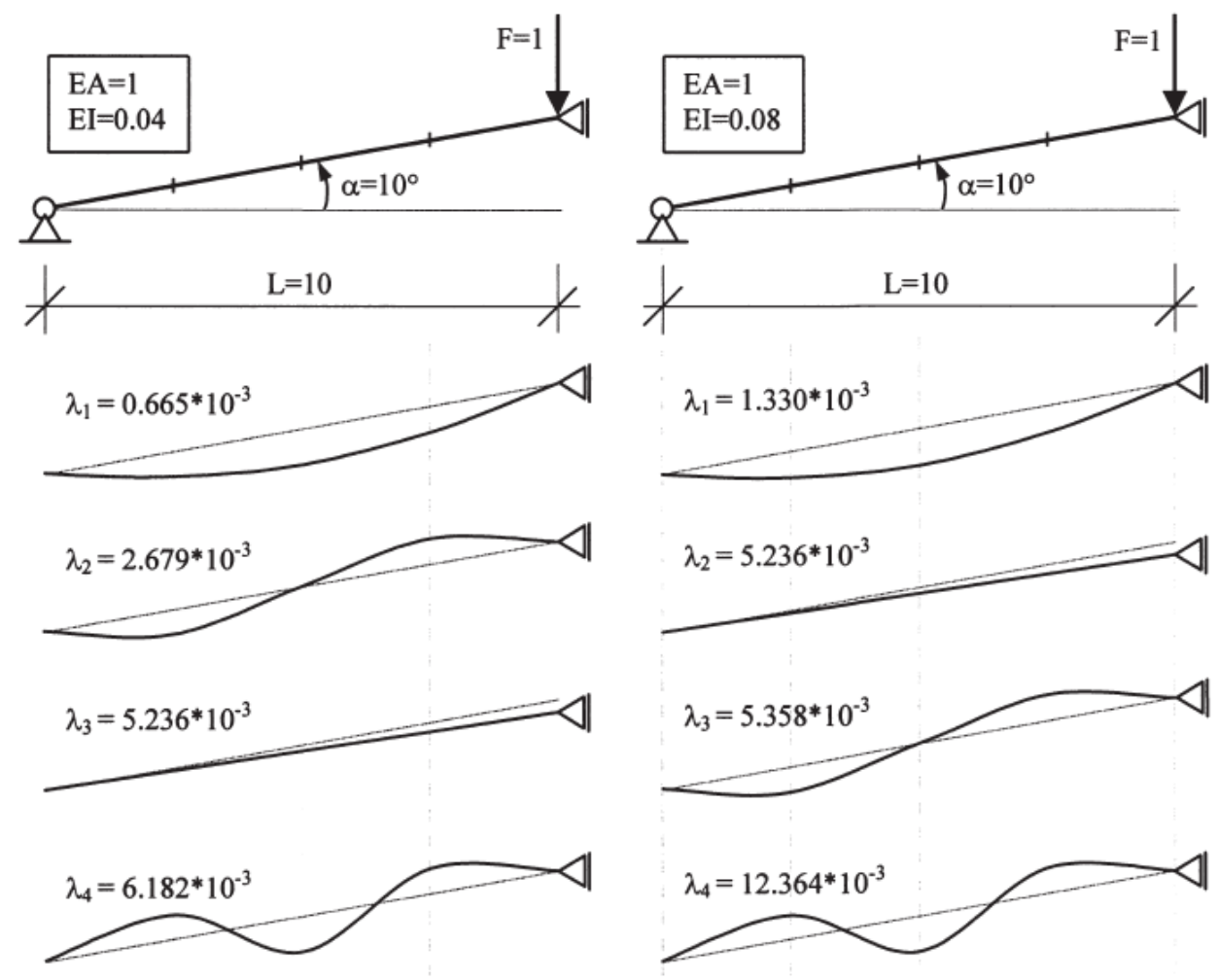

Figura 62: Cargas críticas e modos de flambagem para esbeltez variável. (PSOTNý e RAVINGER, 2002)

Os resultados apresentados no artigo indicam a dependência do parâmetro de carga em função da rigidez a flexão das barras.

Devido a necessidade de se variar a rigidez a flexão do elemento para se adequar o modelo ao exemplo apresentado por (PSOTNý e RAVINGER, 2002), dispõem-se as barras de maneira que a flexão ocorra em torno do eixo principal de inércia, convenientemente orientado conforme o artigo de referência. É possível se estabelecer estas condições manipulando-se criteriosamente os key points utilizados no mapeamento da seção transversal ao longo da linha de referência. Detalhes da construção dos vetores generalizados com o auxílio dos key points estão descritos no único apêndice desta tese.

De posse dessa condição, as dimensões da seção transversal, adotada retangular, deve satisfazer ao seguinte sistema de equações:

$$
\left\{\begin{array}{l}
A=b h=1 \\
I=\frac{b h^{3}}{12}=0,04 \text { ou } 0,08 \text { para o segundo exemplo }
\end{array}\right.
$$


Sendo $b$ e $h$, as dimensões da seção. Com essa condição é possível se reproduzir os dados do exemplo, desde que os eixos principais gerados com os vetores generalizados satisfaçam adequadamente a orientação da seção transversal, como comentado anteriormente.

Os autovalores e autovetores obtidos com a solução do elemento de barra geral para rigidez a flexão $E I=0,04$ encontram-se ilustrados na Figura 63.

$$
\lambda_{1}=6,64 \times 10^{-4} \quad \lambda_{2}=2,65 \times 10^{-3}
$$
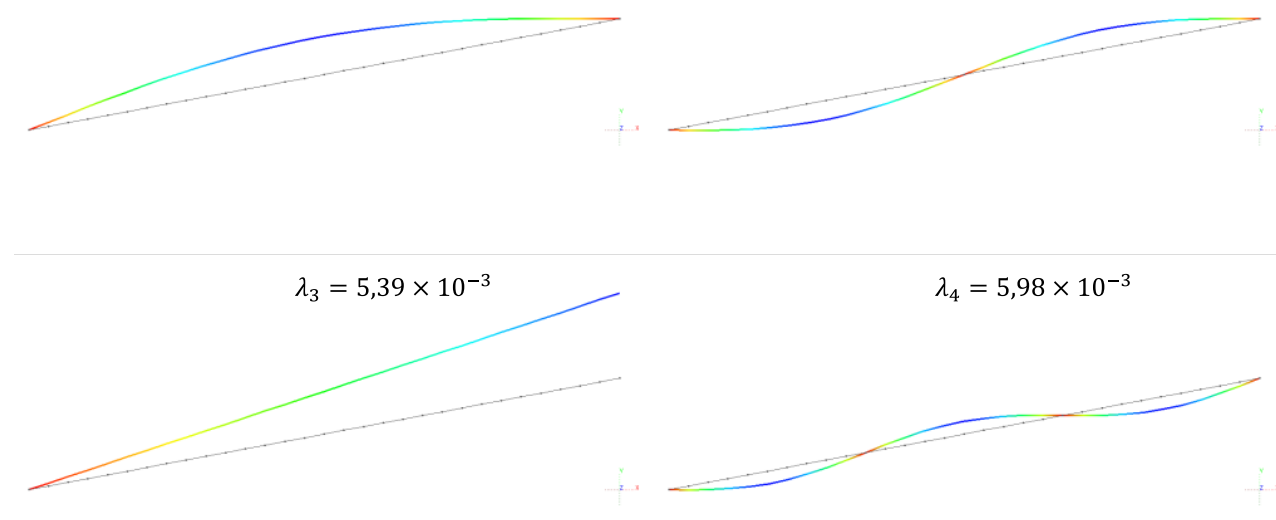

Figura 63: Autovalores e autovetores obtidos com o elemento de barra geral rotulado

São utilizadas três dicretizações para o estudo de convergência. Utilizam-se as malhas com um, cinco e dez elementos cúbicos ao longo do eixo longitudinal da barra. Na seção transversal mantem-se a discretização fixa com trinta e dois elementos triangulares de aproximação quadrática. Na Tabela 6 são apresentados os resultados dos autovalores obtidos nesse estudo.

Tabela 6: Parâmetros de carregamento para a rigidez a flexão $E I=0,04$

\begin{tabular}{|c|c|c|c|c|}
\hline \multicolumn{5}{|c|}{ El =0,04 } \\
\hline Modo & 1 Elem. & 5 Elem. & 10 Elem. & Referência \\
\hline 1 & $6.662 \mathrm{E}-04$ & $6.649 \mathrm{E}-04$ & $6.649 \mathrm{E}-04$ & $6.650 \mathrm{E}-04$ \\
\hline 2 & $2.760 \mathrm{E}-03$ & $2.660 \mathrm{E}-03$ & $2.659 \mathrm{E}-03$ & $2.679 \mathrm{E}-03$ \\
\hline 3 & $5.399 \mathrm{E}-03$ & $5.399 \mathrm{E}-03$ & $5.399 \mathrm{E}-03$ & $5.236 \mathrm{E}-03$ \\
\hline 4 & $8.276 \mathrm{E}-03$ & $5.985 \mathrm{E}-03$ & $5.984 \mathrm{E}-03$ & $6.182 \mathrm{E}-03$ \\
\hline
\end{tabular}

Variando-se a rigidez a flexão da estrutura, estudou-se os resultados dos autovalores e autovetores calculados para $E I=0,08$, cujos resultados estão ilustrados na Tabela 7 . 
Tabela 7: Parâmetros de carregamento para a rigidez a flexão $E I=0,08$

\begin{tabular}{|c|c|c|c|c|}
\hline \multicolumn{5}{|c|}{ El $=0,08$} \\
\hline Modo & 1 Elem. & 5 Elem. & 10 Elem. & Referência \\
\hline 1 & $1.332 \mathrm{E}-03$ & $1.330 \mathrm{E}-03$ & $1.330 \mathrm{E}-03$ & $1.330 \mathrm{E}-03$ \\
\hline 2 & $5.399 \mathrm{E}-03$ & $5.319 \mathrm{E}-03$ & $5.319 \mathrm{E}-03$ & $5.236 \mathrm{E}-03$ \\
\hline 3 & $5.435 \mathrm{E}-03$ & $5.399 \mathrm{E}-03$ & $5.399 \mathrm{E}-03$ & $5.358 \mathrm{E}-03$ \\
\hline 4 & $1.455 \mathrm{E}-02$ & $1.197 \mathrm{E}-02$ & $1.197 \mathrm{E}-02$ & $1.236 \mathrm{E}-02$ \\
\hline
\end{tabular}

Os autovetores correspondentes estão ilustrados na Figura 64.

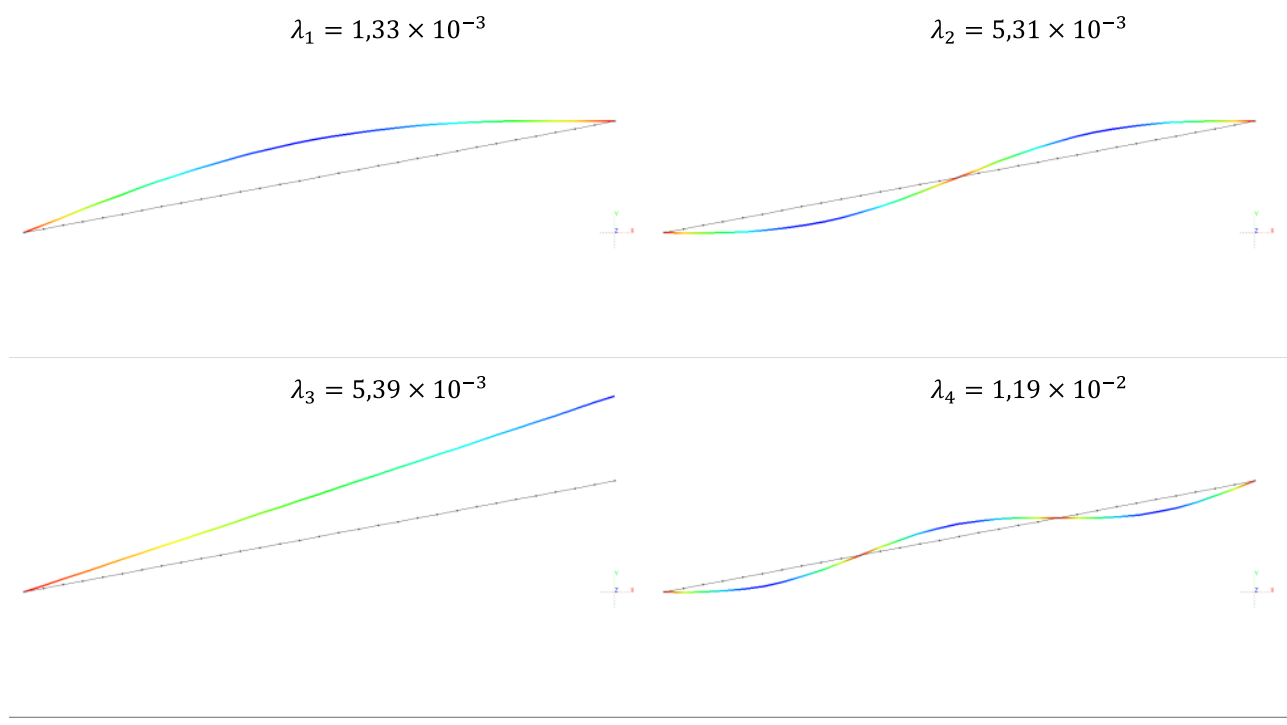

Figura 64: Autovalores e autovetores obtidos para a inercia EI=0,08

A discretização com apenas um elemento cúbico é suficiente para reproduzir satisfatoriamente os resultados apresentados no artigo de referência. $\mathrm{O}$ aumento do número de elementos no eixo de referência flexibiliza a estrutura compensando o ganho de rigidez com a inércia da seção. Essa afirmação se baseia na observação do modo relativo a rotação de barra rígida ilustrado por (PSOTNý e RAVINGER, 2002). No artigo de referência esse autovetor se manifesta no segundo modo de flambagem. Na presente pesquisa esse modo só foi reproduzido quando se utilizou um número limitado de elementos para descrever o eixo de referência. Quando se aumenta rigidez EI para valores acima de 0,08, nota-se que o autovetor relativo ao giro de barra rígida surge no primeiro modo, caracterizando a precedência do ponto limite em relação ao ponto de bifurcação. Esses resultados ilustram a influência da esbeltez da barra na instabilidade da estrutura. 
Para a análise em grandes deslocamentos, assume-se o primeiro autovetor como a imperfeição geométrica da estrutura. Na Figura 65 ilustram-se as trajetórias fundamental e bifurcada com o elemento de barra geral para $E I=0,04$.

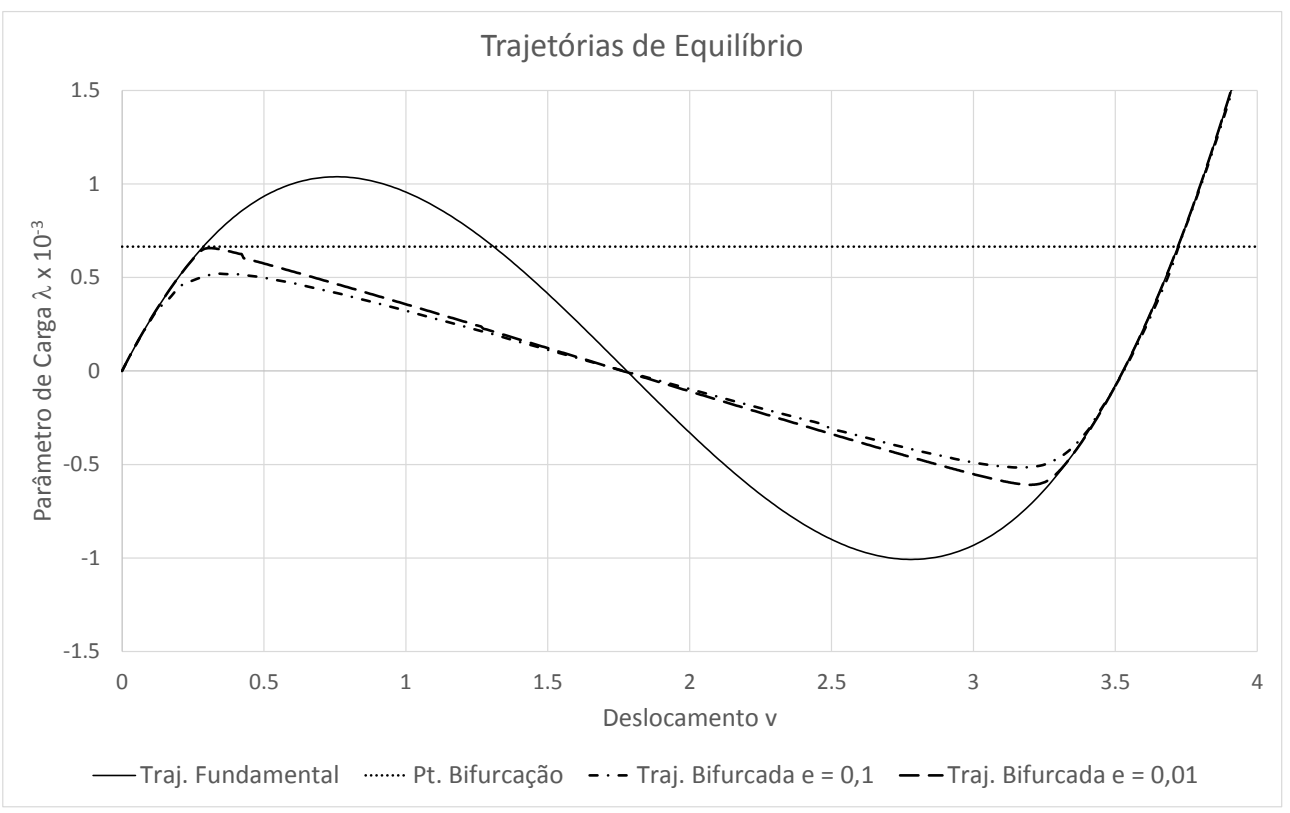

Figura 65: Trajetória fundamental e bifurca da Treliça de Mises

As imperfeições consideradas referem-se a amplitude atribuída ao modo de flambagem. A metodologia para determinação desses valores consiste em normalizar o autovetor correspondente ao primeiro modo e em seguida atribuir um fator de escala com a magnitude da imperfeição. Utilizou-se o algoritmo de Newton-Raphson com o controle dos deslocamentos para se determinar as trajetórias completas verificando-se a boa adequação do algoritmo.

\subsubsection{Instabilidade Lateral de Vigas Esbeltas}

Neste exemplo, estuda-se em primeira instância, a instabilidade lateral de vigas com seção transversal retangular delgada. Posteriormente estuda-se o problema aplicado ao perfil estrutural de uma viga com seção I. Toma-se como referência a solução analítica apresentada em (TIMOSHENKO e GERE, 1961).

Considere-se uma viga engastada sujeita a um carregamento aplicado no centro de gravidade da extremidade livre. Nessas condições a viga pode flambar lateralmente devido ao momento de torção induzido no eixo da viga. Quando atingido o momento crítico ocorre a instabilidade devido uma combinação dos esforços de flexão e torsão (BAžANT e CEDOLIN, 2010). 
O momento crítico para vigas com seção retangular delgada é calculado pela equação:

$$
M_{c r}=\frac{2 \kappa}{L} \sqrt{E I_{y} C}
$$

Sendo, $I_{y}$ o momento de segunda ordem em relação ao eixo de menor inércia; $C=G I_{t}$ a rigidez a torção e $\kappa$ as raízes da equação de Bessel $J_{-1 / 4}(x)$.

Considera-se uma viga de comprimento $L=300 \mathrm{~cm}$, cujas dimensões da seção transversal são: altura $h=15 \mathrm{~cm}$ e largura $b=1 \mathrm{~cm}$. As propriedades mecânicas do material são: módulo de elasticidade longitudinal, $E=2,1 \times 10^{4} \mathrm{kN} / \mathrm{cm}^{2}$ e coeficiente de Poisson, $v=0,3$. Para a seção em questão, o valor do momento de inércia a torção vale: $I_{t}=4,79115 \mathrm{~cm}^{4}$.

Na Figura 66 ilustra-se o modelo com dez elementos cúbicos sobre o eixo de referência e vinte elementos triangulares, com aproximação quadrática na seção transversal.

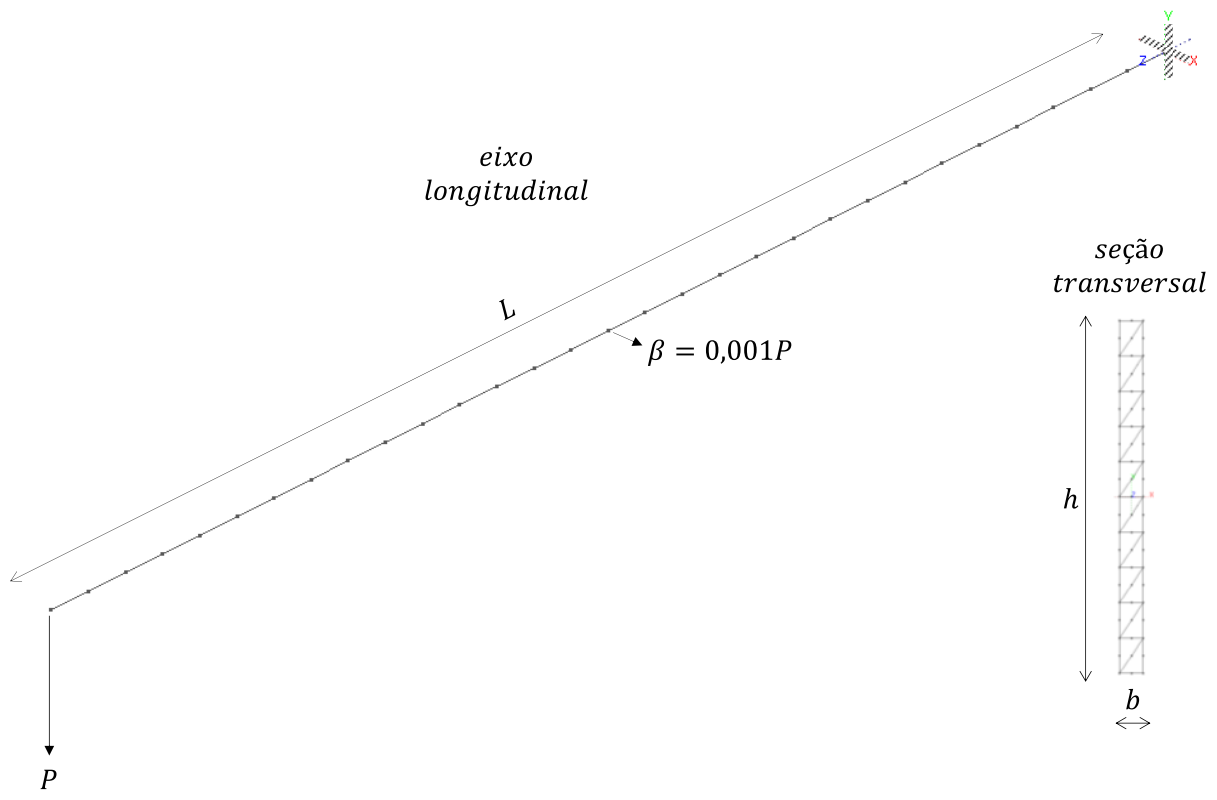

Figura 66: Flambagem lateral da viga engastada com seção retangular delgada

Evidentemente os momentos de flambagem maiores que o valor crítico só possui significado físico se a viga estudada for contida lateralmente. Mas, com a intenção de testar o algoritmo de solução, apresentam-se as seis primeiras cargas de flambagem obtidas analiticamente empregando-se as raízes da equação de Bessel com precisão até a quita casa 
decimal. Em conjunto apresentam-se os resultados numéricos com o elemento finito posicional de barra geral não-linear geométrico.

Na Tabela 8 constam os valores obtidos nas análises.

Tabela 8: Momentos de flambagem lateral

\begin{tabular}{|c|c|c|c|}
\hline$\kappa$ & $M_{c r}$ (Analítico) $[\mathrm{kNcm}]$ & $\mathrm{M}_{\mathrm{cr}}$ (Numérico) $[\mathrm{kNcm}]$ & Erro Relativo (\%) \\
\hline 2.00629 & 426.29 & 426.33 & 0.00875 \\
\hline 5.12306 & 1088.54 & 1089.36 & 0.07522 \\
\hline 8.25795 & 1754.64 & 1758.19 & 0.20220 \\
\hline 11.39646 & 2421.51 & 2430.92 & 0.38875 \\
\hline 14.53629 & 3088.66 & 3108.24 & 0.63404 \\
\hline 17.67675 & 3755.94 & 3791.14 & 0.93714 \\
\hline
\end{tabular}

Realiza-se também uma análise em grande deslocamento considerando-se uma imperfeição inicial produzida pelo carregamento transversal aplicado no meio do vão.

As trajetórias de deslocamento nas direções dos eixos cartesianos podem ser conferidas na Figura 67, onde se verifica uma mudança de comportamento da elástica no valor exato do momento crítico obtido com a equação (8.20)

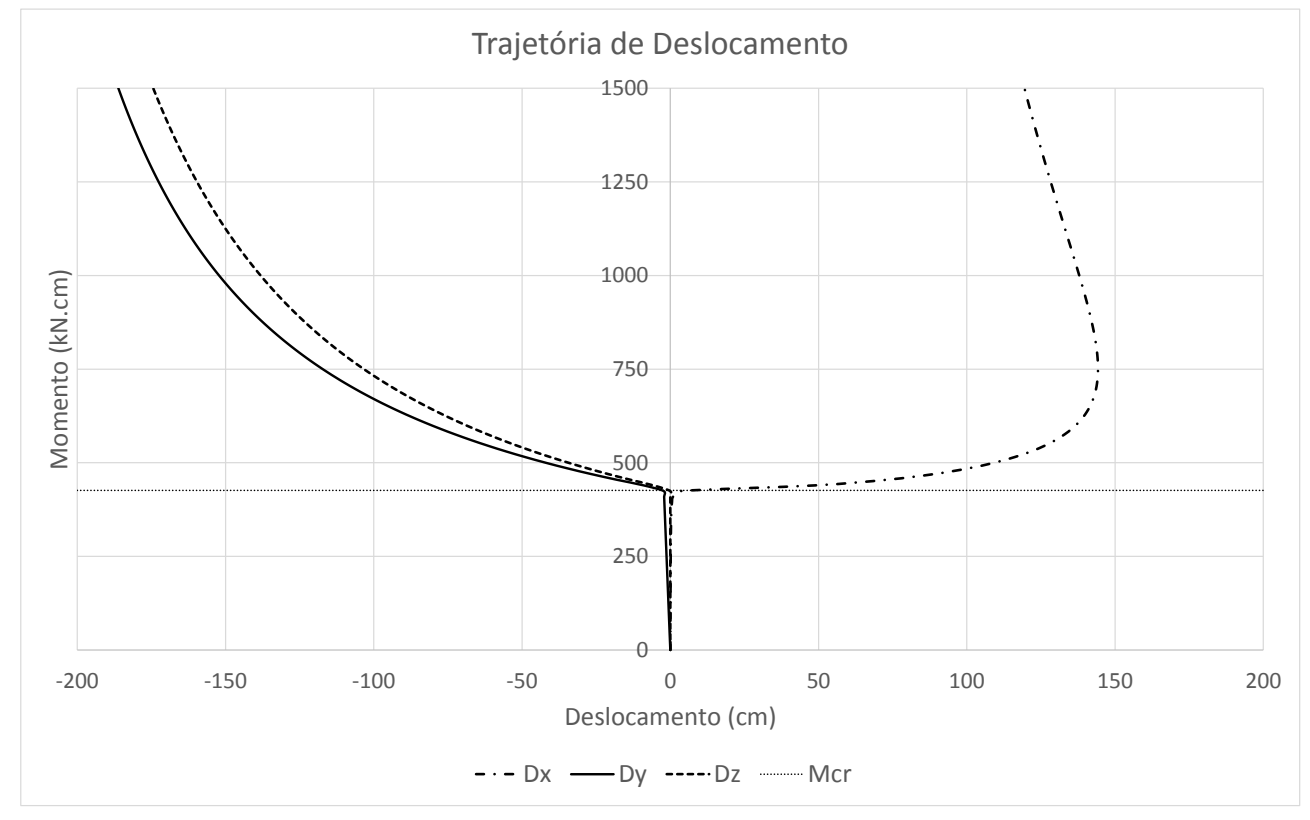

Figura 67: Trajetória de deslocamentos da extremidade livre

Verifica-se também os deslocamentos que se desenvolvem fora do plano da viga caracterizando, no trecho pós-crítico, a flexão lateralmente devido o momento de torção sobre o eixo longitudinal da peça. 
Por outro lado, a flambagem lateral em vigas com perfil simétrico do tipo I ocorre devido a instabilidade do flange comprimido e o efeito estabilizador do flange tracionado provocando rotações da seção transversal acompanhada pelo empenamento da seção.

Perfis estruturais do tipo I são amplamente utilizados em projetos de estruturas de aço, sejam fabricados por laminação ou soldagem de chapas (PFEIL e PFEIL, 2009).

A determinação do momento de flambagem lateral para vigas I é apresentada por (TIMOSHENKO e GERE, 1961), obtida com base na solução aproximada em termos de uma série infinita.

Para a viga com engaste perfeito e carregamento aplicado no centroide da extremidade livre, a equação do momento crítico é calculada pela equação:

$$
M_{c r}=\gamma \frac{\sqrt{E I_{y} C}}{L}
$$

Sendo $\gamma=2 \kappa /\left(1-\sqrt{C_{1} / L^{2} C}\right)$, um valor adimensional, aplicável quando a relação $L^{2} C / C_{1}$ cresce. A constante $C_{1}=E C_{w}$, é a rigidez ao empenamento da seção.

A seguir, avalia-se a instabilidade lateral de uma viga com seção simétrica I com os elementos de barra geral e de casca.

$\mathrm{Na}$ Figura 68 indicam-se as dimensões do modelo considerado na análise com o elemento de barra geral. 


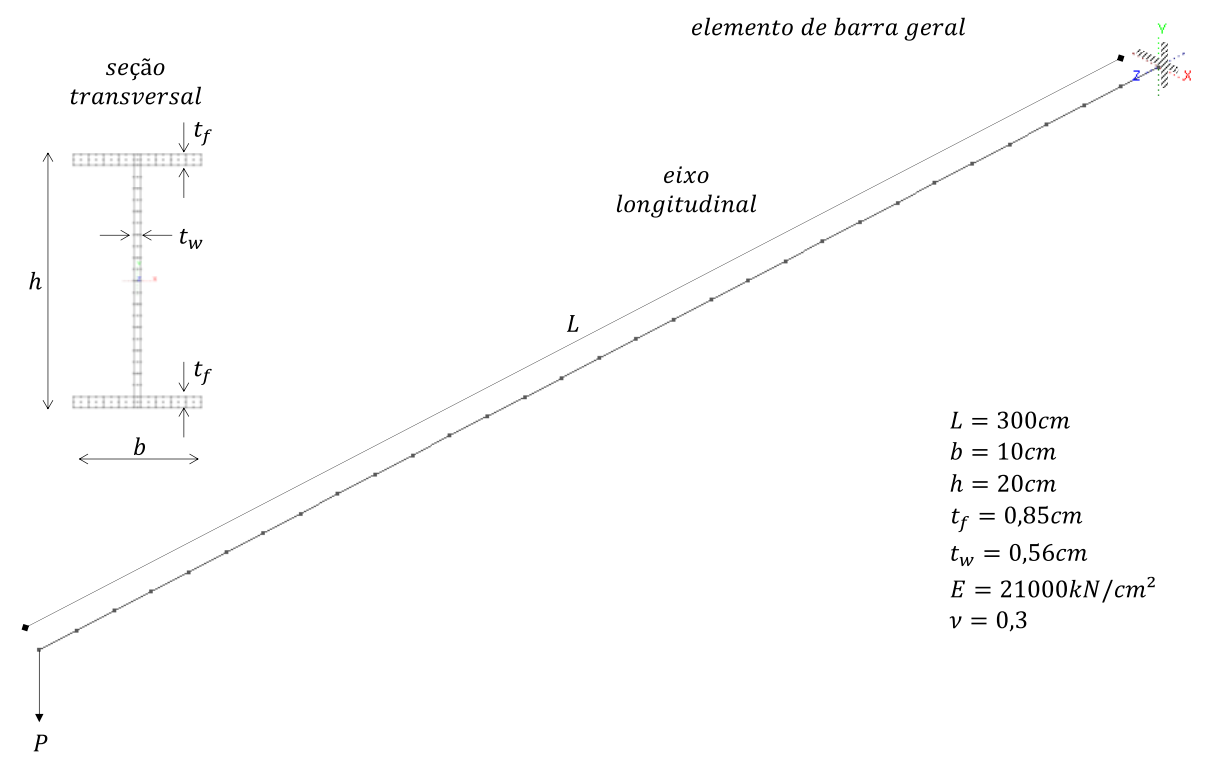

Figura 68: Modelo de barra geral usado na análise de instabilidade lateral

Na Figura 69 ilustra-se o modelo de casca utilizado na análise de flambagem lateral da viga engastada.

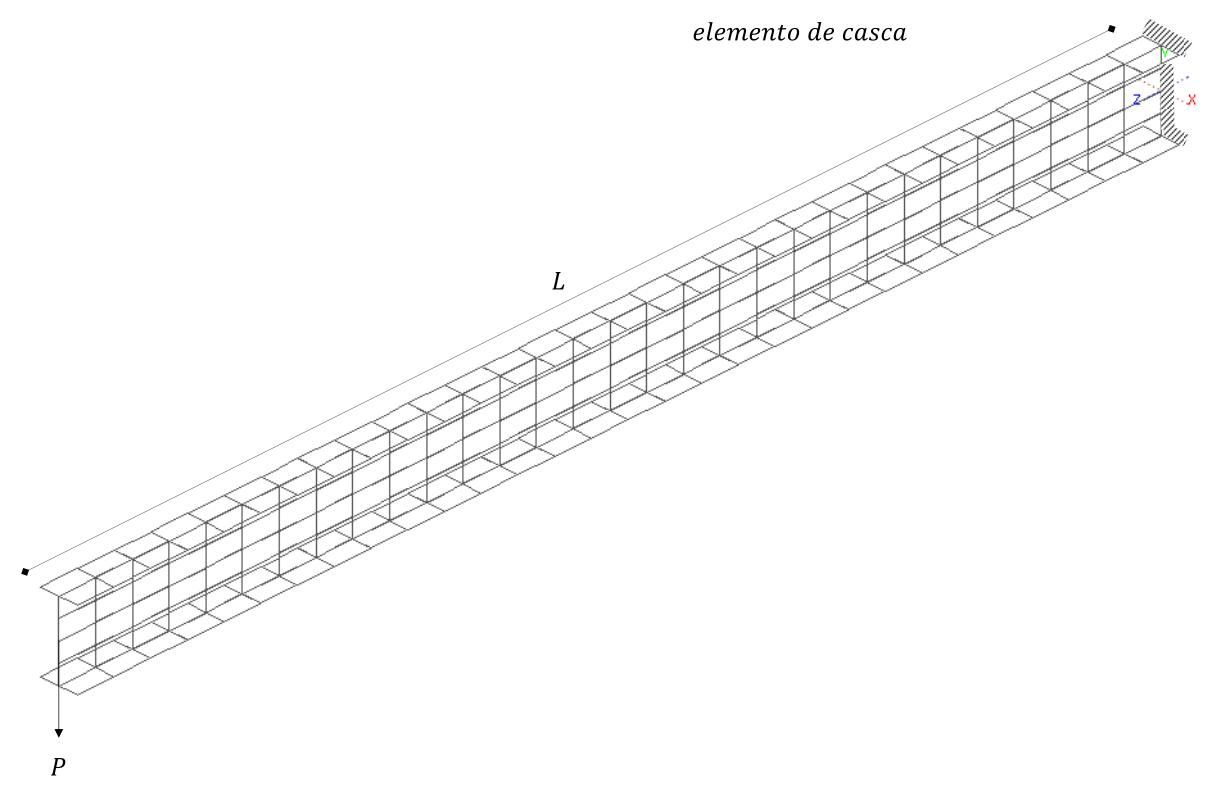

Figura 69: Modelo de casca usado na análise de instabilidade lateral

Os valores das propriedades geométricas da seção transversal são: $I_{y}=141,93 \mathrm{~cm}^{4}$, $I_{t}=5,22 \mathrm{~cm}^{4}$ e $C_{w}=12988,09 \mathrm{~cm}^{6}$. O momento crítico calculado com a equação $(8.21)$ resulta: $M_{c r}=8851,29 \mathrm{kNcm}$. 
As soluções da análise de autovalores com os elementos de barra geral e casca produzem os respectivos momentos críticos: $M_{c r}=8592,13 \mathrm{kNcm}$ e $M_{c r}=7890,17 \mathrm{kNcm}$.

Do ponto de vista mecânico as soluções obtidas com os elementos finitos posicional são mais flexíveis do que a solução analítica, o que é totalmente compreensível pelo fato de ambos considerarem a influência das tensões de cisalhamento na formulação cinemática e liberarem empenamento da seção para o elemento de barra. Verifica-se ainda que o elemento de casca é mais flexível que o de barra. Esse fato também se justifica devido a cinemática do elemento de casca ser livre de travamento volumétrico decorrente do efeito produzido pelo coeficiente de Poisson.

Do ponto de vista do projeto estrutural, para se obter os resultados do problema de flambagem lateral é necessário se determinar um fator de ajuste ao momento crítico padrão. Esse valor é definido como sendo o momento elástico de flambagem lateral com torção de uma viga com seção transversal bissimétrica, isenta de qualquer tipo de imperfeição sujeita a um momento fletor constante ao longo de seu comprimento. De acordo com (DE SOUZA, 2012) é necessário ainda que a viga seja considerada apoiada sobre um vínculo de garfo, de maneira a impedir os deslocamentos laterais e as rotações no apoio e liberar o empenamento.

O valor do momento crítico padrão sob todas essas condições é deduzido em (TIMOSHENKO e GERE, 1961), a partir do sistema de equações de equilíbrio e vale:

$$
M_{c r}^{*}=\frac{\pi}{L} \sqrt{E I_{y} G I_{t}+\frac{\pi^{2}}{L^{2}} E I_{y} E C_{w}}
$$

Com a expressão do momento crítico padrão é possível se determinar o valor do momento crítico para uma série de condições de contorno, inclusive para a viga engastada com carregamento pontual na extremidade livre.

O valore do momento crítico, pode ser então obtido como uma combinação do momento crítico padrão, a partir da equação:

$$
M_{c r}=C_{b} M_{c r}^{*}
$$

Sendo $C_{b}$ um fator de ajuste. 
Para (DE SOUZA, 2012) esse coeficiente é encarado como um parâmetro de uniformização do momento e tem o mesmo papel que o coeficiente de flambagem para as barras sob compressão.

De acordo com (FRUCHTENGARTEN, 2005) um grande número de pesquisadores trabalham com vista a desenvolver expressões cada vez mais realista para estimar o valor de $C_{b}$. A Norma Brasileira NBR 8800 de 2008 estabelece um valor para o fator de ajuste com base nas recomendações da norma americana, calculado como:

$$
C_{b}=\frac{12,5 M_{\text {máx }}}{2,5 M_{\text {máx }}+3 M_{A}+4 M_{B}+3 M_{C}} \leq 3,0
$$

Sendo $C_{b}=1,0$ para a viga em balanço. Os valores de $M_{\text {máx }}, M_{A}, M_{B}$ e $M_{C}$ da equação (8.24) referem-se respectivamente ao momento máximo, a um quarto, a metade e a três quartos entre os extremo restringido, obtidos do diagrama de momento fletor para as demais condições de contorno e carregamento.

Para se aplicar a equação (8.23) ao exemplo de flambagem lateral do perfil I, realiza-se uma análise paramétrica para se determinar o valor do fator de redução empregando-se os elementos de barra geral e casca não-linear.

A análise segue a metodologia proposta por (SALVADORI, 1955) apud (FRUCHTENGARTEN, 2005), o qual utiliza o programa PEFSYS para realizar as análises. O elemento de barra usado pelo PEFSYS consta de sete parâmetros nodais, a saber: três translações, três rotações e um modo de empenamento. Os resultados obtidos pelo autor são reproduzidos na Figura 70 para que comparações possam ser realizadas. 


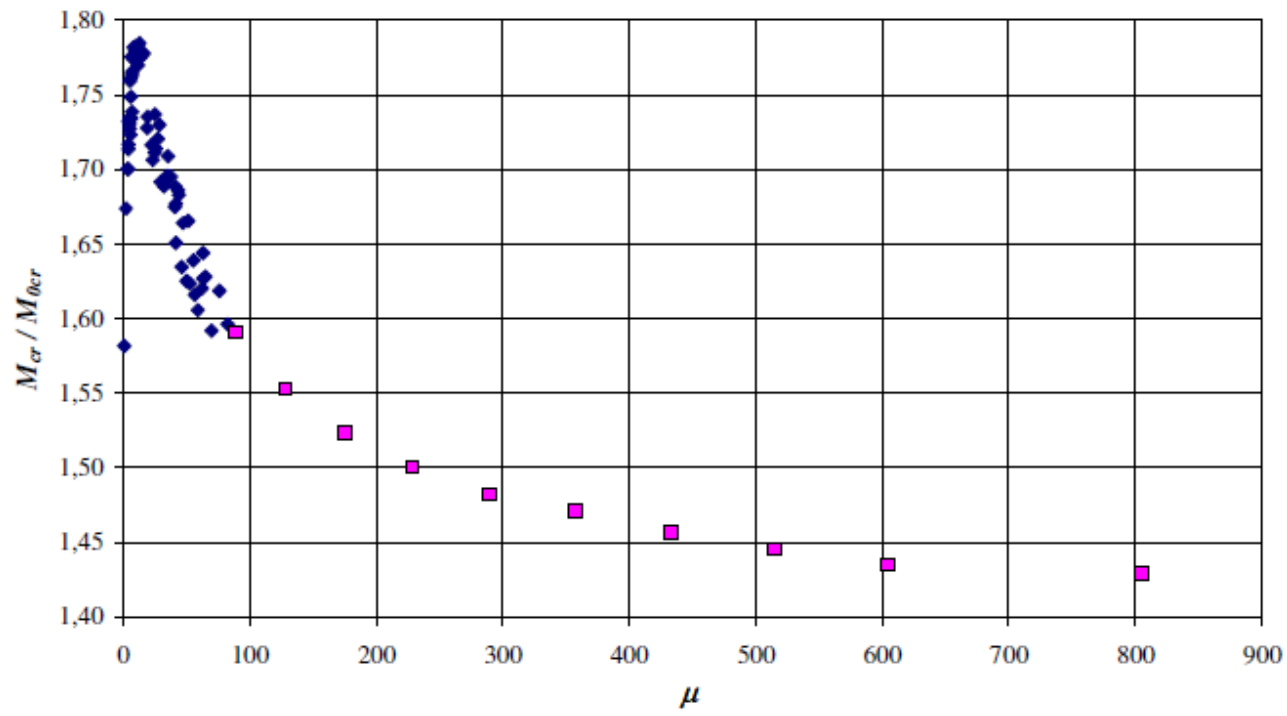

$\bullet$ PEFSYS (Inicial) $\square$ Casos Adicionais

Figura 70: Análise paramétrica para vigas em balanço. (FRUCHTENGARTEN, 2005)

O parâmetro $\mu$ é calculado como:

$$
\mu=\frac{G I_{t}}{E C_{w}} L^{2}
$$

Nas análises a seguir, mantem-se as dimensões do perfil constante e varia-se o comprimento da viga, portanto, o valor do parâmetro passa a ser expresso como: $\mu=1,544368 \times 10^{-4} L^{2}$.

Para que as soluções deduzidas analiticamente em (TIMOSHENKO e GERE, 1961) possam ser avaliadas, o fator de ajuste deve ser expresso por meio da seguinte equação:

$$
C_{b}=\frac{\gamma}{\pi \sqrt{1+\frac{\pi^{2}}{\mu}}}
$$

No gráfico da figura estão expressos os resultados obtidos com o elemento de barra geral e de casca não-linear geométrico. Apresentam-se também os resultados empregando-se as equações (8.21) e (8.22) propostas por (TIMOSHENKO e GERE, 1961). 


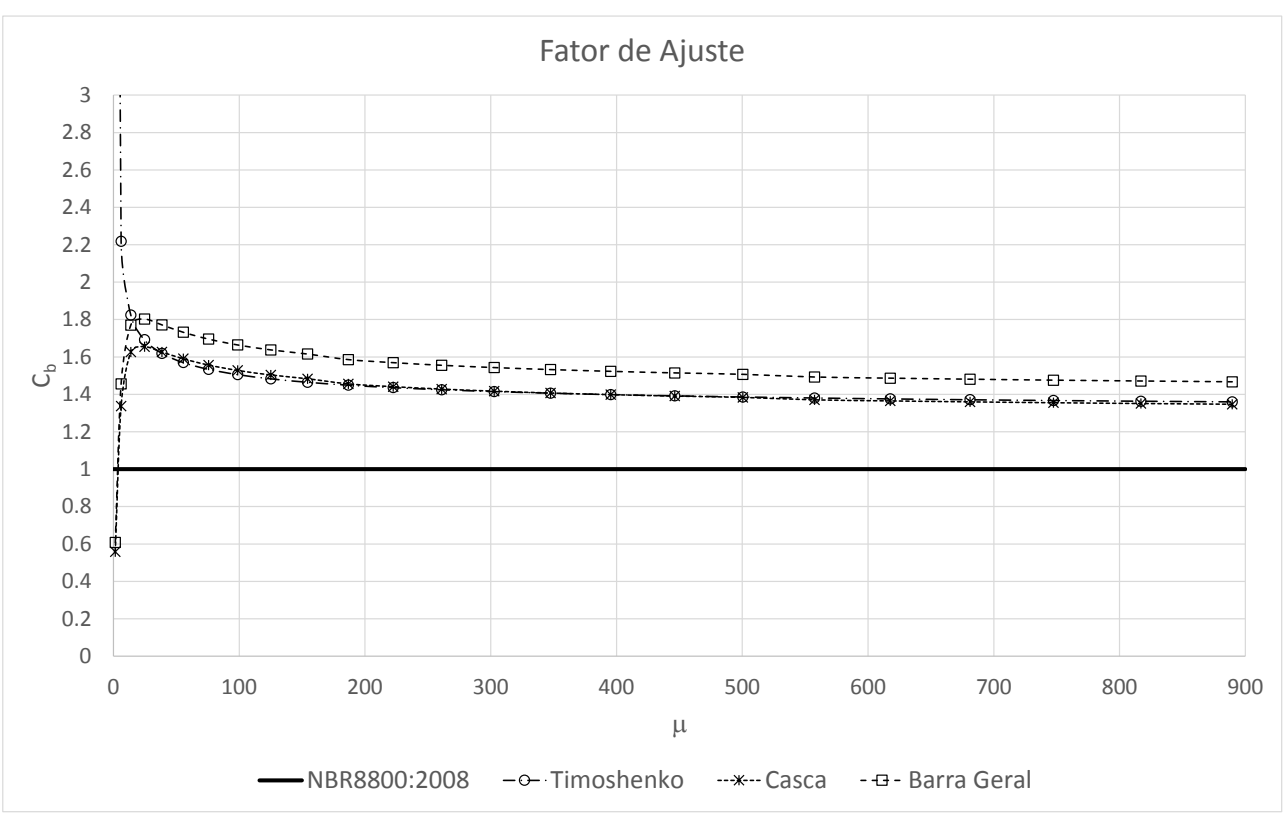

Figura 71: Análise paramétrica para vigas em balanço. Fator de ajuste do momento crítico

Com os resultados da Figura 71 é possível concluir primeiramente que o valor proposto pela norma NBR 8800:2008 é bastante conservador para o caso da viga engastada. Quanto aos resultados obtidos com os elemento posicional não-linear geométrico verifica-se por conta do travamento ocorrido no elemento de barra geral os resultados se mostram a favor da segurança, enquanto que os valores obtidos para o elemento de casca praticamente coincidem com os resultados das equações analíticas. Para vigas de comprimento $L \geq 300 \mathrm{~cm}$ a diferença entre a solução apresentada por (TIMOSHENKO e GERE, 1961) não passa de 1\% dos resultados obtidos com o elemento de casca. Os resultados do momento crítico obtidos para uma faixa usual de comprimento da viga estão ilustrados na Tabela 9.

Tabela 9: Momento crítico para vigas engastadas com carga na extremidade livre

\begin{tabular}{|c|c|c|c|}
\hline \multicolumn{4}{|c|}{ Mcr (kN.cm) } \\
\hline $\mathrm{L}(\mathrm{cm})$ & Mcr Casca & Mcr Barra & Mcr Timoshenko \\
\hline 300 & 7890.17 & 8592.13 & 8851.30 \\
\hline 400 & 5448.90 & 5933.67 & 5570.73 \\
\hline 500 & 4058.32 & 4419.37 & 4039.44 \\
\hline 600 & 3201.83 & 3486.69 & 3160.88 \\
\hline 700 & 2632.33 & 2866.52 & 2593.29 \\
\hline 800 & 2229.98 & 2428.38 & 2197.20 \\
\hline 900 & 1932.08 & 2103.97 & 1905.42 \\
\hline 1000 & 1703.28 & 1854.81 & 1681.69 \\
\hline 1100 & 1512.08 & 1646.61 & 1504.78 \\
\hline 1200 & 1366.31 & 1487.86 & 1361.41 \\
\hline 1300 & 1245.96 & 1356.81 & 1242.90 \\
\hline 1400 & 1144.97 & 1246.84 & 1143.32 \\
\hline 1500 & 1059.05 & 1153.27 & 1058.48 \\
\hline
\end{tabular}


Nota-se que os valores obtidos por (FRUCHTENGARTEN, 2005) também se mostram a favor da segurança, cuja tendência do fator é $C_{b}=1,4$ para valores de $\mu>80$, que compreende as vigas da ordem de $L>800 \mathrm{~cm}$.

Verifica-se que esta tendência permanece no gráfico da Figura 71, porem chega-se a parâmetros da ordem de $C_{b}=1,34$, para o elemento de casca e $C_{b}=1,46$, para o elemento de barra geral.

Apesar da estimativa com o elemento de casca ser menos conservadora do que a observada no artigo de referência, ainda é superior aos valores das fórmulas disponíveis na literatura, que chegam a $C_{b}=1,28$ quando $\mu \rightarrow \infty$.

Para que se verifiquem fatores dessa magnitude é necessário, além da consideração da variação do comprimento a valores completamente fora da realidade de projeto, é preciso que se realize uma análise paramétrica variando-se também as dimensões do perfil. Esse tipo de análise leva a uma estimativa mais rigorosa do fator de ajuste.

De maneira geral, os resultados para o momento crítico de vigas engastadas com seção I simétricas e carregamento aplicado no centro de torção, mostraram-se satisfatórios. Recomendando-se o elemento de casca para se proceder as análises do fenômeno de instabilidade lateral com torção.

Das análises anteriores é possível constatar que ao se empregar a cinemática do elemento finito de barra geral na modelagem de perfis de parede fina, verifica-se a ocorrência de um certo tipo de travamento, justificável pela falta de mobilidade que a seção transversal tem em se deformar conforme os modos locais de chapa.

De acordo com (BABUšKA e SURI, 1992 a) distinguem-se três principais tipos de travamento no método dos elementos finitos, o travamento volumétrico, o travamento devido ao cisalhamento e o travamento de membrana.

Diferentes técnicas para contornar o fenômeno de travamento são citadas em (MUKHERJEE e PRATHAP, 2001) dentre as quais destaca-se as técnicas com base nos aprimoramentos das deformações, e que será utilizada neste trabalho. 
No que segue, apresenta-se a metodologia considerada na introdução dos aprimoramentos da cinemática do elemento finito de barra geral. São inseridas novas mobilidades na da seção transversal com a finalidade de se captar os efeitos da instabilidade local e distorcional no plano e forra do plano, característica dos perfis esbeltos.

\subsection{Aprimoramentos nas Mobilidades da Seção Transversal}

O elemento de barra geral ainda não está preparado para modelar problemas onde as tensões de compressão induzam a instabilidade local da seção. Esse efeito pode ser tratado como um tipo de travamento, pois existe uma lacuna de mobilidades na cinemática da barra, incapaz de quantificar a influência das deformações da seção transversal na instabilidade da estrutura. Inserir essas mobilidades no elemento e estudar a instabilidade local de perfis esbeltos é o objeto de estudo da presente pesquisa. O caráter inovador desse estudo consiste em se aprimorar a cinemática do elemento finito posicional de barra geral.

No que segue, apresenta-se a metodologia proposta capaz de avaliar a mudança de forma das seções transversais durante a deformação longitudinal da barra. A formulação baseia-se na introdução de novas mobilidades geradas no plano e fora do plano da seção transversal.

As mobilidades no plano da seção são inseridas a partir de uma nova parcela na cinemática do elemento, enquanto as mobilidades fora do plano da seção são introduzidas na parcela do modo de empenamento.

As configurações deformadas da seção são obtidas analisando-as com o elemento de casca não linear geométrico, que será detalhado no próximo capítulo. Após se proceder uma a análise linear de instabilidade obtém-se os autovetores com o espectro de mobilidades da seção.

\subsubsection{Aprimoramentos no Plano da Seção Transversal}

Apresenta-se primeiramente a proposta de enriquecimento cinemático de uma mobilidade específica no plano da seção transversal. Em seguida, adota-se a mesma estratégia, para generalizar o procedimento e considerar um número qualquer de graus de liberdade associados as diferentes mobilidades não-lineares. Por fim, apresentam-se a contribuição das mobilidades fora do plano da seção, na parcela cinemática do empenamento. 
Considera-se o caso elementar de uma barra geral com seção transversal do tipo canal ou C. Admite-se a barra sob flexão pura, portanto, considera-se o carregamento sobre o centro de cisalhamento do perfil, na direção perpendicular ao eixo de maior inércia.

Na seção transversal haverá uma região comprimida capaz de provocar instabilidade local. Se o perfil possui geometria idealmente reta ocorrerá um ponto de bifurcação, caso contrário, a seção irá se deformar conforme as configurações ilustradas na Figura 72.

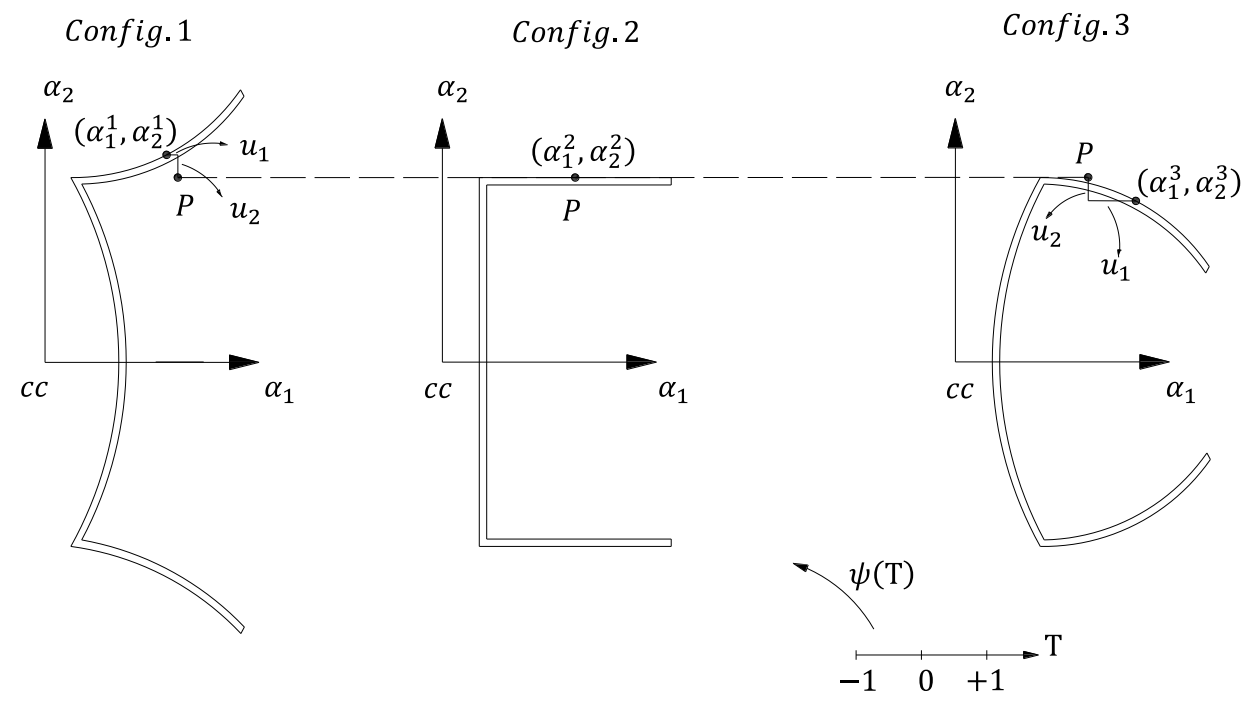

Figura 72: Mobilidades no plano da seção

As configurações 1 e 3 representam as deformadas do perfil após perda de estabilidade. A configuração 2 representa o perfil em sua posição indeformada.

Para que essa característica seja inserida no elemento introduz-se um enriquecimento cinemático relativo a mobilidade não-linear, capaz de detectar as deformações da seção transversal.

O mapeamento dado em (8.8) passa a ter os seguintes termos adicionais: 


$$
\begin{aligned}
& Y_{i}(P)=\varphi_{j}\left(\xi_{1}\right) y_{i j}+ \\
& {\left[\vartheta_{k}\left(\xi_{2}, \xi_{3}\right) \alpha_{k}^{1}\right] \varphi_{j}\left(\xi_{1}\right) g_{i j}^{1}+} \\
& {\left[\vartheta_{k}\left(\xi_{2}, \xi_{3}\right) \alpha_{k}^{2}\right] \varphi_{j}\left(\xi_{1}\right) g_{i j}^{2}+} \\
& {\left[\vartheta_{k}\left(\xi_{2}, \xi_{3}\right) \alpha_{k}^{1}\right]^{2}\left[\varphi_{\ell}\left(\xi_{1}\right) a_{\ell}^{1}\right] \varphi_{j}\left(\xi_{1}\right) g_{i j}^{1}+} \\
& {\left[\vartheta_{k}\left(\xi_{2}, \xi_{3}\right) \alpha_{k}^{2}\right]^{2}\left[\varphi_{\ell}\left(\xi_{1}\right) a_{\ell}^{2}\right] \varphi_{j}\left(\xi_{1}\right) g_{i j}^{2}+} \\
& {\left[\vartheta_{k}\left(\xi_{2}, \xi_{3}\right) w_{k}\right]\left[\varphi_{j}\left(\xi_{1}\right) \varpi_{j}\right]\left[\varphi_{a}\left(\xi_{1}\right) g_{a p}^{1}\right]\left[\varphi_{b}\left(\xi_{1}\right) g_{b q}^{2}\right] \varepsilon_{p q i}+} \\
& {\left[\vartheta_{k}\left(\xi_{2}, \xi_{3}\right) u_{k}^{1}\right] \varphi_{j}\left(\xi_{1}\right) g_{i j}^{1}+\left[\vartheta_{k}\left(\xi_{2}, \xi_{3}\right) u_{k}^{2}\right] \varphi_{j}\left(\xi_{1}\right) g_{i j}^{2}}
\end{aligned}
$$

Sendo $u_{k}^{1}$ e $u_{k}^{2}$ as componentes do deslocamento da seção. Ao se flexibilizar a seção com esses deslocamentos, a mudança de forma no plano da seção poderá ser ativada durante a deformação da estrutura.

O espectro dos deslocamentos gerado pelas mobilidades transversais é obtido a partir das configurações ilustradas na Figura 72, a partir de uma interpolação ou extrapolação polinomial. A seguir descreve-se a interpretação do parâmetro nodal correspondente a mobilidade da seção.

\subsubsection{Mobilidades Transversais como Parâmetros Nodais}

A interpolação ou extrapolação do modo transversal é obtido procedendo-se o mapeamento das configurações deformadas com o auxílio do espaço de coordenadas de Gauss, através da função interpoladora $\psi(\mathrm{T})$.

A fim de esclarecer essa correspondência, considere-se as configurações 1,2 e 3 do espaço físico através do mapeamento dado por meio da função interpoladora $\psi(\mathrm{T})$. Essa função associa o espaço de coordenadas adimensionais ao espaço físico correspondente a cada uma das configurações deformadas. Por exemplo: a configuração deformada 1 está associada a coordenada $\mathrm{T}=-1$, a configuração indeformada 2 , a coordenada $\mathrm{T}=0$ e a configuração deformada 3 a coordenada $\mathrm{T}=+1$.

As funções de forma são geradas a partir dos polinômios de Lagrange de ordem qualquer. Neste exemplo, adota-se o polinômio quadrático pois, cada configuração pode ser 
associada a uma coordenada do espaço adimensional, sendo a configuração indeformada, ou a configuração de referência, sempre correspondente ao ponto médio do intervalo adimensional.

A mudança de forma não linear é obtida a partir da interpolação das configurações representadas na Figura 72.

Adotando-se o sistema de referência com origem no centro de cisalhamento. Qualquer configuração intermediária será calculada a partir das equações:

Na direção de $\alpha^{1}$ :

$$
e_{k}^{1}=\psi_{1}(\mathrm{~T}) \alpha_{1 k}^{1}+\psi_{2}(\mathrm{~T}) \alpha_{2 k}^{1}+\psi_{3}(\mathrm{~T}) \alpha_{3 k}^{1}
$$

Na direção de $\alpha^{2}$ :

$$
e_{k}^{2}=\psi_{1}(\mathrm{~T}) \alpha_{1 k}^{2}+\psi_{2}(\mathrm{~T}) \alpha_{2 k}^{2}+\psi_{3}(\mathrm{~T}) \alpha_{3 k}^{2}
$$

De maneira geral escreve-se:

$$
e_{k}^{n}=\psi_{\ell}(\mathrm{T}) \alpha_{\ell k}^{n}
$$

O índice ${ }_{n}$ representa as componentes das coordenadas físicas da seção transversal e o subscrito $\ell$ indica a configuração da seção. $O$ índice $k$ representa o nó usado na discretização da seção transversal.

As componentes dos deslocamentos são calculadas sempre em relação a configuração indeformada da seção, com $\mathrm{T}=0$. Assim, a deformação de qualquer nó da seção obtida fazendo-se:

$$
u_{k}^{n}=e_{k}^{n}-\alpha_{2 k}^{n}=\psi_{\ell}(\mathrm{T}) \alpha_{\ell k}^{n}-\psi_{2}(0) \alpha_{2 k}^{n}
$$

De posse das equações (8.28) e (8.29) o deslocamento é obtido a partir do desenvolvimento:

$$
u_{k}^{n}=\psi_{1}(\mathrm{~T}) \alpha_{1 k}^{n}+\psi_{2}(\mathrm{~T}) \alpha_{2 k}^{n}+\psi_{3}(\mathrm{~T}) \alpha_{3 k}^{n}-\psi_{2}(0) \alpha_{2 k}^{n}
$$

Ou ainda, devido a propriedade da partição da unidade, tem-se: 


$$
u_{k}^{n}=\psi_{1}(\mathrm{~T}) \alpha_{1 k}^{n}+\left[\psi_{2}(\mathrm{~T})-1\right] \alpha_{2 k}^{n}+\psi_{3}(\mathrm{~T}) \alpha_{3 k}^{n}
$$

Usando uma notação mais compacta, faz-se:

$$
u_{k}^{n}=\bar{\psi}_{\ell}(\mathrm{T}) \alpha_{\ell k}^{n}
$$

Sendo, $\bar{\psi}_{1}(\mathrm{~T})=\psi_{1}(\mathrm{~T}), \bar{\psi}_{2}(\mathrm{~T})=\psi_{2}(\mathrm{~T})-1$ e $\bar{\psi}_{3}(\mathrm{~T})=\psi_{3}(\mathrm{~T})$ as funções de forma associadas à mudança de configuração da seção, em relação à configuração de referência.

O parâmetro T representa a mobilidade não-linear no plano da seção transversal. Qualquer seção ao longo da linha de referência experimentará a influência dessa mobilidade. Para que essa característica seja inserida ao elemento, a mudança de forma das seções em todos os pontos da linha de referência deverá ser calculada com a interpolação:

$$
\mathrm{T}=\varphi_{j}\left(\xi_{1}\right) \tau_{j}
$$

Sendo $\tau_{j}$ a nova variável, energeticamente conjugada a força capaz de produzir a mudança de forma da seção transversal. Esse valor é do novo parâmetro nodal associado a mobilidade da seção.

Inserindo-se a equação (8.34) em (8.35) obtêm-se o campo de deslocamento, $u_{k}^{n}$, em função da intensidade do parâmetro nodal $\tau_{j}$, dado por:

$$
u_{k}^{n}=\bar{\psi}_{\ell}\left(\varphi_{j}\left(\xi_{1}\right) \tau_{j}\right) \alpha_{\ell k}^{n}
$$

Substituindo as componentes dos deslocamentos (8.36) na equação (8.27), obtém-se o mapeamento geral com as mobilidades no plano da seção transversal. 


$$
\begin{aligned}
& Y_{i}(P)=\varphi_{j}\left(\xi_{1}\right) y_{i j}+ \\
& {\left[\vartheta_{k}\left(\xi_{2}, \xi_{3}\right) \alpha_{k}^{1}\right] \varphi_{j}\left(\xi_{1}\right) g_{i j}^{1}+} \\
& {\left[\vartheta_{k}\left(\xi_{2}, \xi_{3}\right) \alpha_{k}^{2}\right] \varphi_{j}\left(\xi_{1}\right) g_{i j}^{2}+} \\
& {\left[\vartheta_{k}\left(\xi_{2}, \xi_{3}\right) \alpha_{k}^{1}\right]^{2}\left[\varphi_{\ell}\left(\xi_{1}\right) a_{\ell}^{1}\right] \varphi_{j}\left(\xi_{1}\right) g_{i j}^{1}+} \\
& {\left[\vartheta_{k}\left(\xi_{2}, \xi_{3}\right) \alpha_{k}^{2}\right]^{2}\left[\varphi_{\ell}\left(\xi_{1}\right) a_{\ell}^{2}\right] \varphi_{j}\left(\xi_{1}\right) g_{i j}^{2}+} \\
& {\left[\vartheta_{k}\left(\xi_{2}, \xi_{3}\right) w_{k}\right]\left[\varphi_{j}\left(\xi_{1}\right) \varpi_{j}\right]\left[\varphi_{a}\left(\xi_{1}\right) g_{a p}^{1}\right]\left[\varphi_{b}\left(\xi_{1}\right) g_{b q}^{2}\right] \varepsilon_{p q i}+} \\
& {\left[\vartheta_{k}\left(\xi_{2}, \xi_{3}\right)\left\{\bar{\psi}_{\ell}\left(\varphi_{j}\left(\xi_{1}\right) \tau_{j}\right) \alpha_{\ell k}^{1}\right\}\right] \varphi_{j}\left(\xi_{1}\right) g_{i j}^{1}+} \\
& {\left[\vartheta_{k}\left(\xi_{2}, \xi_{3}\right)\left\{\bar{\psi}_{\ell}\left(\varphi_{j}\left(\xi_{1}\right) \tau_{j}\right) \alpha_{\ell k}^{2}\right\}\right] \varphi_{j}\left(\xi_{1}\right) g_{i j}^{2}}
\end{aligned}
$$

Como comentado anteriormente, a introdução desse grau de liberdade considera apenas a mudança de forma da seção devido a uma mobilidade não-linear, porém, a seção pode se deformar segundo diversas mobilidades. É de interesse, generalizar a formulação a fim de considerar um número qualquer de formas com que a seção deformará.

A mudança de forma ocorre de forma mais ou menos suave, de acordo com a existência de defeitos na seção transversal, porém, nada impede que ao longo da trajetória de equilíbrio se encontrem pontos de bifurcação.

Ao se considerar um número qualquer de formas não lineares, com qualquer grau de aproximação, alerta-se para o uso específico de polinômios de grau par, tendo em vista que é conveniente se associar a configuração indeformada à coordenada média do espaço adimensional de coordenadas, ou seja, a coordenada com valor nulo.

Para a generalização do procedimento obedece-se a mesma estrutura e metodologia apresentada no início da seção.

O mapeamento geral considerando um número qualquer de mobilidades é obtido fazendo-se:

$$
Y_{i}=\bar{Y}_{i}+W_{i}+M_{i}
$$

Sendo, 


$$
\begin{aligned}
& \bar{Y}_{i}(P)=\varphi_{j}\left(\xi_{1}\right) y_{i j}+ \\
& {\left[\vartheta_{k}\left(\xi_{2}, \xi_{3}\right) \alpha_{k}^{1}\right] \varphi_{j}\left(\xi_{1}\right) g_{i j}^{1}+} \\
& {\left[\vartheta_{k}\left(\xi_{2}, \xi_{3}\right) \alpha_{k}^{2}\right] \varphi_{j}\left(\xi_{1}\right) g_{i j}^{2}+} \\
& {\left[\vartheta_{k}\left(\xi_{2}, \xi_{3}\right) \alpha_{k}^{1}\right]^{2}\left[\varphi_{\ell}\left(\xi_{1}\right) a_{\ell}^{1}\right] \varphi_{j}\left(\xi_{1}\right) g_{i j}^{1}+} \\
& {\left[\vartheta_{k}\left(\xi_{2}, \xi_{3}\right) \alpha_{k}^{2}\right]^{2}\left[\varphi_{\ell}\left(\xi_{1}\right) a_{\ell}^{2}\right] \varphi_{j}\left(\xi_{1}\right) g_{i j}^{2}}
\end{aligned}
$$

$\mathrm{E}$

$$
\begin{aligned}
& M_{i}=\left[\vartheta_{k}\left(\xi_{2}, \xi_{3}\right)\left\{\bar{\psi}_{\ell}\left(\varphi_{j}\left(\xi_{1}\right) \tau_{j}^{t}\right) \alpha_{\ell k}^{1 t}\right\}\right] \varphi_{j}\left(\xi_{1}\right) g_{i j}^{1}+ \\
& {\left[\vartheta_{k}\left(\xi_{2}, \xi_{3}\right)\left\{\bar{\psi}_{\ell}\left(\varphi_{j}\left(\xi_{1}\right) \tau_{j}^{t}\right) \alpha_{\ell k}^{2 t}\right\}\right] \varphi_{j}\left(\xi_{1}\right) g_{i j}^{2}}
\end{aligned}
$$

\subsubsection{Aprimoramentos Fora do Plano da Seção Transversal}

Com a mesma ideia usada na generalização do número de mobilidades no plano da seção, introduz-se as mobilidades fora do plano, equação (8.40). Esses parâmetros são adicionados a parcela do empenamento da seção, chamada de $W_{i}$.

$$
W_{i}=\left[\vartheta_{k}^{r}\left(\xi_{2}, \xi_{3}\right) w_{k}^{r}\right]\left[\varphi_{j}\left(\xi_{1}\right) \varpi_{j}\right]\left[\varphi_{a}\left(\xi_{1}\right) g_{a p}^{1}\right]\left[\varphi_{b}\left(\xi_{1}\right) g_{b q}^{2}\right] \varepsilon_{p q i}
$$

Como o índice $t$ e $r$ são índices mudos, cabe salientar que a sua ocorrência não condiciona o número de modos transversais coplanares ser igual ao número de modos não coplanares. Além disso, a primeira mobilidade, devido ao empenamento, continua sendo igual a mobilidade unitária calculada a partir do problema da torção livre de Saint-Venant, enquanto as demais, são obtidas da mesma maneira, porém, pré-processadas a partir da análise dos vetores próprios do elemento de casca não linear geométrico.

De posse da cinemática do elemento de barra geral é necessário se determinar o gradiente da transformação para se contabilizar a variação da função devido as deformações que ocorrem no sólido. A seguir demonstram-se os cálculos do gradiente nas configurações inicial e atual. 


\subsection{Gradiente da Transformação}

Nesta seção apresentam-se os desenvolvimentos utilizados no cálculo do gradiente da função mudança de configuração inicial e atual, tal como implementadas no código computacional desenvolvido.

\subsubsection{Gradiente na Configuração Inicial}

Reescrevendo a cinemática do elemento de barra geral na configuração inicial, tem-se:

$$
f_{i}^{0}=\varphi_{j}\left(\xi_{1}\right) x_{i j}+\left[\vartheta_{k}\left(\xi_{2}, \xi_{3}\right) \alpha_{k}^{1}\right] \varphi_{j}\left(\xi_{1}\right) v_{i j}^{1}+\left[\vartheta_{k}\left(\xi_{2}, \xi_{3}\right) \alpha_{k}^{2}\right] \varphi_{j}\left(\xi_{1}\right) v_{i j}^{2}
$$

O gradiente na configuração inicial é dado por:

$$
A_{i \ell}^{0}=\frac{\partial f_{i}^{0}}{\partial \xi_{\ell}}=f_{i, \ell}^{0}
$$

Cujas componentes são:

$$
\begin{aligned}
f_{i, 1}^{0} & =\varphi_{j, 1}\left(\xi_{1}\right) x_{i j}+\left[\vartheta_{k}\left(\xi_{2}, \xi_{3}\right) \alpha_{k}^{1}\right] \varphi_{j, 1}\left(\xi_{1}\right) v_{i j}^{1}+\left[\vartheta_{k}\left(\xi_{2}, \xi_{3}\right) \alpha_{k}^{2}\right] \varphi_{j, 1}\left(\xi_{1}\right) v_{i j}^{2} \\
f_{i, 2}^{0} & =\left[\vartheta_{k, 2}\left(\xi_{2}, \xi_{3}\right) \alpha_{k}^{1}\right] \varphi_{j}\left(\xi_{1}\right) v_{i j}^{1}+\left[\vartheta_{k, 2}\left(\xi_{2}, \xi_{3}\right) \alpha_{k}^{2}\right] \varphi_{j}\left(\xi_{1}\right) v_{i j}^{2} \\
f_{i, 3}^{0} & =\left[\vartheta_{k, 3}\left(\xi_{2}, \xi_{3}\right) \alpha_{k}^{1}\right] \varphi_{j}\left(\xi_{1}\right) v_{i j}^{j}+\left[\vartheta_{k, 3}\left(\xi_{2}, \xi_{3}\right) \alpha_{k}^{2}\right] \varphi_{j}\left(\xi_{1}\right) v_{i j}^{2}
\end{aligned}
$$

\subsubsection{Gradiente na Configuração Atual}

Com a finalidade de tornar mais didática a obtenção do gradiente na configuração atual, reescreve-se o gradiente como a soma das seguintes parcelas:

$$
f_{i}^{1}=B_{i}^{1}+C_{i}^{1}+D_{i}^{1}+M_{i}^{1}+W_{i}^{1}
$$

Sendo:

$$
\begin{gathered}
B_{i}^{1}=\varphi_{j}\left(\xi_{1}\right) y_{i j} \\
C_{i}^{1}=\left[\vartheta_{k}\left(\xi_{2}, \xi_{3}\right) \alpha_{k}^{1}\right] \varphi_{j}\left(\xi_{1}\right) g_{i j}^{1}+\left[\vartheta_{k}\left(\xi_{2}, \xi_{3}\right) \alpha_{k}^{2}\right] \varphi_{j}\left(\xi_{1}\right) g_{i j}^{2}
\end{gathered}
$$




$$
\begin{gathered}
D_{i}^{1}=\left[\vartheta_{k}\left(\xi_{2}, \xi_{3}\right) \alpha_{k}^{1}\right]^{2}\left[\varphi_{\ell}\left(\xi_{1}\right) a_{\ell}^{1}\right] \varphi_{j}\left(\xi_{1}\right) g_{i j}^{1}+ \\
{\left[\vartheta_{k}\left(\xi_{2}, \xi_{3}\right) \alpha_{k}^{2}\right]^{2}\left[\varphi_{\ell}\left(\xi_{1}\right) a_{\ell}^{2}\right] \varphi_{j}\left(\xi_{1}\right) g_{i j}^{2}} \\
M_{i}^{1}=\left[\vartheta_{k}\left(\xi_{2}, \xi_{3}\right)\left\{\bar{\psi}_{\ell}\left(\varphi_{j}\left(\xi_{1}\right) \tau_{j}^{t}\right) \alpha_{\ell k}^{1 t}\right\}\right] \varphi_{j}\left(\xi_{1}\right) g_{i j}^{1}+ \\
{\left[\vartheta_{k}\left(\xi_{2}, \xi_{3}\right)\left\{\bar{\psi}_{\ell}\left(\varphi_{j}\left(\xi_{1}\right) \tau_{j}^{t}\right) \alpha_{\ell k}^{2 t}\right\}\right] \varphi_{j}\left(\xi_{1}\right) g_{i j}^{2}}
\end{gathered}
$$

E finalmente,

$$
W_{i}^{1}=\left[\vartheta_{k}^{r}\left(\xi_{2}, \xi_{3}\right) w_{k}^{r}\right]\left[\varphi_{j}\left(\xi_{1}\right) \varpi_{j}\right]\left[\varphi_{a}\left(\xi_{1}\right) g_{a p}^{1}\right]\left[\varphi_{b}\left(\xi_{1}\right) g_{b q}^{2}\right] \varepsilon_{p q i}
$$

Portanto, na configuração atual o gradiente da transformação é dado por:

$$
A_{i m}^{1}=\frac{\partial}{\partial \xi_{m}}\left\{B_{i}^{1}+C_{i}^{1}+D_{i}^{1}+M_{i}^{1}+W_{i}^{1}\right\}=B_{i, m}^{1}+C_{i, m}^{1}+D_{i, m}^{1}+M_{i, m}^{1}+W_{i, m}^{1}
$$

A seguir, calcula-se o gradiente de cada parcela:

Parcela $B_{i, m}^{1}$ :

$$
\begin{aligned}
& B_{\mathrm{i}, 1}^{1}=\varphi_{j, 1}\left(\xi_{1}\right) y_{i j} \\
& B_{\mathrm{i}, 2}^{1}=0 \\
& B_{\mathrm{i}, 3}^{1}=0
\end{aligned}
$$

Parcela $C_{i, m}^{1}$ :

$$
\begin{aligned}
C_{i, 1}^{1} & =\left[\vartheta_{k}\left(\xi_{2}, \xi_{3}\right) \alpha_{k}^{1}\right] \varphi_{j, 1}\left(\xi_{1}\right) g_{i j}^{1}+\left[\vartheta_{k}\left(\xi_{2}, \xi_{3}\right) \alpha_{k}^{2}\right] \varphi_{j, 1}\left(\xi_{1}\right) g_{i j}^{2} \\
C_{i, 2}^{1} & =\left[\vartheta_{k, 2}\left(\xi_{2}, \xi_{3}\right) \alpha_{k}^{1}\right] \varphi_{j}\left(\xi_{1}\right) g_{i j}^{1}+\left[\vartheta_{k, 2}\left(\xi_{2}, \xi_{3}\right) \alpha_{k}^{2}\right] \varphi_{j}\left(\xi_{1}\right) g_{i j}^{2} \\
C_{i, 3}^{1} & =\left[\vartheta_{k, 3}\left(\xi_{2}, \xi_{3}\right) \alpha_{k}^{1}\right] \varphi_{j}\left(\xi_{1}\right) g_{i j}^{1}+\left[\vartheta_{k, 3}\left(\xi_{2}, \xi_{3}\right) \alpha_{k}^{2}\right] \varphi_{j}\left(\xi_{1}\right) g_{i j}^{2}
\end{aligned}
$$

Parcela $D_{i, m}^{1}$ : 


$$
\begin{aligned}
& D_{\mathrm{i}, 1}^{1}=\left[\vartheta_{k}\left(\xi_{2}, \xi_{3}\right) \alpha_{k}^{1}\right]^{2}\left[\varphi_{\ell, 1}\left(\xi_{1}\right) a_{\ell}^{1}\right] \varphi_{j}\left(\xi_{1}\right) g_{i j}^{1}+ \\
& {\left[\vartheta_{k}\left(\xi_{2}, \xi_{3}\right) \alpha_{k}^{1}\right]^{2}\left[\varphi_{\ell}\left(\xi_{1}\right) a_{\ell}^{1}\right] \varphi_{j, 1}\left(\xi_{1}\right) g_{i j}^{1}} \\
& {\left[\vartheta_{k}\left(\xi_{2}, \xi_{3}\right) \alpha_{k}^{2}\right]^{2}\left[\varphi_{\ell, 1}\left(\xi_{1}\right) a_{\ell}^{2}\right] \varphi_{j}\left(\xi_{1}\right) g_{i j}^{2}+} \\
& {\left[\vartheta_{k}\left(\xi_{2}, \xi_{3}\right) \alpha_{k}^{2}\right]^{2}\left[\varphi_{\ell}\left(\xi_{1}\right) a_{\ell}^{2}\right] \varphi_{j, 1}\left(\xi_{1}\right) g_{i j}^{2}} \\
& D_{\mathrm{i}, 2}^{1}=2 \vartheta_{k}\left(\xi_{2}, \xi_{3}\right) \alpha_{k}^{1}\left[\vartheta_{k, 2}\left(\xi_{2}, \xi_{3}\right) \alpha_{k}^{1}\right]\left[\varphi_{\ell}\left(\xi_{1}\right) a_{\ell}^{1}\right] \varphi_{j}\left(\xi_{1}\right) g_{i j}^{1}+ \\
& 2 \vartheta_{k}\left(\xi_{2}, \xi_{3}\right) \alpha_{k}^{2}\left[\vartheta_{k, 2}\left(\xi_{2}, \xi_{3}\right) \alpha_{k}^{2}\right]\left[\varphi_{\ell}\left(\xi_{1}\right) a_{\ell}^{2}\right] \varphi_{j}\left(\xi_{1}\right) g_{i j}^{2} \\
& D_{\mathrm{i}, 3}^{1}=2 \vartheta_{k}\left(\xi_{2}, \xi_{3}\right) \alpha_{k}^{1}\left[\vartheta_{k, 3}\left(\xi_{2}, \xi_{3}\right) \alpha_{k}^{1}\right]\left[\varphi_{\ell}\left(\xi_{1}\right) a_{\ell}^{1}\right] \varphi_{j}\left(\xi_{1}\right) g_{i j}^{1}+ \\
& 2 \vartheta_{k}\left(\xi_{2}, \xi_{3}\right) \alpha_{k}^{2}\left[\vartheta_{k, 3}\left(\xi_{2}, \xi_{3}\right) \alpha_{k}^{2}\right]\left[\varphi_{\ell}\left(\xi_{1}\right) a_{\ell}^{2}\right] \varphi_{j}\left(\xi_{1}\right) g_{i j}^{2}
\end{aligned}
$$

Antes de determinar o gradiente de $M_{i}^{1}$ é necessário calcular a derivada de $\bar{\psi}_{\ell}\left(\varphi_{j}\left(\xi_{1}\right) \tau_{j}^{t}\right)$ em relação a $\xi_{1}$.

A derivada da função composta fica:

$$
\bar{\psi}_{\ell, 1}(\mathrm{~T})=\bar{\psi}_{\ell, \mathrm{T}}(\mathrm{T}) \varphi_{j, 1}\left(\xi_{1}\right) \tau_{j}^{t}
$$

A componente $M_{i, 1}^{1}$ é então obtida da seguinte maneira:

$$
\begin{aligned}
& M_{\mathrm{i}, 1}^{1}=\left[\vartheta_{k}\left(\xi_{2}, \xi_{3}\right)\left\{\bar{\psi}_{\ell, 1}\left(\varphi_{j}\left(\xi_{1}\right) \tau_{j}^{t}\right) \alpha_{\ell k}^{1 t}\right\}\right] \varphi_{j}\left(\xi_{1}\right) g_{i j}^{1}+ \\
& {\left[\vartheta_{k}\left(\xi_{2}, \xi_{3}\right)\left\{\bar{\psi}_{\ell}\left(\varphi_{j}\left(\xi_{1}\right) \tau_{j}^{t}\right) \alpha_{\ell k}^{1 t}\right\}\right] \varphi_{j, 1}\left(\xi_{1}\right) g_{i j}^{1}+} \\
& {\left[\vartheta_{k}\left(\xi_{2}, \xi_{3}\right)\left\{\bar{\psi}_{\ell, 1}\left(\varphi_{j}\left(\xi_{1}\right) \tau_{j}^{t}\right) \alpha_{\ell k}^{2 t}\right\}\right] \varphi_{j}\left(\xi_{1}\right) g_{i j}^{2}+} \\
& {\left[\vartheta_{k}\left(\xi_{2}, \xi_{3}\right)\left\{\bar{\psi}_{\ell}\left(\varphi_{j}\left(\xi_{1}\right) \tau_{j}^{t}\right) \alpha_{\ell k}^{2 t}\right\}\right] \varphi_{j, 1}\left(\xi_{1}\right) g_{i j}^{2}}
\end{aligned}
$$

Substituindo (8.55) em (8.56) é possível encontrar o valor do gradiente de $M_{i}^{1}$.

Parcela $M_{i, m}^{1}$ : 


$$
\begin{aligned}
& M_{\mathrm{i}, 1}^{1}=\left[\vartheta_{k}\left(\xi_{2}, \xi_{3}\right)\left\{\bar{\psi}_{\ell, \mathrm{T}}(\mathrm{T}) \varphi_{j, 1}\left(\xi_{1}\right) \tau_{j}^{t} \alpha_{\ell k}^{1 t}\right\}\right] \varphi_{j}\left(\xi_{1}\right) g_{i j}^{1}+ \\
& {\left[\vartheta_{k}\left(\xi_{2}, \xi_{3}\right)\left\{\bar{\psi}_{\ell}\left(\varphi_{j}\left(\xi_{1}\right) \tau_{j}^{t}\right) \alpha_{\ell k}^{1 t}\right\}\right] \varphi_{j, 1}\left(\xi_{1}\right) g_{i j}^{1}+} \\
& {\left[\vartheta_{k}\left(\xi_{2}, \xi_{3}\right)\left\{\bar{\psi}_{\ell, \mathrm{T}}(\mathrm{T}) \varphi_{j, 1}\left(\xi_{1}\right) \tau_{j}^{t} \alpha_{\ell k}^{2 t}\right\}\right] \varphi_{j}\left(\xi_{1}\right) g_{i j}^{2}+} \\
& {\left[\vartheta_{k}\left(\xi_{2}, \xi_{3}\right)\left\{\bar{\psi}_{\ell}\left(\varphi_{j}\left(\xi_{1}\right) \tau_{j}^{t}\right) \alpha_{\ell k}^{2 t}\right\}\right] \varphi_{j, 1}\left(\xi_{1}\right) g_{i j}^{2}} \\
& M_{\mathrm{i}, 2}^{1}=\left[\vartheta_{k, 2}\left(\xi_{2}, \xi_{3}\right)\left\{\bar{\psi}_{\ell}\left(\varphi_{j}\left(\xi_{1}\right) \tau_{j}^{t}\right) \alpha_{\ell k}^{1 t}\right\}\right] \varphi_{j}\left(\xi_{1}\right) g_{i j}^{1}+ \\
& {\left[\vartheta_{k, 2}\left(\xi_{2}, \xi_{3}\right)\left\{\bar{\psi}_{\ell}\left(\varphi_{j}\left(\xi_{1}\right) \tau_{j}^{t}\right) \alpha_{\ell k}^{2 t}\right\}\right] \varphi_{j}\left(\xi_{1}\right) g_{i j}^{2}} \\
& M_{\mathrm{i}, 3}^{1}=\left[\vartheta_{k, 3}\left(\xi_{2}, \xi_{3}\right)\left\{\bar{\psi}_{\ell}\left(\varphi_{j}\left(\xi_{1}\right) \tau_{j}^{t}\right) \alpha_{\ell k}^{1 t}\right\}\right] \varphi_{j}\left(\xi_{1}\right) g_{i j}^{1}+ \\
& {\left[\vartheta_{k, 3}\left(\xi_{2}, \xi_{3}\right)\left\{\bar{\psi}_{\ell}\left(\varphi_{j}\left(\xi_{1}\right) \tau_{j}^{t}\right) \alpha_{\ell k}^{2 t}\right\}\right] \varphi_{j}\left(\xi_{1}\right) g_{i j}^{2}}
\end{aligned}
$$

Parcela $W_{i, m}^{1}$ :

$$
\begin{aligned}
& W_{\mathrm{i}, 1}^{1}=\left[\vartheta_{k}^{r}\left(\xi_{2}, \xi_{3}\right) w_{k}^{r}\right]\left[\varphi_{j, 1}\left(\xi_{1}\right) \varpi_{j}\right]\left[\varphi_{a}\left(\xi_{1}\right) g_{a p}^{1}\right]\left[\varphi_{b}\left(\xi_{1}\right) g_{b q}^{2}\right] \varepsilon_{p q i}+ \\
& {\left[\vartheta_{k}^{r}\left(\xi_{2}, \xi_{3}\right) w_{k}^{r}\right]\left[\varphi_{j}\left(\xi_{1}\right) \varpi_{j}\right]\left[\varphi_{a, 1}\left(\xi_{1}\right) g_{a p}^{1}\right]\left[\varphi_{b}\left(\xi_{1}\right) g_{b q}^{2}\right] \varepsilon_{p q i}+} \\
& {\left[\vartheta_{k}^{r}\left(\xi_{2}, \xi_{3}\right) w_{k}^{r}\right]\left[\varphi_{j}\left(\xi_{1}\right) \varpi_{j}\right]\left[\varphi_{a}\left(\xi_{1}\right) g_{a p}^{1}\right]\left[\varphi_{b, 1}\left(\xi_{1}\right) g_{b q}^{2}\right] \varepsilon_{p q i}} \\
& W_{\mathrm{i}, 2}^{1}=\left[\vartheta_{k, 2}^{r}\left(\xi_{2}, \xi_{3}\right) w_{k}^{r}\right]\left[\varphi_{j}\left(\xi_{1}\right) \varpi_{j}\right]\left[\varphi_{a}\left(\xi_{1}\right) g_{a p}^{1}\right]\left[\varphi_{b}\left(\xi_{1}\right) g_{b q}^{2}\right] \varepsilon_{p q i} \\
& W_{\mathrm{i}, 3}^{1}=\left[\vartheta_{k, 3}^{r}\left(\xi_{2}, \xi_{3}\right) w_{k}^{r}\right]\left[\varphi_{j}\left(\xi_{1}\right) \varpi_{j}\right]\left[\varphi_{a}\left(\xi_{1}\right) g_{a p}^{1}\right]\left[\varphi_{b}\left(\xi_{1}\right) g_{b q}^{2}\right] \varepsilon_{p q i}
\end{aligned}
$$

A introdução destes parâmetros ao código computacional desenvolvido pelo o grupo de mecânica computacional do departamento de estruturas da EESC-USP contempla os objetivos precípuos desta pesquisa.

No que segue apresenta-se a segunda série de exemplos, agora inserindo-se os aprimoramentos nas mobilidades da seção transversal.

\subsection{Segunda Série de Exemplos: Barra Geral com Aprimoramentos}

Nesta segunda série de exemplos apresentam-se os resultados da análise linear de instabilidade considerando-se os aprimoramentos na seção transversal do elemento finito de barra geral.

No primeiro exemplo estuda-se a instabilidade de uma viga com seção transversal aberta de parede fina. Introduz-se as mobilidades na seção e verificam-se as da carga crítica a partir 
da análise de autovalores e autovetores com o elemento aprimorado. No segundo exemplo, realizam-se as mesmas análises, porém aplicada a um pórtico tridimesnional.

Os resultados são comparados com o programa de casca posicional, com o GBTUL e CUFSM e com trabalhos já consagrados na literatura.

\subsection{Perfil C com Aprimoramento}

Neste exemplo determinam-se as cargas críticas de flambagem do perfil $C 75 \times 25$ empregando-se o elemento finito de barra geral com aprimoramentos. Emprega-se a mesma estrutura utilizada nas análises apresentadas no capítulo 7, porém, adota-se o modelo sem as imperfeições geométricas sugeridas por (GARCEA, 2001) e (GARCEA, MADEO e CASCIARO, 2012).

A primeira análise refere-se a determinação das cargas e modos de instabilidade obtidos com a solução do problema de autovalores e autovetores do elemento de barra geral com aprimoramentos. Analisa-se uma coluna sob compressão uniforme e sem restrição ao empenamento. Na Figura 73 ilustra-se o modelo empregado na análise.

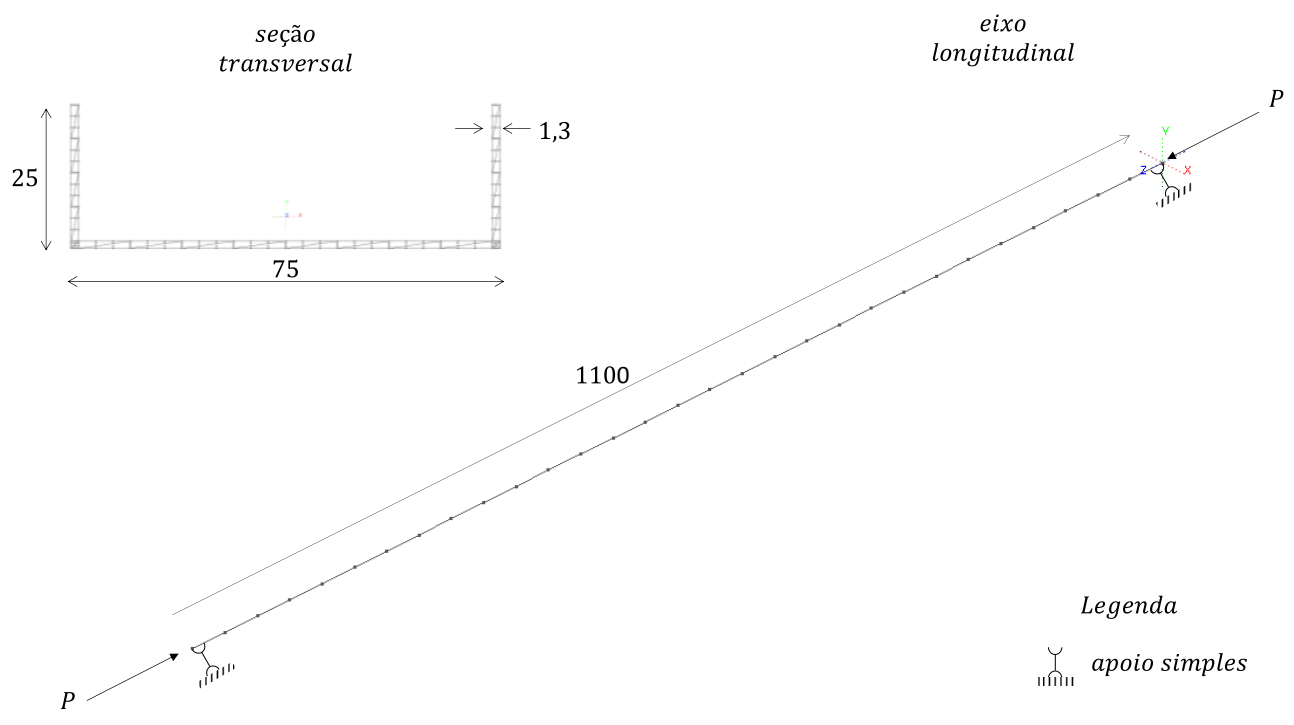

Figura 73: Modelo da coluna com o elemento de barra geral

São adotadas como referência as soluções obtidas com o elemento de casca posicional e com os programas CUFSM e GBTUL usados na determinação das cargas de flambagem.

Para se atingir o objetivo do exemplo é necessário seguir a seguinte metodologia: modelar a seção transversal com o elemento finito de casca posicional e submete-lo a uma 
distribuição de tensão de modo a se realizar uma análise dos autovalores e autovetores da seção. As configurações deformadas (autovetores) são então consideradas as novas mobilidades da seção. Com esses valores definem-se as mobilidades usadas na análise com o elemento de barra geral aprimorado.

Neste se insere dezoito mobilidades, nove no plano e nove fora do plano da seção transversal. Cabe mencionar que os autovetores utilizados são normalizados, de modo a se associar valores unitários a essas mobilidades.

Na Figura 74 apresentam-se as nove mobilidades no plano da seção transversal.
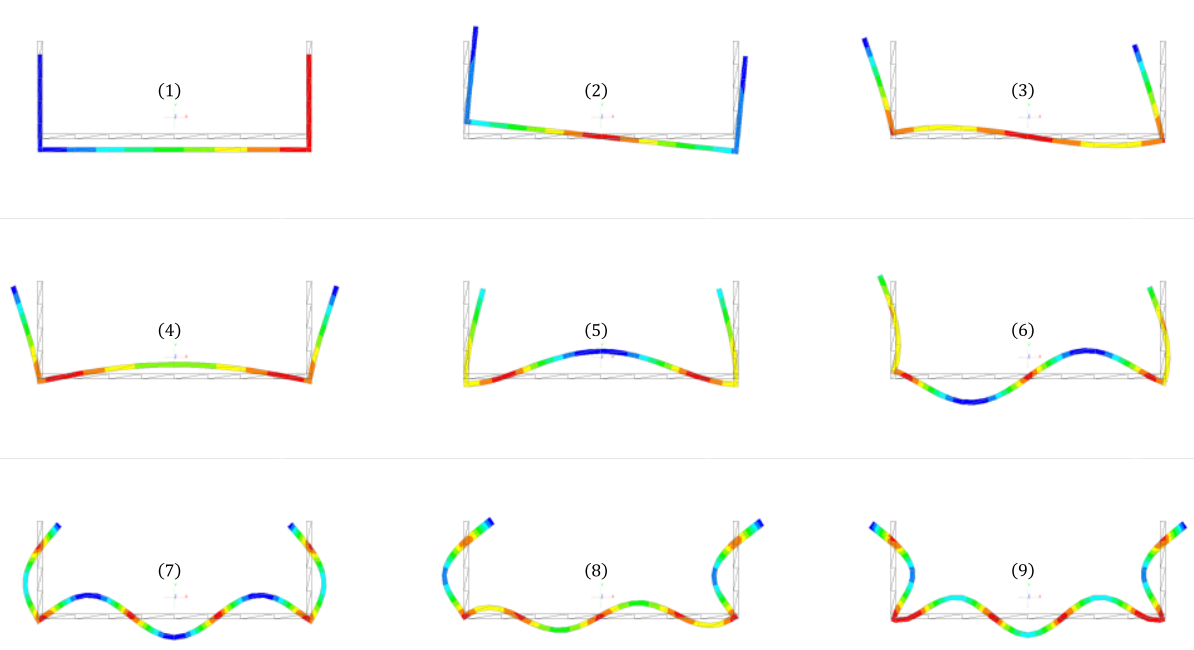

\section{Figura 74: Mobilidades no plano da seção transversal}

Na Figura 75 são agrupadas as outras nove mobilidades fora do plano da seção, as quais serão introduzidas na parcela do modo de empenamento. 


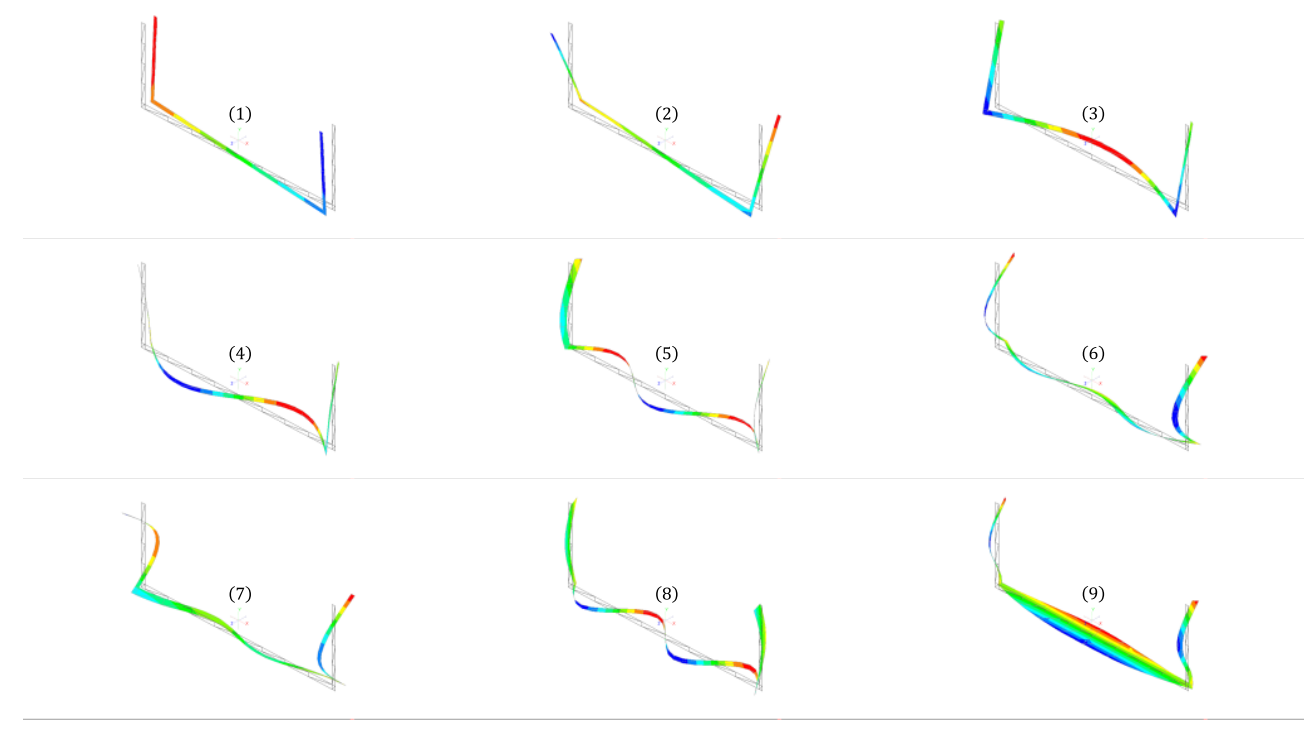

Figura 75: Mobilidades fora do plano da seção transversal

Verifica-se que a análise linear de instabilidade realizada a priori é útil para se determinar os principais modos de flambagem da seção. É possível se distinguir na Figura 74 e na Figura 75, a ocorrência dos modos globais, distorcionais e locais.

Outra observação importante é a consideração das configurações simétricas de cada mobilidade. Essa condição é necessária para se completar o espectro de mobilidades usados na interpolação dos graus de liberdade dos aprimoramentos, conforme a formulação apresentada anteriormente. Lembrando-se que para as interpolações de grau par o valor médio da coordenada adimensional está associado a configuração indeformada da seção. Neste exemplo emprega-se a interpolação quadrática para as mobilidades.

Inicia-se a discussão dos resultados apresentando-se as respostas obtidas com os programas GBTUL e CUFSM.

Apresentam-se as curvas relativas ao primeiro modo de flambagem. Destacam-se nesses gráficos onze pontos, os quais são tomados como referência para a simulação do problema utilizando os elementos de barra geral e casca posicional.

No que segue, apresentam-se as respostas obtidas com os programas.

A curva de flambagem, o diagrama de participação modal e as configurações dos modos obtidos com o GBTUL estão ilustrados na Figura 76 e Figura 77, respectivamente. 

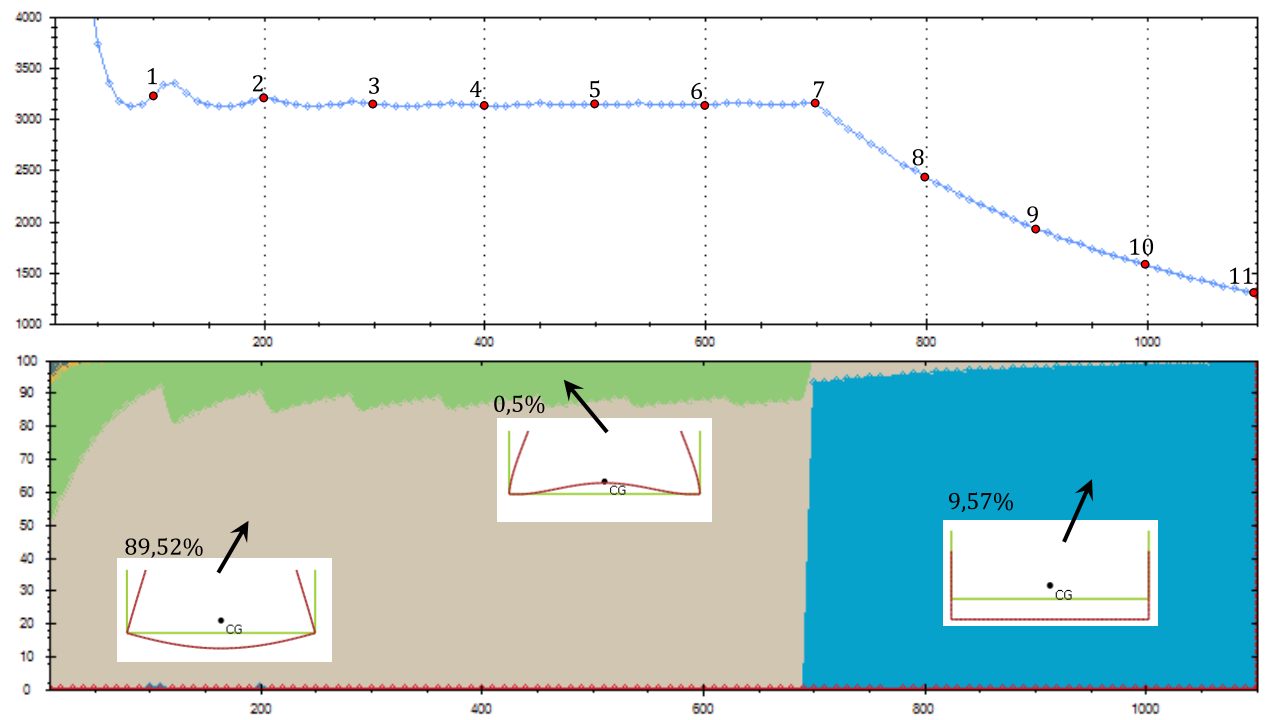

Figura 76: Curva de flambagem e diagrama de participação modal do GBTUL

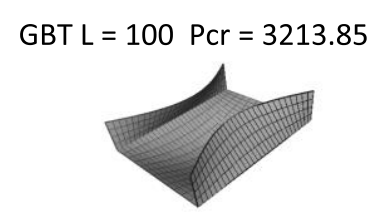

GBT L $=400$ Pcr $=3127.86$

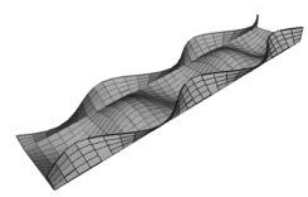

GBT L $=700$ Pcr $=3146.86$

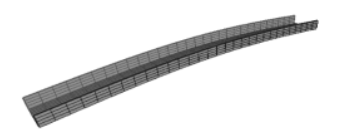

GBT L $=1000 \operatorname{Pcr}=1567.63$

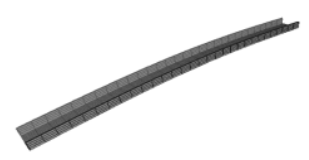

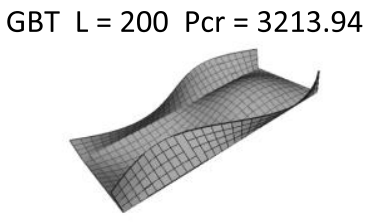

GBT L $=500$ Pcr $=3131.25$

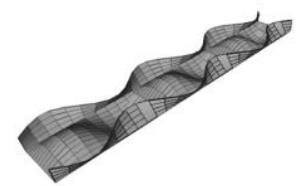

GBT L $=800$ Pcr $=2431.53$

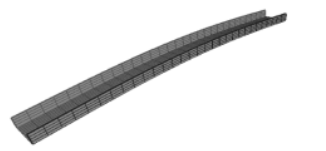

GBT L $=1100$ Pcr $=1297.54$

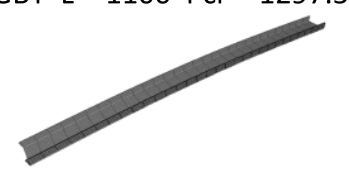

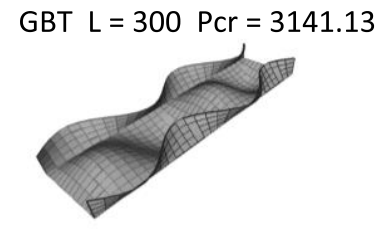

GBT L $=600$ Pcr $=3140.04$

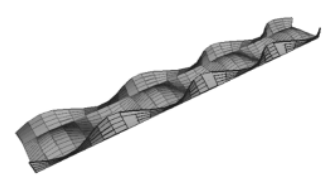

GBT $L=900$ Pcr $=1930.30$

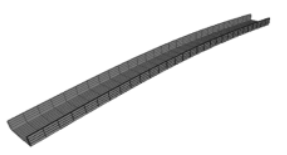

Figura 77: Modos críticos gerados pelo GBTUL em função do comprimento da coluna

A título de informação, os programas foram executados considerando-se a participação dos dezoito modos de flambagem. Em ambas as respostas é possível se visualizar a predominância dos modos locais de chapa seguida do modo global de flexão.

As respostas obtidas com o CUFSM podem ser visualizadas na Figura 78 e Figura 79. 

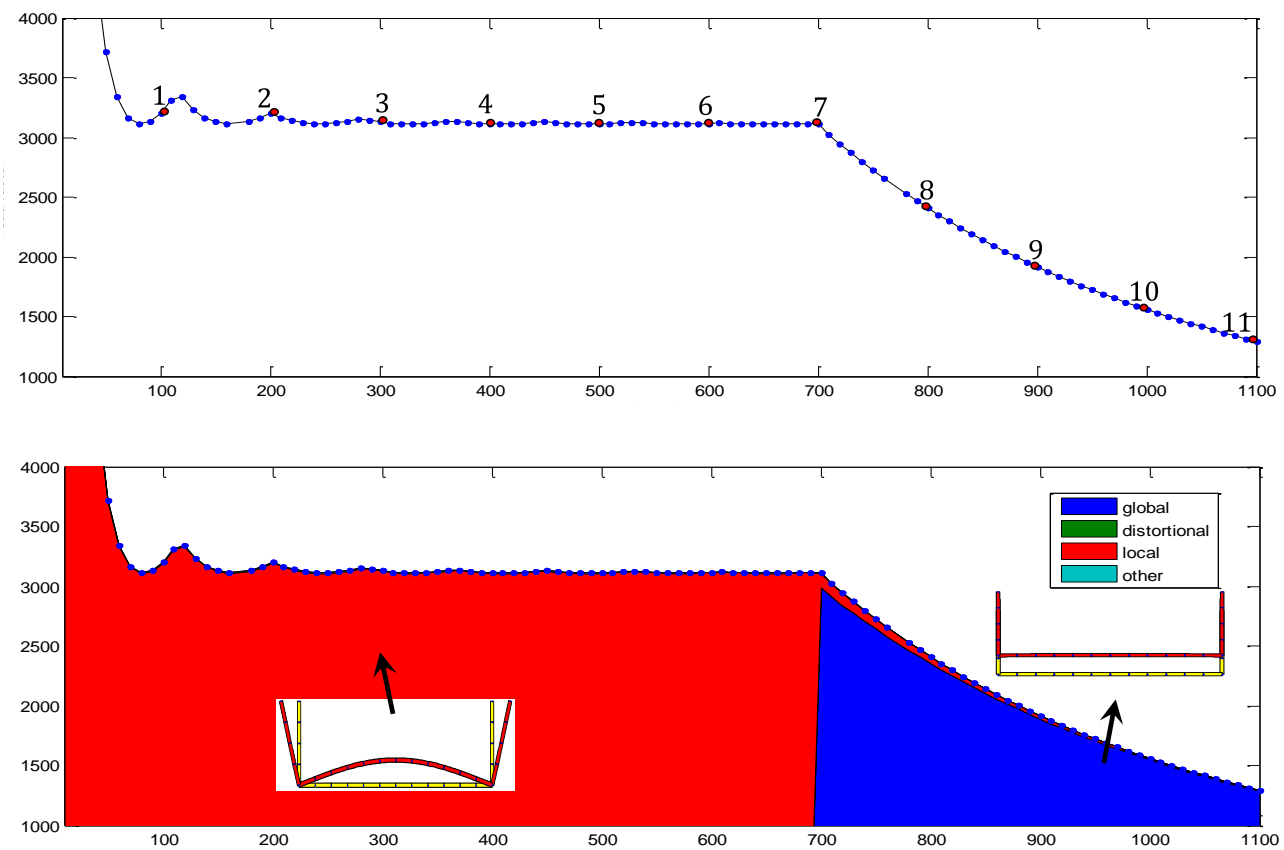

Figura 78: Curva de flambagem e diagrama e participação modal CUFSM

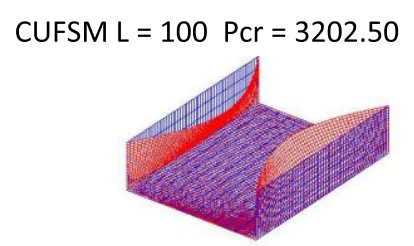

CUFSM L $=400 \mathrm{Pcr}=3113.01$

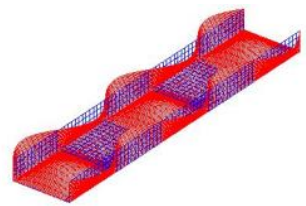

CUFSM L $=700 \mathrm{Pcr}=3109.69$

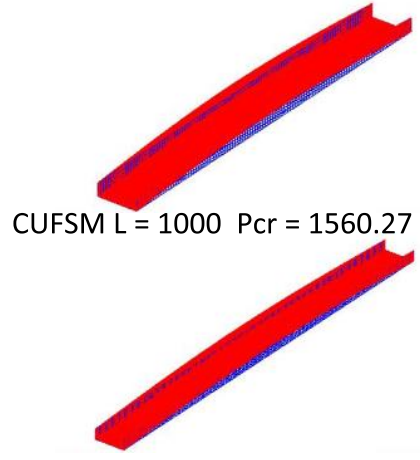

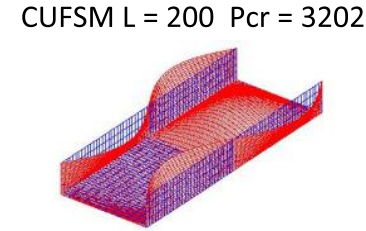

CUFSM L $=500$ Pcr $=3112.73$

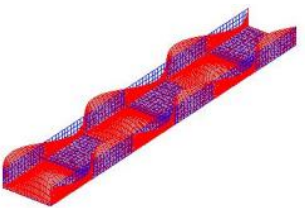

CUFSM L $=800$ Pcr $=2410.60$

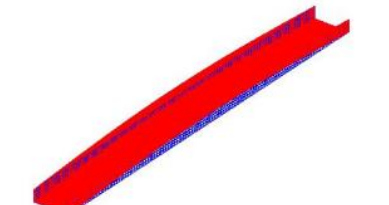

CUFSM L $=1100 \mathrm{Pcr}=1293.04$

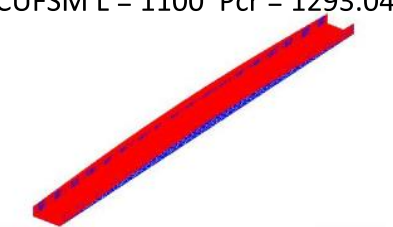

CUFSM L $=300$ Pcr $=3128.77$

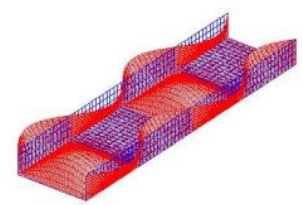

CUFSM L $=600$ Pcr $=3116.86$

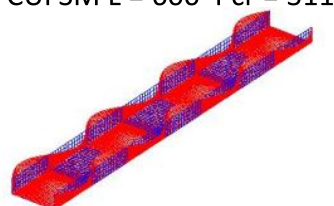

CUFSM L $=900$ Pcr $=1918.06$

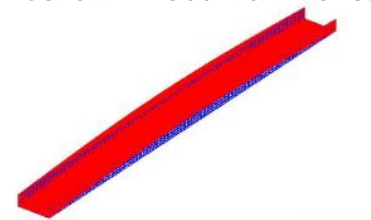

Figura 79: Modos críticos gerados pelo CUFSM em função do comprimento da coluna

Comparando-se as respostas produzidas pelos programas, observa-se a concordância dos valores das cargas e modos críticos para os pontos destacados nos gráficos. 
Para os onze pontos foram realizadas também a simulação e determinação dos autovalores e autovetores empregando-se os elementos de barra geral aprimorado e o elemento de casca não-linear geométrico.

Para simular a estrutura utilizando o elemento de barra geral foram considerados dez elementos com aproximação cúbica sobre o eixo de referência e trinta e seis elementos triangulares com aproximação cúbica na seção transversal. Para a simulação com o elemento de casca adotou-se uma malha variável, porém com elementos de tamanho fixos, medindo cinco unidades de comprimento. Na simulação com o elemento de casca foram utilizados elementos quadrilaterais com aproximação quadrática, devido a boa resposta estrutural em relação aos elementos com aproximação linear e o menor tempo de processamento em relação a elementos com aproximações de ordem mais elevadas.

Na Tabela 10 reúne-se os valores obtidos com os programas de barra, de casca, GBTUL e CUFSM. No gráfico da Figura 80 ilustram-se as curvas de flambagem correspondentes.

Tabela 10: Carregamentos do primeiro modo de flambagem

\begin{tabular}{|c|c|c|c|c|c|c|c|c|c|c|c|}
\hline \multicolumn{10}{|c|}{ Cargas Críticas } \\
\hline Elem /L & 100 & 200 & 300 & 400 & 500 & 600 & 700 & 800 & 900 & 1000 & 1100 \\
\hline BARRA & 3441.85 & 3523.31 & 3391.51 & 3411.33 & 3490.81 & 3597.02 & 3663.91 & 2771.43 & 2294.87 & 1924.97 & 1552.53 \\
\hline CASCA & 3065.30 & 3105.27 & 3049.95 & 3044.66 & 3049.76 & 3056.37 & 3058.59 & 2401.25 & 1910.89 & 1554.62 & 1288.49 \\
\hline GBTUL & 3213.86 & 3213.94 & 3141.14 & 3127.86 & 3131.26 & 3140.05 & 3146.87 & 2431.54 & 1930.30 & 1567.63 & 1297.54 \\
\hline CUFSM & 3202.50 & 3202.50 & 3202.50 & 3113.01 & 3112.73 & 3116.86 & 3109.69 & 2410.61 & 1918.06 & 1560.27 & 1293.04 \\
\hline
\end{tabular}

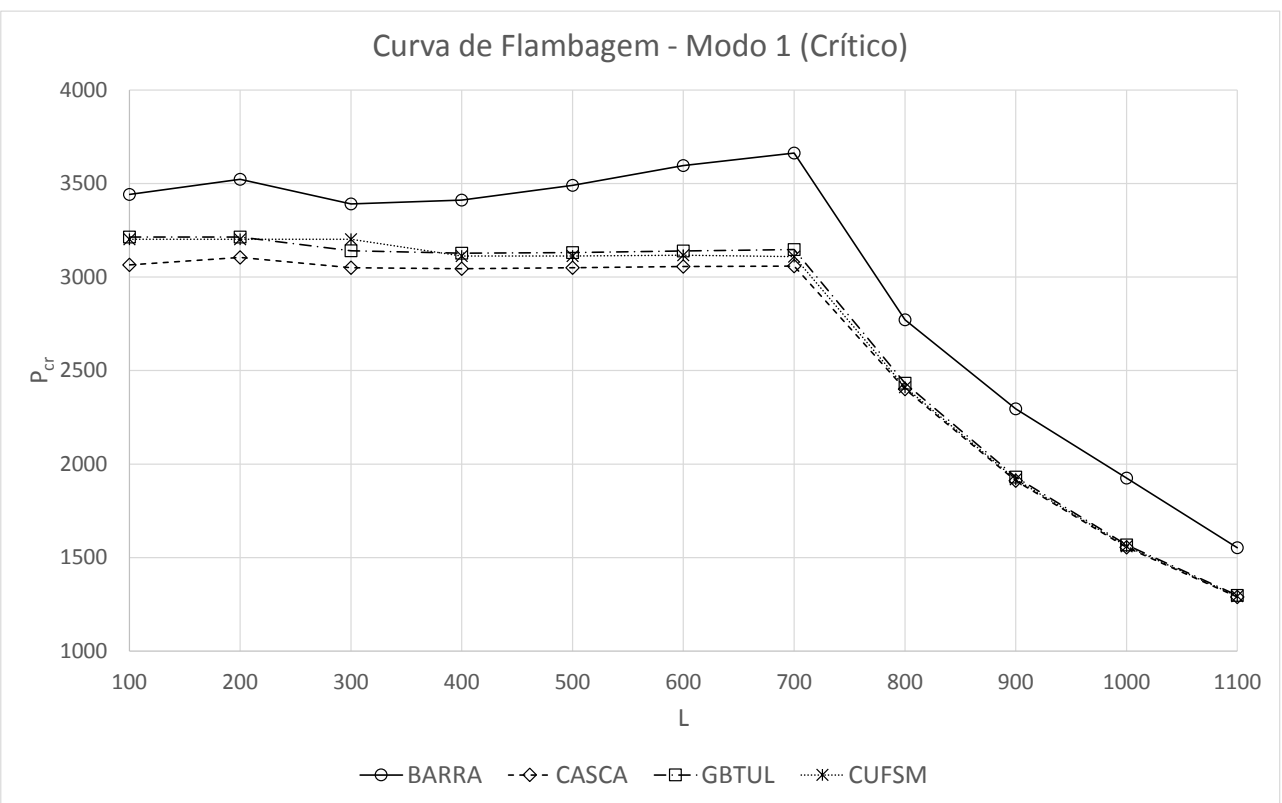

Figura 80: Curvas de flambagem para o primeiro modo 
Verifica-se no gráfico da Figura 80 que o elemento de casca, dada a sua cinemática livre de travamento, apresenta uma resposta mais flexível se comparada as soluções das demais formulações. De acordo com (SILVESTRE, 2005) a ocorrência simultânea, ou quase simultânea de mais de um modo de flambagem, conduz a valores iguais ou muito próximos do parâmetro de carga devido o efeito de interação modal.

O ganho de flexibilidade com o elemento de casca permitiu se captar com maior precisão os pontos de interação modal.

Pelo contrário, a resposta estrutural obtida com o elemento de barra geral, apresentou uma resposta mais rígida que das demais formulações. Essa característica se deve ao travamento ocorrido no elemento finito.

Um grande número de conceitos tem sido desenvolvido para definir, explicar e quantificar o fenômeno de travamento. Para (BABUšKA e SURI, 1992 b) não há teoria ou formulação matemática capaz de eliminar definitivamente o travamento do método dos elementos finitos, porém, algumas estratégias são empregadas com vista a suavizar esses problemas. Nesse trabalho a introdução das mobilidades na seção transversal tem como finalidade flexibilizar a cinemática do elemento, conferindo-lhe novas mobilidades. Caso estas mobilidades não sejam consideradas na análise só ocorrerão modos de corpo rígido.

Porém, apesar de mais rígido, o elemento finito de barra geral com aprimoramentos é capaz de indicar a participação modal ativando as mobilidades da seção durante a análise. De fato, como os graus de liberdade adicionais são os conjugados energéticos das deformações da seção, as respostas desses valores, quando a estrutura atinge o equilíbrio, indicam a intensidade dos modos ativados após a análise.

Na Figura 81 ilustram-se os modos críticos obtidos com o elemento de casca posicional para as onze colunas analisadas. 

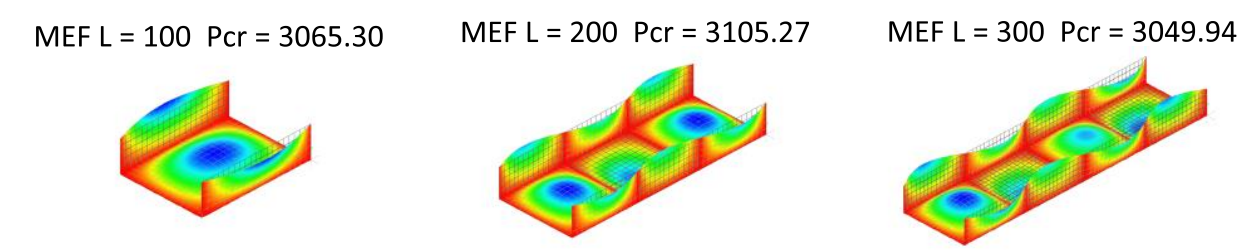

MEF L $=400 \mathrm{Pcr}=3044.66$

MEF L $=500$ Pcr $=3049.75$

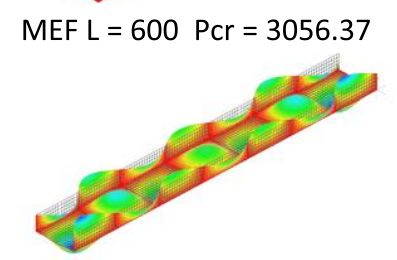

MEF L $=700 \mathrm{Pcr}=3058.59$

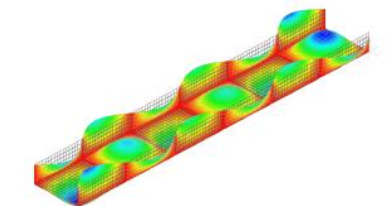

MEF L $=800 \mathrm{Pcr}=2401.24$

MEF L $=900$ Pcr $=1910.88$
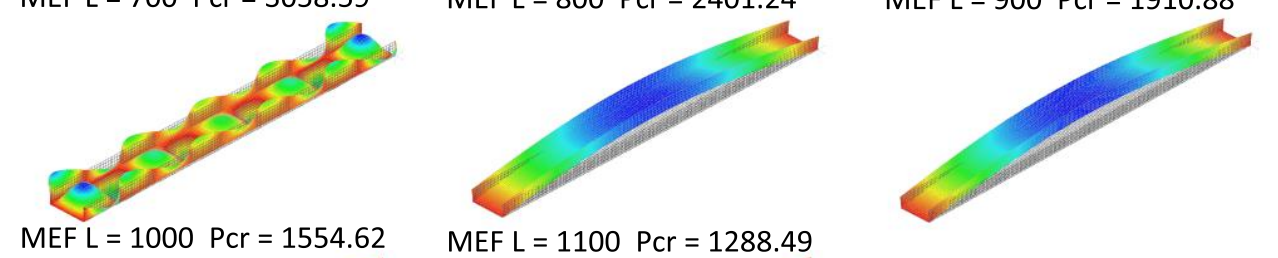

MEF L = 1000 Pcr $=1554.62$

MEF L $=1100 \mathrm{Pcr}=1288.49$
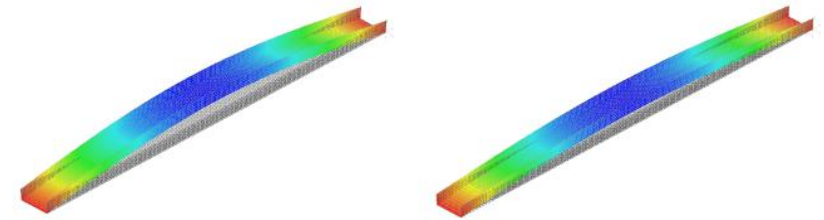

\section{(1)}

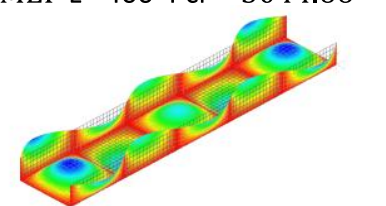

Figura 81: Modos críticos gerados pelo elemento finito de casca posicional em função do comprimento da coluna

Analisando-se os resultados apresentados na Figura 77, Figura 79 e Figura 81 é possível se verificar uma diferença nos modos críticos nos pontos $2(L=200)$ e $7(L=700)$, encontrados com o GBTUL e o CUFSM, em relação aos autovetores do elemento de casca posicional. Esse resultado se justifica, novamente, em razão da flexibilidade do elemento de casca posicional. Devido a interação modal latente nesses pontos, o elemento de casca posicional conseguiu distinguir com mais eficiência o carregamento crítico correspondente. Logo, com o elemento de casca, nota-se que há a participação dos modos locais e globais simultaneamente, o que não pode ser captado com maior precisão pelos programas GBTUL e CUFSM.

Os resultados a seguir ilustram as curvas dos cinco primeiros modos de flambagem obtidas com os programas GBTUL e CUFSM e com os elementos de barra geral e de casca. 


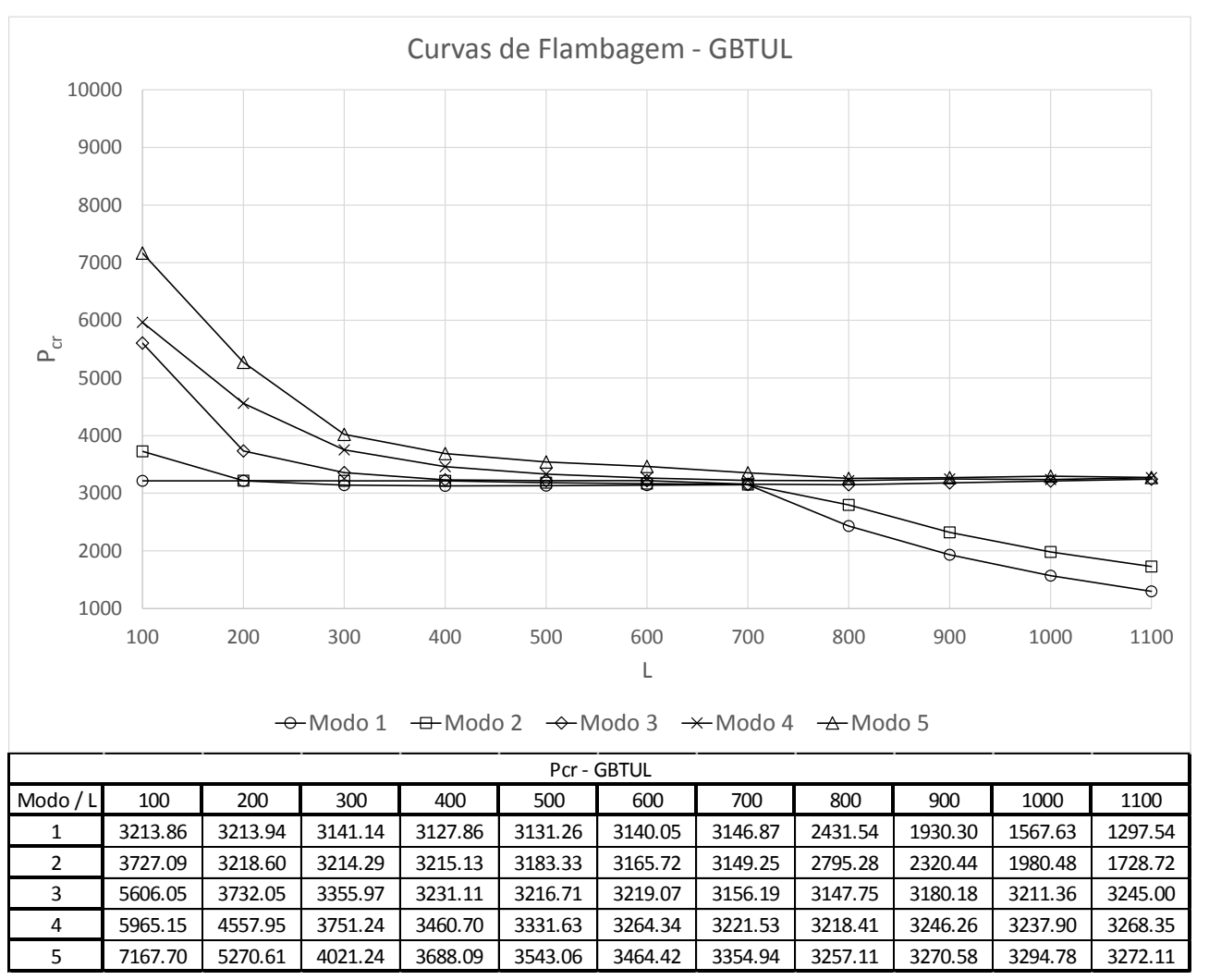

Figura 82: Gráfico e tabela com os valores das cargas de flambagem - GBTUL

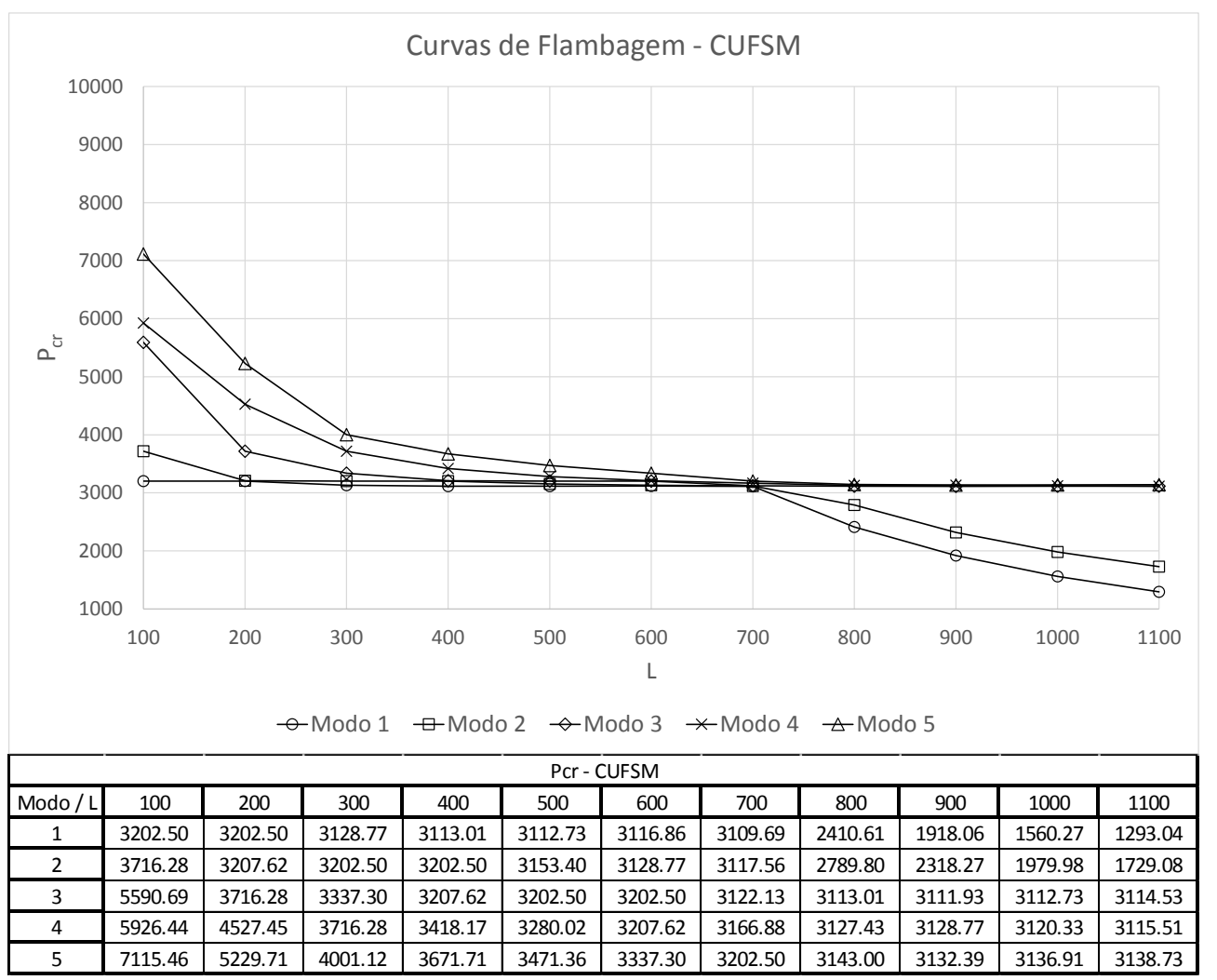

Figura 83: Gráfico e tabela com os valores das cargas de flambagem-CUFSM 


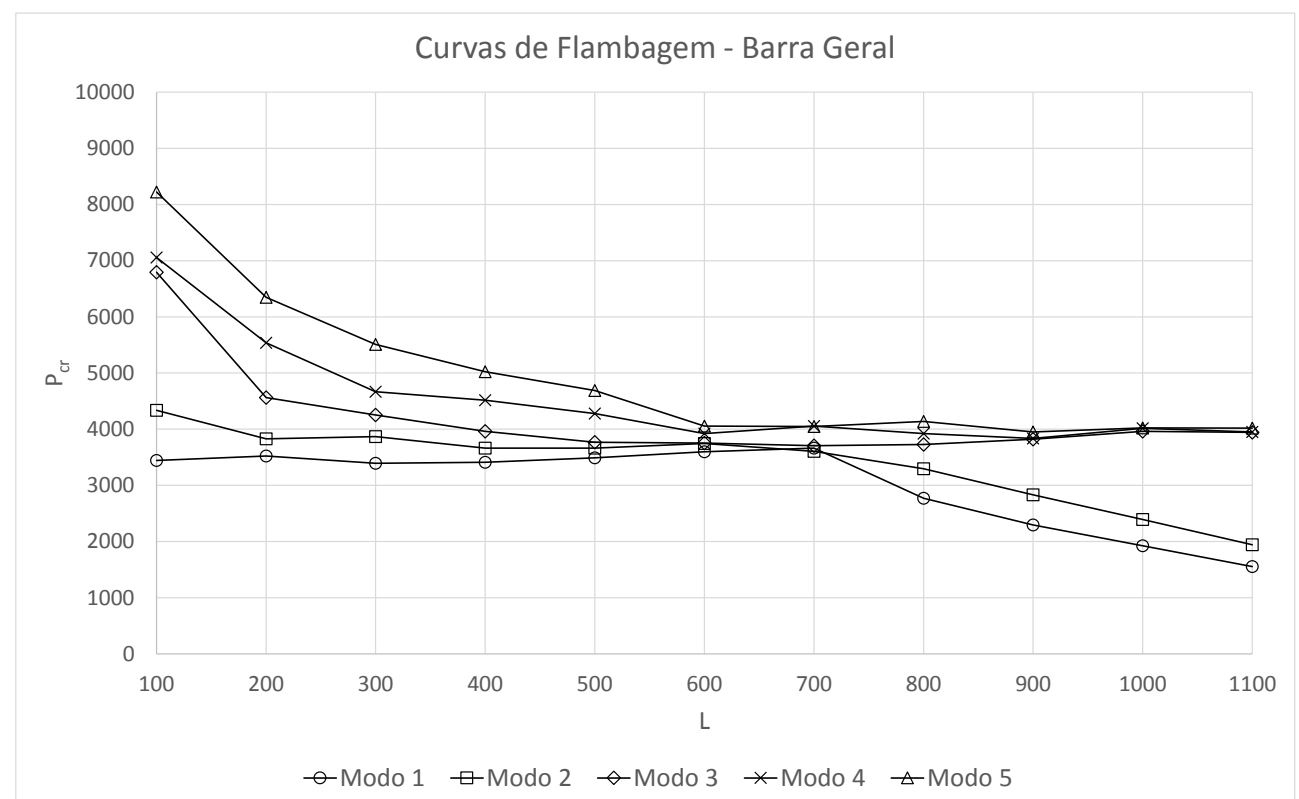

\begin{tabular}{|c|c|c|c|c|c|c|c|c|c|c|c|}
\hline \multicolumn{10}{|c|}{ Pcr - Barra Geral } \\
\hline Modo/ & 100 & 200 & 300 & 400 & 500 & 600 & 700 & 800 & 900 & 1000 & 1100 \\
\hline 1 & 3441.85 & 3523.31 & 3391.51 & 3411.33 & 3490.81 & 3597.02 & 3663.91 & 2771.43 & 2294.87 & 1924.97 & 1552.53 \\
\hline 2 & 4334.55 & 3827.19 & 3867.82 & 3661.79 & 3661.58 & 3745.25 & 3606.77 & 3297.18 & 2830.45 & 2392.12 & 1941.05 \\
\hline 3 & 6793.69 & 4562.77 & 4253.28 & 3960.65 & 3766.01 & 3754.43 & 3704.53 & 3727.62 & 3822.67 & 3960.19 & 3944.18 \\
\hline 4 & 7055.39 & 5538.71 & 4668.79 & 4515.35 & 4277.43 & 3921.80 & 4056.00 & 3921.97 & 3833.80 & 4016.56 & 3951.66 \\
\hline 5 & 8224.41 & 6348.73 & 5510.27 & 5024.41 & 4690.28 & 4054.02 & 4049.21 & 4137.22 & 3949.03 & 4023.28 & 4020.41 \\
\hline
\end{tabular}

Figura 84: Gráfico e tabela com os valores das cargas de flambagem - Barra Geral

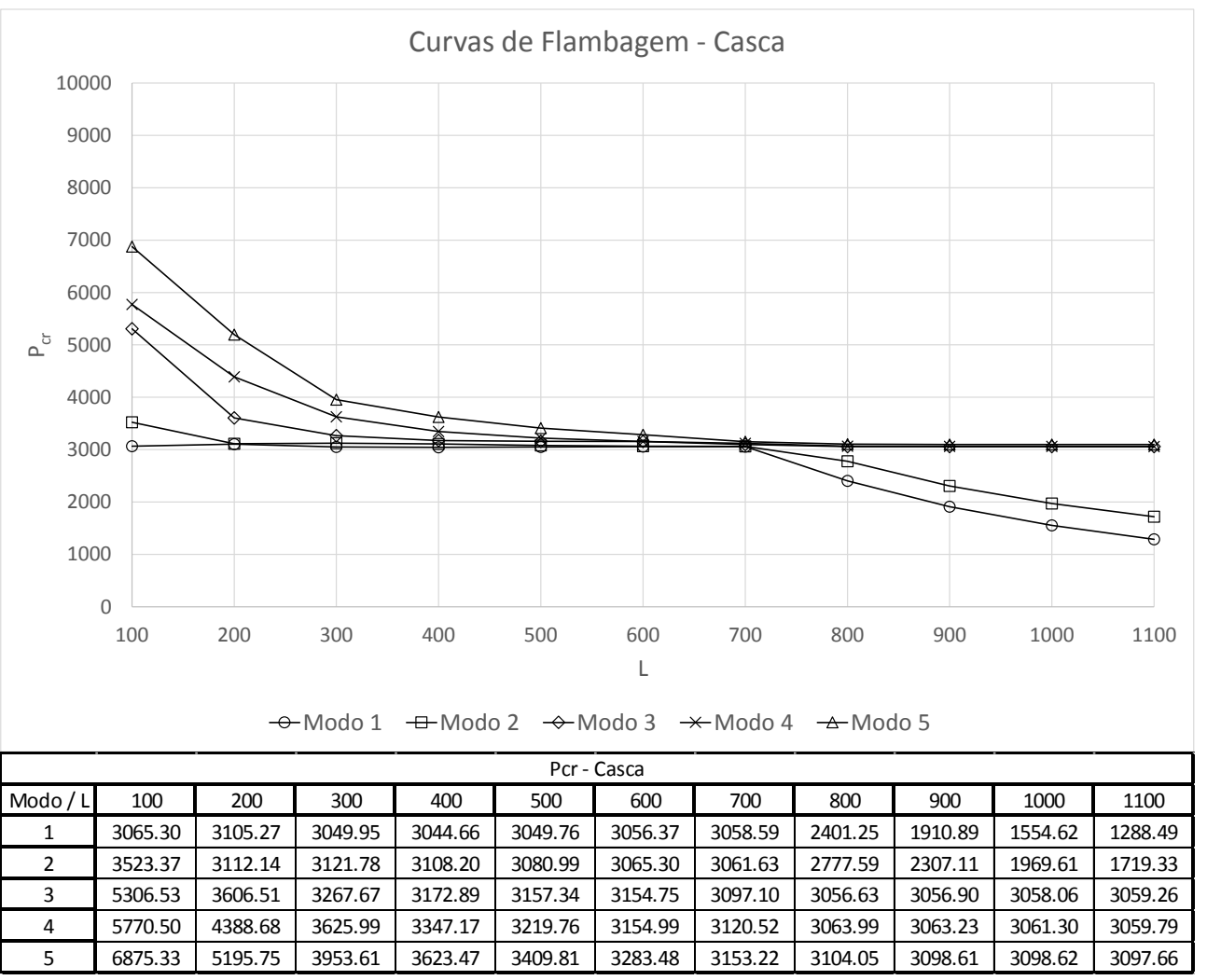

Figura 85: Gráfico e tabela com os valores das cargas de flambagem - Casca 
Para livre conferência e comparações das respostas empregando os elementos finitos posicional não-linear geométrico, apresentam-se, na Tabela 11 e na Tabela 12, os valores dos vinte carregamentos de flambagem em função do comprimento da coluna.

Com este exemplo e possível concluir que o elemento de casca posicional não linear geométrico é muito eficaz para se resolver problemas lineares de instabilidade, inclusive quando ocorre forte interação modal. Além disso, quando comparado com o elemento de barra com aprimoramentos, o elemento de casca mostrou-se mais eficiente pois o número de operações necessárias para se obter uma resposta é bem reduzido. Esse fato se deve ao menor número de interpolações e integrações numéricas necessárias na resolução do problema. 
Tabela 11: Tabela com os vinte primeiros autovalores obtidos com o elemento de barra geral aprimorado

\begin{tabular}{|c|c|c|c|c|c|c|c|c|c|c|c|}
\hline \multicolumn{12}{|c|}{ Autovalores - barra geral com aprimoramentos } \\
\hline Modo / L & 100 & 200 & 300 & 400 & 500 & 600 & 700 & 800 & 900 & 1000 & 1100 \\
\hline 1 & 3441.85 & 3523.31 & 3391.51 & 3411.33 & 3490.81 & 3597.02 & 3663.91 & 2771.43 & 2294.87 & 1924.97 & 1552.53 \\
\hline 2 & 4334.55 & 3827.19 & 3867.82 & 3661.79 & 3661.58 & 3745.25 & 3606.77 & 3297.18 & 2830.45 & 2392.12 & 1941.05 \\
\hline 3 & 6793.69 & 4562.77 & 4253.28 & 3960.65 & 3766.01 & 3754.43 & 3704.53 & 3727.62 & 3822.67 & 3960.19 & 3944.18 \\
\hline 4 & 7055.39 & 5538.71 & 4668.79 & 4515.35 & 4277.43 & 3921.80 & 4056.00 & 3921.97 & 3833.80 & 4016.56 & 3951.66 \\
\hline 5 & 8224.41 & 6348.73 & 5510.27 & 5024.41 & 4690.28 & 4054.02 & 4049.21 & 4137.22 & 3949.03 & 4023.28 & 4020.41 \\
\hline 6 & 9325.25 & 7442.16 & 4888.22 & 4875.51 & 4048.65 & 4117.79 & 4223.76 & 4173.91 & 3869.61 & 4319.32 & 4197.38 \\
\hline 7 & 8531.77 & 6736.18 & 5892.85 & 4841.44 & 4244.77 & 3918.53 & 4274.49 & 4260.76 & 4104.99 & 4034.93 & 3900.48 \\
\hline 8 & 9813.47 & 7662.16 & 6355.31 & 5029.81 & 4723.25 & 4135.72 & 4101.11 & 4279.84 & 4376.90 & 4155.11 & 3966.34 \\
\hline 9 & 9709.92 & 7959.32 & 7058.00 & 5546.80 & 5255.86 & 4707.79 & 4740.39 & 4301.65 & 4360.89 & 4047.09 & 4307.97 \\
\hline 10 & 11494.48 & 8614.90 & 6613.35 & 6457.10 & 5607.86 & 4571.46 & 4802.49 & 4131.62 & 4462.09 & 4317.42 & 3641.67 \\
\hline 11 & 13560.69 & 8282.56 & 8028.27 & 7154.13 & 5860.73 & 4814.60 & 4652.24 & 4788.54 & 4641.85 & 4342.58 & 4397.66 \\
\hline 12 & 15848.61 & 8280.23 & 8016.04 & 7000.91 & 6703.43 & 5786.27 & 4914.63 & 4388.92 & 4637.36 & 4459.93 & 4022.59 \\
\hline 13 & 13973.79 & 9009.49 & 8778.82 & 7711.28 & 7609.89 & 5387.42 & 5156.78 & 4878.30 & 4282.82 & 5177.36 & 3811.38 \\
\hline 14 & 18808.21 & 9692.39 & 7316.51 & 7469.51 & 7537.65 & 5109.43 & 5414.89 & 4272.14 & 4555.41 & 4844.93 & 4098.62 \\
\hline 15 & 17864.63 & 10381.37 & 8308.40 & 7780.73 & 7376.66 & 5887.47 & 5538.45 & 5049.94 & 4712.37 & 4427.26 & 5120.69 \\
\hline 16 & 15439.53 & 9185.33 & 9702.48 & 8119.13 & 7170.65 & 6679.01 & 6176.05 & 5460.54 & 5433.47 & 5186.48 & 4935.92 \\
\hline 17 & 17767.11 & 10633.88 & 9922.40 & 8533.27 & 6737.96 & 6723.77 & 5631.76 & 5863.04 & 5243.30 & 5298.70 & 4567.73 \\
\hline 18 & 20745.24 & 10420.97 & 8703.45 & 8718.37 & 7567.70 & 7143.08 & 5471.54 & 5075.78 & 5239.57 & 5357.27 & 4324.60 \\
\hline 19 & 22559.01 & 9652.44 & 9143.84 & 8209.87 & 7187.58 & 7665.42 & 7037.96 & 5349.94 & 5770.31 & 5673.84 & 5145.38 \\
\hline 20 & 23697.47 & 11473.00 & 8566.74 & 9326.91 & 8274.44 & 7521.34 & 7474.52 & 6394.28 & 5767.57 & 5904.61 & 5340.83 \\
\hline
\end{tabular}


Tabela 12: Tabela com os vinte primeiros autovalores obtidos com o elemento de casca

\begin{tabular}{|c|c|c|c|c|c|c|c|c|c|c|c|}
\hline \multicolumn{12}{|c|}{ Autovalores - casca posicional não-linear geométrico } \\
\hline Modo / L & 100 & 200 & 300 & 400 & 500 & 600 & 700 & 800 & 900 & 1000 & 1100 \\
\hline 1 & 3065.30 & 3105.27 & 3049.95 & 3044.66 & 3049.76 & 3056.37 & 3058.59 & 2401.25 & 1910.89 & 1554.62 & 1288.49 \\
\hline 2 & 3523.37 & 3112.14 & 3121.78 & 3108.20 & 3080.99 & 3065.30 & 3061.63 & 2777.59 & 2307.11 & 1969.61 & 1719.33 \\
\hline 3 & 5306.53 & 3606.51 & 3267.67 & 3172.89 & 3157.34 & 3154.75 & 3097.10 & 3056.63 & 3056.90 & 3058.06 & 3059.26 \\
\hline 4 & 5770.50 & 4388.68 & 3625.99 & 3347.17 & 3219.76 & 3154.99 & 3120.52 & 3063.99 & 3063.23 & 3061.30 & 3059.79 \\
\hline 5 & 6875.33 & 5195.75 & 3953.61 & 3623.47 & 3409.81 & 3283.48 & 3153.22 & 3104.05 & 3098.61 & 3098.62 & 3097.66 \\
\hline 6 & 7164.32 & 5418.58 & 4128.96 & 3642.53 & 3479.37 & 3398.06 & 3210.56 & 3145.11 & 3125.36 & 3108.57 & 3100.29 \\
\hline 7 & 7603.89 & 5802.32 & 4741.25 & 4008.11 & 3651.98 & 3456.22 & 3322.35 & 3172.74 & 3163.36 & 3161.38 & 3138.78 \\
\hline 8 & 7618.80 & 5899.56 & 5456.95 & 4436.95 & 3936.65 & 3654.55 & 3362.64 & 3249.09 & 3198.14 & 3163.01 & 3159.86 \\
\hline 9 & 7970.05 & 6321.07 & 5777.43 & 4927.93 & 4266.93 & 3892.03 & 3461.04 & 3325.39 & 3289.71 & 3235.29 & 3196.83 \\
\hline 10 & 9705.01 & 6665.73 & 5812.40 & 5195.53 & 4336.81 & 3959.60 & 3480.84 & 3367.22 & 3300.62 & 3281.31 & 3257.86 \\
\hline 11 & 9942.15 & 6945.78 & 6112.16 & 5476.54 & 4636.66 & 4112.73 & 3659.20 & 3505.36 & 3399.25 & 3324.39 & 3278.02 \\
\hline 12 & 11432.63 & 7029.13 & 6201.65 & 5759.47 & 5043.71 & 4159.06 & 3754.93 & 3626.93 & 3518.97 & 3421.93 & 3348.61 \\
\hline 13 & 12419.88 & 7199.54 & 6271.49 & 5816.28 & 5487.93 & 4452.93 & 3861.48 & 3665.63 & 3551.38 & 3488.94 & 3443.82 \\
\hline 14 & 13110.06 & 7635.24 & 6590.73 & 5919.31 & 5597.04 & 4507.19 & 4083.24 & 3836.40 & 3663.63 & 3538.29 & 3444.80 \\
\hline 15 & 13267.96 & 7672.15 & 6935.17 & 6023.66 & 5759.99 & 4774.76 & 4327.85 & 4028.78 & 3818.79 & 3665.89 & 3551.42 \\
\hline 16 & 13341.08 & 8021.79 & 6966.31 & 6080.29 & 5810.29 & 5121.87 & 4540.76 & 4182.07 & 3959.71 & 3799.38 & 3665.37 \\
\hline 17 & 14289.24 & 8136.56 & 7184.38 & 6337.28 & 5836.56 & 5196.43 & 4593.55 & 4238.31 & 3989.76 & 3819.94 & 3712.12 \\
\hline 18 & 15658.26 & 8353.76 & 7211.37 & 6433.46 & 5967.87 & 5495.68 & 4876.38 & 4460.90 & 4168.14 & 3953.96 & 3792.58 \\
\hline 19 & 16194.68 & 8691.25 & 7217.24 & 6738.57 & 5975.58 & 5764.59 & 5179.56 & 4700.21 & 4362.16 & 4114.57 & 3927.77 \\
\hline 20 & 17186.11 & 9745.88 & 7485.44 & 6742.82 & 6072.60 & 5786.27 & 5741.28 & 4954.32 & 4568.09 & 4284.29 & 4070.61 \\
\hline
\end{tabular}




\subsection{Fechamento}

Neste capítulo foram apresentadas as formulações dos elementos de barra geral, com destaque para os aprimoramentos da na seção transversal. Buscou-se com esses aprimoramentos flexibilizar o elemento a cinemática do elemento, com o objetivo de se identificar os modos de instabilidade local e distorcional específicos das barras com perfis esbeltos de parede fina. Com os exemplos discutido ao longo do capítulo fica evidente a dificuldade da formulação em se determinar os valores dos parâmetros críticos de instabilidade com o elemento de barra aprimorado. A estratégia de decomposição da matriz hessiana em pequenos deslocamentos mostra-se eficiente para se proceder as análises lineares de instabilidade com o algoritmo de Lanczos e cálculo dos autovalores e autovetores. 


\section{Conclusões}

Nesta pesquisa abordou-se o fenômeno de instabilidade estrutural a luz da formulação não-linear geométrica do método dos elementos finitos posicional. Foram desenvolvidos os elementos tridimensionais de barra simples, casca e barra geral.

A proposta original de decomposição da matriz Hessiana permitiu que se realizassem adequadamente as análises linearizadas de instabilidade nas condições de pequenos deslocamentos e ao longo da trajetória de equilíbrio em grandes deslocamentos. Os cálculos dos autovalores e autovetores foram obtidos a partir de chamadas à biblioteca numérica ARPACK de onde são gerenciadas as rotinas de cálculo dos valores e vetores próprios de matrizes esparsas com o algoritmo de Lanczos.

A tese foi organizada em duas etapas claramente identificáveis. Nos primeiros capítulos foram apresentados os fundamentos teóricos e as ferramentas numéricas necessárias para o desenvolvimento de uma proposta original do estudo da instabilidade estrutural. Essa proposta se baseou na descrição Lagrangiana da mecânica dos sólidos deformáveis, de onde foram construídas as formulações cinemáticas com a consideração de não-linearidade geométrica. $\mathrm{O}$ estudo da condição de equilíbrio dessas estruturas forma determinadas a partir de princípios gerais da mecânica, como o princípio da estacionariedade da energia potencial total.

Nos capítulos subsequentes foram apresentados os desenvolvimentos dos elementos finitos, com destaque para os aprimoramentos introduzidos nas relações cinemáticas. Demonstrou-se a adequação das formulações alternativas para o estudo e previsão do fenômeno de instabilidade. Ênfase foi dada ao emprego de parâmetros nodais em posições, ou de maneira mais abrangente, a utilização de graus de liberdade descritos em coordenadas generalizadas. Tomando-se em mãos o conceito de variáveis energeticamente conjugadas pode-se prever a participação dos graus de liberdade na determinação do equilíbrio.

Comprovaram-se as propostas por meio de exemplos onde foram verificadas as características do comportamento mecânico e numérico das estruturas e dos elementos finitos, respectivamente. Esses exemplos foram selecionados com o propósito de se explorar com bastante profundidade várias nuances do fenômeno de instabilidade, como por exemplo, a ocorrência de múltiplos pontos de instabilidade nas trajetórias de equilíbrio. 
A discussão dos resultados se iniciou avaliando-se os exemplos de estruturas modeladas com os elementos de barra simples (treliças). Constatou-se que para descrever e identificar os pontos críticos na trajetória de equilíbrio era necessário se adotar algoritmos de continuação como os métodos com base no controle do arco, arc-length. Porém, não se descartou a utilização prática do algoritmo de Newton-Raphson com controle de força ou de posição na identificação das cargas críticas que ocorrem na estrutura, principalmente se essas estratégias trabalham em paralelo com os algoritmos de avaliação de autovalores. Próximo ao ponto de descontinuidade a matriz de rigidez do elemento torna-se singular, ocorredo um salto na configuração de equilíbrio, para uma condição afastada da configuração adjacente, para o mesmo nível de carregamento. O método de Newton-Raphson em conjunto com o algoritmo de Lanczos pode determinar com precisao significativa os valores das cargas limites da estrutura.

No entanto, verificou-se que próximo a mudança na direção dos deslocamento, nos pontos onde a trajetória apresenta a componente tangencia paralela ao eixos dos carregamentos, os métodos de Newton-Raphson falham, devendo-se inevitavelmente se recorrer às estratégias de continuação. Ainda neste capítulo fez-se uma crítica ao fato do método do arc-length não representar, de fato, quantidades físicas identificáveis, sendo que este tipo de análise é desapercebido em grande parte da literatura técnica ao se referir uma medida de comprimento de arco. Nestas conclusões destaca-se novamente o fato dessa medida ser simplesmente uma quantidade matemática abstrata, pois a norma estabelecida pertencer ao espaço de configurações de força e deslocamento.

Mostrou-se que a aplicação da metodologia de decomposição da matriz Hessiana para o elemento de treliça reproduz perfeitamente os pontos críticos na trajetória de equilíbrio. Destacou-se que estes pontos caracterizam perda de estabilidade global, não capturando instabilidade local, para o qual os elementos de barra geral foram aplicados. A interpretação dos resultados das trajetórias bifurcadas com o auxílio do método do arc-length apontam para uma condição de perda de simetria da estrutura.

Aplicando-se os autovetores das configurações indeslocada como os defeitos iniciais da estrutura (assimetrias impostas) foi possível se analisar as trajetórias de equilíbrio que emergem dos postos de bifurcação. Verificou-se que por mais complexas que as trajetórias pós-críticas se apresentem, há sempre uma tendência da estrutura em retornar a trajetória fundamental retomando a configuração de simetria durante as deformações. 
Em seguida mostrou-se a excelente reprodutibilidade do problema de instabilidade estrutural utilizando-se a formulação do elemento de casca não-linear geométrico.

O cálculo dos autovalores e autovetores a partir da decomposição da matriz Hessiana desses elementos mostrou-se uma ferramenta alternativa eficiente para se modelar estruturas constituídas de perfis abertos de chapa fina. Foram apresentadas também, as respostas póscríticas no regime de grandes deslocamentos, a partir da introdução de pequenas imperfeições geométricas iniciais.

Com o elemento de casca foi possível demonstrar a diferença entre os modos de falhas que identificam os tipos de instabilidade, como por exemplo: a instabilidade dos flanges, com predominância dos modos distorcionais, os modos de flambagem de chapa, também denominados de modos locais e a instabilidade global das peças.

A partir do emprego das rotinas de funções de forma de qualquer ordem de aproximação, foi possível se realizar um estudo sobre a influência do grau do polinômio interpolador em relação a resposta estrutural. Na maioria dos exemplos foram escolhidos os elementos quadrilaterais com aproximação quadrática devido a boa precisão e um menor tempo de processamento se comparado aos elementos com aproximação polinomial de ordem mais elevada.

O elemento de casca em conjunto com a rotina de autovalor e autovetor possibilitou que fossem obtidas as mobilidades da seção em correspondência aos modos de flambagem. Essa possibilidade foi de grande relevância para se construir a proposta de aprimoramentos nas deformações da seção transversal do elemento de barra geral.

Da formulação do elemento de barra geral, destacam-se a introdução dos vetores generalizados na definição da base ortogonal dos eixos principais da seção transversal. Devido a generalidade dessa descrição é possível se trabalhar com modelos de barras capazes de levar em conta grandes deslocamentos e rotações. Com essa cinemática é possível se flexibilizar o elemento de modo que as deformações decorrentes das tensões de cisalhamento, presentes na cinemática das vigas de Timoshenko e o modo de empenamento da teoria da torção livre de Saint-Venant, possam ser introduzidos sem a necessidade de parâmetros indiretos como os propostos na formulação corrotacional. 
Numa primeira etapa de análise de resultados verificou-se que a aplicação da proposta de decomposição da Matriz Hessiana para o elemento de barra geral permitiu se obter resultados extremamente precisos para os parâmetros de carregamento relativos as cargas críticas das estruturas. Mostrou-se que para um número pequeno de elementos utilizados na discretização foi possível se chegar nas respostas obtidas com as formulações analíticas para um grande número de parâmetros de carga crítica.

Avaliou-se também as respostas dos problemas de instabilidade global devido a flambagem dos componentes. Nesse exemplo considerou-se a estrutura modelada com o elemento de barra geral e se verificou a influência dos parâmetros de esbeltez da seção na flambagem do elemento estrutural. Considerando-se outro exemplo no qual foram estudadas as características do fenômeno de instabilidade lateral com torção foi possível constatar que o elemento apresentou resultados bem próximos dos valores analíticos propostos na literatura, com isso foi possível concluir que os elementos de barra geral conseguem reproduzir diversos problemas de instabilidade estrutural presentes em estruturas de uso corrente na prática de projeto.

Porém, verificou-se que para perfis estruturais com seção aberta de parede fina ocorre uma espécie de travamento ao se modelar a estrutura com o elemento de barra geral. Para tentar corrigir esse problema foram propostos novos aprimoramentos com a finalidade de flexibilizar a estrutura de maneira que os efeitos da instabilidade local e distorcional pudessem ser levados em consideração durante a deformação. Introduzindo-se as mobilidades geradas com o elemento de casca, como comentado anteriormente, viu-se que são obtidos ganhos na flexibilidade, mas não o suficiente, como esperado. Além disso, verificou-se ainda um aumento significativo no tempo de processamentos dos elementos com os aprimoramentos na seção transversal, em especial quando são utilizados vários modos de instabilidade dentro na cinemática. Esse custo computacional ocorre devido as inúmeras integrações numéricas experimentadas pelos elementos que compõem a seção transversal.

Comparando-se esses resultados com os resultados gerados com a estrutura modelada com o elemento de casca não linear geométrico, verificou-se que o elemento de casca é o mais eficiente, pois o tempo de processamento dos modelos, com relação aos de barra aprimorado, é bem menor, e mais eficaz pois foi capaz de captar os modos de instabilidade locais e distorcionais, com maior precisão inclusive, do que os programas específicos para esse fim e que estão disponíveis na literatura técnica. 
Com base nessas conclusões recomenda-se a utilização do elemento de casca não-linear geométrico para a modelagem de estruturas com perfis esbeltos de parede fina.

Como proposta para futuras pesquisas recomenda-se otimizar o processo de geração das barras com parede fina, a partir dos elementos de casca, criando-se também dispositivos de ligação facilitando a aplicação dos elementos de casca na modelagem de estruturas de barra geral. A vantagem de se utilizar o elemento de casca não-linear geométrico é que nenhum tipo de restrição será considerado nas condições de contorno do problema, o que é ainda uma das limitações na formulação do método das faixas finitas.

Outra proposta, agora com relação aos aspectos gerais da formulação, consiste em se introduzir os termos de ordem superior nas expressões da energia potencial total, de modo a se automatizar o estudo das trajetórias de bifurcação com o emprego dos métodos assintóticos da teoria de Koiter. Com o emprego dessa formulação será possível, dentre outras funcionalidades, automatizar as leis de imperfeições iniciais.

Empregando-se a metodologia de decomposição da matriz Hessiana propõem-se realizar um estudo de instabilidade linear de estruturas constituídas de com vários materiais, inclusive a consideração de materiais compósitos.

Com a introdução dessas funcionalidades no código do grupo de mecânica computacional, recomenda-se avaliar a consideração de não-linearidade física, com os modelos de plasticidade, e sua influência nos parâmetros de carga crítica da estrutura. Dessa mesma forma recomenda-se incluir o comportamento temporal e se avaliar o feito dos carregamentos dinâmicos no parâmetro de carregamento devido as vibrações e amortecimento.

Com esses estudos será possível se ter uma resposta mais realistas do comportamento das estruturas sujeitas aos diversos tipos fenômenos que conduzem a instabilidade estrutural. 



\section{REFERÊNCIAS}

ÁDÁNY, S. Global buckling of thin-walled simply supported columns: Analytical solutions based on shell model. Thin-Walled Structures, v. 55, p. 64-75, June 2012.

ÁDÁNY, S.; SCHAFER, B. W. Buckling mode decomposition of single-branched open cross-section members via finite strip method: Derivation. Thin-Walled Structures, v. 44, n. 5, p. 563-584, May 2006 a.

ÁDÁNY, S.; SCHAFER, B. W. Buckling mode decomposition of single-branched open cross-section members via finite strip method: Application and examples. Thin-Walled Structures, v. 44, n. 5, p. 585-600, May 2006 b.

ÁDÁNY, S.; SCHAFER, B. W. A full modal decomposition of thin-walled, single-branched open cross-section members via the constrained finite strip method. Journal of

Constructional Steel Research, v. 64, n. 1, p. 12-29, January 2008.

ALFUTOV, N. A. Stability of Elastic Structures. Fundations of Engineering Mechanics. ed. Heidelberg: Spring-Verlag Berlin, 2000.

ANDRONOV, A.; PONTRYAGIN, L. Systèemes grossières. Dokl. Akad. Nauk SSSR, v. 14, p. 247-251, 1937.

BABUšKA, I.; SURI, M. Locking effects in the finite element approximation of elasticity problems. Numerische Mathematik, v. 62, n. 1, p. 439-463, December 1992 a.

BABUšKA, I.; SURI, M. On locking and robustness in the finite element method. SIAM Journal on Numerical Analysis, v. 29, n. 5, p. 1261-1293, October 1992 b.

BAZÁN, F. S. V. Autovalores de Polinômios Matriciais: Sensibilidade, Computação e Aplicações. Departemento de Matemática da Universidade Federal de Santa Catarina. Florianópolis, p. 166. 2003.

BAžANT, Z. P. Elastic, Anelastic, and Disintegrating Structures: A Conspectus of Main Results. ZAMM• Z. Angew. Math. Mech, v. 80, n. 11-12, p. 709-732, 2000.

BAžANT, Z. P. Stability of Elastic, Anelastic, and Disintegrating Structures, and Finite Strain Effects: an Overview. Oxford: Elsevier, 2003.

BAžANT, Z. P.; CEDOLIN, L. Stability of Structures: Elastic, Inelastic, Fracture and Damage Theories. [S.1.]: World Scientific, 2010.

BELYTSCHKO, T.; GLAUM, L. Application of high order corotational stretch theories to nonlinear finite element analysis. Computers and structures, v. 10, p. 175-182, 1979.

BELYTSCHKO, T.; HSIEH, B. J. Non-linear transient finite element analysis with convected co-coordinates. International Journal for Numerical Methods in Engineering, v. 7, p. 225$271,1973$. 
BIGONI, D. Extremely Deformable Structures. Udine: Springer, v. CISM International Center for Mechanical Sciences 562, 2015.

BISCHOFF, M.; RAMM, E. On the physical significance of higher order kinematic and static variables in a three-dimensional shell formulation. International Journal of Solids and Structures , v. 37, n. 46, p. 6933-6960, November 2000.

BRYAN, G. H. On the stability of elastic systems. Proceedings of the Cambridge Philosophical Society, Mathematical and physical sciences, v. 6, 1888.

BUDIASKY, B.; HUTCHINSON, J. W. Dynamic buckling of imperfection-sensitive structures. Proc. Int. Appl. Mech., v. 11, p. 636-651, 1964.

BUTKOV, E. Mathematical Physics. Massachusetts: Addison-Wesley Publish Company, 1973.

CARDOSO, A. M. L. Estudo da rigidez efetiva do cabo de pontes estaiadas. (Dissertação de Mestrado). Escola de Engenharia de São Carlos, Universidade de São Paulo: São Carlos. 2013. p. 79.

CARRAZEDO, R. Estudo e desenvolvimento de código computacional para análise de impacto entre estruturas levando em consideração efeitos térmicos. (Tese de Doutorado). Escola de Engenhara de São Carlos: São Carlos. 2009. p. 152.

CASCIARO, R.; SALERNO, G.; LANZO, A. D. Finite element asymptotic analysis of slender elastic structures: a simple approach. Int. J. Numer. Methods Eng., v. 35, p. 13971426, 1992. ISSN 7.

CHEN, Y. J.; HE, H. Y.; ZHANG, S. L. A new algebra interpolation polynomial without Runge phenomenon. Applied Mechanics and Materilas, n. 303-306, p. 1085-1088, 2013.

CODA , H. B.; PACCOLA, R. R. An alternative positional FEM formulation for geometrically non-linear analysis of shells: Curved triangular isoparametric elements. Computational Mechanics, v. 40, n. 1, p. 185-200, June 2007.

CODA , H. B.; PACCOLA, R. R.; SAMPAIO, M. S. M. Fully adherent fiber matrix FEM formulation for geometrically nonlinear 2D solid analysis. Finite Elements in Analysis and Design, v. 66, p. 12-25, 2013.

CODA, H. B. A solid-like FEM for geometrically non-linear 3D frames. Computer Methods in Applied Mechanics and Engineering, v. 198, n. 47-48, p. 3712-3722, 2009.

CODA, H. B. A solid-like FEM for geometrically non-linear 3D frames. Computer Methods in Applied Mechanics and Engineering, v. 198, n. 47-48, p. 3712-3722, August 2009.

CODA, H. B.; GRECO, M. A simple FEM formulation for large deflection 2D frame analysis based on position description. Computer Methods in Applied Mechanics and Engineering, v. 193, n. 33-35, p. 3541-3557, August 2004. 
CODA, H. B.; PACCOLA, R. R. A positional FEM Formulation for geometrical non-linear analysis of shells. Latin American Journal of Solids and Structures, v. 5, p. 205-223, 2008. ISSN 3.

CODA, H. B.; PACCOLA, R. R. Unconstrained Finite Element for Geometrical Nonlinear Dynamics of Shells. Mathematical Problems in Engineering, v. 2009, p. 32, 2009.

CODA, H. B.; PACCOLA, R. R. Improved finite element for 3D laminate frame analysis including warping for any cross-section. Applied Mathematical Modelling, v. 34, n. 4, p. 1107-1137, 2010.

CODA, H. B.; PACCOLA, R. R. A FEM procedure based on positions and unconstrained vectors applied non-linear dynamic of 3D frame. Finite Elements in Analysis and Design, v. 47, p. 319-333, January 2011.

COIMBRA, A. L. Lições de Mecânica do Continuo. São Paulo: Edgard Blücher, 1978.

CRISFIELD, M. A. A fast incremental iterative solution procedure tha handles snap-through. Computer and Structures, v. 13, p. 55-62, 1981.

CRISFIELD, M. A. A Fast Incremental/Iterative Solution Procedure That Handles SnapThrough. Comput. Struct., v. 13, n. 1-3, p. 55-62, 1981.

CRISFIELD, M. A. Non-Linear Finite Element Analysis of Solids and Structures. England: John Wiley \& Sons, 1991.

CRISFIELD, M. A. Non-linear finite element analysis of solids and structures: Advanced Topics. London: John Wiley, v. 2, 1997.

CUFSM. http://www.ce.jhu.edu/bschafer/cufsm/. CUFSM: Elastic Buckling Analysis of Thin-Walled Members by Finite Strip Analysis, 4.05.

CUlluM, J. K.; WILLOUGHBY, R. A. Lanczos Algorithms for Large Symmetric Eigenvalue Computation. Boston: SIAM, v. I: Theory, 1985.

DE SOUZA, A. S. C. Dimensionamento de Elementos Estruturais de Aço Segundo a NBR8800: 2008. Série Apontamentos. ed. São Carlos: EdufSCar, 2012.

DE SOUZA, A. S. C. Dimensionamento de Elementos Estruturais de Aço Segundo a NBR8800:2008. Universidade Federal de São Carlos. São Carlos, p. 109. 2012.

DINIS, P. B.; CAMOTIM, D.; SILVESTRE, N. GBT formulation to analyse the buckling behaviour of thin-walled with arbitrarily 'branched' open cross-sections. Thin-Walled Structures, v. 44, n. 1, p. 20-38, January 2006.

ELISHAKOFF, I. Elastic stability: From euler to koiter there was none like koiter. Meccanica, v. 35, n. 4, p. 375-380, 2000.

ELISHAKOFF, I. Essay on the Contributors to the Elastic Stability Theory. Meccanica, v. 40, n. 1, p. 75-110, 2005. 
ENGESSER, F. Die Knickfestigkeit gerader Stäbe. Z. Architekten und Ing. Vereins zu Hannover, v. 35, p. 455, 1889.

EULER, L. Methodus inveniendi lineas curvas maximi minimivi propreitate gaudentes. Additamentum I (De curvis elasticas)., v. 20, n. 1, p. 72-160, 1744.

EULER, L. Methodus inveniendi lineas curvas maximi minimivi propreitate gaudentes. Additamentum I (De curvis elasticas). Leonardi Euleri Opera Omnia IXXIV, 231-297. English translation: Oldfather W A, Ellis C A, Brown D M (1930) Leonhard Euler's elastic curves, v. 20, n. 1, p. 72-160, 1744.

FRANCO, N. B. Cálculo Numérico. São Paulo: Pearson Prentice Hall, v. 1, 2006.

FRUCHTENGARTEN, J. Sobre o estudo da flambagem lateral de vigas de aço por meio da utilização de uma teoria não-linear geometricamente exata. (Dissertação de Mestrado). Escola Politécnica da Universidade de São Paulo: São Paulo. 2005. p. 251.

GARCEA, G. Mixed formulation in Koiter analysis of thin-walled beams. Comput. Methods Appl. Mech. Engrg., v. 190, p. 3369-3399, 2001.

GARCEA, G.; MADEO, A.; CASCIARO, R. The implicit corotational method and its use in the derivation of nonlinear structural models for beams and plates. J. Mech. Mater. Struct, v. 7, p. 509-538, 2012. ISSN 6.

GBTUL. http://www.civil.ist.utl.pt/gbt/. GBTUL 1.0b Buckling and Vibration Analysis of Thin-Walled Members, 1.0.

GENOESE, A. et al. Buckling analysis through a generalized beam model including section distortions. Thin-WalledStructures, v. 85, p. 125-141, 2014.

GOLUBA, G. H.; VAN DER VORST, H. A. Eigenvalue computation in the 20th century. Journal of Computational and Applied Mathematics, v. 123, p. 35-65, 2000.

GONÇALVES, R.; DINIS, P. B.; CAMOTIM, D. GBT formulation to analyse the first-order and buckling behaviour of thin-walled members with arbitrary cross-sections. Thin-Walled Structures, v. 47, n. 5, p. 583-600, May 2009.

GRECO, M. Análise de problemas de contato/impacto em estruturas de comportamento não linear pelo método dos elementos finitos. (Tese de Doutorado). Escola de Engenharia de São Carlos, Universidade de São Paulo: São Carlos. 2004. p. 163.

HANGAI, ; KAWAMATA, S. Perubation method in the analysis of geometrically nonlinear and stability problems. Advance in Computational Methods in Structural Mechanics and Design, p. 473-489, 1972.

HOLZAPFEL, G. A. Nonlinear solid mechanics: a continuum approach for engineering. Chichester, England: John Wiley \& Sons Ltd., 2000.

HUBOLT , J. C.; STOWEL, E. Z. Critical Stress of Plate Columns. NACA Tech, Note 2163. [S.1.]. 1950. 
KÁRMÁN, T. V.; DUNN, L. G.; TSIEN, H. S. The Influence of Curvature on the Buckling Characteristics of Structures. Journal of the Aeronautical Sciences, v. 7, n. 7, p. 276-289, 1940.

KÁRMÁN, T. V.; TSIEN, H. S. The buckling of thin cylindrical shell under axial compression. Journal of the Aeronautical Sciences, v. 8, n. 8, p. 303-312, 1941.

KIRCHHOFF, G. R. Über das Gleichgewicht und die Bewegung eines unendlich dünnen elastischen Stabes. Journal of Math. (Crelle), v. 56, p. 285-313, 1859.

KOITER, W. T. On the stability of elastic equilibrium. National Aeronautics and Space Administration. Washington. 1967.

KURRER, K. E. The history of the theory of structures: from arc analysis to computational mechanics. Berlin: Ernst \& Sons, 2008.

KUZNETSOV, Y. A. Elements of Applied Bifurcation Theory. New York: Springer, 2004.

KWASNIEWSKI, L. Complete equilibrium paths for Mises trusses. International Journal of Non-Linear Mechanics, v. 44, n. 1, p. 19-26, 2009.

LACARBONARA, W. Nonlinear structural mechanics. New York: Springer Verlag, 2013.

LANCZOS, C. An eficient method for the Solution of the Eigenvalue Problem of Linear Differential and Integral Operators. Journal of Research of National Bureau of Standards, v. 45, n. 4, p. 255-282, 1950.

LI, Z. Finite Strip Modeling of Thin Walled Members. (Tese de Doutorado). Johns Hopkins University: Baltimore, Maryland. 2011. p. 261.

LI, Z.; SCHAFER, B. W. Application of the finite strip method in cold-formed steel member design. Journal of Constructional Steel Research, v. 66, n. 8-9, p. 971-980, AugustSeptember 2010 a.

LI, Z.; SCHAFER, B. W. Buckling analysis of cold-formed steel members with general boundary conditions using CUFSM: conventional and constrained finite strip methods. Twentieth International Specialty Conference on Cold-Formed Steel Structures. Saint Louis, Missouri, USA: In http://www.ce.jhu.edu/bschafer/cufsm/cufsm403/zli_schafer_new_CUFSM_v5_revised.pdf. 2010 b. p. 15.

LYAPUNOV, A. M. Problème générale de la stabilité du mouvement. Harkov: [s.n.], 1892.

MACIEL, D. N. Análise de problemas elásticos não-lineares geométricos empregando o método dos elementos finitos posicional. (Tese de Doutorado). Escola de Engenharia de São Carlos, Universidade de São Paulo: São Carlos. 2008. p. 180.

MARQUES, G. C. S. C. Estudo e desenvolvimento de código computacional baseado no MEF para análise dinâmica não linear geométrica de sólidos bidimensionais. 
(Dissertação de Mestrado). Escola de Engenharia de São Carlos, Universidade de São Paulo: São Carlos. 2006. p. 103.

MEGSON, T. H. G. Introduction on aircraft structural analysis. 2nd. ed. Oxford: Elsevier Ltd, 2014.

MEIRELLES, C. R. M.; PIMENTA, P. M. Análise Linear da Estabilidade de Treliças Utilizando O Método de Lanczos. Boletim Técnico da Escola Politécnica, São Paulo, v. 14, p. 1-15, 1995.

MILNE, I.; RITCHIE, R. O.; KARIHALOO, B. Comprehensive Structural Integrity. [S.1.]: Elsevier, v. 1-10, 2003.

MINSKI, R. L. Aprimoramento de formulação de identificação e solução do impacto bidimensional entre estrutura e anteparo rígido. (Dissertação de Mestrado). Escola de Engennharia de São Carlos, Universidade de São Paulo: São Carlos. 2008. p. 148.

MOURA, C. A. Aplicação de formulação baseada no Método dos Elementos Finitos Posicional na análise bidimensional elástica de compósitos particulados. (Dissertação de Mestrado). Escola de Engenharia de São Carlos, Universidade de São Paulo: São Carlos. 2015. p. 85 .

MUKHERJEE, S.; PRATHAP, G. Analysis of shear locking in Timoshenko beam elements using the function space approach. Communications in Numerical Methods in Engineering, v. 17, n. 6, p. 385-393, June 2001.

NEDELCU, M. GBT formulation to analyse the behaviour of thin-walled members with variable cross-section. Thin-Walled Structures, v. 48, n. 8, p. 629-638, August 2010.

NETO, E. A.; FENG, Y. T. On the determination of path direction for arc-length ,ethods in the presence of bifurcations and snap-backs. Computer Methods in Applied Mechanics and Engineering, v. 179, p. 81-89, 1999.

NOGUEIRA, G. V. Formulação de elemento finito posicional para modelagem numérica de pórticos planos constituídos por compósitos laminados: uma abordagem não linear geométrica baseada na teoria Layerwise. (Dissertação de Mestrado). Escola de Engenharia de São Carlos, Universidade de São Paulo: São Carlos. 2015. p. 228.

OGDEN, R. W. Non-linear elastic deformation. New York: Dover Publication, 1997.

PAIGE, C. C. Error Analysis of the Lanczos Algorithm for Tridiagonalizing a Symmetric Matriz. J. Inst. Math. Applics. , v. 18, p. 341-349, 1976.

PARLETT, B. N.; OMID, B. N. Towards a black box Lanczos program. Computer Physics Communication, v. 53, n. 1-3, p. 169-179, 1989.

PASCON, J. P. Modelos constitutivos para materiais hiperelásticos, estudo e implementação computacional. (Dissertação de Mestrado). Escola de Engenharia de São Carlos, Universidade de São Paulo: São Carlos. 2008. p. 232. 
PASCON, J. P. Sobre modelos constitutivos não lineares para materiais com gradação funcional exibindo grandes deformações, implementação numérica em formulação não linear geométrica. (Tese de Doutorado). Escola de Engenharia de São Carlos, Universidade de São Paulo: São Carlos. 2012. p. 480.

PASCOTE, C. C. On the aplication of catastrophe theory to stability analyses of elastic structures. (Doctoral Thesis). Royal Intitute of Technology, Department of Structural Mechanics and Engineering: Stockholm. 1993. p. 265.

PFEIL, W.; PFEIL, M. Estruturas de Aço: Dimensionamento prático de acordo com a norma 8800:2008. 8ª ed. Rio de Janeiro : LTC, 2009.

PISKOUNOV, N. Cálculo diferencial e integral. 18ª ed. Porto: Lopes da Silva, v. 1, 2000.

POICARÉ, H. Sur l'equilibre d'une mass fluide animée dune mouvement de rotation. Acta Mathematica, v. 7, 1885.

PSOTNý, M.; RAVINGER, J. Von Misses Truss with Imperfections. Slovak Journal of Civil Engineering, v. 2, p. 1-7, 2002.

RACHID, M.; MORI, D. D. Instabilidade: Conceitos - Aplicação na flambagem por flexão. Escola de engenharia de São Carlos, Universidade de São Paulo. São Paulo, p. 129. 2006.

REDDY, J. N. An Introduction to the Finite Element Method. 3. ed. [S.1.]: McGraw-Hill Education, 2005.

REIS, A.; CAMOTIM, D. Estabilidade estrutural. Lisboa: Portugal: McGRAW-HILL, 2001.

REIS, M. C. J. Análise não linear geométrica de pórticos planos considerando ligações semirrígidas elastoplásticas. (Dissertação de Mestrado). Escola de Engenharia de São Carlos, Universidade de São Paulo: São Carlos. 2012. p. 118.

RIGOBELLO, R. Desenvolvimento e aplicação de código computacional para análise de estruturas de aço aporticadas em situação de incêndio. (Tese de Doutorado). Escola de Engenharia de São Carlos, Universidade de São Paulo: São Carlos. 2011. p. 296.

RIKS,. Buckling. pp. xii+830 in Encyclopedia of computational mechanics. ed. Chichester: Wiley, v. 2, 2004.

RISK, E. The aplication of newton's method to the problem of elastic stability. Journal Appl. Mech., v. 39, p. 1060-1066, 1972.

SAAD, Y. Numerical methods for large eigenvalue problems. New York: John Wiley and Sons, 1992.

SALVADORI, M. G. Lateral Buckling of I Beams. Journal of Structural Division, Transactions, v. 120, p. 1165-1177, 1955. 
SAMPAIO, M. S. M. Análise não linear geométrica de cascas laminadas reforçadas com fibras. (Tese de Doutorado). Escola de Engenharia de São Carlos, Universidade de São Paulo: São Carlos. 2014. p. 190.

SAMPAIO, M. S. M.; PACCOLA, R. R.; CODA, H. B. A geometrically nonlinear FEM formulation for the analysis of fiber reinforced laminated plates and shells. Composite Structures, v. 119, p. 799-814, 2015.

SANCHES, R. A. K. Análise bidimensional de interação fluido-estrutura: desenvolvimento de código computacional. (Dissertação de mestrado). Escola de Engenharia de São Carlos, Universidade de São Paulo: São Carlos. 2006. p. 124.

SANCHES, R. A. K. Sobre o acoplamento fluido-casca utilizando o Método dos

Elementos Finitos. (Tese de Doutorado). Escola de Engenharia de São Carlos, Universidade de São Paulo: São Carlos. 2011. p. 2014.

SANCHEZ, J. A. G. Uma formulação em elementos finitos para a análise dinâmica e estática não linear de Risers incluindo o contato com o leito do mar. (Tese de Doutorado). Escola de Engenharia de São Carlos, Universidade de São Paulo: São Carlos. 2013. p. 173.

SANTOS, A. P. F. Aprimoramento de formulação do MEF para barra geral laminada tridimensional pela consideração da cinemática de empenamento para seção qualquer. (Dissertação de Mestrado). Escola de Engenharia de São Carlos, Universidade de São Paulo: São Carlos. 2008. p. 226.

SCHAFER, B. W.; ÁDÁNY, S. Buckling analysis of cold-formed steel members using CUFSM: conventional and constrained finite strip methods. 18th International Specialty Conference on Cold-Formed Steel Structures. Orlando, Florida: In http://www.ce.jhu.edu/bschafer/cufsm/cufsm403/umr2006_cFSMpaper_v4.pdf. 2006. p. 16.

SCHARDT, R. Generalized beam theory — an adequate method for coupled stability problems. Thin-Walled Structures, v. 19, n. 2-4, p. 161-180, 1994.

SEWELL, B. J. A method of post buckling analysis. J. Mech. Phys. Solids, v. 17, p. 219-233, 1969.

SEWELL, M. J. Some Mechanical Examples of Catastrofe Theory. Bull. Inst. Math. Appl., v. 12, p. 163-172, 1976.

SILVA, W. Q. Análise não linear geométrica do acoplamento solo-estrutura através da combinação MEC-MEF. (Dissertação de Mestrado). Escola de Engenharia de São Carlos: São Carlos. 2010. p. 148.

SILVA, W. Q. Sobre análise não linear geométrica de edifícios considerando o empenamento dos núcleos estruturais e a interação solo-estrutura. (Tese de Doutorado). Escola de Engenharia de São Carlos, Universidade de São Paulo: São Carlos. 2014. p. 190.

SILVESTRE, N. Teoria Generalizada de Vigas: Formulações, Implementação Numérica e Aplicações. (Tese de Doutorado). Instituto Superior Técnico. Universidade Ténica de Lisboa: Lisboa. 2005. 
SILVESTRE, N.; CAMOTIM, D. GBT-Based local and global vibration analysis of loaded composite open-section thin-walled members. International Journal of Structural Stability and Dynamics, v. 6, n. 1, p. 1-29, March 2006 a.

SILVESTRE, N.; CAMOTIM, D. Local-plate and distortional postbuckling behavior of coldformed steel lipped channel columns with intermediate stiffeners. Journal of Structural Engineering, v. 132, n. 4, p. 529-540, April 2006 b.

SILVESTRE, N.; CAMOTIM, D.; SILVA, N. F. Generalized beam theory revisited: From the kinematical assumptions to the deformation mode determination. International Journal of Structural Stability and Dynamics, v. 11, n. 5, p. 969-997, 2011.

SIMITSES, G. J.; HODGES, D. H. Fundamentals of Structural Stability. Oxford: Elsevier, 2006.

SMIRNOV, V. I. Biography of Alexander Mikhailovich Lyapunov. International Journal of Control, v. 3, n. 55, p. 775-784, 1992.

SORENSEN, D. C. Implicitly restarted arnoldi/lanczos methods for large scale eigenvalue calculations. Department of Computational and Applied Mathematics - Rice University. Houston, Texas, p. 36. 1995.

SOUTHWELL, R. V. On the general theory of elastic stability. Philosophical Transaction of the Royal Society of London, n. 213, p. 187-244, 1913.

STEWART, I. APPLICATIONS OF CATASTROPHE THEORY TO THE PHYSICAL SCIENCES. Physica 2D, p. 245-305, 1981.

SYMON, K. R. Mechanics. Massachusetts: Addison-Wesley Publish Company, 1960.

THOM, R. Stabilité Structurelle et Morphogénèse. New York: Benjamin, 1972.

THOMPSON, J. M. T. Basic principle in the theory of elastic stability. Journal of Mech. Phys. Solids, v. 11, p. 13-20, 1963.

THOMPSON, J. M. T.; HUNT, G. W. A General Theory of Elastic Stability. London: John Wiley, 1973.

THORNTON, C. H.; LEW , I. P. Investigation of the causes of Hartford. International Conference on Space Structures. Guildford, UK: Elsevier Applied Science. 1983. p. 636-641.

TIMOSHENKO, S. P. On the correction for shear of the diferential equation for transverse vibrations of bars of uniform cross-section. Philosophical Magazine, v. 744, 1921.

TIMOSHENKO, S. P. History of Strength of Materials. New York: McGraw-Hill, 1953.

TIMOSHENKO, S. P.; GERE, J. M. Theory of elastic stability. 2nd. ed. New York: McGraw-Hill, 1961.

TIMOSHENKO, S. P.; KRIEGER, S. W. Theory of plate and shell. New York: McGrawHill, 1959. 
TODHUNTER, I. A history of the theory of elasticity and of the strength of materials: from Galilei to the present time. Cambridge, UK: Cambridge University Press., 1893.

ZAGARI, G. Koiter's asymptotic numerical methods for shell structures using a corotational formulations. (Tese de Doutorado). Università della Calabria: Consenza, Calabria. 2009. p. 121. 


\section{APÊNDICE A: Base de Vetores da Seção Transversal}

No capítulo 8, sobre a cinemática do elemento de barra geral determinou-se os vetores generalizados considerando-os unitários e ortogonais a linha de referência na configuração indeformada da estrutura. Na configuração deformada, mostrou-se que tal imposição não é necessariamente utilizada e a seção transversal se deforma segundo a cinemática de Timoshenko.

Neste apêndice apresenta-se a metodologia de obtenção dos vetores generalizados para o mapeamento da configuração indeformada, uma vez que após a deformação, esses vetores são as incógnitas a se determinar após a resolução do sistema de equações não-linear.

Considera-se como diretriz para a demonstração, os vetores ilustrados na Figura 86:

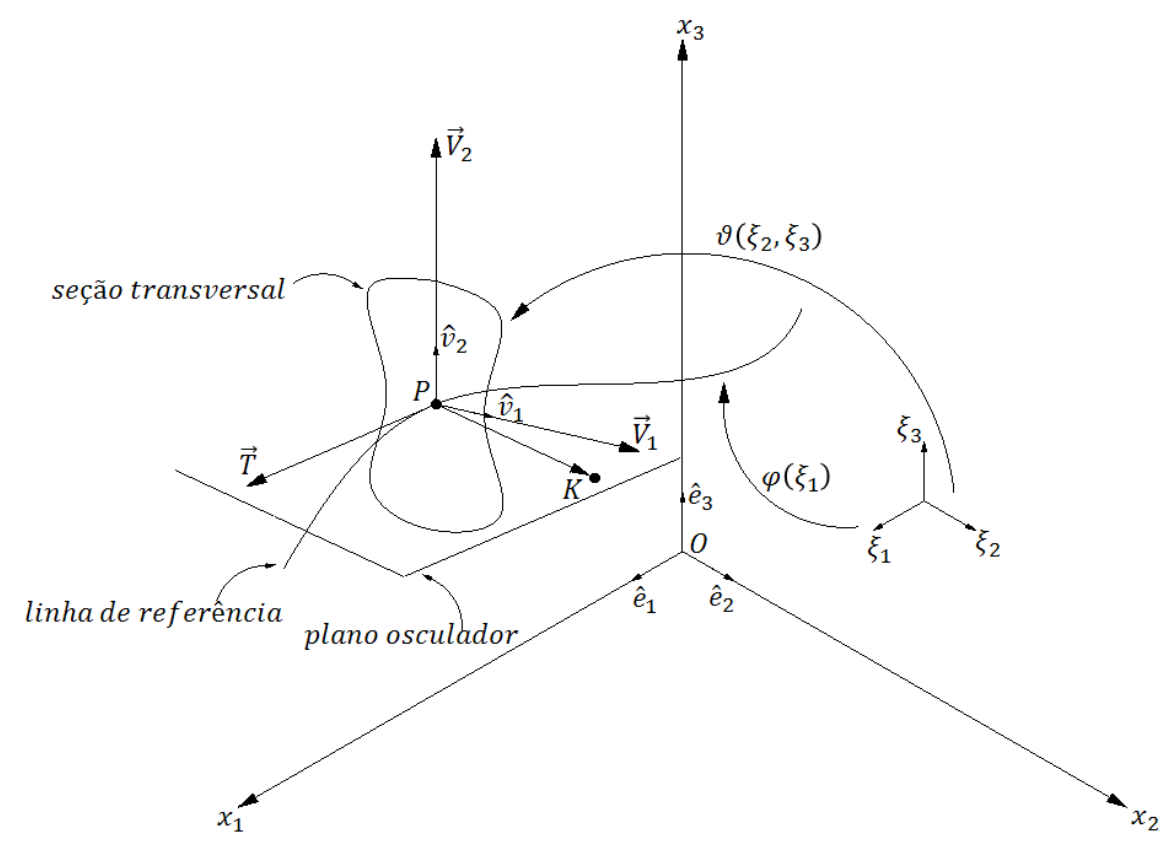

Figura 86: Vetores generalizados na configuração inicial.

Na Figura 86 apresentam-se todos os entes algébricos e geométricos utilizados no cálculo dos vetores base. Considera-se, por questão de generalidade, uma linha de referência curva e uma seção transversal qualquer parametrizada no espaço tridimensional.

A primeira asserção refere-se ao sentido de orientação dos eixos do sistema de coordenadas. Considera-se o sentido dextrogiro, tal que a base desse sistema atende a equação:

$$
\hat{e}_{i} \times \hat{e}_{j}=\hat{e}_{k} \varepsilon_{i j k}
$$


Sendo: $\hat{e}_{i}$, as componentes cartesianas dos vetores unitários (base ortonormal) e, $\varepsilon_{i j k}, \mathrm{o}$ símbolo de Levi-Civita, definido como:

$$
\varepsilon_{i j k}=\left\{\begin{array}{c}
1, \operatorname{se}(i, j, k) \equiv(1,2,3) \text { ou }(3,1,2) \text { ou }(2,3,1) \\
-1, \operatorname{se}(i, j, k) \equiv(1,3,2) \text { ou }(3,2,1) \text { ou }(2,3,1) \\
0, \operatorname{se}(i=j) \text { ou }(j=k) \text { ou }(i=k)
\end{array}\right.
$$

Com isso garante-se também a orientação da seção transversal.

Uma curva paramétrica no espaço bidimensional possui vetores tangentes e normais pertencentes ao mesmo plano. No entanto, curvas parametrizadas no espaço tridimensional, o plano com os vetores normais e tangentes, em geral, não é fixo e varia de ponto a ponto ao longo da curva. A esse plano dar-se o nome de plano osculador.

Para construir a curva paramétrica nesse espaço (linha de referência) é necessário se obter as orientações do plano osculador em relação aos pontos da curva. Isso se faz definindose pontos auxiliares denominados de key points. Na Figura 86 o ponto $k$ é o key point associado ao ponto $P$ da linha de referência e que pertence a um elemento finito. O vetor $\overrightarrow{P K}$ é definido como ortogonal ao vetor tangente $\vec{T}$ no ponto $P$ e ambos são paralelos ao plano osculador.

Além do plano osculador destacam-se dois outros planos, o plano normal e o plano retificante. Essas novas definições necessitam da obtenção de um terceiro vetor, denominado vetor binormal. Na Figura 86 o vetor binormal é representado pelo vetor $\vec{V}_{2}$. Assim, $\overrightarrow{P K}, \vec{T}$ e $\vec{V}_{2}$ formam o denominado triedro de Frenet-Serret utilizado para caracterizar qualquer curva paramétrica no espaço tridimensional, independente do sistema de coordenadas adotado, Ávila (2010).

Voltando-se as definições", o plano paralelo ao vetor normal $\overrightarrow{P K}$ e ao vetor binormal $\vec{V}_{2}$ denomina-se plano normal. O plano paralelo ao vetor tangente $\vec{T}$ e ao vetor binormal $\vec{V}_{2}$ denomina-se plano retificante. A seguir descreve-se o método de cálculo dos vetores e dos planos que formam o triedro.

O mapeamento da linha de referência é efetuado pela combinação linear entre as funções de forma unidimensionais e os valores nodais das posições dos elementos finitos.

As componentes do vetor posição são calculadas como: 


$$
X_{i}=\varphi_{j}\left(\xi_{1}\right) x_{i j}
$$

Sendo:

$x_{i j}$, as coordenada nodais dos elementos finitos, com $i=1,2,3 \mathrm{e}$

$\varphi_{j}\left(\xi_{1}\right)$, as funções de forma unidimensionais com $j=1,2 \ldots p+1$, sendo $p$ o grau da aproximação utilizada para representar a linha de referência.

Uma vez mapeada a linha de referência, o vetor tangente é calculado procedendo-se a derivada da Equação (A.3) em relação ao parâmetro $\xi_{1}$. As componentes do vetor são expressas pela equação:

$$
\frac{d X_{i}}{d \xi_{1}}=\frac{d \varphi_{j}\left(\xi_{1}\right)}{d \xi_{1}} x_{i j}
$$

Na forma vetorial o vetor tangente $\vec{T}$ é representado por:

$$
\vec{T}=\frac{d X_{1}}{d \xi_{1}} \hat{e}_{1}+\frac{d X_{2}}{d \xi_{1}} \hat{e}_{2}+\frac{d X_{3}}{d \xi_{1}} \hat{e}_{3}
$$

O plano osculador será completamente caracterizado calculando-se o vetor normal. Esse vetor será obtido com as informações a cerca das coordenadas do key point. As componentes do vetor normal $\overrightarrow{P K}$ são determinadas fazendo-se:

$$
x_{i}^{\overrightarrow{P K}}=\left(x_{i}^{K}-x_{i}^{P}\right)
$$

Na representação vetorial, o vetor normal $\overrightarrow{P K}$ fica representado como:

$$
\overrightarrow{P K}=\left(x_{1}^{K}-x_{1}^{P}\right) \hat{e}_{1}+\left(x_{2}^{K}-x_{2}^{P}\right) \hat{e}_{2}+\left(x_{3}^{K}-x_{3}^{P}\right) \hat{e}_{3}
$$

De posse dos vetores tangentes e normais é possível se determinar o vetor binormal $\vec{V}_{2}$ procedendo-se o produto vetorial:"

$$
\vec{V}_{2}=\vec{T} \times \overrightarrow{P K}
$$


As componentes do vetor binormal $\vec{V}_{2}$ formam uma das bases usadas para representar a seção transversal. As outras componentes da base da seção transversal são obtidas procedendo-se ao produto vetorial:

$$
\vec{V}_{1}=\vec{V}_{2} \times \vec{T}
$$

Essa definição decorre da orientação assumida para o as seções transversais no sistema de coordenadas cartesianas.

Tem-se que os vetores $\vec{V}_{1}$ e $\vec{V}_{2}$ obtidos desta forma são mutuamente ortogonais e ortogonais a linha de referência. A normalização deles é dada por:

$$
\hat{v}_{i}=\frac{\vec{V}_{i}}{\left|\vec{V}_{i}\right|}, i=1,2
$$

Com essa metodologia é possível calcular a tríade de vetores, a curva no espaço tridimensional e a base vetorial para mapear os elementos da seção transversal. 